\title{
Segmentação de movimento usando morfologia matemática
}

\author{
Arnaldo Câmara Lara \\ DissertaÇÃo APRESENTADA \\ $\mathrm{AO}$ \\ Instituto de Matemática e Estatística \\ DA \\ Universidade de SÃo Paulo \\ PARA \\ OBTENÇÃO DO TÍTULO \\ $\mathrm{DE}$ \\ Mestre em CiÊnCias

\begin{abstract}
Área de Concentração: Ciência da Computação Orientador: Prof. Dr. Roberto Hirata Jr.
\end{abstract}

Durante o desenvolvimento deste trabalho o autor recebeu auxílio financeiro do CNPq 


\section{Segmentação de movimento usando morfologia matemática}

Este exemplar corresponde à redação final da dissertação devidamente corrigida

e defendida por Arnaldo Câmara Lara e aprovada pela Comissão Julgadora.

Banca Examinadora:

- Prof. Dr. Roberto Hirata Júnior (orientador) - IME-USP.

- Prof. Dr. Roberto Marcondes César Júnior - IME-USP.

- Prof. Dr. Roberto de Alencar Lotufo - FEEC-UNICAMP. 


\section{Agradecimentos}

Gostaria de agradecer a todos aqueles com quem tive oportunidade de conhecer e conviver durante este período de mestrado e também a todos que me ajudaram direta ou indiretamente neste trabalho. Em especial, gostaria de agradecer:

ao Prof. Roberto Hirata Júnior, pela orientação neste trabalho, pela amizade, pelo incentivo, pelos ensinamentos e pelo entusiasmo que demonstra pelo seu trabalho;

aos membros da banca de qualificação, Prof. Dr. Júnior Barrera e Prof. Dr. Roberto Marcondes César Jr., e aos membros da banca de defesa, Prof. Dr. Roberto de Alencar Lotufo e Prof. Dr. Roberto Marcondes César Jr., pelas importantes contribuições e sugestões que deram a este trabalho; aos meus pais, Marília e Francisco, que sempre incentivaram minha educação e apoiaram minhas decisões;

às minhas irmãs, Flávia e Lígia, pela amizade e pelo apoio;

à minha namorada, Carol, pelo companheirismo, pela paciência, pelas palavras de incentivo e confiança que nunca faltaram;

aos demais familiares e amigos que torceram por mim nesta empreitada;

ao CNPQ que me apoio financeiramente durante o desenvolvimento deste trabalho;

aos professores do IME que contribuíram na minha formação científica e tornaram este trabalho possível;

aos funcionários do IME, em especial da CPG, pela boa vontade em ajudar sempre;

aos colegas do mestrado pela convivência e troca de experiências; 
aos colegas do laboratório de Visão pela amizade, pelos bons momentos juntos e pelo incentivo e sugestões a este trabalho;

aos administradores da Rede Vision pelo empenho e competência em manter os recursos computacionais disponíveis;

ao Jonas Teixeira Coimbra que me auxiliou na correção deste trabalho. 


\section{Resumo}

Esta dissertação apresenta um novo método para segmentação de movimento em seqüências de vídeo que usa contornos dos objetos obtidos através do gradiente morfológico externo ao invés da intensidade dos pixels que normalmente é utilizada nos algoritmos clássicos. A segmentação de movimento é a etapa básica das aplicações de análise de vídeo e é nesta etapa que são delimitadas as regiões de interesse para as etapas subseqüêntes. Aplicações de análise de vídeo, em especial as aplicações de vigilância inteligente, têm se tornado de grande interesse atualmente. Devido ao seu baixo custo, câmeras de segurança são instaladas em vários locais. Porém, o número de câmeras instaladas excede a capacidade humana de monitorá-las de maneira adequada e, com isto, é perdido o potencial de prevenção de acidentes e atos criminosos que as imagens provenientes destas câmeras possuem. Aplicações de vigilância inteligente analisam em tempo real as imagens das câmeras de segurança com a finalidade de disparar eventos para intervenção humana quando ações perigosas estejam acontencendo ou em vias de acontecer.

O trabalho faz um estudo do problema da segmentação de movimento, mostrando aspectos gerais, abordagens para tratar o problema, principais algoritmos, métodos de avaliação de desempenho e desafios. A técnica proposta juntamente com outros algoritmos foram implementados em uma mesma plataforma de desenvolvimento e testados na base pública de vídeos do projeto CAVIAR. Foram utilizados 45 vídeos, divididos em 3 grupos e aproximadamente 50000 quadros. Os resultados foram avaliados por duas abordagens distintas: uma pontual e outra baseada em objetos. O algoritmo proposto apresentou ótimos resultados quantitativos pelas duas abordagens de avaliação de resultados. Algumas situações específicas também foram analisadas e a solução proposta se mostrou mais robusta a falsos positivos e a falsos negativos que as outras técnicas comparadas.

Palavras-chave: segmentação movimento, visão computacional, detecção, análise de vídeo, vigilância inteligente, Morfologia Matemática. 


\section{Abstract}

This dissertation presents a novel method to motion segmentation in video sequences that uses contours of the objects obtained by external morphological gradient instead of the intensity of the pixels that is usually used by the classical techniques. Motion segmentation is the initial step of motion-related applications and it is in this step that are delimited the regions of interest to the next steps. Motion-related applications, in special smart surveillance applications, have become very common nowadays. Because of its low cost, security cameras have been installed in many places, however, the number of installed cameras exceeds the human capacity to track them adequately and, then, it is lost the crime prevention potential of the images from these cameras. Smart surveillance applications analyze in real-time the images from the security cameras to throw alarms for human operators when some dangerous actions is happening or is going to happen.

This work studies the motion segmentation problem, showing some general aspects, approaches used to deal the problem, main classical algorithms, performance evaluation techniques and the challengings. The proposed technique and some other algorithms were implemented in the same development platform and they were tested in the public video database of CAVIAR project. It were tested 45 videos, divided in 3 groups and about 50000 frames. The results were evaluated by two different approaches: a pixel-based approach and an object-based approach. The proposed algorithms presented great quantitative results using both approaches. Some specific situations were analyzed and the proposed technique showed to be more robust to false positives and to false negatives than other compared techniques.

Keywords: motion segmentation, computer vision, detection, video analysis, smart surveillance, Mathematical Morphology. 


\section{Sumário}

Lista de Abreviaturas

Lista de Figuras $\quad$ xiii

Lista de Tabelas $\quad$ xvii

1 Introdução 1

1.1 Contribuições . . . . . . . . . . . . . . . . . . . . . 7

1.2 Organização do texto . . . . . . . . . . . . . . . . . . . 8

2 Segmentação de Movimento $\quad 9$

2.1 Definições preliminares . . . . . . . . . . . . . . . . . . . . . 9

2.2 Aspectos Gerais . . . . . . . . . . . . . . . . . . . 13

2.2 .1 Restrições . . . . . . . . . . . . . . . . . . . . . . 13

2.2 .2 Iluminação . . . . . . . . . . . . . . . . . . . . . . . . . 13

2.2 .3 Registro . . . . . . . . . . . . . . . . . . . 16

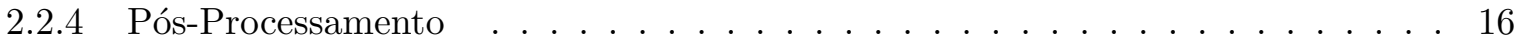

2.2 .5 Situações Desafiadoras . . . . . . . . . . . . . . . . . 16

2.3 Abordagens de Segmentação de Movimento . . . . . . . . . . . . . . . . . . . . . 18

2.3 .1 Diferenciação Temporal . . . . . . . . . . . . . . . . . . . 18

vii 
2.3 .2 Subtração de Fundo . . . . . . . . . . . . . . . . . . . . . . . . 19

2.3.3 Abordagem Estatística . . . . . . . . . . . . . . . . . . . 29

2.3 .4 Fluxo Óptico . . . . . . . . . . . . . . . . . . 34

2.4 Avaliação de Resultados . . . . . . . . . . . . . . . . . . . . . . 38

2.4 .1 Medições Baseadas em Pixels . . . . . . . . . . . . . . . 38

2.4.2 Medições Baseadas em Objetos . . . . . . . . . . . . . . . . 40

3 Morfologia Matemática $\quad 43$

3.1 Definições Básicas . . . . . . . . . . . . . . . . . . . . . 44

3.1.1 Reticulados Completos . . . . . . . . . . . . . . . 45

3.1.2 Operações em Reticulados Completos . . . . . . . . . . . . . . . . 46

3.2 Dilatações e Erosões . . . . . . . . . . . . . . . . . . . . . . 47

3.2 .1 Gradientes . . . . . . . . . . . . . . . . . 50

3.3 Abertura e Fechamento . . . . . . . . . . . . . . . . . . 50

$3.3 .1 \quad$ Filtro Alternado Seqüencial . . . . . . . . . . . . . . . . . . 54

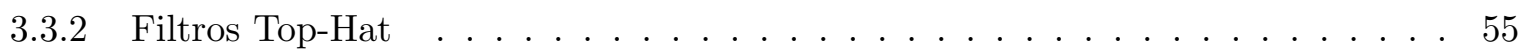

3.4 Filtros Condicionais . . . . . . . . . . . . . . . . . . . 57

3.4.1 Erosões e Dilatações Condicionais . . . . . . . . . . . . . . 58

3.4.2 Regiões Planas e Operadores Conexos . . . . . . . . . . . . . . . . . 60

3.4.3 Abertura e Fechamento por Reconstrução . . . . . . . . . . . . . . . . . 61

3.4.4 Filtros de Contraste e Volume . . . . . . . . . . . . . . . . . 64

4 Segmentação de Movimento Usando MM $\quad 67$

4.1 Algoritmo da Solução Proposta . . . . . . . . . . . . . . . . . . . 67

4.1 .1 Estimação do Fundo . . . . . . . . . . . . . . . . . . . 68 
4.1 .2 Obtenção dos Alvos . . . . . . . . . . . . . . . . . . 70

$4.1 .3 \quad$ Filtragens de Ruído . . . . . . . . . . . . . . . . . . . 71

4.1.4 Heurística de Coerência Temporal . . . . . . . . . . . . . . . . . . 72

4.2 Implementação . . . . . . . . . . . . . . . . . . . . . . . . . . 73

$\begin{array}{lll}5 & \text { Resultados Experimentais } & 77\end{array}$

5.1 Bases de Dados . . . . . . . . . . . . . . . . . . . . 77

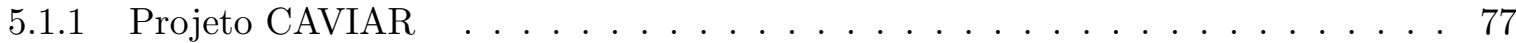

5.2 Implementações . . . . . . . . . . . . . . . . . . . . . . . . . 84

5.2 .1 Diferenciação temporal . . . . . . . . . . . . . . . . . 84

5.2 .2 Subtração de fundo . . . . . . . . . . . . . . . . . . 85

5.2 .3 Abordagem estatística $\ldots \ldots \ldots \ldots \ldots \ldots$

5.3 Resultados Quantitativos . . . . . . . . . . . . . . 86

5.4 Análise de Situações Específicas . . . . . . . . . . . . . . . . . 118

6 Conclusão $\quad 125$

6.1 Trabalhos Futuros . . . . . . . . . . . . . . . . . . . . 128

Referências Bibliográficas $\quad 133$ 


\title{
Lista de Abreviaturas
}

\author{
2D bidimensional \\ 3D tridimensional \\ CAVIAR visão dependente de contexto usando reconhecimento ativo baseado em imagens \\ (Context Aware Vision using Image-based Active Recognition) \\ CD detecção correta (correct detection) \\ CF caixa de Feret \\ DIF2 diferenciação temporal usando dois quadros \\ DIF3 diferenciação temporal usando três quadros \\ DR taxa de detecção (detection rate) \\ EF estatística de fundo \\ FAR taxa de falsos alarmes (false alarm rate) \\ FN falso negativo (false negative) \\ FP falso positivo (false positive) \\ GB Gigabyte \\ GS modelo gaussiano simples \\ INRIA Instituto Nacional de Pesquisa em Ciência da Computação e em Automação \\ (em francês Institut National de Recherche en Informatique et en Automatique) \\ JC coeficiente de Jaccard \\ JR região conjunta (join region) \\ JSR região conjunta-dividida (join-split region) \\ MM Morfologia Matemática ou segmentação de movimento usando Morfologia Matemática \\ MMACH máquina morfológica (morphological machine)
}


MPEG Grupo de Especialistas em Vídeo (Moving Picture Experts Group)

$\mathrm{N} \quad$ ruído (noise)

ND não detecção (non-detection)

NDR taxa de não detecção (non-detection rate)

NR taxa de ruído (noise rate)

NTSC Comitê do Sistema de Televisão Nacional (National Television System Committee)

PAL linha com alternância de fase (phase alternating line)

PCA análise do componente principal (principal component analysis)

PCC percentual de classificação correta

Q1 primeiro quartil

Q3 terceiro quartil

RGB vermelho, verde, azul (red, green, blue)

SECAM cor seqüencial com memória (em francês Séquentiel couleur à mémoire)

SFME subtração de fundo estimado pela média

SFMD subtração de fundo estimado pela mediana

SFMDJ subtração de fundo estimado pela mediana dos últimos quadros

SR região dividida (split region)

TN negativo verdadeiro (true negative)

TP positivo verdadeiro (true positive)

TRDR taxa de detecção de rastreamento(tracking detection rate)

VC Visão Computacional

W4 Quem? Quando? Onde? O que? (Who? When? Where? What?)

YC coeficiente de Yule 


\section{Lista de Figuras}

1.1 Etapas de uma aplicação de vigilância inteligente. . . . . . . . . . . . . . . . 2

2.1 Diferenciação temporal de dois quadros. Foram utilizados quadros da seqüência TwoEnterShopgfront do Projeto CAVIAR. . . . . . . . . . . . . . . . 21

2.2 Comparação dos resultados da diferenciação de dois e três quadros. . . . . . . . . . . 22

2.3 Quadros 100, 200, 300, 400 e 500 da seqüência LeftBag do projeto CAVIAR. . . . . 23

2.4 Modelo de fundo da seqüência LeftBag do projeto CAVIAR estimado pela média dos quadros. . . . . . . . . . . . . . . . . . . . . . 24

2.5 Comparação entre os modelos de fundo estimados pela média e pela mediana. . . . . 25

2.6 Alvos da subtração de fundo estimados pela média e mediana. . . . . . . . . . . . . . . 27

2.7 Aplicação do método Lucas \& Kanade nos quadros 200 e 203 da seqüência ShopAssistant1cor do Projeto CAVIAR. . . . . . . . . . . . . . . . . 37

3.1 Efeitos da dilatação e da erosão em uma imagem binária. . . . . . . . . . . . . . . . 48

3.2 Erosão e dilatação em uma imagem em níveis de cinza (Quadro 1084 da seqüência Walk1 do Projeto CAVIAR. . . . . . . . . . . . . . . . . . 49

3.3 Gradiente interno, externo e morfológico em imagens binárias. . . . . . . . . . . . . 51

3.4 Gradiente morfológico de uma imagem em níveis de cinza (Quadro 1890 da seqüência WalkByShop1cor do Projeto CAVIAR) . . . . . . . . . . . . . 52

3.5 Operadores Abertura e Fechamento . . . . . . . . . . . . . . . . . 53 
3.6 Eliminação de ruídos em uma imagem pela abertura. . . . . . . . . . . . . . 55

3.7 Eliminando ruído do tipo sal e pimenta de uma imagem . . . . . . . . . . . . . 56

3.8 Diferença de iluminação de fundo compensada pelo filtro Abertura Top-Hat. . . . 57

3.9 Exemplo de dilatação condicional de uma imagem em níveis de cinza, o Quadro 20 da seqüência Fight_RunAway1 do Projeto CAVIAR. . . . . . . . . . . . . . . . . . . 59

3.10 Filtro reconstrução inf-geodésico em uma imagem binária. . . . . . . . . . . . 60

3.11 Imagem apresenta número diferente de regiões planas dependendo da conectividade

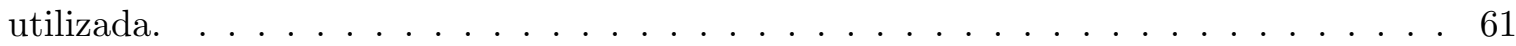

3.12 Imagens reais geralmente possuem muito mais regiões planas que imagens sintéticas. $\quad 62$

3.13 Exemplo do filtro fechamento por reconstrução. . . . . . . . . . . . . . . . . 63

3.14 Aplicação do filtro alternado seqüencial conexo para diminuição do número de regiões planas de uma imagem real em níveis de cinza. . . . . . . . . . . . . . . . . . 64

4.1 Esquema do algoritmo proposto. . . . . . . . . . . . . . . . . . . . 69

4.2 Etapas do algoritmo de segmentação de movimento usando Morfologia Matemática no processamento do quadro 180 da seqüência Fight_OneManDown do Projeto CAVIAR. 75

5.1 Alguns quadros de uma seqüência do grupo 1, no caso a seqüência Fight_RunAway2. 81

5.2 Quadros da seqüência TwoEnterShop2cor do grupo 2. . . . . . . . . . . . . . . 82

5.3 Quadros da seqüência TwoEnterShop2front do grupo 3. Os quadros mostram aproximadamente o mesmo período dos quadros da Figura $5.2 \ldots$. . . . . . . . . . . 83

5.4 Os três tipos de alvos e as respectivas caixas de Feret. . . . . . . . . . . . . . . . 88 
5.5 Esta figura mostra as medições dos pixels em um quadro da seqüência de vídeo. A CF do resultado do algoritmo está preenchida por listas horizontais e a CF do padrão ouro (gabarito) está na região preenchida por listas verticais. Os pixels classificados como TP são aqueles que pertencem a CF do resultado e a CF do padrão ouro. Ou seja, os pixels classificados como TP são aqueles situados na região quadriculada. Os pixels classificados como FN são aqueles que pertencem a CF do padrão ouro, mas não pertencem a $\mathrm{CF}$ do resultado. Estes pixels estão na região de listas verticais. Os pixels classificados como FP são aqueles que pertencem a $\mathrm{CF}$ do resultado, mas não pertencem a CF do padrão ouro, situando na região de listas horizontais. Os pixels classificados como TN são aqueles que não pertencem nem a CF do padrão ouro nem a CF do resultado, ou seja, são aqueles situados na região em branco da figura. . 89

5.6 Boxplot de TP dos conjuntos de vídeos 1 e $2 \ldots \ldots \ldots \ldots$. . . . . . . . . 91

5.7 Boxplot de TP do conjunto de vídeos 3 e do total dos vídeos. . . . . . . . . . . . . . 92

5.8 Boxplot de TN dos conjuntos de vídeos 1 e $2 \ldots \ldots \ldots \ldots$. . . . . . . . . 93

5.9 Boxplot de TN do conjunto de vídeos 3 e do total dos vídeos. . . . . . . . . . . . . . 94

5.10 Boxplot de FP dos conjuntos de vídeos 1 e $2 \ldots \ldots \ldots$. . . . . . . . . . . . 96

5.11 Boxplot de FP do conjunto de vídeos 3 e do total dos vídeos. . . . . . . . . . . . . . 97

5.12 Boxplot de $\mathrm{FN}$ dos conjuntos de vídeos 1 e $2 . \quad \ldots \ldots \ldots$. . . . . . . . . . 98

5.13 Boxplot de FN do conjunto de vídeos 3 e do total dos vídeos. . . . . . . . . . . . . 99

5.14 Boxplot de PCC dos conjuntos de vídeos 1 e $2 \ldots \ldots$. . . . . . . . . . . . . . . . 102

5.15 Boxplot de PCC do conjunto de vídeos 3 e do total dos vídeos. . . . . . . . . . . . . 103

5.16 Boxplot de JC dos conjuntos de vídeos 1 e 2 . . . . . . . . . . . . . . . . . . . . . 104

5.17 Boxplot de JC do conjunto de vídeos 3 e do total dos vídeos. . . . . . . . . . . . . 105

5.18 Boxplot do TRDR e FAR para o conjunto de vídeos $1 . \quad \ldots \ldots$. . . . . . . . . 108

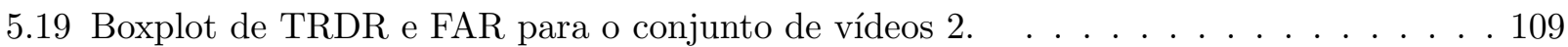

5.20 Boxplot de TRDR e FAR para o conjunto de vídeos $3 . \quad \ldots \ldots$. . . . . . . . . 110

5.21 Boxplot de TRDR e FAR para o total dos vídeos. . . . . . . . . . . . . . . . 111 


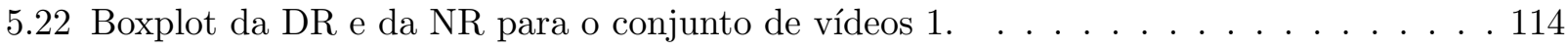

5.23 Boxplot da DR e da NR para o conjunto de vídeos $2 . \ldots \ldots$. . . . . . . . 115

5.24 Boxplot da DR e da NR para o conjunto de vídeos $3 . \quad \ldots \ldots$. . . . . . . . . 116

5.25 Boxplot da DR e da NR para o total de vídeos. . . . . . . . . . . . . . . 117

5.26 Situação específica que mostra a maior robustez a falsos positivos do algoritmo MM em relação ao SFMDJ. Quadros da seqüência LeftBag_PickedUp do Projeto CAVIAR. 121

5.27 Resultado do algoritmo MM em alguns quadros iniciais da seqüência Browse1 do projeto CAVIAR. . . . . . . . . . . . . . . . . . . 122

5.28 Resultados dos algoritmos MM, GS e W4 no quadro 101 da seqüência TwoEnterShop1cor ilustrando o melhor resultado do algoritmo MM após um período de treinamento onde alvos permaneceram em cena. . . . . . . . . . . . . . . . . . . 123

5.29 Resultados dos algoritmos MM e SFMDJ para o quadro 300 da seqüência ShopAssistant2cor mostrando a maior robustez a falsos negativos e o não aparecimento de rastros no algoritmo MM. . . . . . . . . . . . . . . . . . 124 


\section{Lista de Tabelas}

4.1 Parâmetros de entrada do arquivo de configuração utilizados na implementação do algoritmo de segmentação de movimento usando MM. . . . . . . . . . . . . . . . . . 74

5.1 Bases de vídeos para testes de aplicações de vigilância inteligente. . . . . . . . . . 78

5.2 Número de vídeos, totais de quadros e tempos de vídeo por agrupamento de vídeos e a totalização dos valores apresentados. . . . . . . . . . . . . . . 79

5.3 Seqüências de vídeo testadas do grupo 1 do projeto CAVIAR. . . . . . . . . . . . 79

5.4 Seqüências de vídeo testadas do grupo 2 do projeto CAVIAR. . . . . . . . . . . . 80

5.5 Seqüências de vídeo testadas do grupo 3 do projeto CAVIAR. . . . . . . . . . . . 80

5.6 Algoritmos de segmentação de movimento implementados. . . . . . . . . . . . . . 84

5.7 Tipos de máscara alvo-fundo produzidas como saída em cada um dos algoritmos im-

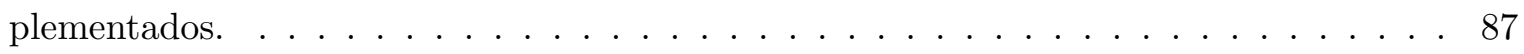

5.8 Número de quadros iniciais utilizados como período de treinamento para cada algoritmo implementado. . . . . . . . . . . . . . . . . . . . 89

5.9 Número médio de pixels, por quadro, para cada uma das medições (TP, TN, FP e FN), para os conjuntos de vídeos 1 e $2 \ldots \ldots \ldots$. . . . . . . . . . . . . . . . . .

5.10 Número médio de pixels, por quadro, para cada uma das medições (TP, TN, FP e FN), para o conjunto de vídeos 3 e para o total de vídeos testados. . . . . . . . . 100

5.11 Valores médios de PCC e JC por quadro para os conjuntos de vídeos 1, 2, 3 e para o total de vídeos da base. . . . . . . . . . . . . . . . . . . . 106 
5.12 Valores médios de TRDR e FAR por quadro para os conjuntos de vídeos 1, 2, 3 e para o total de vídeos da base. . . . . . . . . . . . . . . . . . . . . . . . 112

5.13 Valores médios de DR e NR por quadro para os conjuntos de vídeos 1, 2, 3 e para o total de vídeos da base. . . . . . . . . . . . . . . . . . . . . 113 


\section{Capítulo 1}

\section{Introdução}

A vigilância inteligente ${ }^{1}$ é a observação, em tempo real, de pessoas, automóveis, animais ou objetos com o entendimento de suas atividades e interações e a respectiva classificação do potencial de periculosidade [71,17]. A vigilância inteligente tem se tornado um dos campos de pesquisa mais ativos na área de Visão Computacional (VC) [10].

Por causa do baixo custo de instalação, câmeras de segurança são encontradas em vários locais como, por exemplo, centros comerciais, bancos, estacionamentos, condomínios residenciais e vias públicas. Porém, o número de câmeras instaladas excede a capacidade humana de monitorá-las de maneira adequada e o potencial de prevenção de ações criminosas ou perigosas que as imagens dessas câmeras possuem não é devidamente aproveitado. Assim, as imagens das câmeras de segurança tornam-se apenas ferramentas de investigação policial após a ocorrência do ato criminoso ou acidente [5]. O principal objetivo das aplicações de vigilância inteligente é o monitoramento das imagens vindas de câmeras de segurança com a intenção de detectar, em tempo real, ações ou situações potencialmente perigosas, acontecendo ou em vias de acontecer. Ao detectar tais situações, um alarme é acionado para que um operador humano tome as devidas providências.

Uma aplicação de vigilância inteligente é composta, geralmente, de três etapas [88]. A etapa mais básica é a deteç̧ão. Nessa etapa, os objetos em movimento são detectados e separados do fundo. A etapa intermediária é o rastreamento onde ocorre a correspondência entre cada objeto identificado na etapa anterior e os sucessivos quadros presentes na seqüência de imagens [40,92]. Aqui também pode ocorrer a classificação dos alvos baseando-se em características extraídas na segmentação de movimento e no rastreamento. Modelos do fundo da cena e dos objetos podem

\footnotetext{
${ }^{1}$ smart surveillance em inglês
} 


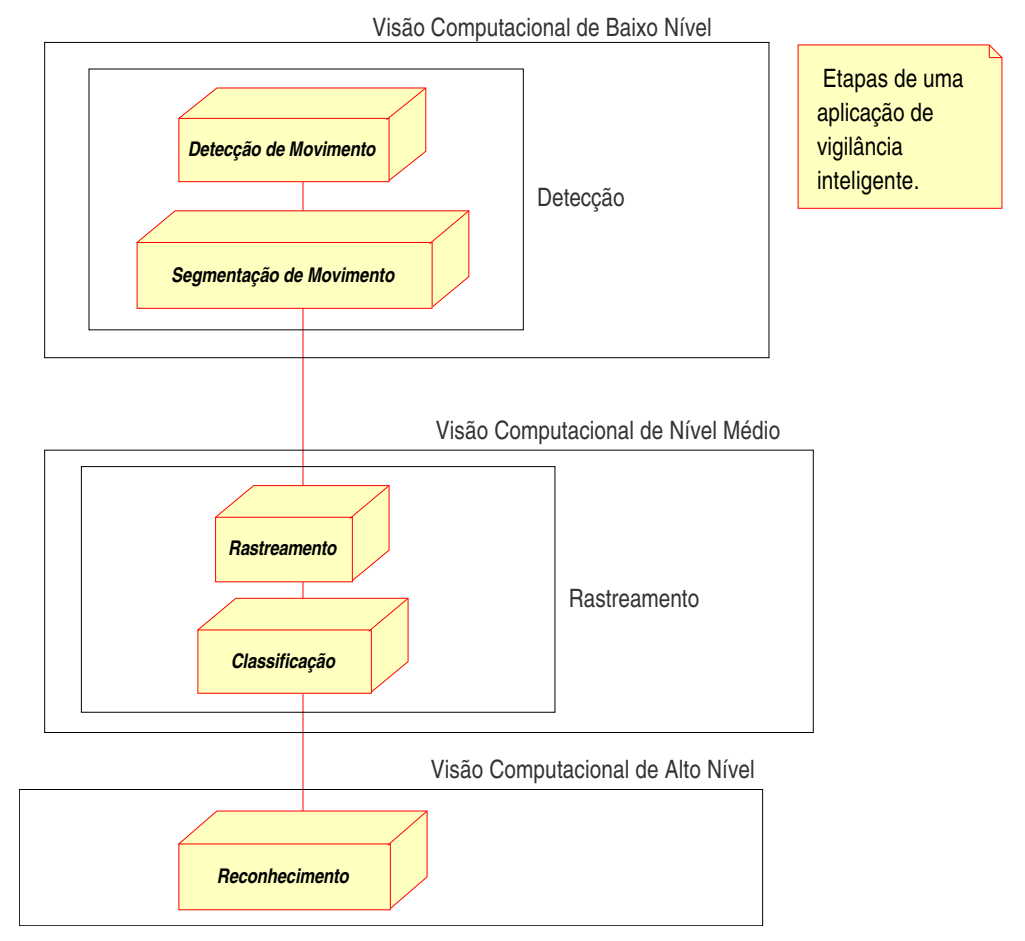

Figura 1.1: Etapas de uma aplicação de vigilância inteligente.

ser criados para facilitar o processo de segmentação ou de rastreamento. E, finalmente, temos a fase de reconhecimento [1], onde ocorre o reconhecimento das ações efetuadas pelos objetos e a classificação do potencial de perigo de cada uma $[66,65,14]$. A Figura 1.1 ilustra as etapas de uma aplicação de vigilância inteligente agrupadas segundo uma classificação hierárquica. A primeira etapa, a detecção, pode ser vista também como uma etapa de Visão Computacional de baixo nível onde são manipulados, principalmente, pixels. A próxima etapa, rastreamento, pode ser vista como uma etapa de Visão Computacional de nível médio onde são manipulados, principalmente, objetos (ou componentes conexos). E a última etapa, reconhecimento, pode ser vista como uma etapa de Visão Computacional de alto nível onde são definidos papéis semânticos para os objetos da cena.

A percepção e interpretação do movimento desempenham um papel importante no sistema visual humano. Em uma dada cena, os objetos em movimento são mais facilmente percebidos e prendem mais a atenção do observador. Várias informações, como profundidade, peso, rigidez, podem ser inferidas a partir do movimento dos objetos em uma cena [9]. Portanto, para um bom entendimento 
semântico de uma cena, a análise do movimento se torna imprescindível. Com isto, a segmentação dos objetos em movimento, que ocorre na etapa de detecção (etapa inicial de aplicações relacionadas ao movimento) [88,23], é de fundamental importância para as etapas posteriores [80]. É nesta etapa que são delimitadas as regiões de interesse das próximas etapas. É um problema bastante estudado, entretanto, permanece um problema difícil, mesmo para imagens adquiridas por uma câmera estacionária.

Um dos primeiros aspectos a serem considerados na etapa de segmentação de movimento é sobre quais restrições serão consideradas que facilitarão a criação das máscaras alvo-fundo, objetivo da etapa. Quanto mais restrições, mais simples torna-se a tarefa de criação da máscara alvo-fundo [63]. Porém, as aplicações de vigilância inteligente devem ser as mais robustos possíveis. Restrições como, por exemplo a câmera permanece estática durante a aquisição da seqüência de vídeo, são muito utilizadas. Esta restrição em especial, evita ser necessário tratar o registro entre quadros consecutivos da seqüência. Algumas restrições tornam a etapa praticamente trivial, como a restrição que o alvo ou o fundo são de uma cor conhecida. Nestes casos, um operador limiar simples é suficiente para segmentar o alvo do fundo. Outro aspecto muito importante na etapa de segmentação de movimento é a iluminação. Sombras, superfícies espelhadas, alterações na intensidade e no posicionamento das fontes de luz podem causar o aparecimento de falsos positivos, falsos negativos ou, ainda, invalidar o modelo de fundo utilizado [60]. Para evitar tais problemas, são necessárias medidas como uma etapa de pré-processamento para normalização da iluminação, uma etapa para remoção de sombras ou a utilização de um algoritmo de segmentação de movimento que seja robusto a alterações na iluminação. Existem algumas situações, listadas em [86], que são consideradas desafios para os algoritmos de segmentação de movimento. Praticamente todas as técnicas estudadas falham em algumas das situações listadas.

De acordo com [88], as principais abordagens utilizadas para lidar com o problema são a diferenciação temporal, a subtração de fundo, a abordagem estatística e o fluxo óptico.

- Diferenciação temporal - Esta abordagem utiliza a diferença simétrica entre dois ou mais quadros sucessivos identificando como alvo as regiões do último quadro que se alteraram.

- Subtração de fundo - Constrói-se um modelo do fundo aplicando-se alguma estatística em uma coleção de quadros sucessivos da seqüência de vídeo. O alvo atual será obtido utilizando-se a diferença simétrica entre o quadro atual e um quadro que representa o modelo de fundo da cena. 
- Abordagem estatística - Neste caso, um modelo estatístico mais complexo é construído para representar o fundo e, baseado neste modelo, classifica-se um pixel como pertencente ao fundo ou ao alvo.

- Fluxo óptico - O fluxo óptico é uma malha em 2D dos vetores de deslocamento aparente entre quadros sucessivos. A segmentação do alvo baseada no fluxo óptico utiliza características desses vetores.

Na diferenciação temporal, além do algoritmo trivial que compara dois quadros consecutivos, é proposto em [11] um algoritmo que utiliza três quadros consecutivos e tornando-se, com isto, mais robusto a ruídos. Os algoritmos da subtração de fundo geralmente utilizam-se de um número específico de quadros no início da seqüência como período de treinamento para construir um modelo de fundo. Uma estatística dos quadros no período de treinamento é utilizada para gerar um quadro que represente o fundo da cena. A média ou a mediana são as estatísticas mais utilizadas para obter o fundo da cena. O fundo pode ser construído no início e atualizado constantemente podendo então se adaptar a alterações no cenário. Na abordagem estatística, modelos estatísticos mais sofisticados são utilizados para representar o fundo da cena. Por exemplo, em [91], usa-se uma gaussiana para modelar cada pixel do fundo da cena e, em [81], são usadas várias gaussianas para este fim. O fluxo óptico pode ser calculado usando técnicas diferenciais, técnicas baseadas em freqüência e técnicas de casamento.

Alguns outros autores como [39] e [64] classificam a subtração de fundo e a abordagem estatística como sendo uma mesma abordagem. Existem ainda várias técnicas híbridas que utilizam alguma combinação das abordagens acima citadas. Em [11,44], por exemplo, os autores utilizam um algoritmo que mistura a diferenciação temporal e a subtração de fundo obtendo bons resultados. Em [2], a diferenciação temporal foi adaptada para ser utilizada com o gradiente [24] de dois quadros consecutivos e um modelo humano 3D é encaixado ao resultado (utiliza-se hardware especializado para obtenção de resposta em tempo real). Em [50], usa-se uma combinação de fluxo óptico e subtração de fundo para a segmentação do alvo. Em [83], são usados filtros morfológicos em conjunto com técnicas de diferenciação temporal para detectar alvos.

Efetuada a segmentação do movimento, uma etapa importante é avaliar o resultado desta segmentação. Esta avaliação pode ser qualitativa ou quantitativa. O problema da avaliação qualitativa é toda a subjetividade que a ela é inerente [74]. Várias pessoas podem avaliar uma mesma segmentação de maneiras diferentes. Para realizar uma avaliação quantitativa, é necessário que exista 
o padrão ouro que é o resultado correto que o algoritmo deve produzir. Produzir um padrão ouro manualmente é um trabalho impraticável. Muitas vezes são escolhidos alguns quadros da seqüência e estes quadros são segmentados manualmente para serem comparados aos resultados dos algoritmos. Outras vezes a segmentação alvo-fundo é feita através de uma figura geométrica que inclui os alvos, como uma caixa de Feret. Definido o padrão ouro, pode-se utilizar duas abordagens diferentes de avaliação dos resultados. A primeira, uma abordagem pontual, faz medições nos quadros para contar quantos pixels acertaram ou erraram os alvos comparando os resultados dos algoritmos de segmentação de movimento com o padrão ouro utilizado [74]. A segunda abordagem, baseada em objetos, não se preocupa em medições individuais dos pixels, mas em medir o percentual dos objetos que foi encontrado pelos algoritmos e o percentual dos objetos que não possui correspondência no padrão ouro, ou seja, é ruído [69].

Este trabalho propõe uma nova técnica para segmentação de movimento baseada em conceitos de Morfologia Matemática (MM). A técnica proposta pertence a abordagem de subtração de fundo. Ela recebe como entrada uma seqüência de vídeo e um conjunto de parâmetros e retorna como saída uma seqüência onde em cada quadro são mostrados os contornos dos alvos identificados. A técnica utiliza os contornos dos quadros e não a intensidade dos pixels que geralmente é utilizada nos algoritmos clássicos. Para cada quadro da seqüência de entrada, calcula-se os contornos do quadro através do gradiente morfológico externo. Um modelo de fundo dos quadros é calculado usando a mediana dos contornos dos quadros. São utilizados um número específico de quadros anteriores ao quadro atual para gerar o modelo de fundo. Os contornos dos alvos do quadro corrente são calculados excluindo dos contornos do quadro corrente aqueles que aparecem como contornos do modelo de fundo. Assim, apenas contornos pertencentes aos alvos estarão nos resultados. Vários filtros conexos são aplicados para reduzir o ruído. O resultado é convertido para binário e adicionado a seqüência de saída. A MM é um ramo do processamento e análise não linear de imagens digitais que utiliza conceitos da Álgebra (como teoria dos conjuntos e reticulados completos) e da Geometria (como translação, convexidade e distância) [33]. Originou-se dos trabalhos de Matheron e Serra [59,78]. Dois operadores básicos da MM são a erosão e a dilatação cuja idéia central é examinar a estrutura geométrica de uma imagem digital através de casamentos entre a imagem principal e pequenos padrões. Esses padrões, chamados de elementos estruturantes, podem variar de tamanho e forma extraindo informações numéricas úteis. Outras operações morfológicas são resultantes da combinação dos operadores básicos com a união, intersecção e a negação (operações básicas da MM). Alguns filtros morfológicas, chamados de conexos, apresentam a propriedade de preservar os principais contornos da cena e não criar novos contornos. 
Ou seja, todos os contornos presentes na imagem resultante também estão na imagem original [15]. Uma região plana é uma região maximal com intensidade de pixel constante. Estes operadores nunca aumentam o número de regiões planas de uma imagem, o que é uma característica interessante para o processo de segmentação.

O algoritmo proposto neste trabalho e alguns algoritmos clássicos de segmentação de movimento foram implementados em uma mesma plataforma de desenvolvimento e comparados utilizando a base pública de vídeos do projeto CAVIAR. Este é um projeto de VC da Universidade de Edimburgo, do Instituto Superior Técnico de Portugal e do Instituto Politécnico Nacional de Grenoble, França. Os vídeos dessa base de dados são coloridos, codificados em MPEG2, com resolução de 288 x 384 pixels e capturados a 25 quadros por segundo. Os vídeos são divididos em 3 grupos: dois deles mostram imagens de clientes em um centro de compras e outro mostra atores no salão de entrada de um laboratório. Foram utilizados 45 vídeos dos 3 grupos da base de dados e quase 50000 quadros nos testes realizados. Todos os quadros dos vídeos da base do CAVIAR estão anotados. Padrão ouro é o resultado esperado da segmentação. O padrão ouro dos vídeos do projeto CAVIAR possui uma caixa de Feret delimitando cada um dos alvos identificados. Como os algoritmos implementados produzem saídas de tipos diferentes, como contornos no algoritmo proposto e o formato completo dos alvos nos outros algoritmos, foram utilizadas caixas de Feret para delimitar cada um dos alvos dos resultados. Isso propicia uma comparação mais justa com o padrão ouro, que também as utiliza. Foram utilizadas duas abordagens de avaliação dos resultados, uma pixel a pixel e outra baseada em objetos. A partir das medidas feitas em cada uma das abordagens, foram calculados diferentes coeficientes que têm o objetivo de expressar em números absolutos a eficiência dos algoritmos em relação a resposta correta. Através dos coeficientes obtidos fica possível comparar os vários algoritmos implementados. A abordagem pontual para avaliação dos resultados baseia-se em quatro medidas: positivos verdadeiros (TP), falsos positivos (FP), negativos verdadeiros (TN) e falsos negativos (FN). A partir destas medidas, em [76], são propostos alguns coeficientes como o PCC e o JC e, em [5], são propostos os coeficientes TRDR e FAR que devem ser analisados em conjunto. A abordagem baseada em objetos, proposta em [67], baseia-se em seis medidas que levam em consideração se um objeto foi detectado corretamente, se foi detectado parcialmente (três medidas diferentes: detecção conjunta, detecção dividida e detecção conjunta-dividida), se o objeto é um ruído ou se ele não foi detectado. Baseando-se nestas seis medidas pode-se propor coeficientes como a taxa de detecção, taxa de não detecção e a taxa de ruído.

O algoritmo proposto obteve ótimos resultados numéricos em praticamente todos os coeficientes 
utilizados nas duas abordagens de avaliação utilizadas. Foram feitas também análises qualitativas onde o algoritmo proposto foi avaliado em algumas situações específicas. Nestas comparações, o algoritmo proposto mostrou-se mais robusto a falsos positivos e a falsos negativos que os outros algoritmos analisados. Os resultados da análise quantitativa corroboraram algumas hipóteses de trabalho usuais relativas aos algoritmos de segmentação de movimento.

\subsection{Contribuições}

As principais contribuições deste trabalho são:

- Estudo detalhado do problema da segmentação de movimento.

- Uma revisão bibliográfica da área de segmentação de movimento que inclui a descrição de aspectos gerais, como a influência da iluminação, registro, restrições utilizadas, situações desafiadoras e a etapa de pós-processamento.

- Um estudo das principais abordagens existentes para tratar o problema e dos algoritmos clássicos de segmentação de movimento.

- Estudo de alguns métodos de avaliação dos resultados obtidos, usando uma abordagem pontual e uma abordagem baseada em componentes conexos.

- Proposta de uma nova técnica para segmentação de movimento baseada na abordagem de modelagem e subtração de fundo que utiliza filtros morfológicos e os contornos dos quadros ao invés de intensidade dos pixels. Esta solução apresentou ótimos desempenhos numéricos e se mostrou mais robusta a problemas em algumas situações analisadas.

- Implementação do algoritmo proposto e de alguns algoritmos clássicos de segmentação de movimento em uma mesma plataforma de desenvolvimento.

- Testes quantitativos dos diversos algoritmos implementados utilizando vários métodos de avaliação de resultados e uma base pública de vídeos. Análise dos resultados obtidos.

- Estudo comparando alguns dos algoritmos implementados em algumas situações particulares, mostrando a maior robustez a falsos positivos e a falsos negativos nas situações avaliadas do algoritmo proposto neste trabalho. 
- A publicação do artigo completo Motion Segmentation Using Mathematical Morphology no XIX Simpósio Brasileiro em Computação Gráfica e Processamento de Imagens (SIBGRAPI 2006) [47] onde foi descrito o algoritmo proposto neste trabalho e alguns resultados preliminares da técnica.

- O trabalho A Morphological Gradient-Based Method to Motion Segmentation para a sessão de pôsteres técnicos do VIII Simpósio Internacional de Morfologia Matemática (ISMM 2007) [48].

- O artigo Segmentação de Movimento Usando Morfologia Matemática para o Workshop de Teses e Dissertações do XX Simpósio Brasileiro em Computação Gráfica e Processamento de Imagens (SIBGRAPI 2007) [49].

- A monografia Segmentação de Movimento para Aplicações de Vigilância Eletrônica, disponível no sítio na Web http://barney.ime.usp.br/〜ronaldo/topicos_2006/assignment/242/429/ monografia.pdf, que descreve o problema da segmentação de movimento, os principais algoritmos e as abordagens utilizadas para tratar o problema.

\subsection{Organização do texto}

O presente capítulo introduz o problema e suas motivações e lista as principais contribuições do trabalho. O Capítulo 2 apresenta algumas definições básicas, os aspectos gerais relativos aos algoritmos de segmentação de movimento, tais como iluminação, registro, restrições, desafios e pósprocessamento, as principais abordagens existentes para tratar o problema, os algoritmos clássicos e métodos de avaliações dos resultados destes algoritmos. O Capítulo 3 apresenta os fundamentos básicos da Morfologia Matemática e introduz vários filtros morfológicos utilizados na técnica proposta. O Capítulo 4 descreve o algoritmo de segmentação de movimento proposto. O Capítulo 5 descreve as implementações dos algoritmos, a base pública de vídeos utilizada, apresenta os resultados numéricos obtidos utilizando vários métodos de avaliação e apresenta uma análise qualitativa em algumas situações específicas. O Capítulo 6 apresenta a conclusão do trabalho e as perspectivas de trabalhos futuros. 


\section{Capítulo 2}

\section{Segmentação de Movimento}

Este capítulo estuda a segmentação de movimento, uma das etapas mais importantes em aplicações de análise de vídeo. A Seção 2.1 apresenta algumas definições básicas necessárias ao restante do trabalho. Na Seção 2.2, são apresentados alguns aspectos gerais dos métodos de segmentação de movimento como o pré e o pós-processamento, aspectos referentes a iluminação, restrições, desafios e registro. Na Seção 2.3, são relacionados os métodos de segmentação de movimento de maior destaque, seja por razões históricas, seja pela originalidade da técnica utilizada. E, finalmente, a Seção 2.4 apresenta alguns métodos de avaliação dos resultados de segmentação de movimento. São estudadas duas abordagens de avaliação de resultados: uma pontual e outra baseada em objetos.

\subsection{Definições preliminares}

Nesta seção, são apresentadas algumas definições importantes para a compreensão do restante do texto. As definições a seguir são válidas no contexto deste trabalho.

Imagem digital: uma imagem pode ser definida como uma função, $f(x, y)$, onde $x$ e $y$ são coordenadas espaciais e a amplitude de $f$ em um ponto $(x, y)$ é chamada de nível de cinza. Quando os valores de $x, y$ e o nível de cinza são todos finitos e discretos, dá-se o nome de imagem digital à função $f[24]$.

De uma maneira mais formal, seja $\mathbb{Z}$ o conjunto dos números inteiros, seja $\mathbb{E}$ um subconjunto de $\mathbb{Z}^{2}$, seja $K$ o intervalo $[0, k-1] \in \mathbb{Z}$, com $k>1$. O produto cartesiano de $K$ é denotado por $K^{d}$, onde $d$ é a quantidade de vezes que $K$ aparece no produto. Assim, podemos definir uma imagem digital como sendo a função de $\mathbb{E}$ em $K$ e o conjunto de todas as imagens digitais possíveis é denotado por $K^{\mathbb{E}}[3,33]$. O valor de $k$ é o número de níveis de cinza que a imagem digital possui. Geralmente, as 
imagens digitais são denotadas por letras do alfabeto romano minúsculas como $f$ ou $g$.

Pixel: é cada um dos elementos espaciais finitos que compõem uma imagem digital [24].

Imagem em níveis de cinza: ver imagem digital.

Imagem binária: uma imagem digital é dita binária se sua amplitude (ou níveis de cinza) apresentar apenas dois valores possíveis, geralmente 0 e 1. Ou seja, o tamanho do contradomínio na definição de imagem digital vale 2 .

Imagem multibandas: é uma imagem digital que possui mais de um valor para cada pixel. Cada valor do pixel está associado a uma banda da imagem.

Imagem colorida: é uma imagem multibanda cujas bandas estão associadas a um modelo de cor.

Modelo de cor: um sistema de coordenadas tridimensional onde cada cor é representada por um único ponto [24].

$\boldsymbol{R G B}$ : o modelo de cor mais popular, baseado num sistema de coordenadas de três eixos definindo um subespaço em forma de cubo. Os eixos representam a intensidade de vermelho, verde e azul [24].

$\boldsymbol{Y} \boldsymbol{U} \boldsymbol{V}$ : modelo de cor que possui um eixo representando o brilho e outros dois representando a informação de cor. Este modelo é utilizado nos padrões de vídeo PAL, NTSC e SECAM.

Vizinhança de um pixel: a definição de vizinhança de um pixel é importante para diversos processamentos e conceitos como contornos e conectividade. Geralmente são definidos 2 tipos de vizinhança: a vizinhança 4 e a vizinhança 8 . Para o pixel localizado na posição $(x, y)$, a vizinhança 4 é o conjunto de pixels localizados nas posições: $(x+1, y),(x, y+1),(x-1, y)$ e $(x, y-1)$; a vizinhança 8 é o conjunto de pixels localizados nas posições: $(x+1, y),(x+1, y+1),(x, y+1),(x-1, y+1),(x-$ $1, y),(x-1, y-1),(x, y-1)$ e $(x+1, y-1)[12]$.

Caminho conexo: dois pontos $P$ e $Q$ possuem um caminho conexo entre si se existir uma seqüência de pontos: $p_{1}, p_{2}, p_{3}, \ldots p_{N}$ onde $p_{i}$ é vizinho a $p_{i+1}$ com $p_{1}=P$ e $p_{N}=Q$. Observe que este conceito depende da definição de vizinhança (4 ou 8).

Componente conexo: é um conjunto de pontos onde, para quaisquer pixels $P$ e $Q$ pertencentes ao conjunto, existe um caminho conexo entre eles.

Objeto: no contexto deste trabalho, objeto é um componente conexo obtido através de uma 
segmentação de imagens.

Contorno: linha que delimita um componente conexo.

Borda: ver contorno.

Conectividade: um operador utiliza conectividade 4 ou 8 dependendo do conceito de vizinhança (4 ou 8) que é adotado em sua execução.

Menor retângulo envolvente: menor retângulo que contém um componente conexo específico $[12]$.

Caixa de Feret: menor retângulo envolvente alinhado a um dos eixos da imagem digital [12].

Vídeo digital: pode ser definido como uma lista ordenada de imagens digitais, $\mathcal{V}=\left(f_{1}, f_{2}, f_{3}, \ldots, f_{n}\right)$, onde cada imagem digital da seqüência, $f_{i} \in K^{\mathbb{E}}$, é chamada de quadro. A ordem dos quadros do vídeo pode ser dada pelo tempo e, em geral, são apresentados em intervalos regulares de tempo.

Formato MPEG: formatos de codificação de vídeo e áudio definidos pelo grupo de mesmo nome.

Pico: vendo uma imagem digital como uma superfície topológica, um pico é um ou mais pixels que possuem amplitude maior que seus pixels vizinhos, uma região de máximo local.

Base: vendo uma imagem digital como uma superfície topológica, uma base é um ou mais pixels que possuem amplitude menor que seus pixels vizinhos, uma região de mínimo local.

Alvo: objeto de interesse em uma imagem ou vídeo digital. No contexto deste trabalho, alvos são objetos em movimento na seqüência de vídeo, como pessoas, animais e veículos.

Objeto alvo: ver alvo.

Fundo: todo o resto da imagem ou do quadro do vídeo que não é alvo. Neste trabalho, o fundo é geralmente o que não se move, como o cenário, a mobília, plantas, objetos de decoração, entre outros. Os conceitos de alvo e fundo são subjetivos e geralmente vão depender do contexto da imagem ou da seqüência de vídeo.

Segmentação: é o processo de particionar uma imagem digital em suas partes constituintes ou em objetos [24].

Segmentação de movimento: processo de particionar os objetos que estejam em movimento em uma seqüência de vídeo. 
Segmentação de objetos em movimento: ver segmentação de movimento.

Segmentação de alvos: processo de particionar objetos de interesse em uma imagem digital, os alvos.

Segmentação alvo-fundo: ver segmentação de alvos.

Máscara alvo: é uma imagem binária resultado do processo de segmentação de alvos. A máscara alvo contém pixels de valor 1 onde existe um alvo e contém pixels de valor 0 na região do fundo.

Máscara alvo-fundo: ver máscara alvo.

Positivo verdadeiro: um pixel corretamente classificado como alvo por um algoritmo de segmentação de movimento.

Negativo verdadeiro: um pixel corretamente classificado como fundo por um algoritmo de segmentação de movimento.

Falso positivo: um pixel classificado como alvo, porém, pertencendo ao fundo.

Falso negativo: um pixel classificado como fundo, porém, pertencendo ao alvo.

Fantasma: ver falso positivo.

Modelo de fundo: é um modelo utilizado para classificar se um pixel pertence ou não ao fundo de uma seqüência de vídeo.

Estimação de fundo: é o processo de construção do modelo de fundo.

Estimação de fundo fixa: é quando o fundo é estimado apenas no início da seqüência de vídeo e não é mais atualizado para refletir alterações que, por ventura, tenham ocorrido no cenário ao longo da seqüência.

Estimação de fundo dinâmica: é quando o processo de construção do modelo de fundo estima e atualiza constantemente o modelo que passa a refletir alterações que, por ventura, tenham ocorrido no cenário.

Período de treinamento: período durante o qual os dados estão sendo analisados para a criação de um modelo. 


\subsection{Aspectos Gerais}

Nesta seção, são apresentados aspectos gerais aos algoritmos de segmentação de movimento. Na Seção 2.2.1, são apresentadas algumas restrições utilizadas pelas aplicações de vigilância inteligente para simplificar os modelos. Aspectos referentes a iluminação são tratados na Seção 2.2.2. Na Seção 2.2.3, é abordada a utilização do registro entre os quadros de uma seqüência de vídeo e o pósprocessamento é tratado na Seção 2.2.4. A Seção 2.2.5 lista situações desafiadoras em que grande parte dos algoritmos de segmentação de movimento falham.

\subsubsection{Restrições}

Como em muitas aplicações na área de VC, os métodos de segmentação de movimento fazem uso de várias restrições com a finalidade principal de simplificar os modelos utilizados [63].

Quanto menos restrições existirem em uma aplicação, mais robusta ela se torna. Porém, quanto mais restrições, mais simples se torna o sistema [63]. Aplicações de vigilância inteligente, por exemplo, devem possuir o menor número possível de restrições para que se tornem as mais robustas possíveis.

Uma restrição importante é que a câmera permaneça estática (sem movimento), como em [47]. Isto simplifica bastante os algoritmos, pois, nesta situação, eles não precisam tratar o problema do registro entre um quadro e o próximo, isto é, alinhá-los segundo um mesmo sistema de coordenadas. Outra restrição bastante usada é a de iluminação constante no cenário, o que evita a necessidade de tratar eventuais diferenças na iluminação entre quadros consecutivos numa seqüência de imagens.

Algumas restrições tornam o problema da segmentação de movimento trivial, sendo necessário apenas a aplicação de um operador limiar [24] para efetuar o processo de segmentação com sucesso, como na técnica Chroma key [18], bastante utilizada no cinema. Dentre essas restrições, estão a de que o fundo possua uma cor uniforme e conhecida, os alvos possuam marcadores específicos ou os alvos sejam de uma cor conhecida e uniforme.

\subsubsection{Iluminação}

Em várias aplicações, a segmentação de movimento necessita ser robusta a alterações na iluminação. Várias características em um cenário, como por exemplo, sombras, superfícies espelhadas e alterações na intensidade ou no posicionamento das fontes de luz, podem causar problemas aos métodos de segmentação de movimento [60,74]. Esses problemas podem ocorrer tanto em ambientes 
externos quanto internos.

A presença de sombras e superfícies espelhadas na cena podem causar a detecção de falsos positivos e prejudicar os resultados das fases posteriores como a classificação ou o rastreamento [19]. Existem técnicas específicas para a remoção de sombras, como em [25] e em [22]. As alterações na intensidade e no posicionamento das fontes de luz podem invalidar o modelo de fundo utilizado. Nestes casos, os algoritmos de segmentação de movimento devem estar preparados para adaptarem-se a essas alterações na iluminação.

Várias são as técnicas disponíveis para compensar estas alterações na iluminação. Uma solução é utilizar uma fase de pré-processamento que compensaria as diferenças de iluminação entre os quadros comparados [74]. Assim, a diferença de iluminação não influenciaria no resultado do método de deteç̧ão e segmentação de movimento. Como técnicas para compensar as alterações na iluminação em uma fase de pré-processamento, podem ser citadas:

- A normalização de intensidade é a mais antiga técnica utilizada para correção de variações na iluminação [52]. Consiste em normalizar uma imagem para que os valores de intensidade de seus pixels tenham a mesma média e a mesma variância que outra imagem:

$$
\tilde{f}_{i}(x, y)=\frac{\sigma_{i-1}}{\sigma_{i}}\left\{f_{i}(x, y)-\mu_{i}\right\}+\mu_{i-1}
$$

onde $f_{i}(x, y) \in K$ é o valor do pixel $(x, y)$ do quadro $i$ da seqüência, $\tilde{f}_{i}(x, y) \in K$ é o valor normalizado do pixel $(x, y)$ do quadro $i, \mu_{i-1}$ e $\mu_{i}$ são as médias das intensidades de todos os pixels nos quadros $i-1$ (anterior) e $i$ (atual), respectivamente, e $\sigma_{i-1}$ e $\sigma_{i}$ são os desvios-padrões dos quadros $i-1$ e $i$, respectivamente.

Uma alternativa é normalizar ambas as imagens para ter média 0 e variância 1 . Outra alternativa seria, ao invés de utilizar em cada pixel uma estatística global, dividir as imagens em blocos e utilizar estatísticas desses blocos locais no processo de normalização [74].

- A filtragem homomórfica é bastante utilizada em cenas contendo superfícies lambertianas [74]. Superfícies lambertianas são aquelas que seguem a lei do cosseno de Lambert [21]. Esta lei diz que a intensidade da luz visível observada é diretamente proporcional ao cosseno do ângulo que se forma entre a linha que vai do observador até a superfície e a normal a esta superfície. Portanto, nestes cenários, a intensidade da imagem observada no pixel $(x, y)$ no quadro $i$ pode ser modelada como o produto entre duas componentes, a iluminação das fontes de luz, $l_{i}(x, y)$, 
e a reflectância da superfície do objeto que pixel pertence, $r_{i}(x, y)$ :

$$
f_{i}(x, y)=l_{i}(x, y) r_{i}(x, y)
$$

Este é o modelo de sombra de Phong [73]. Apenas o componente de reflectância $r_{i}(x, y)$ possui informações sobre os objetos na cena. Se for possível filtrar o componente de iluminação $l_{i}(x, y)$, tem-se um resultado invariante a iluminação. Sabe-se que a componente de iluminação $l_{i}(x, y)$ possui uma freqüência espacial menor do que a freqüência da componente de reflectância $r_{i}(x, y)$ [85]. Aplica-se então o logaritmo em ambos os lados da Equação 2.2:

$$
\ln \left(f_{i}(x, y)\right)=\ln \left(l_{i}(x, y)\right)+\ln \left(r_{i}(x, y)\right)
$$

Assim o modelo de sombras passa a ter termos aditivos que podem ser separados utilizando-se um filtro passa-alta $\psi$. O componente reflectância do quadro $i$ pode ser estimado por:

$$
\tilde{r_{i}}(x, y)=e^{\psi\left(\ln \left(f_{i}(x, y)\right)\right)}
$$

onde $\psi$ é um filtro passa-alta e $\tilde{r}_{i}(x, y)$ é o componente de reflectância estimado para o quadro $i$.

- Outros modelos de iluminação são usados para cenários que não se adequam a suposição Lambertiana. Eles são necessários em várias situações, como, por exemplo, em imagens embaixo d'água. Em [70], foi proposto um modelo linear genérico para imagens de uma mesma cena; $\mathrm{PCA}^{1}[16]$ é usado em [26] para extrair um conjunto de imagens base que representa a cena em todas as condições de iluminação possíveis. Em [60], é assumido que o modelo Lambertiano para modelar as superfícies não é perfeito e então é gerada uma imagem de reflectância para cada quadro da seqüência de imagens; com estas múltiplas imagens de reflectância, é proposto um método mais eficiente para remoção das sombras dos objetos estáticos. Em [62], é utilizado o gradiente para auxiliar no processo de remoção de sombras.

Outra alternativa é utilizar modelos de fundo que se adaptem rapidamente às alterações de iluminação no ambiente. Alguns desses modelos serão vistos na Seção 2.3.

\footnotetext{
${ }^{1}$ do inglês principal component analysis ou análise do componente principal
} 


\subsubsection{Registro}

Registro é a tarefa de alinhar duas ou mais imagens tiradas em tempos diferentes, por diferentes sensores ou de diferentes pontos de vista [7]. Nas seqüências de vídeo, onde a câmera permanece estática, o registro não é necessário, pois todos os quadros têm a mesma visada. Por outro lado, se a câmera é móvel, o registro torna-se necessário, já que a cada instante a câmera apresenta uma visada ligeiramente diferente da visada anterior.

Existem inúmeras técnicas de registro de imagens. Elas, porém, geralmente seguem uma mesma idéia [94]. Em primeiro lugar, são detectadas características marcantes nas imagens a serem registradas. Essas detecções podem ocorrer tanto manualmente quanto automaticamente. A seguir, é feito um casamento entre as mesmas características nas duas imagens usadas, uma função de mapeamento é gerada com os parâmetros sendo calculados baseados no alinhamento das características. E, finalmente, a imagem final registrada é gerada aplicando-se a função de mapeamento definida na etapa anterior.

\subsubsection{Pós-Processamento}

A maioria dos algoritmos de segmentação de movimento utilizam uma abordagem pixel a pixel. Esta abordagem de tratar os pixels de maneira independente causa alguns inconvenientes nas saídas dos algoritmos. Os resultados geralmente são ruidosos, apresentando pequenos componentes conexos isolados, buracos nos alvos e contornos serrilhados [74], o que normalmente requer uma etapa de pós-processamento. Geralmente, são utilizadas técnicas de filtragem para minimizar os problemas citados, como o filtro da mediana [24] ou um filtro morfológico [78].

Uma abordagem preferível é a utilização de alguma restrição espacial no próprio algoritmo de segmentação do alvo, evitando assim a necessidade desta etapa de pós-processamento. Várias destas técnicas que tentam reforçar a consistência regional na segmentação alvo-fundo utilizam conceitos de campos aleatórios de Markov-Gibbs [74].

\subsubsection{Situações Desafiadoras}

Em [86], são listadas várias situações que ainda são difíceis para os algoritmos de segmentação de movimento. As situações listadas dificultam a criação e a atualização de um modelo de fundo eficaz para a cena. A maior parte dos algoritmos de segmentação de movimento falham em alguma das situações listadas. 
- A primeira situação ocorre quando objetos do fundo se movem durante a seqüência. O exemplo clássico para esta situação é uma cadeira que tenha sido arrastada durante a cena. A mobília é tipicamente um objeto de fundo da cena e o algoritmo deve ter a possibilidade de se adaptar a estas alterações que, por ventura, ocorram. Caso o algoritmo não se adapte, falsos positivos (nas posições original e atual do objeto que se moveu) estarão presentes em todo o restante da cena.

- A próxima situação desafiadora para os algoritmos de segmentação de movimento é a alteração da intensidade e do posicionamento das fontes de luz durante a cena. O exemplo mais comum para esta situação ocorre em filmagens em ambiente externo, ao longo do dia, quando a fonte de iluminação (Sol) tem sua intensidade e posição alteradas.

- Ligar ou desligar fontes de iluminação artificiais em uma cena interna provoca a alteração dos valores do pixel em toda a cena e, provavelmente, invalida o modelo de fundo utilizado até então.

- Cenas com fundo dinâmico como, por exemplo, árvores balançando ao vento, água corrente ou nuvens se deslocando. Tipicamente, são situações de fundo de cena, mas os modelos de fundo tradicionais têm dificuldades em incorporá-los.

- A camuflagem ocorre quando um alvo possui partes com valores de pixels muito próximos ao do fundo da cena. Assim, estas partes dos alvos não são detectadas e se confundem com o fundo da cena.

- A abertura ocorre quando um alvo possui uma parte grande de textura homogênea. Os algoritmos de segmentação de movimento podem não conseguir detectar o alvo por completo durante um deslocamento na cena. As partes mais próximas do contorno do alvo são mais fáceis de detectar do que as partes internas do alvo quando a textura é homogênea.

- Uma pessoa dormindo ou acordando faria parte ou não do fundo da cena? Estas são situações que necessitam de um entendimento semântico da cena para a segmentação correta. Os algoritmos de segmentação de movimento são algoritmos de visão de baixo nível e, portanto, não devem possuir o entendimento semântico da cena. Assim, este tipo de segmentação deve ser deixada para etapas posteriores que possuam mais informações para interpretar a cena.

- A presença de sombras na cena, como já foi visto, dificulta o processo de segmentação de alvos e também é uma das situações desafiadoras listadas. 


\subsection{Abordagens de Segmentação de Movimento}

Esta seção apresenta as principais abordagens usadas para lidar com o problema de segmentação de movimento segundo a classificação proposta por [88].

\subsubsection{Diferenciação Temporal}

É a mais simples das quatro abordagens. A técnica mais comum nesta abordagem é calcular a diferença simétrica entre o pixel do quadro atual e seu correlato do quadro anterior. Caso a diferença seja maior que um limiar, o pixel pertence ao alvo; caso contrário, pertence ao fundo. Como pontos positivos dessa abordagem, pode-se citar a simplicidade, a rapidez do algoritmo e a robustez em relação a alterações na iluminação. Contudo, o resultado apresenta uma forma bastante pobre do alvo e também é muito influenciado por ruídos. Conseqüentemente, aparecem buracos nos alvos da cena [88]. Uma alternativa para reduzir o ruído é utilizar informações de três quadros consecutivos [11]. Para recuperar o formato completo do alvo, pode-se utilizar algum operador conexo [15].

A diferenciação de dois quadros ou diferenciação simples é o algoritmo mais utilizado [74]. A máscara alvo-fundo, $A_{i} \in K^{\mathbb{E}}$, no instante de processamento do quadro $i$ para o pixel $(x, y)$ vale:

$$
A_{i}(x, y)= \begin{cases}1 & \text { se }|D(x, y)|>\tau \\ 0 & \text { caso contrário }\end{cases}
$$

onde $|D(x, y)|$ é a diferença absoluta entre o valor do pixel $(x, y)$ no quadro atual $i, f_{i}(x, y)$, e o seu valor no quadro anterior, $f_{i-1}(x, y), \tau$ é um limiar definido previamente para delimitar o alvo do fundo.

Geralmente, $\tau$ é definido empiricamente e a técnica é muito dependente deste limiar. Porém, existem estudos para definição automática deste limiar [75,76]. As Figuras 2.1(a) e 2.1(b) mostram dois quadros de uma seqüência do projeto CAVIAR. Os resultados da diferenciação temporal usando esses dois quadros são mostrados nas Figuras 2.1(c), 2.1(d), 2.1(e) e 2.1(f) utilizando os limiares 5, 10, 20 e 50, respectivamente. Nota-se que, quando foi utilizado um valor baixo para o limiar, aparece bastante ruído nos resultados. Por outro lado, caso o limiar seja de valor alto, partes do alvo desaparecem dos resultados.

Uma tentativa de diminuir o ruído nos resultados foi introduzida em [11] com a diferenciação 
de três quadros. Este algoritmo é bem parecido com o algoritmo anterior, onde a máscara-alvo, $A_{i}(x) \in K^{\mathbb{E}}$, do quadro $i$ é definida por:

$$
A_{i}(x, y)= \begin{cases}1 & \text { se }\left(\left|D_{1}(x, y)\right|>\tau\right) \wedge\left(\left|D_{2}(x, y)\right|>\tau\right) \\ 0 & \text { caso contrário, }\end{cases}
$$

onde $D_{1}$ e $D_{2}$ são duas funções em $K^{\mathbb{E}}$, com $\left|D_{1}(x)\right|=\left|f_{i}(x, y)-f_{i-1}(x, y)\right|$ e $\left|D_{2}(x, y)\right|=\mid$ $f_{i}(x, y)-f_{i-2}(x, y) \mid$.

Na Figura 2.2, é feita uma comparação entre os resultados da diferenciação temporal usando dois (Figura 2.2(a)) e três quadros (Figura 2.2(b)). O resultado usando três quadros apresenta menos ruído que o algoritmo anterior.

\subsubsection{Subtração de Fundo}

A segmentação de movimento pode ser obtida analisando cada quadro em relação a um quadro representando o modelo do fundo da cena. A diferença simétrica [31] entre cada pixel do quadro atual e do quadro que representa o modelo de fundo é calculado e, se esta diferença for maior que um limiar previamente definido, este pixel é considerado como pertencente ao alvo. Caso contrário, o pixel será considerado como pertencente ao fundo. Como vantagens desta abordagem, pode-se citar a simplicidade e a boa recuperação da forma do alvo. Por outro lado, esta abordagem é bastante suscetível a alterações na iluminação e existe ainda o custo computacional de criar e manter um modelo do fundo [86]. Esta abordagem é indicada para situações em que o fundo se altera pouco ou lentamente [88].

\section{Modelos de Fundo}

A criação de um modelo de fundo confiável é fundamental para o sucesso dos métodos desta abordagem. Uma solução trivial para criar modelos de fundo é filmar o cenário sem os alvos ou, então, estabelecer uma cor específica para o fundo, como na técnica Chroma key [18]. Porém, ambas as soluções são impossíveis em cenários não controlados. Uma solução mais realística seria utilizar um subconjunto dos quadros iniciais da seqüência de imagens para estimar o fundo utilizando alguma estatística (como a média ou a mediana). A média é simples e eficiente, mas é muito influenciada por valores discrepantes. A mediana é uma estatística mais robusta [88], contudo implica em um maior custo computacional e de armazenamento. A Figura 2.3 mostra alguns quadros (quadros número 
100, 200, 300, 400 e 500) da seqüência LeftBag do projeto CAVIAR e a Figura 2.4 mostra o modelo de fundo estimado para a mesma seqüência usando a média dos 100, 200, 300, 400 e 500 primeiros quadros. Na Figura 2.5, é feita uma comparação entre o modelo de fundo estimado pela média e pela mediana para a mesma seqüência usando os 100, 200 e 300 primeiros quadros da seqüência. Pode-se notar que o resultado do modelo de fundo usando a mediana, após um número suficiente de quadros, 300 no caso, é menos ruidoso que o resultado utilizando a média.

As representações dos modelos de fundo geralmente estão em níveis de cinza ou no espaço RGB, mas outros modelos de cores também podem ser utilizados [64]. Em [55], é proposta uma técnica criação de um modelo de fundo para câmeras móveis que faz uma junção das regiões de fundo dos quadros formando um grande mosaico como modelo de fundo. Em cenários não controlados, o modelo de fundo requer uma atualização constante. A iluminação se altera e objetos se deslocam no cenário, como cadeiras que são arrastadas ou uma porta que é aberta. Estas modificações acabam invalidando o modelo de fundo corrente, sendo necessária a atualização. Para controlar as alterações no fundo da cena, pode-se utilizar uma taxa de aprendizado que define a velocidade com que as alterações do fundo serão incorporadas ao modelo [62].

A inicialização de vários modelos exige que exista um período sem movimento na cena. Esta exigência impossibilita a utilização desses algoritmos em cenários reais onde é impossível ter este período sem movimento no cenário. Uma solução para iniciar um modelo de fundo, mesmo na presença de movimento, é utilizar a mediana dos valores de pixels de um período relativamente grande da seqüência de vídeo. Assume-se que, durante este período, mais da metade do tempo o fundo permaneça visível.

\section{Fundo Estimado pela Média}

A subtração de fundo estimado pela média, citada em [69], utiliza alguns quadros inicias da seqüência de vídeo para estimar o fundo a partir da média. O modelo do fundo $B \in K^{\mathbb{E}}$ é estimado como:

$$
B(x, y)=\frac{1}{m} \sum_{i=1}^{m} f_{i}(x, y),
$$

onde $m$ o número de quadros iniciais da seqüência, com $1 \leq m \leq n$ e $n$ é o número total de quadros da seqüência.

A máscara alvo-fundo para o quadro $i, A_{i}$, é calculada como a diferença simétrica maior do que 


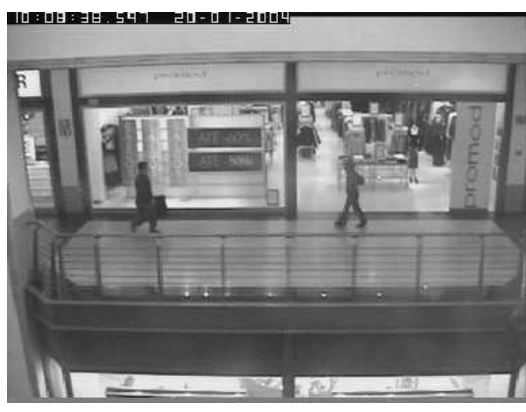

(a) Quadro 49 .

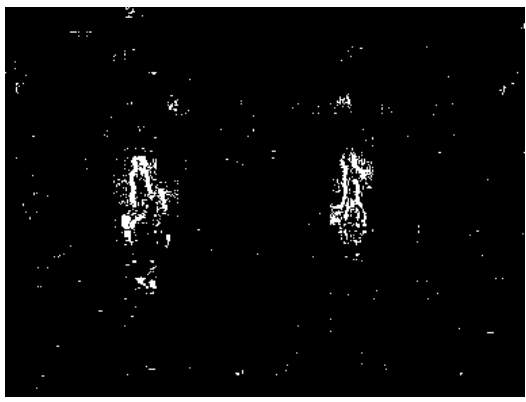

(c) Resultados da diferenciação de dois quadros (limiar 5).

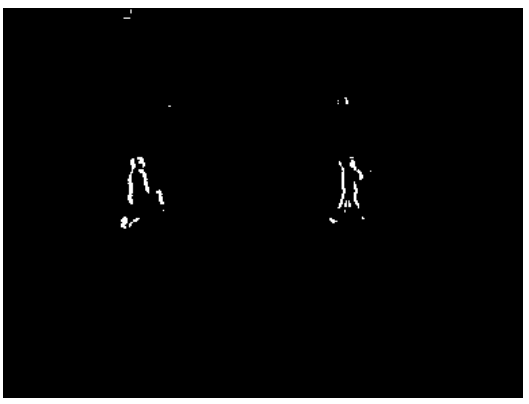

(e) Resultados com limiar 20.

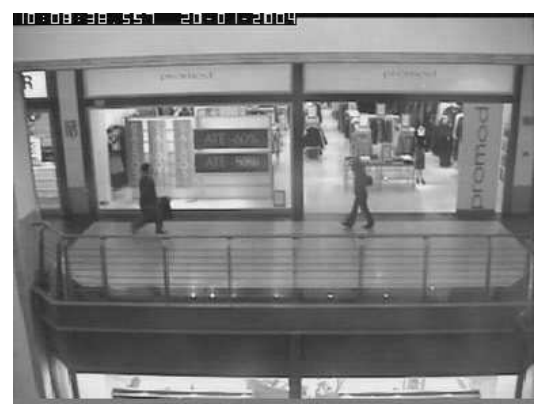

(b) Quadro 50.

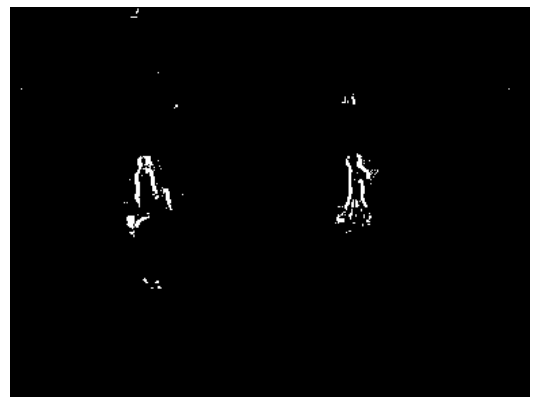

(d) Resultados com limiar 10.

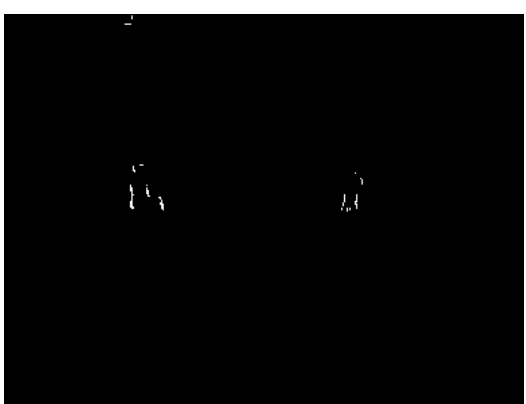

(f) Resultados com limiar 50.

Figura 2.1: Diferenciação temporal de dois quadros. Foram utilizados quadros da seqüência TwoEnterShop2front do Projeto CAVIAR. 


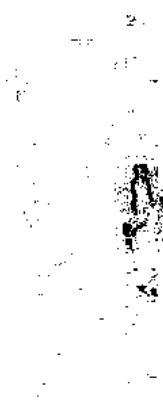

(a) Diferenciação temporal usando dois quadros (50 e 49) da seqüência TwoEnterShop2front do projeto CAVIAR (limiar 5).

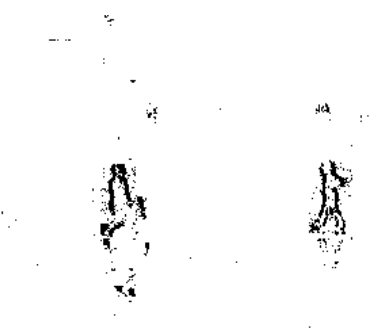

(b) Diferenciação temporal usando três quadros (50, 49 e 48) da mesma seqüência (limiar 5).

Figura 2.2: Comparação dos resultados da diferenciação de dois e três quadros. 


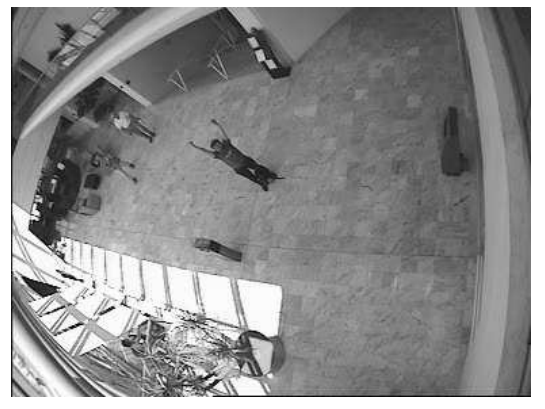

(a) Quadro 100 .

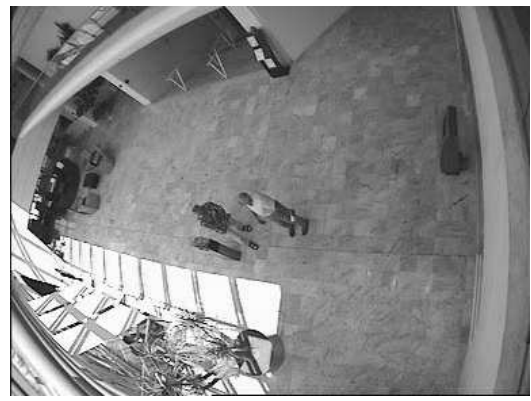

(c) Quadro 300 .

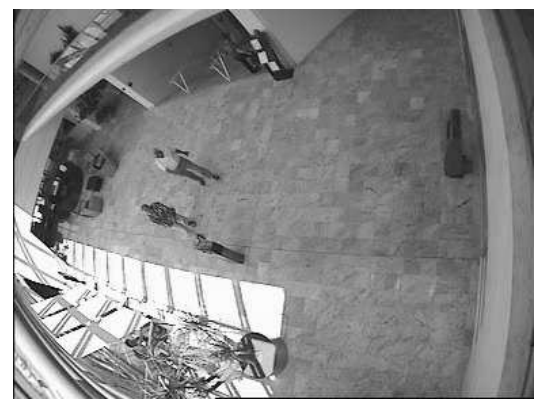

(b) Quadro 200.

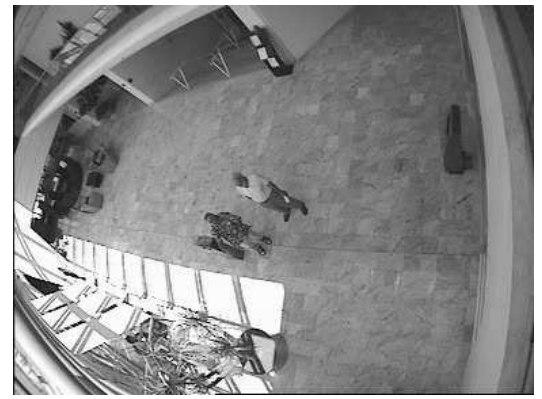

(d) Quadro 400 .

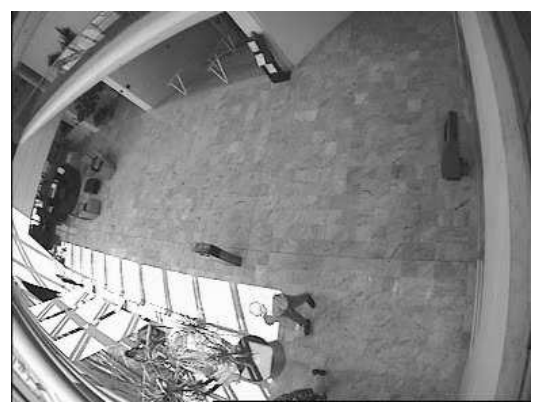

(e) Quadro 500 .

Figura 2.3: Quadros 100, 200, 300, 400 e 500 da seqüência LeftBag do projeto CAVIAR. 


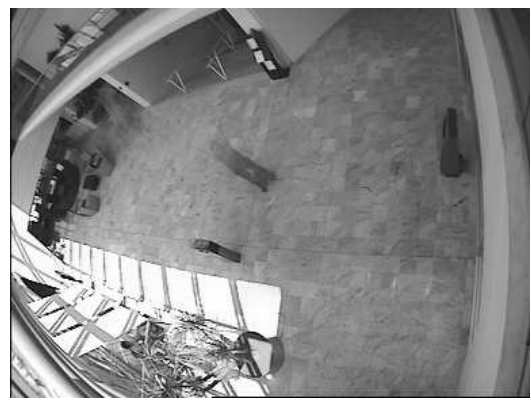

(a) Fundo estimado pela média dos 100 primeiros quadros da seqüência.

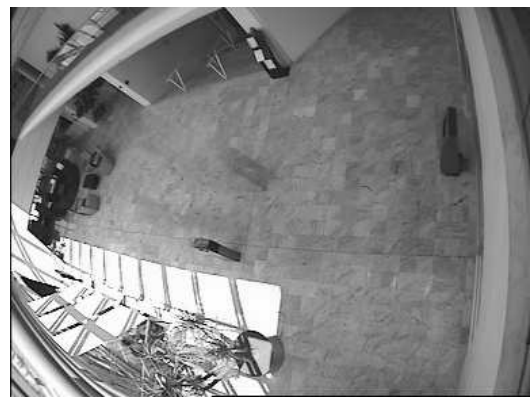

(c) Fundo estimado pela média dos 300 primeiros quadros da seqüência.

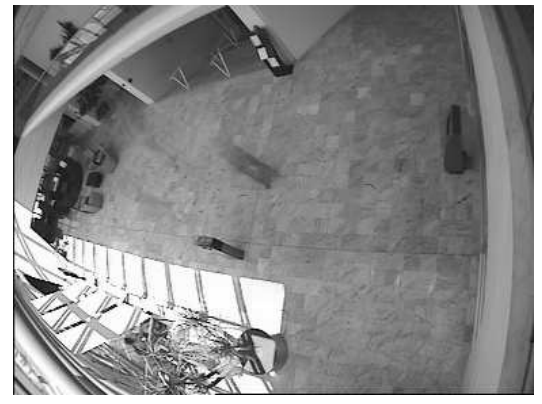

(b) Fundo estimado pela média dos 200 primeiros quadros da seqüência.

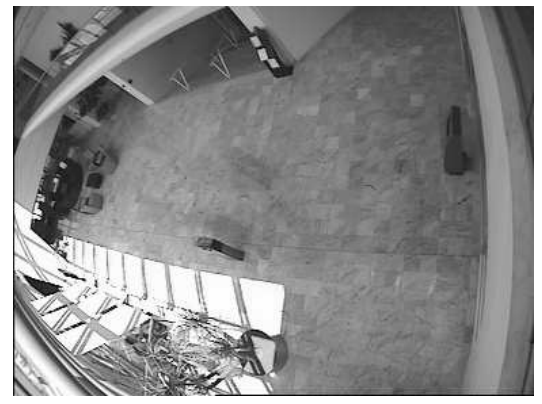

(d) Fundo estimado pela média dos 400 primeiros quadros da seqüência.

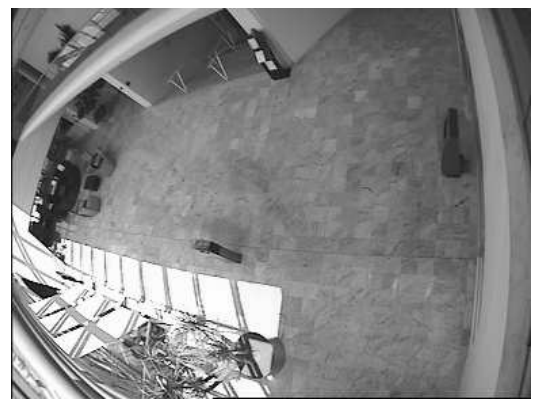

(e) Fundo estimado pela média dos 500 primeiros quadros da seqüência.

Figura 2.4: Modelo de fundo da seqüência LeftBag do projeto CAVIAR estimado pela média dos quadros. 


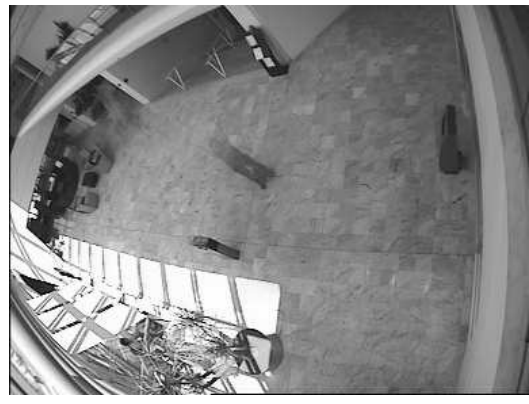

(a) Fundo estimado pela média dos 100 primeiros quadros da seqüência.

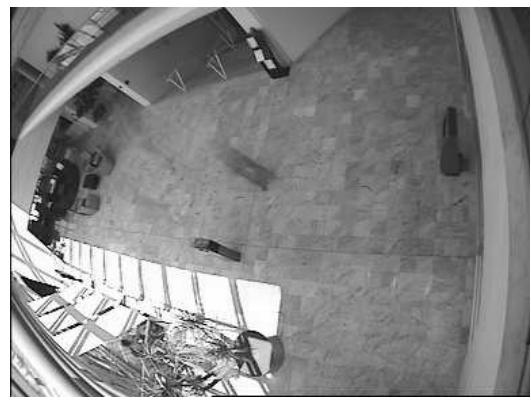

(c) Fundo estimado pela média dos 200 primeiros quadros da seqüência.

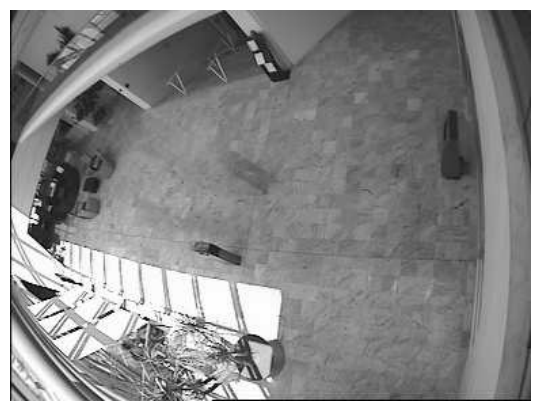

(e) Fundo estimado pela média dos 300 primeiros quadros da seqüência.

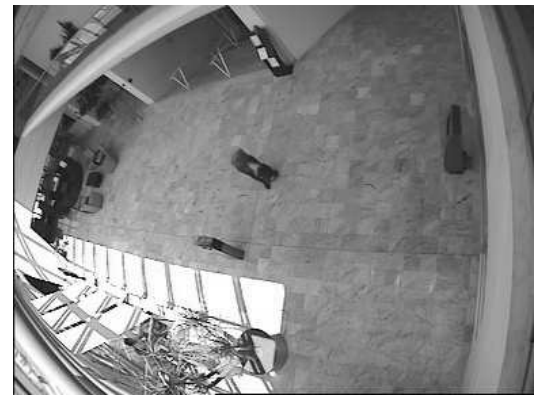

(b) Fundo estimado pela mediana dos 100 primeiros quadros da seqüência.

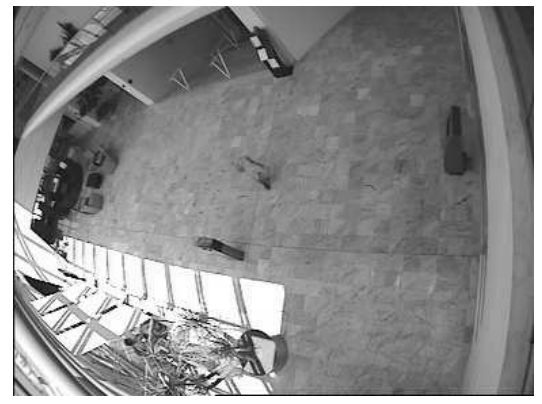

(d) Fundo estimado pela mediana dos 200 primeiros quadros da seqüência.

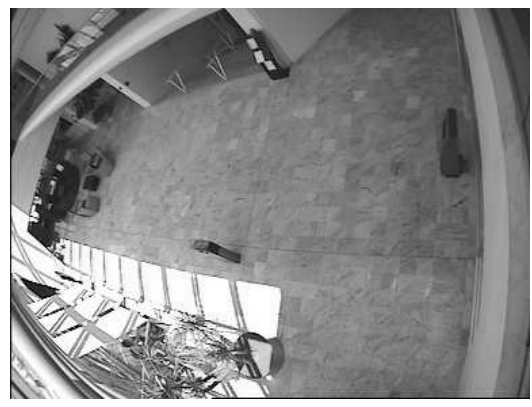

(f) Fundo estimado pela mediana dos 300 primeiros quadros da seqüência.

Figura 2.5: Comparação entre os modelos de fundo estimados pela média e pela mediana. 
um limiar pré-definido $\tau$ entre o quadro atual, $f_{i}$, e o modelo estimado $B$ :

$$
A_{i}(x, y)=\left|f_{i}(x, y)-B(x, y)\right|>\tau
$$

Este algoritmo é rápido, porém, o resultado depende muito do limiar escolhido $\tau$ e não é muito robusto, podendo produzir um bom resultado para algumas seqüências e para outras, não. Como já foi citado, a utilização da média para a estimação do fundo não é o ideal, pois é uma estatística muito suscetível a valores discrepantes.

Um problema deste algoritmo é a falta de adaptação do fundo a alterações no cenário. Estimado o fundo, ele não é mais atualizado. Assim, algum objeto na cena que se moveu após a estimação do fundo sempre aparecerá no resultado como falso positivo. Um exemplo é o móvel que foi arrastado no cenário após a estimação de fundo. Calculada a diferença simétrica entre o quadro atual e o fundo estimado, a posição anterior onde o móvel se encontrava e a posição atual do móvel na cena aparecerão no resultado como falsos positivos.

\section{Fundo Estimado pela Mediana}

Um algoritmo mais robusto em relação a valores discrepantes é a estimação do fundo baseada na mediana. Estima-se o fundo calculando a mediana dos valores dos pixels dos $m$ primeiros quadros da seqüência:

$$
B(x, y)=\text { mediana }_{\{1 \leq i \leq m\}} f_{i}(x, y),
$$

onde $B \in K^{\mathbb{E}}$ é o modelo de fundo, $m$ é o número de quadros da seqüência utilizados na estimação do fundo, com $1 \leq m \leq n$, $n$ é o número de quadros da seqüência.

A máscara alvo-fundo para o quadro $i, A_{i} \in K^{\mathbb{E}}$, é calculada como o algoritmo anterior utilizandose um limiar pré-definido $\tau$. Este algoritmo, como o anterior, também possui o fundo estático. A Figura 2.6 mostra a máscara alvo-fundo produzida pela subtração de fundo estimado pela média (Figura 2.6(a)) e pela subtração de fundo estimado pela mediana (Figura 2.6(b)). Foi utilizada a seqüência LeftBag do Projeto CAVIAR. O alvo é relativo ao quadro 300 da seqüência. O quadro original da seqüência pode ser visto na Figura 2.3(c) e as máscaras alvo-fundo foram estimados utilizando os 200 primeiros quadros. 

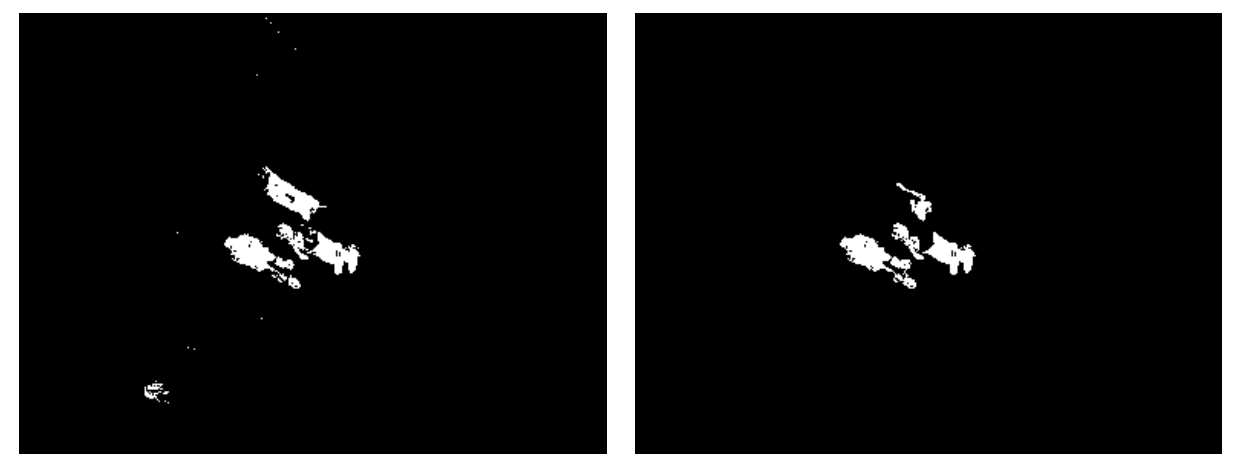

(a) Alvo da subtração de fundo estimado pela média

(b) Alvo da subtração de fundo estimado pela mediana

Figura 2.6: Alvos da subtração de fundo estimados pela média e mediana.

\section{Fundo Estimado pela Média Adaptativa}

A média adaptativa é uma outra técnica utilizada na estimação de fundo quando não existe um subconjunto inicial da seqüência de vídeo sem alvos. Para esta estimação, atribui-se o primeiro quadro da seqüência ao fundo estimado. A cada novo quadro da seqüência de vídeo, o modelo do fundo é atualizado. Nesta atualização, é utilizada a taxa de aprendizado que é um parâmetro entre 0 e 1 que define quanto do quadro atual será utilizado na estimação do novo fundo. Assim, o modelo vai se adaptando às mudanças na iluminação e no ambiente [11].

O modelo do fundo estimado para o quadro $i, B_{i} \in K^{\mathbb{E}}$, utilizando uma taxa de aprendizado $\alpha$, é definido por:

$$
B_{i}(x, y)=\left\{\begin{array}{cc}
f_{1}(x, y) & \text { se } i=2 \\
(1-\alpha) B_{i-1}(x, y)+\alpha f_{i}(x, y) & \text { se } i>2
\end{array}\right.
$$

onde $\alpha \in(0,1)$ é a taxa de aprendizado, $f_{i}$ e $B_{i} \in K^{\mathbb{E}}$ são, respectivamente, o quadro $i$ e o modelo de fundo estimado para o quadro $i$.

A máscara alvo-fundo referente ao quadro $i, A_{i}$, é calculada como sendo a diferença simétrica cujos pixels são maiores que o $\operatorname{limiar} \tau$ entre o quadro atual $f_{i}$ e o modelo do fundo atual $B_{i}$ :

$$
A_{i}(x, y)=\left|f_{i}(x, y)-B_{i}(x, y)\right| \geq \tau
$$


onde $A_{i}, f_{i}, B_{i} \in K^{\mathbb{E}}$.

Um dos principais problemas deste algoritmo é conseguir determinar uma taxa de aprendizado que funcione bem para a seqüência. Caso a taxa de aprendizado seja muito perto de zero, o fundo irá se adaptar muito lentamente às alterações no cenário; caso a taxa de aprendizado seja muito próxima de 1 , o fundo irá adaptar-se rapidamente às alterações no cenário. No primeiro caso, o cenário pode ser modificado e o modelo de fundo pode não corresponder a este cenário modificado, causando problemas de falsos positivos por um longo período. No segundo caso, quando o fundo se adapta de maneira muito rápida às alterações no cenário, partes do alvo irão ser perdidas por serem rapidamente consideradas como pertencentes ao fundo, gerando falsos negativos. O algoritmo de diferenciação de dois quadros é um caso particular deste algoritmo quando $\alpha=1$.

\section{Fundo Adaptativo}

Em [62], é proposto um algoritmo similar ao anterior. Durante o período de treinamento em que não existem alvos se deslocando na cena, são computadas a média e a variância dos quadros iniciais. Após isto, usa-se uma taxa de aprendizado $\alpha$ para atualizar a média e a variância:

$$
\begin{gathered}
\mu_{i}(x, y)=(1-\alpha) \mu_{i-1}(x, y)+\alpha f_{i}(x, y) \\
\sigma_{i}^{2}(x, y)=(1-\alpha)\left(\sigma_{i-1}^{2}(x, y)+\left(\mu_{i}(x, y)-\mu_{i-1}(x, y)\right)^{2}\right)+\alpha\left(f_{i}(x, y)-\mu_{i}(x, y)\right)^{2},
\end{gathered}
$$

onde $\alpha$ é a taxa de aprendizado, $\operatorname{com} \alpha \in(0,1), f_{i}(x, y)$ é a intensidade do pixel $(x, y)$ no quadro $i, \mu_{i}(x, y)$ e $\mu_{i-1}(x, y)$ são as médias dos valores do pixel $(x, y)$ calculadas nos quadros $i$ e $i-1$, respectivamente, $\sigma_{i}^{2}(x, y)$ e $\sigma_{i-1}^{2}(x, y)$ são as variâncias dos valores do pixel $(x, y)$ calculadas nos quadros $i$ e $i-1$.

A máscara alvo-fundo $A_{i}(x, y)$ pode então ser calculada:

$$
A_{i}(x, y)=\left|f_{i}(x, y)-\mu_{i}(x, y)\right| \geq 3 \sigma_{i}(x, y)
$$

onde $\sigma_{i}(x, y)$ é o desvio-padrão do pixel $(x, y)$ no quadro $i$. 


\section{Fundo Estimado pela Mediana dos Últimos Quadros}

Para evitar o uso de uma taxa de aprendizado, pode-se utilizar a mediana dos $m$ últimos quadros para estimar o fundo da seqüência, com $m \in(1, n)$, onde $n$ é o número de quadros da seqüência de vídeo. O fundo para o quadro $i, B_{i}$, é estimado para o pixel $(x, y)$ como:

$$
B_{i}(x, y)=\left\{\begin{array}{cc}
\text { mediana }_{\{1 \leq j<i\}} f_{j}(x, y) & \text { se } i-m<1, \\
\text { mediana }_{\{i-m \leq j<i\}} f_{j}(x, y) & \text { se } i-m \geq 1 .
\end{array}\right.
$$

A máscara alvo-fundo, $A_{i}$, é calculada como na Equação 2.11. Este algoritmo é mais fácil de ser parametrizado pois não possui uma taxa de aprendizado e o resultado é bastante robusto. Entretanto, implica na computação da mediana a cada iteração, sendo portanto mais pesado computacionalmente.

\subsubsection{Abordagem Estatística}

A abordagem estatística vem se tornando bastante popular, principalmente devido à robustez a fundos dinâmicos e alterações na iluminação. Aqui, um modelo de fundo também é construído, como na subtração de fundo (Seção 2.3.2), porém, a maior diferença é que na abordagem estatística não é construído um quadro para representar o fundo da cena, mas um classificador [16] é utilizado para classificar cada pixel da imagem como pertencente ao alvo ou ao fundo. Modelos estatísticos sofisticados, como em [84], podem ser utilizados para representar o modelo de fundo da cena.

$\mathbf{W}^{4}$

Este algoritmo foi proposto em [29,28]. A primeira etapa é a construção do modelo de fundo. Esta etapa começa com o cálculo da média, da mediana e do desvio-padrão para cada pixel do quadro utilizando um período inicial da seqüência de vídeo. São calculados também, no mesmo período inicial e para cada pixel, o menor valor, o maior valor e a maior diferença de valores entre quadros consecutivos. Esses três últimos valores são calculados apenas quando a diferença absoluta entre o valor do pixel corrente e a mediana for menor que duas vezes o desvio-padrão. O modelo de fundo é formado por esses três valores. Formalizando, o modelo de fundo é o vetor $B=[m, n, d]$ que é 
definido por:

$$
B(x, y)=\left[\begin{array}{c}
m(x, y) \\
n(x, y) \\
d(x, y)
\end{array}\right]=\left[\begin{array}{c}
\min _{\left\{1 \leq i \leq n_{t}\right\}} f_{i}(x, y) \\
\max _{\left\{1 \leq i \leq n_{t}\right\}} f_{i}(x, y) \\
\max _{\left\{1<i \leq n_{t}\right\}}\left|f_{i}(x, y)-f_{i-1}(x, y)\right|
\end{array}\right]
$$

se $\mid f_{i}(x, y)-$ mediana $_{(x, y)} \mid<2 \sigma(x, y)$, onde $n$ é o número total de quadros da seqüência, $1 \leq n_{t} \leq n$ é o número de quadros utilizados no período inicial da seqüência, $f_{i}(x, y)$ é o valor do pixel $(x, y)$ no quadro $i$ da seqüência de vídeo, $\sigma(x, y)$ é o desvio-padrão do pixel $(x, y)$ no intervalo utilizado, mediana $_{(x, y)}$ é a mediana dos valores do pixel $(x, y)$ no intervalo utilizado, $m(x, y)$ é o menor valor do pixel $(x, y)$ no intervalo utilizado, $n(x, y)$ é o maior valor do pixel $(x, y)$ no intervalo utilizado e $d(x, y)$ é a maior diferença entre dois quadros consecutivos.

A segunda etapa do algoritmo é responsável pela atualização do modelo de fundo $B$. Para esta atualização são levados em consideração os últimos $z$ quadros da seqüência. São criadas duas tabelas nesta etapa. A primeira, chamada de mapa de suporte a detecção, $g S$, armazena o número de vezes que um pixel foi classificado como fundo nos últimos $z$ quadros processados. A segunda tabela, o mapa de suporte ao movimento, $m S$, armazena o número de vezes que um pixel foi classificado como pixel em movimento nos últimos $z$ quadros processados. O mapa de suporte a detecção $g S$ é definido como:

$$
g S_{i}(x, y)=\left\{\begin{array}{cl}
g S_{i-1}(x, y)+1 & \text { se }(x, y) \text { é fundo } \\
g S_{i-1}(x, y) & \text { caso contrário; }
\end{array}\right.
$$

onde $g S_{i}$ é uma função que, para cada quadro $i$ da seqüência, leva o pixel $(x, y)$ a um número inteiro positivo $\mathbb{Z}^{+}$. O mapa de suporte ao movimento $m S$ é definido como:

$$
m S_{i}(x, y)=\left\{\begin{array}{cl}
m S_{i-1}(x, y)+1 & \text { se } M_{i}(x, y)=1 \\
m S_{i-1}(x, y) & \text { se } M_{i}(x, y)=0
\end{array}\right.
$$

onde $m S_{i}$ é uma função que para cada quadro $i$ da seqüência leva o pixel $(x, y)$ a um número inteiro positivo $\mathbb{Z}^{+}$e $M_{i}(x, y)$ vale:

$$
M_{i}(x, y)= \begin{cases}1 & \text { se }\left(\left|f_{i}(x, y)-f_{i+1}(x, y)\right|>2 \sigma(x, y)\right) \wedge\left(\left|f_{i-1}(x, y)-f_{i}(x, y)\right|>2 \sigma(x, y)\right), \\ 0 & \text { caso contrário }\end{cases}
$$

onde $f_{i}(x, y)$ é o valor do pixel $(x, y)$ no quadro $i$ da seqüência e $\sigma(x, y)$ é o desvio-padrão para os 
valores do pixel $(x, y)$ calculado na primeira etapa do algoritmo.

O modelo do fundo passa então a ser computado em separado, sendo calculado um modelo $\left[m^{f}(x, y), n^{f}(x, y), d^{f}(x, y)\right]$, caso $(x, y)$ seja considerado pertencente ao alvo e um modelo $\left[m^{b}(x, y)\right.$, $\left.n^{b}(x, y), d^{b}(x, y)\right]^{2}$, caso o pixel $(x, y)$ seja considerado fundo. O modelo de fundo final $\left[m_{i}(x, y)\right.$, $\left.n_{i}(x, y), d_{i}(x, y)\right]$ para o pixel $(x, y)$ do quadro $i$ é então atualizado:

$$
\left[m_{i}(x, y), n_{i}(x, y), d_{i}(x, y)\right]=\left\{\begin{array}{cl}
{\left[m^{b}(x, y), n^{b}(x, y), d^{b}(x, y)\right]} & \text { se }\left(g S_{i}(x, y)>k z\right), \\
{\left[m^{f}(x, y), n^{f}(x, y), d^{f}(x, y)\right]} & \text { se }\left(g S_{i}(x, y)<k z\right), \\
& \vee\left(m S_{i}(x, y)<r z\right) \\
{\left[m_{i-1}(x, y), n_{i-1}(x, y), d_{i-1}(x, y)\right]} & \text { caso contrário }
\end{array}\right.
$$

onde $z$ é o número de quadros já processados levados em consideração, $k \in(0,1)$ vale tipicamente 0,8 e $r \in(0,1)$ vale tipicamente 0,1 .

A máscara alvo-fundo, $A_{i}(x, y) \in K^{\mathbb{E}}$, é então calculada como sendo:

$$
A_{i}(x, y)= \begin{cases}1 & \text { se }\left(f_{i}(x, y)-m_{i}(x, y)\right)<v d_{\mu} \vee\left(f_{i}(x, y)-n_{i}(x, y)\right)<v d_{\mu} \\ 0 & \text { caso contrário }\end{cases}
$$

onde $v$ é um limiar definido empiricamente como 2 e $d_{\mu}$ é a mediana das maiores diferenças absolutas inter-quadros calculada na primeira etapa do algoritmo.

\section{Método Gaussiano Simples}

O método gaussiano simples foi proposto no projeto Pfinder [91]. Neste método, a intensidade e cor de cada pixel são representadas por um vetor $[y, u, v]^{T}$ no modelo de cores YUV. Uma restrição forte ao algoritmo é que o fundo da cena não tem alterações ou as alterações são lentas. Durante um período inicial da seqüência de vídeo, são computadas a média e a matriz de covariância [42] para cada pixel $(x, y)$ dos quadros. A atualização da média e da matriz de covariância é feita a cada quadro processado após o período inicial utilizando uma taxa de aprendizado. Esta taxa indica quanto do valor atual do pixel entrará no cálculo da atualização. A fórmula para atualização da média é definida por:

$$
\mu_{i}(x, y)=(1-\alpha) \mu_{i-1}(x, y)+\alpha f_{i}(x, y)
$$

\footnotetext{
${ }^{2}$ onde f vem do inglês foreground e b vem do inglês background.
} 
onde $f_{i} \in K^{\mathbb{E}} \times K^{\mathbb{E}} \times K^{\mathbb{E}}, f_{i}(x, y)$ é o valor do pixel $(x, y)$ utilizando o modelo de cores YUV para o quadro atual $i$ e $\alpha \in(0,1)$ é a taxa de aprendizado.

A matriz de covariância $K_{i}(x, y)$ para cada pixel $(x, y)$ é atualizada por:

$$
K_{i}(x, y)=(1-\alpha) K_{i-1}(x, y)+\alpha v_{i}(x, y) v_{i}(x, y)^{T}
$$

onde $v_{i}(x, y)=f_{i}(x, y)-\mu_{i}(x, y)$.

Para definir se um determinado pixel $(x, y)$ pertence ao alvo ou ao fundo, calcula-se o logaritmo da verossimilhança [16] da diferença entre a imagem corrente e o fundo:

$$
l(x, y)=-\frac{1}{2} v_{i}(x, y)^{T} K_{i}(x, y)^{-1} v_{i}(x, y)-\frac{1}{2} \ln \left|K_{i}\right|-\frac{3}{2} \ln (2 \pi)
$$

A máscara alvo-fundo, $A_{i}(x, y)$, para o pixel $(x, y)$ é definida como:

$$
A_{i}(x, y)= \begin{cases}1 & \text { se } l(x, y)<t \\ 0 & \text { caso contrário }\end{cases}
$$

onde $t$ é um limiar definido empiricamente. Em [27], foram utilizados como parâmetros na implementação deste algoritmo $\alpha=0,005$ e $t=-300$.

\section{Método Gaussiano Múltiplo}

Para modelar cenários complexos cujas cenas de fundo se alteram rapidamente, uma solução tem sido adotar um modelo de fundo adaptativo que utiliza uma mistura de gaussianas para atualização [81,61]. Quando uma única fonte de luz influencia a intensidade de um pixel observado na cena, um modelo gaussiano simples é suficiente para modelar o fundo. Mas, geralmente, não é isto que ocorre. A intensidade do pixel é resultante da reflectância de várias superfícies presentes na cena e de múltiplas fontes de luz que variam durante a seqüência de imagens, o que torna o modelo gaussiano múltiplo mais apropriado.

Um pixel $(x, y)$ do quadro $i$ tem seus valores modelados como uma mistura de $k$ gaussianas:

$$
P_{i}(x, y)=\sum_{j=1}^{k} \omega_{j, i}(x, y) \eta\left(f_{i}(x, y), \mu_{j, i}(x, y), K_{j, i}(x, y)\right),
$$


onde $P_{i}(x, y)$ é a função que modela os valores do pixel $(x, y)$ até o quadro $i$ da seqüência como misturas de gaussianas, $k$ é o número de distribuições, $\omega_{j, i}(x, y)$ é a estimação do peso da j-ésima gaussiana na mistura computando até o quadro $i$ da seqüência, $\mu_{j, i}(x, y)$ e $K_{j, i}(x, y)$ são a média e a matriz de covariância da j-ésima gaussiana da mistura até o quadro $i$ da seqüência e $\eta\left(f_{i}(x, y), \mu_{j, i}(x, y), K_{j, i}(x, y)\right)$ é a função densidade probabilidade gaussiana da j-ésima gaussiana calculada até o quadro $i$ da seqüência. A função densidade probabilidade é definida por:

$$
\eta\left(f_{i}(x, y), \mu_{j, i}(x, y), K_{j, i}(x, y)\right)=\frac{1}{(2 \pi)^{n / 2}\left|K_{j, i}(x, y)\right|^{\frac{1}{2}}} e^{-\frac{1}{2}\left(f_{i}(x, y)-\mu_{j, i}(x, y)\right)^{T} K_{j, i}(x, y)^{-1}\left(f_{i}(x, y)-\mu_{j, i}(x, y)\right)},
$$

onde $f_{i}(x, y)$ é o valor do pixel $(x, y)$ no quadro $i, K_{j, i}(x, y)$ é a matriz de covariância da j-ésima gaussiana calculada até o quadro $i,\left|K_{j, i}(x, y)\right|$ é o determinante da matriz de covariância $K$, $\mu_{j, i}(x, y)$ é a média da j-ésima gaussiana calculada até o quadro $i$.

O número $k$ de gaussianas na mistura é definido empiricamente ficando, geralmente, entre 3 e 5. Também, para diminuir o custo computacional, assume-se que a matriz de covariância tenha a forma:

$$
K_{j, i}=\sigma_{j, i}^{2} f_{i}
$$

onde $K_{j, i}$ é a matriz de covariância para a j-ésima gaussiana até o quadro $i, \sigma_{j, i}^{2}$ é o desvio-padrão da j-ésima gaussiana calculada até o quadro $i$.

A cada novo valor $f_{i}(x, y)$ do pixel $(x, y)$ no quadro $i$, este valor é comparado com as $k$ gaussianas até que ocorra um casamento. Um casamento ocorre quando o valor do pixel está dentro de 2,5 desvios-padrões da distribuição. Se nenhuma das $k$ distribuições casam com o valor corrente do pixel, a distribuição menos provável é atualizada com este valor de pixel. Os pesos das $k$ distribuições são atualizados por:

$$
\omega_{j, i}=(1-\alpha) \omega_{j, i-1}+\alpha\left(M_{j, i}\right)
$$

onde $\alpha \in(0,1)$ é uma taxa de aprendizado, $M_{j, i}$ vale 1 para a distribuição que casou com o pixel e 0 para as demais distribuições, $\omega_{j, i}$ é o peso da j-ésima gaussiana durante o processamento do quadro $i$.

Os pesos das gaussianas são então normalizados, ou seja, $\Sigma_{j=1}^{k} \omega_{j, i}=1$. A média e o desvio-padrão da distribuição que casou com o valor do pixel são atualizados respectivamente por:

$$
\mu_{i}=(1-\rho) \mu_{i-1}+\rho f_{i}(x, y)
$$




$$
\sigma_{i}^{2}=(1-\rho) \sigma_{i-1}^{2}+\rho\left(f_{i}(x, y)-\mu_{i}\right)^{T}\left(f_{i}(x, y)-\mu_{i}\right)
$$

onde $\rho$ é uma taxa de aprendizado utilizada para atualização da média e do desvio-padrão da distribuição que casou com o valor do pixel corrente.

As comparações para o casamento do valor do pixel corrente com as gaussianas seguem uma ordenação das gaussianas. Elas são ordenadas pela razão $\frac{\omega}{\sigma}$. Esta ordem implica que as gaussianas com maior peso e menor desvio-padrão estarão melhor colocadas. O fundo da cena, $B_{i}$, no quadro $i$ é definido como as primeiras $c$ distribuições que satisfazem uma proporção $T \in(0,1)$ dos dados observados:

$$
c_{i}=\arg \min _{b}\left(\sum_{j=1}^{b} \omega_{j, i}>T\right) .
$$

Testes efetuados em [27] indicam um valor para o limiar $T=0,97$ e uma taxa de aprendizado utilizada durante o processo $\alpha=0,002$.

\subsubsection{Fluxo Óptico}

Fluxo óptico é definido como uma malha 2D de vetores de velocidade aparente entre os pixels correspondentes de quadros consecutivos e é utilizado para descrever uma movimentação coerente de pontos ou características na seqüência de imagens [79]. Ou seja, o fluxo óptico consiste em um campo denso de velocidade, onde cada pixel está associado a um vetor velocidade. A segmentação baseada em fluxo óptico utiliza características desses vetores para encontrar regiões de deslocamento similar. Um problema desta abordagem é o custo computacional que inibe sua utilização em aplicações que necessitam de respostas em tempo real (como aplicações de vigilância inteligente) sem a utilização de hardware especializado [50].

O fluxo óptico não corresponde exatamente ao campo de deslocamento verdadeiro em uma seqüência de vídeo devido a influência de fatores, como a iluminação, por exemplo. Contudo, é uma boa aproximação desse campo [4]. Os métodos de fluxo óptico, segundo [4], são classificados em técnicas diferenciais, técnicas baseadas em freqüência/energia e técnicas de casamento. As técnicas diferenciais computam a velocidade da imagem a partir das derivadas espaço-temporal da intensidade dos pixels; as técnicas baseadas em freqüência ou energia utilizam filtros de sincronização de velocidade e as técnicas de casamento são utilizados quando as técnicas de diferenciação numéricas são impraticáveis devido ao pequeno número de quadros ou ao ruído. 


\section{Técnicas Diferenciais}

Esses métodos calculam o campo 2D de deslocamento sobre a imagem a partir de derivadas espaço-temporal. Nesta seção, para ficar coerente com a literatura consultada, um quadro de uma seqüência de vídeo será visto como uma função de três variáveis, onde $I(x, y, t)$ é o valor do pixel $(x, y)$ no tempo $t$. Primeiro, é assumido que o intervalo de tempo $\delta t$ entre duas imagens é muito curto e a intensidade da imagem não se altera durante este intervalo de tempo:

$$
I(x, y, t)=I(x+\delta x, y+\delta y, t+\delta t) .
$$

A equação acima expandida (série de Taylor) pode ser reescrita como:

$$
I(x+\delta x, y+\delta y, t+\delta t)=I(x, y, t)+\frac{\delta I}{\delta x} \delta x+\frac{\delta I}{\delta y} \delta y+\frac{\delta I}{\delta t} \delta t+O^{2},
$$

onde $O^{2}$ são os termos de mais alta ordem. Juntando as equações 2.33 e 2.34 e eliminando os termos de mais alta ordem:

$$
I(x, y, t)=I(x, y, t)+\frac{\delta I}{\delta x} \delta x+\frac{\delta I}{\delta y} \delta y+\frac{\delta I}{\delta t} \delta t .
$$

Cortando $I(x, y, t)$ em ambos os lados:

$$
0=\frac{\delta I}{\delta x} \delta x+\frac{\delta I}{\delta y} \delta y+\frac{\delta I}{\delta t} \delta t
$$

Dividindo todos por $\delta t$ :

$$
\frac{\delta I}{\delta x} \frac{\delta x}{\delta t}+\frac{\delta I}{\delta y} \frac{\delta y}{\delta t}+\frac{\delta I}{\delta t}=0
$$

onde $\frac{\delta x}{\delta t}$ e $\frac{\delta y}{\delta t}$ são os componentes do vetor velocidade $\vec{v}$. O gradiente da função imagem nas direções $x$ e $y, \frac{\delta I}{\delta x}$ e $\frac{\delta I}{\delta y}$ pode ser reescrito como $\nabla I$ :

$$
\nabla I \cdot \vec{v}=-I_{t}
$$

onde $I_{t}=\frac{\delta I}{\delta t} \mathrm{O}$ vetor $\vec{v}$ possui dois componentes e apenas uma equação, portanto, não pode ser resolvido. Outras restrições são necessárias para a resolução desta equação. Este é o problema da abertura do fluxo óptico.

Uma solução desenvolvida por Lucas e Kanade [56] assume que o fluxo é constante em um pequena 
janela $W$ de dimensão $m \times m, \operatorname{com} m>1$. Assumindo que a janela possui $n$ pixels:

$$
\begin{aligned}
& I_{x 1} v_{x}+I_{y 1} v_{y}=-I_{t 1} \\
& I_{x 2} v_{x}+I_{y 2} v_{y}=-I_{t 2} \\
& I_{x 3} v_{x}+I_{y 3} v_{y}=-I_{t 3} \\
& \vdots \\
& I_{x n} v_{x}+I_{y n} v_{y}=-I_{t n} .
\end{aligned}
$$

Agora, tem-se mais que duas equações para duas incógnitas, o que torna o sistema determinado em excesso:

$$
\left[\begin{array}{cc}
I_{x 1} & I_{y 1} \\
I_{x 2} & I_{y 2} \\
\vdots & \vdots \\
I_{x n} & I_{y n}
\end{array}\right] \cdot\left[\begin{array}{l}
v_{x} \\
v_{y}
\end{array}\right]=\left[\begin{array}{c}
-I_{t 1} \\
-I_{t 2} \\
\vdots \\
-I_{t n}
\end{array}\right]
$$

$\mathrm{ou}$

$$
A \vec{v}=-b
$$

Resolvendo a Equação 2.41 pelo método dos quadrados mínimos:

$$
\begin{gathered}
A^{T} A \vec{v}=A^{T}(-b), \\
\vec{v}=\left(A^{T} A\right)^{-1} A^{T}(-b) .
\end{gathered}
$$

A Figura 2.7 mostra resultados da aplicação do método Lucas \& Kanade em uma seqüência de vídeo do projeto CAVIAR. As Figuras 2.7(a) e 2.7(b) mostram os quadros originais da seqüência 200 e 203 respectivamente. A Figura 2.7(c) mostra a malha de vetores resultantes sobre o quadro 203 e a Figura 2.7(d) mostra apenas a malha de vetores resultantes. A malha de vetores resultantes foi multiplicada por 3 para facilitar a visualização. Foi mostrado um vetor a cada 9 pixels horizontais e verticais.

Um outro método para resolver o problema da abertura do fluxo óptico foi proposto por Horn \& Schunck [38]. O método parte de uma abordagem global e tenta minimizar uma função energia. 


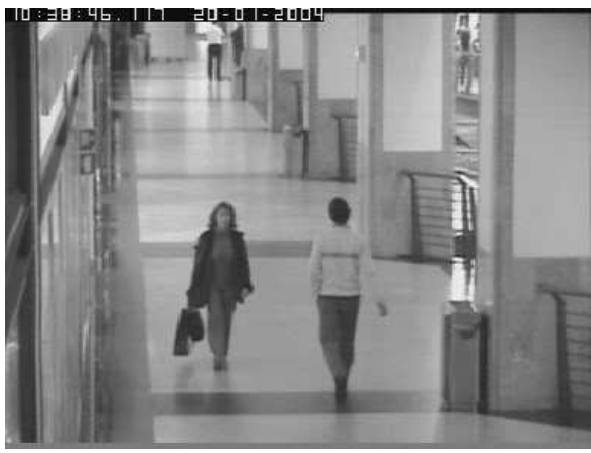

(a) Quadro 200 da seqüência.

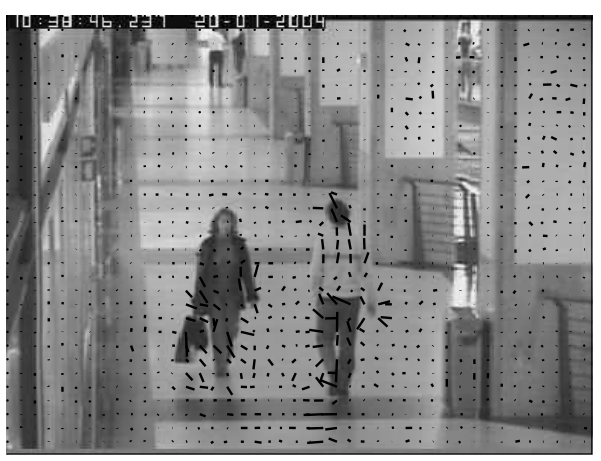

(c) Malha de vetores resultantes sobre o segundo quadro.

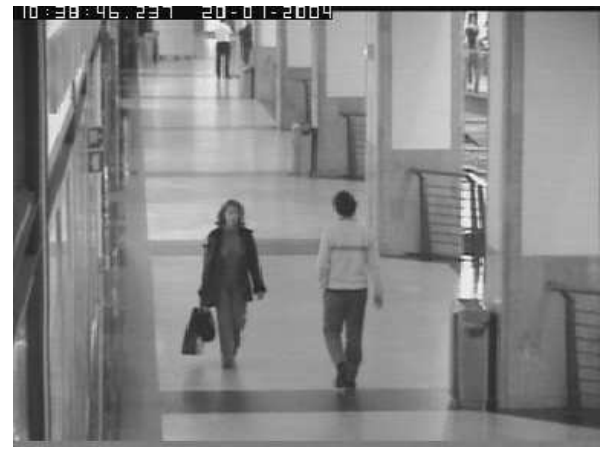

(b) Quadro 203 da seqüência.

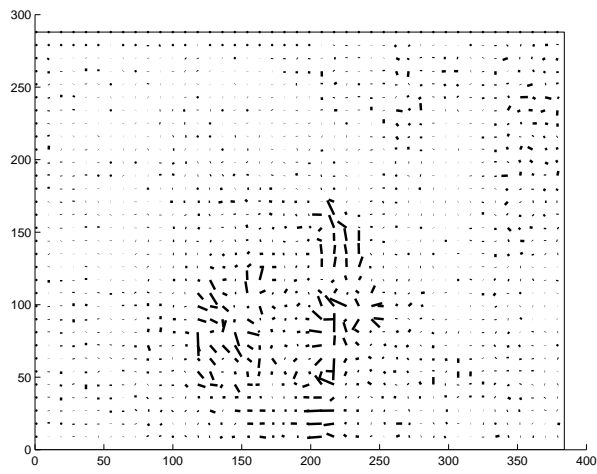

(d) Malha de vetores resultantes.

Figura 2.7: Aplicação do método Lucas \& Kanade nos quadros 200 e 203 da seqüência ShopAssistant1cor do Projeto CAVIAR.

\section{Métodos Baseados em Energia ou Freqüência}

Estes métodos utilizam o domínio das freqüências para descobrir o vetor deslocamento aparente entre pixels correlatos de quadros consecutivos em uma seqüência de vídeo. A principal vantagem de utilizar esta classe de métodos no domínio das freqüências é a robustez a alterações na iluminação. Esta robustez implicará em um resultado mais próximo ao vetor deslocamento real [4]. 


\section{Métodos de Casamento}

Estes métodos tentam encontrar características distintas na imagem que podem ser casadas na próxima imagem. Boas características para serem utilizadas são os contornos e as pontas. Pontas são boas características para serem utilizadas, porém, não são tão comuns em imagens. Os contornos são bem comuns, mas é mais problemático obter casamentos utilizando o contorno. Estes métodos tendem a gerar uma malha muita esparsa, porém, de boa acurácia [4].

\subsection{Avaliação de Resultados}

Os resultados dos algoritmos de segmentação de movimento podem ser avaliados de modo qualitativo ou quantitativo. A avaliação qualitativa, que geralmente é feita, traz toda a subjetividade que a ela é inerente. Cada pessoa pode avaliar um mesmo resultado de maneira diferente e uma mesma pessoa pode dar notas diferentes para um mesmo resultado quando avaliados em tempos diferentes. A maior dificuldade da avaliação quantitativa é a produção do padrão ouro que é a resposta correta que o algoritmo deveria produzir. A dificuldade de produzir um padrão ouro começa no fato de que ele terá que ser produzido manualmente [74]. A segmentação manual da seqüência de vídeo deveria ser feita por várias pessoas, pois, sabe-se que em uma segmentação manual existem diferenças nos resultados produzidos por cada pessoa. Seria produzida então uma segmentação final resultante de uma estatística dessas várias segmentações manuais feitas por diferentes pessoas. Vale ressaltar que a segmentação teria que ser feita quadro a quadro e ela valeria apenas para uma seqüência de vídeo específica [87].

Obviamente, este trabalho é impraticável. O que geralmente ocorre é a escolha de um ou alguns quadros importantes na seqüência de vídeo e então é feita a segmentação manual para estes quadros. Os resultados dos diferentes algoritmos de segmentação são comparados naqueles quadros específicos. Uma outra alternativa possível é segmentar regiões que incluam os alvos como uma caixa de Feret (Seção 2.1) ao invés de uma segmentação perfeita dos alvos. Esta solução reduz o tempo necessário para produzir manualmente o padrão ouro. Esta solução é utilizada pelo projeto CAVIAR que disponibiliza o padrão ouro para todos os quadros de sua base pública de vídeos [27].

\subsubsection{Medições Baseadas em Pixels}

Estabelecido o padrão ouro, pode-se agora estabelecer os métodos de comparação dos algoritmos. Uma abordagem é a contagem dos pixels que acertaram e erraram o alvo. Geralmente, as seguintes 
medidas serão feitas:

- Positivos verdadeiros (TP): número de pixels corretamente classificados como alvo.

- Falsos positivos (FP): número de pixels do fundo classificados como alvo.

- Negativos verdadeiros (TN): número de pixels do fundo corretamente classificados.

- Falsos negativos (FN): número de pixels do alvo classificados como fundo.

Existem um grande número de coeficientes de desempenho de algoritmos de segmentação. Em [76], são sugeridos alguns números para avaliação da segmentação produzida por um algoritmo. O primeiro deles é o percentual de classificação correta $(P C C)$, que calcula a razão entre o número de pixels corretamente classificados e o total do número de pixels no quadro:

$$
P C C=\frac{T P+T N}{T P+F P+T N+F N} .
$$

Uma crítica em relação a este método é que o número de pixels do fundo geralmente é bem maior que o número de pixels dos alvos, fazendo que a correta classificação dos pixels de fundo influencie muito o valor final do índice. Um número que evita este problema é o coeficiente de Jaccard (JC), que não leva em consideração os pixels corretamente classificados como fundo:

$$
J C=\frac{T P}{T P+F P+F N} .
$$

Em [27] e em [5], são feitas comparações entre os algoritmos de segmentação de movimento utilizando dois outros coeficientes, uma taxa de detecção e uma taxa de falsos alarmes. A taxa de detecção de rastreamento $(T R D R)$ é definida como o número de pixels corretamente identificados nos alvos $(T P)$ dividido pelo total de pixels que realmente fazem parte dos alvos $(T P+F N)$ :

$$
T R D R=\frac{T P}{T P+F N} .
$$

A taxa de falsos alarmes (FAR) é definida como o número de pixels classificados incorretamente como alvos $(F P)$ dividido pelo total de pixels que o algoritmo detectou como alvo $(T P+F P)$ :

$$
F A R=\frac{F P}{T P+F P} .
$$




\subsubsection{Medições Baseadas em Objetos}

Esta abordagem para medição de resultados se preocupa em medir o número de alvos que o algoritmo de segmentação corretamente detectou ou perdeu em um quadro específico. As medições baseadas nesta abordagem podem dar uma avaliação quantitativa mais precisa sobre o resultado do algoritmo testado. Esta abordagem não leva em consideração medições individuais dos pixels.

Uma técnica de avaliação que utiliza esta abordagem baseada em objetos é descrita em [67,68,69]. Esta técnica utiliza algumas medidas para comparar o resultado de um algoritmo de segmentação de movimento e o padrão ouro da base de dados utilizada. Estas medidas são:

- Detecção correta (CD): indica que houve um casamento de um para um entre o objeto detectado no resultado do algoritmo e o padrão ouro.

- Ruído (N): não existe correspondência entre um objeto detectado no algoritmo e o padrão ouro.

- Não detecção (ND): o objeto do padrão ouro não tem correspondente no resultado do algoritmo.

- Região conjunta (JR): um objeto detectado pelo algoritmo possui vários correspondentes no padrão ouro.

- Região dividida (SR): vários objetos detectados pelo algoritmo correspondem a um único objeto no padrão ouro.

- Região conjunta-dividida (JSR): quando os dois casos anteriores ocorrem simultaneamente.

Para calcular as medidas acima, uma matriz de correspondência $\mathcal{C}$ é criada. Em um dado quadro, com $T$ regiões $\tilde{R}_{i}$ no padrão ouro e $V$ regiões $R_{j}$ detectadas pelo algoritmo, $\mathcal{C}$ é uma matriz $T \times V$ definida como:

$$
\mathcal{C}(i, j)= \begin{cases}1 & \text { se } \tilde{R}_{i} \cap R_{j} \neq \emptyset, \text { com } i \in\{1,2, \ldots, T\}, j \in\{1,2, \ldots, V\}, \\ 0 & \text { caso contrário. }\end{cases}
$$

Ou seja, a matriz de correspondência $\mathcal{C}$ possui uma linha para cada região do padrão ouro e uma coluna para cada região detectada pelo algoritmo. Caso exista uma intersecção entre uma região 
detectada pelo algoritmo e uma região do padrão ouro, o elemento correspondente na matriz de correspondência vale 1; caso não exista tal correspondência, este elemento vale 0. Existe intersecção entre as duas regiões se a proporção entre a área de intersecção e a área do objeto no padrão ouro (área de $\tilde{R}_{i}$ ) for maior que um limiar específico.

Especificada a matriz de correspondência $\mathcal{C}$, pode-se então definir os métodos de cálculo das 6 medidas descritas. Seja $L(i)$ a soma dos elementos da matriz $\mathcal{C}$ para a linha $i$ e $C(i)$ a soma dos elementos da matriz $\mathcal{C}$ para a coluna $j, L(i)$ e $C(j)$ são definidos, respectivamente, como:

$$
\begin{gathered}
L(i)=\sum_{j=1}^{V} \mathcal{C}(i, j) \text { para } i \in\{1,2, \ldots, T\}, \\
C(j)=\sum_{i=1}^{T} \mathcal{C}(i, j) \text { para } j \in\{1,2, \ldots, V\} .
\end{gathered}
$$

Assim, pode-se definir as relações entre uma região conexa do padrão ouro $\tilde{R}_{i}$ e uma região conexa do resultado do algoritmo $R_{j}$ para um quadro específico da seqüência de vídeo. Considera-se uma deteç̧ão correta $(C D)$, se $\mathcal{C}(i, j)=1$ e $L(i)=C(j)=1$. Uma região conjunta $(J R)$ é identificada se $\mathcal{C}(i, j)=1, L(i)=1$ e $C(j)>1$. Quando $\mathcal{C}(i, j)=1, C(j)=1$ e $L(i)>1$, houve uma região dividida $(S R)$. Se $\mathcal{C}(i, j)=1$ e $L(i)>1 \wedge C(j)>1$, o casamento é considerado como parte de uma região conjunta-dividida $(J S R)$. Se $C(j)=0, R_{j}$ é considerado como ruído $(N)$. Se $L(i)=0$, o objeto do padrão ouro $\tilde{R}_{i}$ não foi detectado $(N D)$.

Alguns coeficientes podem ser definidos baseados nas medidas acima. A taxa de detecção $(D R)$ é o percentual dos alvos do padrão ouro que foi detectado nos resultados:

$$
D R=\frac{C D+S R+J R+J S R}{T} .
$$

A taxa de não detecção $(N D R)$ é o percentual dos alvos do padrão ouro que não foi detectado nos resultados:

$$
N D R=\frac{N D}{T} .
$$

Um outro coeficiente que pode ser utilizado é a taxa de ruído $(N R)$ que é o percentual de regiões do 
resultado que não possui correspondência com alvos do padrão ouro:

$$
N R=\frac{N}{V}
$$




\section{Capítulo 3}

\section{Morfologia Matemática}

Neste capítulo são apresentados os operadores morfológicos e os conceitos básicos da Morfologia Matemática utilizados na solução proposta.

A Morfologia Matemática (MM) é um ramo do processamento e análise não linear de imagens digitais que utiliza fortemente conceitos da Álgebra (como teoria dos conjuntos e reticulados completos) e da Geometria (como translação, convexidade e distância) [33].

A MM se originou dos trabalhos de Georges Matheron [59] e Jean Serra [78]. Eles trabalhavam com mineralogia e petrografia no início dos anos 60 na Escola de Minas de Paris, em Fontainebleau, França. O objetivo do trabalho de ambos era caracterizar propriedades físicas em certos materiais. Estes trabalhos os levaram a desenvolver uma nova abordagem quantitativa em análise de imagens, que seria conhecido mais tarde como MM [32]. Hoje, a MM é reconhecidamente uma poderosa ferramenta de processamento e análise de imagens utilizada em inúmeras áreas, como mineralogia, histologia, análise de imagens médicas, análise de documentos e visão computacional.

A idéia central da MM é examinar a estrutura geométrica de uma imagem através de casamentos entre a imagem principal e pequenos padrões em diversas regiões da imagem. Variando a forma, o tamanho e a localização desses padrões, chamados de elementos estruturantes, é possível extrair características numéricas úteis. MM foi originalmente desenvolvida para imagens binárias, que podem ser representadas como elementos de $\mathcal{P}(\mathbb{E})$ (conjunto das partes de $\mathbb{E}$, o domínio da imagem). Para estes operadores, a MM utiliza essencialmente elementos da Teoria dos Conjuntos, como intersecção, união e complemento de conjuntos. Posteriormente, houve a necessidade de ampliar a teoria para trabalhar com imagens em níveis de cinza. Essa evolução começou com a modelagem das imagens como conjuntos no espaço tridimensional, as chamadas umbras, e, depois, a modelagem em funções 
de $\mathbb{E}$ em $K$. A modelagem via reticulados completos generalizou as abordagens anteriores e tornou-se base da MM $[30,32]$.

\subsection{Definições Básicas}

Esta seção apresenta alguns conceitos básicos necessários às definições dos operadores morfológicos. Para as definições que seguem, assume-se que $\mathbb{E}=\mathbb{Z} \times \mathbb{Z}, K \in \mathbb{Z}^{+}, f, g \in K^{\mathbb{E}}$ e $(x, y) \in \mathbb{E}$.

Seja $h=\left(h_{x}, h_{y}\right) \in \mathbb{E}$ um vetor, a translação horizontal de $f$ por $h, f_{h}$, é definida por:

$$
f_{h}(x, y)=f\left(x-h_{x}, y-h_{y}\right)
$$

A translação vertical de $f$ por $v \in K$, denotada $f+v$, é definida por:

$$
(f+v)(x, y)=f(x, y)+v
$$

Denota-se por $\operatorname{Dom}(f)$ e $\operatorname{Dom}(g)$ os domínios das funções $f$ e $g$, respectivamente.

Sejam $f, g \in K^{\mathbb{E}}$, diz-se que $f \leq g$ :

- se $f(x, y) \leq g(x, y) \forall(x, y) \in \operatorname{Dom}(f) \cup \operatorname{Dom}(g)$,

- se $(x, y) \in \operatorname{Dom}(f), \operatorname{mas}(x, y) \notin \operatorname{Dom}(g) \Rightarrow g(x, y)=-\infty$,

- se $(x, y) \in \operatorname{Dom}(g)$ e $(x, y) \notin \operatorname{Dom}(f) \Rightarrow f(x, y)=-\infty$.

O ínfimo das funções $f$ e $g$ é uma função em $K^{\mathbb{E}}$ definida por:

$$
(f \wedge g)(x, y)=\min \{f(x, y), g(x, y)\}, \text { para }(x, y) \in \mathbb{E} .
$$

A definição dual do ínfimo é o supremo das funções $f$ e $g$ é uma função em $K^{\mathbb{E}}$ definida por:

$$
(f \vee g)(x, y)=\left\{\begin{array}{cl}
\max \{f(x, y), g(x, y)\} & \text { se }(x, y) \in \operatorname{Dom}(f) \cap \operatorname{Dom}(g), \\
f(x, y) & \text { se }(x, y) \in \operatorname{Dom}(f) \text { e }(x, y) \notin \operatorname{Dom}(g), \\
g(x, y) & \text { se }(x, y) \in \operatorname{Dom}(g) \text { e }(x, y) \notin \operatorname{Dom}(f), \\
\text { não definido } & \text { se }(x, y) \notin \operatorname{Dom}(f) \cup \operatorname{Dom}(g) .
\end{array}\right.
$$


A negação de uma função $f$ é denotada por $f^{c}$ e é definida por:

$$
f^{c}(x, y)=-f(x, y), \text { para }(x, y) \in \operatorname{Dom}(f) .
$$

A reflexão $f$ de uma função $f$ é dada por:

$$
\check{f}(x, y)=f(-x,-y), \operatorname{para}(x, y) \in \operatorname{Dom}(f) .
$$

A subtração com saturação entre duas funções $f$ e $g$ é dada por:

$$
(f-g)(x, y)=\left\{\begin{aligned}
f(x, y)-g(x, y) & \text { se } f(x, y) \leq g(x, y) \\
0 & \text { caso contrário }
\end{aligned}\right.
$$

A adição com saturação de duas funções $f$ e $g$ é definida como:

$$
(f+g)(x, y)=\left\{\begin{aligned}
f(x, y)+g(x, y) & \text { se } f(x, y)+g(x, y)<k, \\
k-1 & \text { se } f(x, y)+g(x, y) \geq k,
\end{aligned}\right.
$$

onde $k-1$ é o maior valor do contradomínio de $f$ e $g$.

A diferença simétrica entre as funções $f$ e $g$ é denotada por:

$$
f(x, y) \approx g(x, y)=(f(x, y)-g(x, y)) \vee(g(x, y)-f(x, y))
$$

Seja $B$ um subconjunto de $\mathbb{E}$ e $b$ uma função de $B$ em $\mathbb{Z}, B$ é chamado de elemento estruturante e $b$ de função estruturante.

\subsubsection{Reticulados Completos}

Seja $\mathcal{L}$ um conjunto não vazio e $\leq$ uma relação binária em $\mathcal{L}$. Diz-se que $\mathcal{L}$ é um conjunto parcialmente ordenado se:

a. $X \leq X$,

b. $X \leq Y$ e $Y \leq X \Rightarrow X=Y$,

c. $X \leq Y$ e $Y \leq Z \Rightarrow X \leq Z$, 
para cada $X, Y, Z \in \mathcal{L}$. O conjunto parcialmente ordenado $\mathcal{L}$ ou poset ${ }^{1}$ é denotado por $(\mathcal{L}, \leq)$. Um poset é totalmente ordenado se $X \leq Y$ ou $Y \leq X \forall X, Y \in \mathcal{L}$. Um poset totalmente ordenado é chamado de cadeia [31].

Um reticulado completo é um poset $(\mathcal{L}, \leq)$ onde cada subconjunto de $\mathcal{L}$ possui um limite superior, o supremo, denotado por $I$ e um limite inferior, o ínfimo, denotado por $O$, ambos pertencentes a $\mathcal{L}$.

\subsubsection{Operações em Reticulados Completos}

Sejam $\mathcal{L}$ e $\mathcal{M}$ dois reticulados completos, seja $\psi: \mathcal{L} \rightarrow \mathcal{M}$ um operador de $\mathcal{L}$ em $\mathcal{M}$ e seja $X, X^{\prime} \in \mathcal{L}$. Um operador $\psi$ é dito crescente se $X \leq X^{\prime} \Rightarrow \psi(X) \leq \psi\left(X^{\prime}\right)$. É decrescente se $X \leq X^{\prime} \Rightarrow \psi(X) \geq \psi\left(X^{\prime}\right)$.

Um operador $\psi: \mathcal{L} \rightarrow \mathcal{L}$ é chamado de automorfismo se é crescente e bijetivo. O operador identidade é tal que, para $X \in \mathcal{L}, i d(X)=X$ para cada $X \in \mathcal{L}$.

O operador $\psi$ é chamado de invariante a translação se:

$$
\psi\left(X_{h}\right)=[\psi(X)]_{h},
$$

para cada $X \in \mathcal{L}$ e $h \in \mathbb{E}$.

Um operador $\psi$ é idempotente se $\psi^{2}=\psi \psi=\psi$. Assim, aplicar um operador idempotente mais de uma vez tem o mesmo resultado de aplicá-lo apenas uma vez.

Um operador $\psi: \mathcal{L} \longrightarrow \mathcal{L}$ é chamado de antiextensivo se $\psi(f) \leq f \forall f \in \mathcal{L}$ e de maneira análoga é chamado de extensivo se $f \leq \psi(f)$.

A aplicação de $n$ operadores $\psi$ sucessivos é denotado por $\psi^{n}=\psi \psi \ldots \psi$.

\footnotetext{
${ }^{1}$ do inglês partially ordered set
} 


\subsection{Dilatações e Erosões}

Para a definição de erosão e dilatação se $K$ é finito, é necessário definir duas novas operações. Seja $t, v \in K$, a operação $\dot{+}$ é definida como:

$$
t \dot{+} v=\left\{\begin{array}{cl}
0 & \text { se } t=0 \\
0 & \text { se } t>0 \text { e } t+v \leq 0 \\
t+v & \text { se } t>0 \text { e } 0 \leq t+v<k \\
k-1 & \text { se } t>0 \text { e } t+v \geq k
\end{array}\right.
$$

A operação - é definida como:

$$
t \dot{-} v=\left\{\begin{array}{cl}
0 & \text { se } t<k-1 \text { e } t-v \leq 0 \\
t-v & \text { se } t<k-1 \text { e } 0 \leq t-v<k \\
k-1 & \text { se } t<k-1 \text { e } t-v \geq k \\
k-1 & \text { se } t=k-1
\end{array}\right.
$$

Com as duas novas operações é possível definir as operações de erosão e dilatação. A erosão da imagem $f$ pelo elemento estruturante $g$ é definida como:

$$
(f \ominus g)(x, y)=\min \left\{f(z) \dot{-} g_{(x, y)}(z) \mid z \in \operatorname{Dom}\left(g_{(x, y)}\right) \cap \operatorname{Dom}(f)\right\}
$$

A dilatação de $f$ pelo elemento estruturante $g$ é definida como:

$$
(f \oplus g)(x, y)=\max \left\{f(z) \dot{+} g_{(x, y)}(z) \mid z \in \operatorname{Dom}\left(g_{(x, y)}\right) \cap \operatorname{Dom}(f)\right\} .
$$

A dilatação e a erosão são dois operadores básicos da MM, no sentido que, a partir da combinação deles, podem-se criar vários outros operadores. Na Figura 3.1, pode-se visualizar a aplicação dos operadores dilatação e erosão em uma imagem binária. A Figura 3.1(b) mostra o resultado da imagem original após a dilatação, utilizando um elemento estruturante em forma de disco com raio 3

e centrado na origem. A Figura 3.1(c) mostra o resultado da erosão da mesma imagem original por um elemento estruturante em forma de disco com raio 1 e centrado na origem.

Pode-se observar do resultado da dilatação na imagem binária (Figura 3.1(b)) o desaparecimento de buracos menores que o elemento estruturante utilizado, a ampliação dos objetos da imagem 


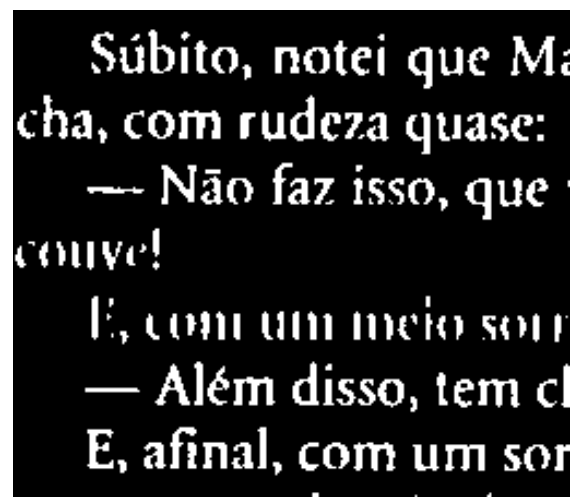

(a) Imagem original.

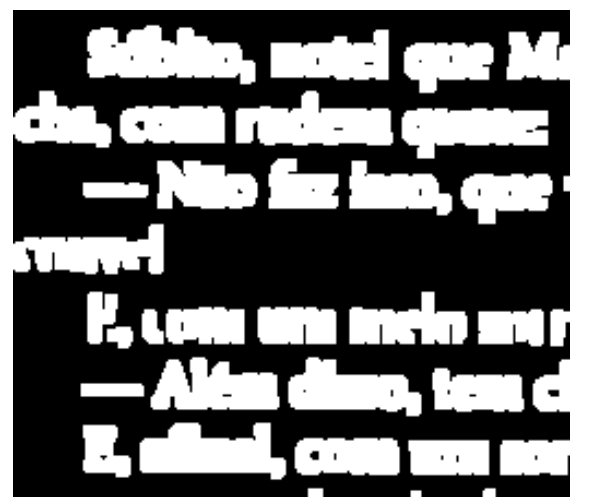

(b) Resultado da dilatação da imagem original por um disco de raio 3 .

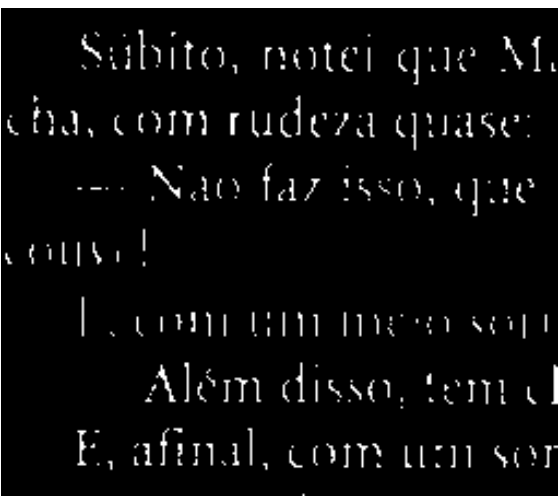

(c) Resultado da erosão da imagem original por um disco de raio 1 .

Figura 3.1: Efeitos da dilatação e da erosão em uma imagem binária.

(obviamente a redução da área de fundo) e a fusão de componentes conexos próximos. Como efeitos da erosão na imagem binária da Figura 3.1(c), pode-se verificar o desaparecimento de objetos menores que o elemento estruturante, a diminuição do tamanho dos objetos (e conseqüente aumento da área de fundo) e uma possível divisão de alguns componentes conexos [36]. Na erosão, não se pode afirmar se o número de componentes conexos na imagem irá aumentar ou diminuir, pois depende do número de pequenos componentes conexos que foram eliminados e dos objetos que foram divididos. 


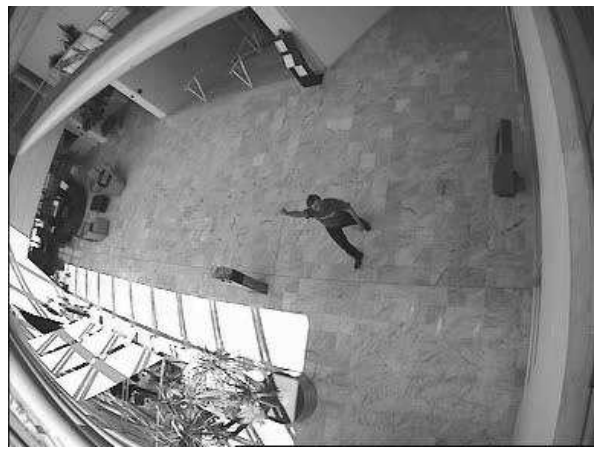

(a) Imagem original em níveis de cinza.

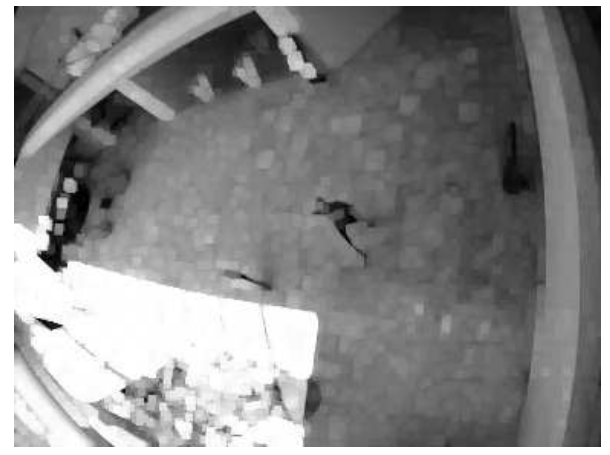

(b) Imagem dilatada.

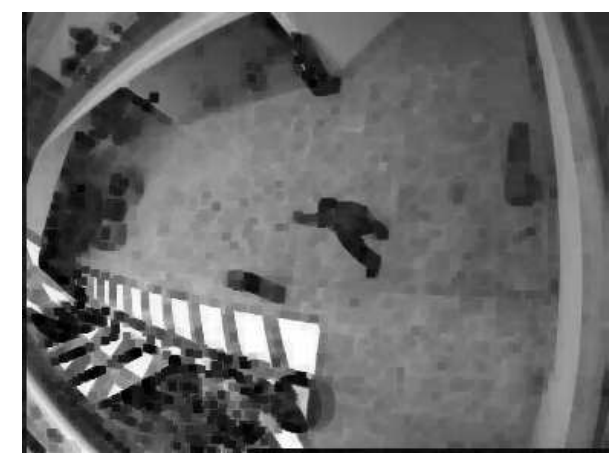

(c) Imagem erodida.

Figura 3.2: Erosão e dilatação em uma imagem em níveis de cinza (Quadro 1084 da seqüência Walk1 do Projeto CAVIAR.

A dilatação e a erosão nas imagens em níveis de cinza apresenta efeitos mais sutis. As partes claras geralmente aumentam em uma imagem dilatada, como na Figura 3.2(b), que é o resultado da dilatação da imagem da Figura 3.2(a) por um elemento estruturante em forma de quadrado de lado 5. Na erosão em imagens em níveis de cinza, as partes claras da imagem geralmente diminuem em relação a imagem original. A Figura 3.2(c) mostra este efeito. O elemento estruturante utilizado na erosão foi o mesmo utilizado na dilatação da Figura 3.2(b). 


\subsubsection{Gradientes}

Pode-se obter as bordas de uma imagem binária utilizando a dilatação, a erosão e a diferença de ambos operadores. O gradiente externo obtém as bordas de uma imagem binária dilatando-a e depois subtraindo a imagem original. O gradiente interno obtém as bordas de uma imagem binária erodindo-a e subtraindo da imagem original. O gradiente morfológico obtém as bordas da imagem erodindo e dilatando a imagem original e, depois, subtraindo a imagem erodida da imagem dilatada.

Formalizando as três operações, tem-se:

$$
\begin{gathered}
\operatorname{grad}_{g}^{e x t}(f)=(f \oplus g)-f,(\text { gradiente externo }), \\
\operatorname{grad}_{g}^{i n t}(f)=f-(f \ominus g),(\text { gradiente interno }), \\
\operatorname{grad}_{g, h}(f)=(f \oplus g)-(f \ominus h), \quad \text { (gradiente morfológico), }
\end{gathered}
$$

onde $f, g, h \in K^{\mathbb{E}}, g$ e $h$ são elementos estruturantes.

A Figura 3.3(b) mostra o gradiente interno do círculo da Figura 3.3(a). Para o cálculo do gradiente interno foi utilizado como elemento estruturante um disco de raio 3 e centrado na origem. A Figura 3.3(c) mostra o gradiente externo do mesmo círculo utilizando o mesmo elemento estruturante e a Figura 3.3(d) mostra o gradiente morfológico.

A Figura 3.4(b) mostra o gradiente morfológico da Figura 3.4(a). Para facilitar a visualização, foi aplicado a operação de complemento ao resultado do gradiente morfológico. Os pontos de maior valor do gradiente mostra onde houve maior diferença entre valores dos pixels vizinhos.

\subsection{Abertura e Fechamento}

Geralmente, é impossível reconstruir a imagem original após a aplicação de um operador morfológico, ou seja, perde-se informação durante a aplicação do operador morfológico [33,34]. A erosão e a dilatação não são operadores inversos [31]. Isto significa que, ao erodir uma imagem $f \in K^{\mathbb{E}}$ por um elemento estruturante $g \in K^{\mathbb{E}}$ e depois dilatá-la pelo mesmo elemento estruturante, a imagem original $f$ não é recuperada, mas sim uma função menor ou igual a imagem original. A este operador 


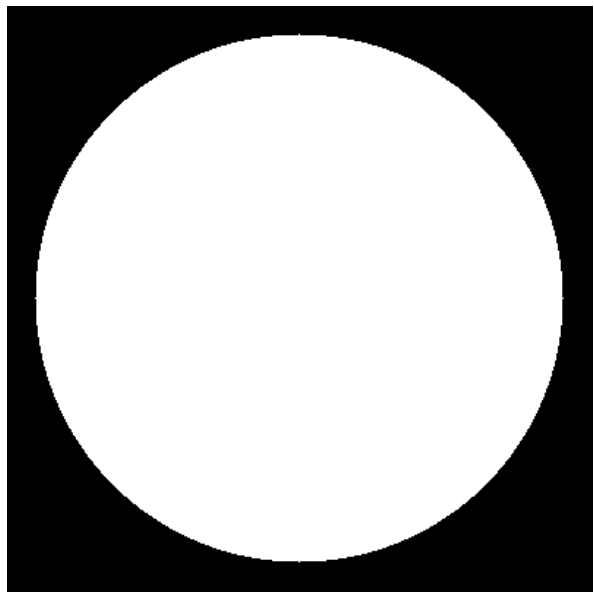

(a) Círculo original.

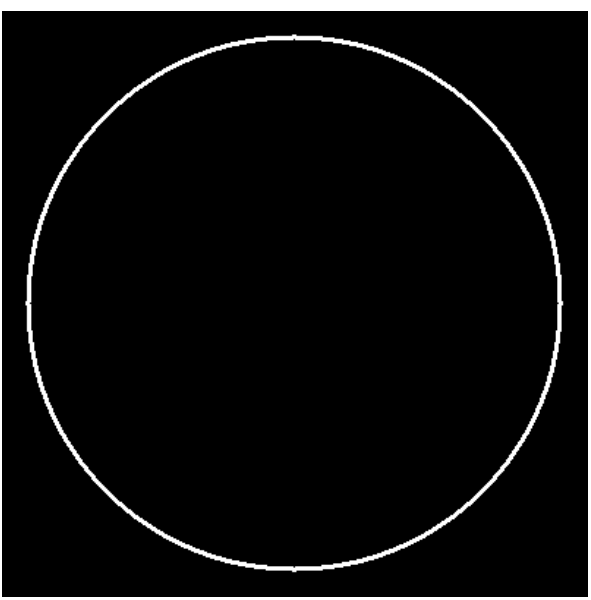

(c) Gradiente externo.

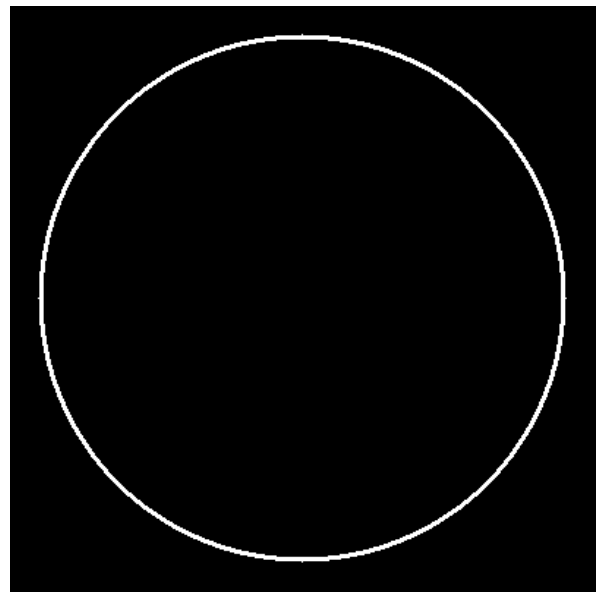

(b) Gradiente interno.

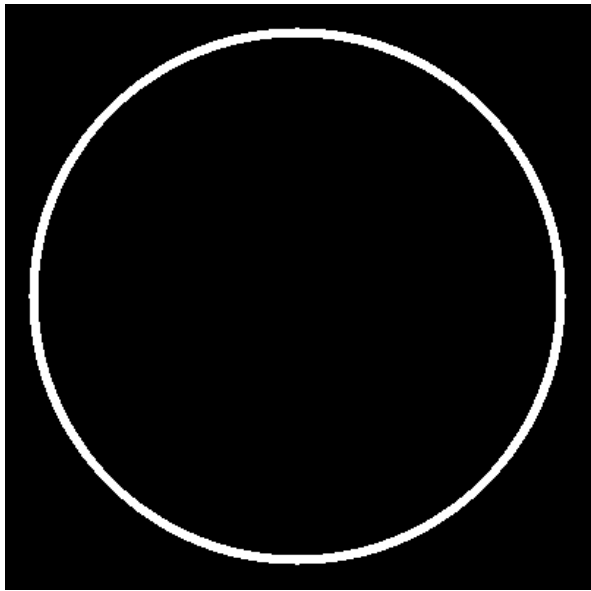

(d) Gradiente morfológico.

Figura 3.3: Gradiente interno, externo e morfológico em imagens binárias.

é dado o nome de abertura:

$$
f \circ g=(f \ominus g) \oplus g .
$$

De maneira análoga, define-se o operador fechamento. Primeiro é feita a dilatação e depois a 


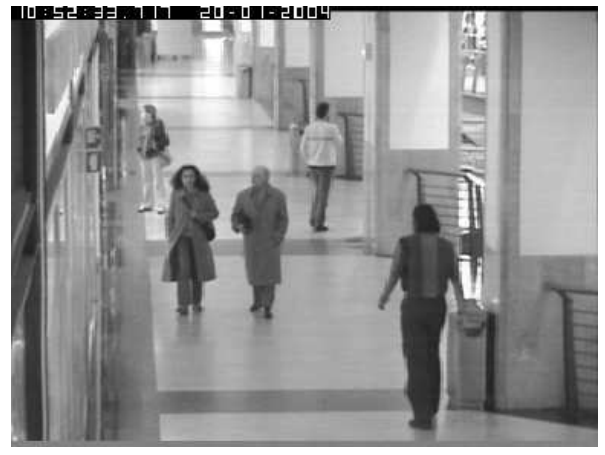

(a) Imagem original.

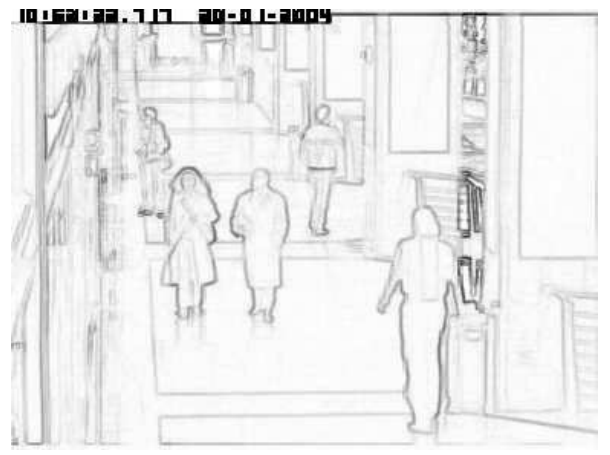

(b) Gradiente morfológico.

Figura 3.4: Gradiente morfológico de uma imagem em níveis de cinza (Quadro 1890 da seqüência WalkByShop1cor do Projeto CAVIAR)

erosão usando um mesmo elemento estruturante:

$$
f \bullet g=(f \oplus g) \ominus g .
$$

O resultado da abertura é sempre menor ou igual a imagem original: $f \circ g \leq f$. De maneira dual, o fechamento sempre produz um resultado maior ou igual a imagem original: $f \leq f \bullet g$.

A Figura 3.5(a) mostra a imagem de um retângulo. A Figura 3.5(b) mostra o elemento estruturante em forma de disco, plano, com raio 10 utilizado na abertura. O resultado da abertura sobre o retângulo é mostrado em 3.5(c). Nota-se que as pontas do retângulo desapareceram (parte acinzentada na imagem), tornando-se arredondadas. A abertura elimina detalhes da imagem original que são menores que o elemento estruturante utilizado. A Figura 3.5(d) mostra a imagem binária original contendo seis retângulos próximos entre si. Na Figura 3.5(e), está o elemento estruturante utilizado, um disco com raio 3. O resultado do fechamento, na Figura 3.5(f), mostra que os seis retângulos foram unidos formando apenas uma figura geométrica. A pequena distância que os separava desapareceu. Ao contrário da abertura, pequenos detalhes da região de fundo que são menores que o elemento estruturante utilizado desaparecerão no resultado do fechamento.

Os operadores abertura e fechamento são idempotentes, isto é $(f \circ g) \circ g=f \circ g$ e $(f \bullet g) \bullet g=f \bullet g$, onde $f, g \in K^{\mathbb{E}}[31]$. 


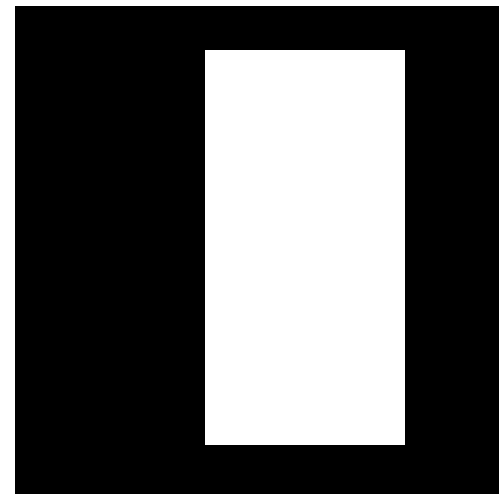

(a) Imagem original e elemento estruturante em forma de disco com raio 10 .

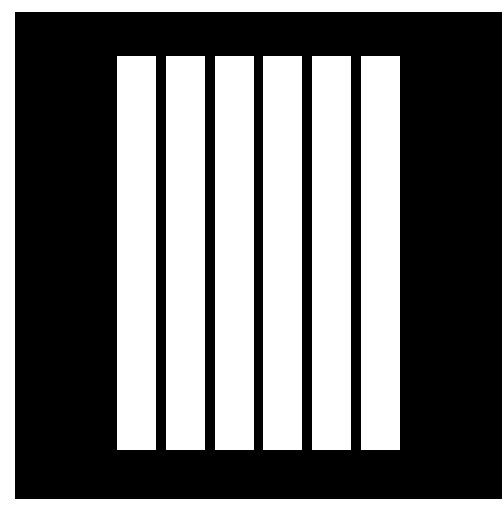

(d) Imagem original e elemento estruturante em forma de disco com 3 .

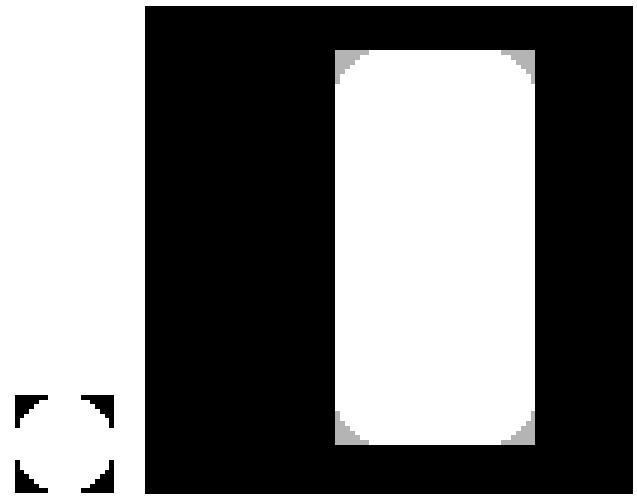

(b)

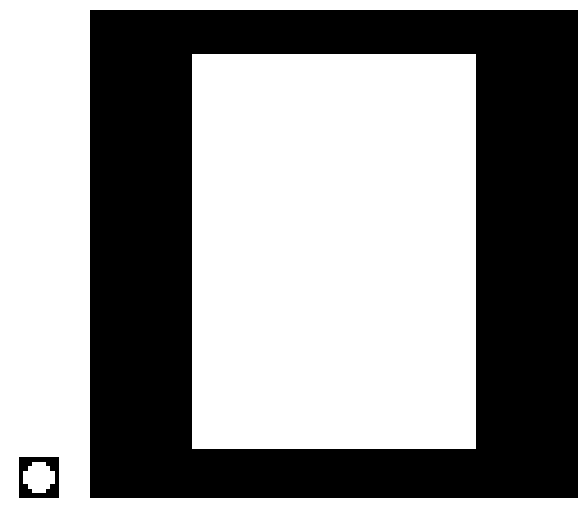

(e) (f) Resultado do fechamento.

Figura 3.5: Operadores Abertura e Fechamento

Abertura e fechamento se relacionam da seguinte maneira:

$$
\begin{aligned}
& (f \circ g)^{c}=f^{c} \bullet \check{g}, \\
& (f \bullet g)^{c}=f^{c} \circ \check{g} .
\end{aligned}
$$


A abertura é um operador crescente, idempotente e antiextensivo. O fechamento é crescente, idempotente e extensivo.

Como a erosão e a dilatação, a abertura e o fechamento também são invariantes a translação [31]:

$$
\begin{aligned}
f_{h} \circ g & =(f \circ g)_{h} \\
f_{h} \bullet g & =(f \bullet g)_{h}
\end{aligned}
$$

onde $h \in \mathbb{E}$ e $f, g$ são funções em $K^{\mathbb{E}}$.

Uma aplicação típica para os operadores abertura e fechamento é a restauração de imagens corrompidas por algum tipo de ruído. A Figura 3.6(a) mostra um círculo sobre um fundo ruidoso (ruído do tipo sal), utilizando um elemento estruturante maior que o ruído, como uma caixa de $3 \times 3$ pixels, pode-se eliminar o ruído e obter uma boa restauração da original (Figura 3.6(b)). A Figura 3.7(a) mostra uma imagem mais difícil de ser restaurada. Tanto o objeto quanto o fundo da imagem estão corrompidos pelo ruído (do tipo sal e pimenta). Para eliminar este tipo de ruído, é necessário utilizar ambos os filtros: abertura e fechamento. A abertura eliminará o ruído no fundo e o fechamento eliminará o ruído no objeto. Na Figura 3.7(b), está o resultado da aplicação da abertura seguida do fechamento e, na Figura 3.7(c), está o resultado da aplicação do fechamento seguido da abertura. Como pode-se notar, a restauração não é perfeita. Ao tentar eliminar, em primeiro lugar, o ruído do fundo através da abertura, buracos próximos no objeto acabam unindose e esses buracos se tornam grandes o suficientes para não serem eliminados durante a aplicação do fechamento, aparecendo então buracos na imagem restaurada. Se, ao contrário, tenta-se primeiro eliminar os buracos dos objetos aplicando o fechamento, ruídos próximos no fundo, acabam unindo-se e não são eliminados quando a abertura é aplicada.

\subsubsection{Filtro Alternado Seqüencial}

Uma solução para eliminar ruídos do tipo sal e pimenta de uma imagem corrompida seria utilizar alternadamente aberturas e fechamentos, inicialmente utilizando um elemento estruturante pequeno e, aos poucos, ampliar os elementos estruturantes utilizados. A cada ciclo de aplicação dos filtros abertura e fechamento, o elemento estruturante atual sofreria uma dilatação pelo elemento estruturante original. O filtro alternado seqüencial que utiliza fechamentos seguidos de aberturas (OC) é definido por:

$$
\left.A S F_{o c, g}^{n}(f)=((((f \bullet g) \circ g) \bullet 2 g) \circ 2 g) \ldots \bullet n g\right) \circ n g
$$




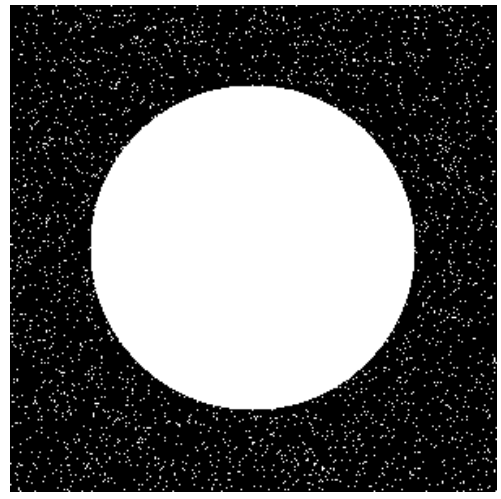

(a) Círculo corrompido por ruído.

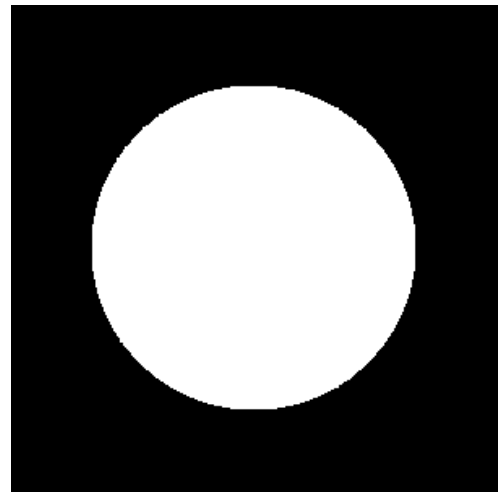

(b) Abertura restaurando a figura geométrica.

Figura 3.6: Eliminação de ruídos em uma imagem pela abertura.

onde $f, g$ são funções em $K^{\mathbb{E}}$ e $n g$ é o elemento estruturante original $g$ dilatado por ele mesmo $n$ vezes. O filtro alternado seqüencial que utiliza aberturas seguidas por fechamentos $(\mathrm{CO})$ é definido como:

$$
A S F_{c o, g}^{n}(f)=(((((f \circ g) \bullet g) \circ 2 g) \bullet 2 g) \ldots \circ n g) \bullet n g,
$$

onde $f, g$ são funções em $K^{\mathbb{E}}$ e $n g$ é o elemento estruturante original $g$ dilatado por ele mesmo $n$ vezes. A Figura 3.7(d) mostra a restauração da imagem da Figura 3.7(a) utilizando um filtro alternado seqüencial $\mathrm{OC}$ por 5 iterações e com elemento estruturante igual a uma caixa de 3x3 pixels.

\subsubsection{Filtros Top-Hat}

Um filtro top-hat é resultado da subtração entre a imagem original e uma abertura. O resultado deste filtro apresenta as regiões de picos da imagem com tamanho inferior ao elemento estruturante utilizado. Esse filtro pode ser utilizado para equalização de iluminação no fundo da imagem e também para extração de pequenos detalhes na imagem que não se encaixam no elemento estruturante utilizado. Esse operador é chamado de abertura top-hat e é definido como:

$$
f \hat{\circ} g=f-(f \circ g),
$$




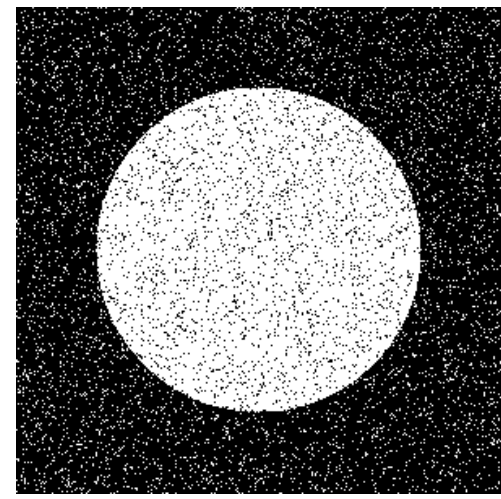

(a) Círculo bastante corrompido por ruído do tipo sal e pimenta.

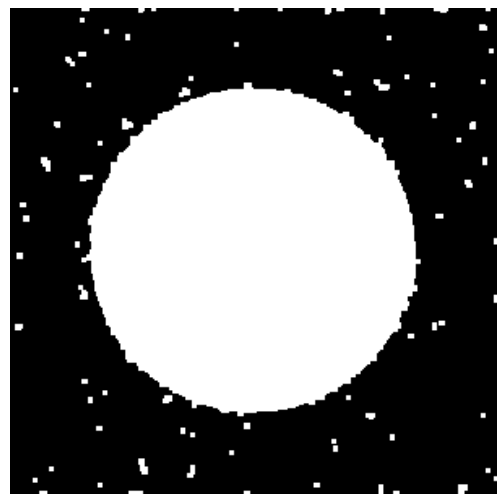

(c) Restaurando a imagem aplicando um filtro fechamento/abertura.

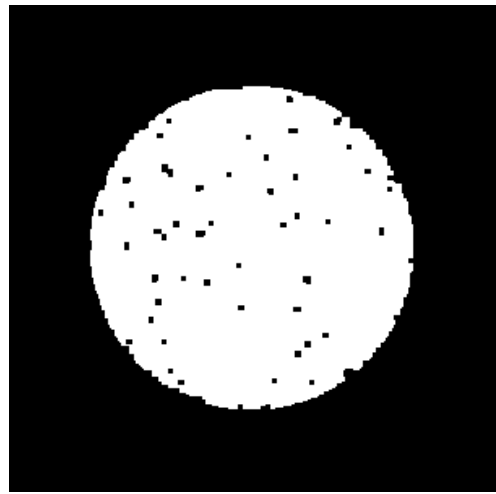

(b) Restaurando a imagem aplicando um filtro abertura/fechamento.

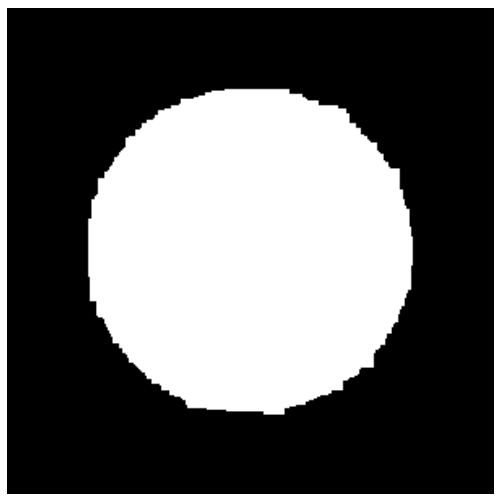

(d) Restaurando a imagem aplicando um filtro alternado seqüencial fechamentoabertura.

Figura 3.7: Eliminando ruído do tipo sal e pimenta de uma imagem

onde $f, g \in K^{\mathbb{E}}$.

O filtro dual da abertura top-hat é o fechamento top-hat. Ele é definido como:

$$
f \hat{\bullet} g=(f \bullet g)-f
$$


onde $f, g \in K^{\mathbb{E}}$.

O fechamento top-hat encontra regiões de vales na imagem menores que o elemento estruturante utilizado. Combinando a abertura e o fechamento top-hat pode-se identificar todos as regiões de picos e vales de uma imagem menores que o elemento estruturante utilizado. Os dois filtros relacionam-se através da equação:

$$
f \hat{\bullet} g=f^{c} \hat{o} \check{g} .
$$

A Figura 3.8(a) mostra uma figura geométrica quadriculada contendo uma diferença de iluminação ao fundo. A compensação da iluminação de fundo aparece no resultado da aplicação do filtro Abertura Top-Hat na Figura 3.8(b). Foi utilizado um elemento estruturante em forma de caixa de dimensões $21 \times 21$ pixels.

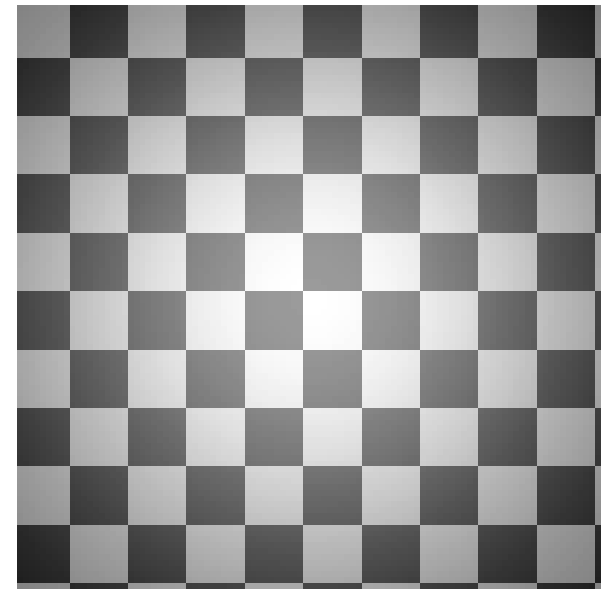

(a) Imagem original quadriculada com diferença de iluminação de fundo.

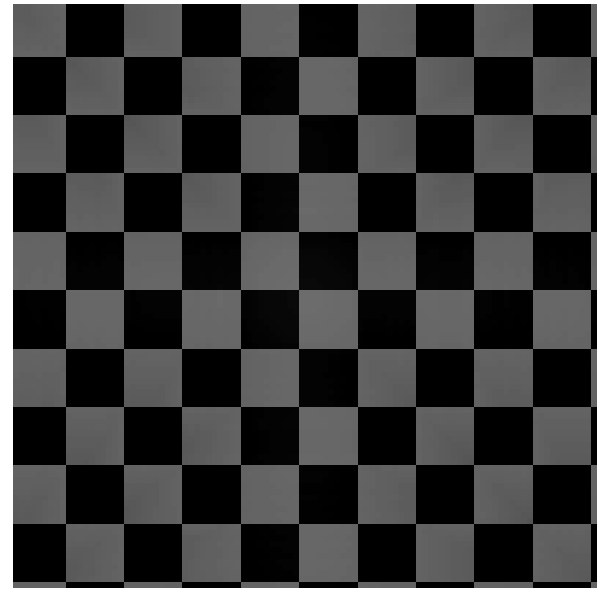

(b) Resultado da aplicação da Abertura Top-Hat.

Figura 3.8: Diferença de iluminação de fundo compensada pelo filtro Abertura Top-Hat.

\subsection{Filtros Condicionais}

Nesta seção são descritos os filtros sujeitos a um marcador, os chamados filtros condicionais. Na Seção 3.4.1, são descritas a erosão e a dilatação condicionais. Na Seção 3.4.2, são introduzidos os conceitos de regiões planas e operadores conexos. A Seção 3.4.3 descreve os operadores abertura por 
reconstrução e fechamento por reconstrução. E, finalmente, na Seção 3.4.4, são descritos filtros de contraste e volume.

\subsubsection{Erosões e Dilatações Condicionais}

A dilatação de uma imagem por um elemento estruturante que contém a sua própria origem fará com que esta imagem se expanda continuamente a cada nova dilatação. Por vezes, pode ser interessante limitar este processo de expansão e para isto pode-se utilizar um marcador que cerceie o processo de expansão da imagem original [15]. A dilatação de uma função $m$ em $K^{\mathbb{E}}$, conhecida como marcador, condicionada a uma função $f \geq m$, a função condicionante, é definida por:

$$
m \oplus_{f} g=(m \oplus g) \wedge f,
$$

onde $g \in K^{\mathbb{E}}$ é o elemento estruturante que define a conectividade utilizada.

A seqüência de $n$ dilatações condicionais utilizando como marcador uma imagem $m \in K^{\mathbb{E}}$, função condicionante $f \in K^{\mathbb{E}}$ e a conectividade de um elemento estruturante $g \in K^{\mathbb{E}}$ é chamada de dilatação geodésica de tamanho $n$ e é definida por:

$$
\left(m \oplus_{f} g\right)^{n}=\underbrace{\left(\left(\left(m \oplus_{f} g\right) \oplus_{f} g\right) \oplus_{f} g\right) \ldots \oplus_{f} g}_{n \text { vezes }} .
$$

Aplicando dilatações condicionais até a estabilidade, temos a operação de reconstrução infgeodésica, isto é, até que $\left(m \oplus_{f} g\right)^{r}=\left(m \oplus_{f} g\right)^{s}$, para $s \geq r$.

A reconstrução inf-geodésica de $m$ em $K^{\mathbb{E}}$ sujeito a função condicionante $f \geq m$ e conectividade definida pelo elemento estruturante $g \in K^{\mathbb{E}}$ é definida por:

$$
f \triangle_{g} m=\left(m \oplus_{f} g\right)^{\infty}
$$

onde $\infty$ é usado para indicar a aplicação do operador até a estabilidade.

De modo dual, define-se erosão condicional, erosão geodésica de tamanho $n$ e reconstrução sup- 
geodésica por, respectivamente:

$$
\begin{array}{r}
m \ominus_{f} g=(m \ominus g) \vee f, \\
\left(m \ominus_{f} g\right)^{n}=\underbrace{\left(\left(\left(m \ominus_{f} g\right) \ominus_{f} g\right) \ominus_{f} \ldots \ominus_{f} g\right)}_{\begin{array}{c}
n \text { vezes } \\
f \nabla_{g} m=\left(m \ominus_{f} g\right)^{\infty}
\end{array}},
\end{array}
$$

onde $f, g, m \in K^{\mathbb{E}}$.

A Figura 3.9(a) mostra a imagem original em níveis de cinza. O ponto (150, 200), sobre o homem na região central da imagem, é usado como marcador, sofreu 20 dilatações condicionais sujeitas a imagem original utilizando como elemento estruturante uma semi-esfera de raio 3, não plano. $\mathrm{O}$ resultado é apresentado na Figura 3.9(b). A Figura 3.10(a) mostra uma imagem binária contendo três círculos. O resultado do filtro reconstrução inf-geodésico é mostrado na Figura 3.10(b), onde um ponto sobre o círculo mais a direita foi utilizado como marcador e o sinal condicional utilizado foi a imagem original.

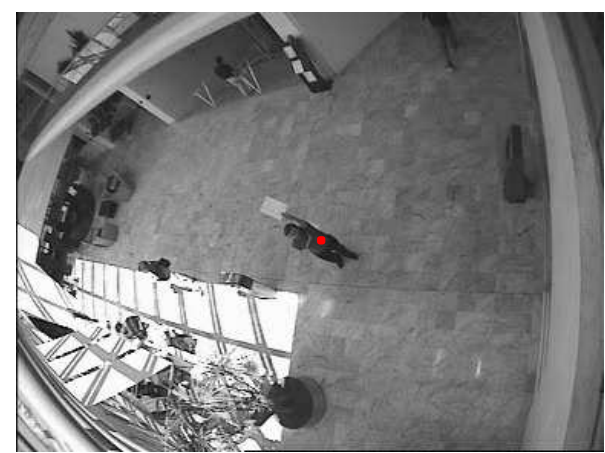

(a) Imagem original em níveis de cinza.

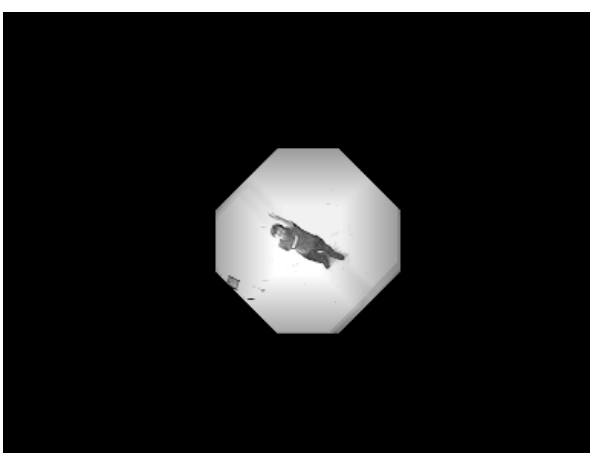

(b) Resultado da dilatação condicional.

Figura 3.9: Exemplo de dilatação condicional de uma imagem em níveis de cinza, o Quadro 20 da seqüência Fight_RunAway1 do Projeto CAVIAR. 


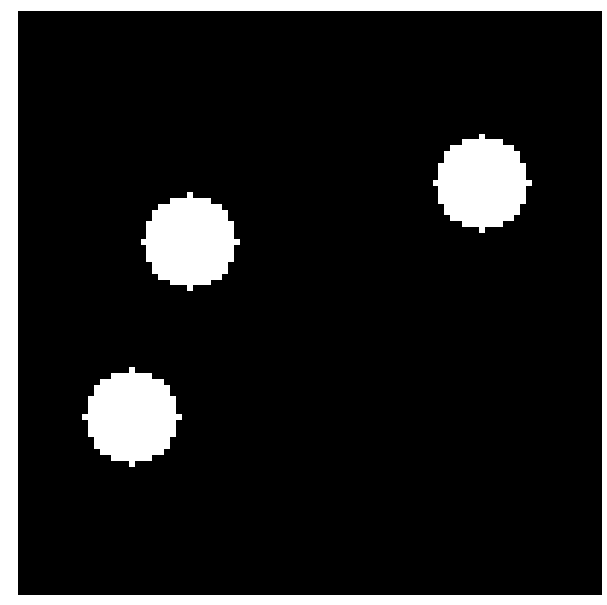

(a) Imagem binária original.

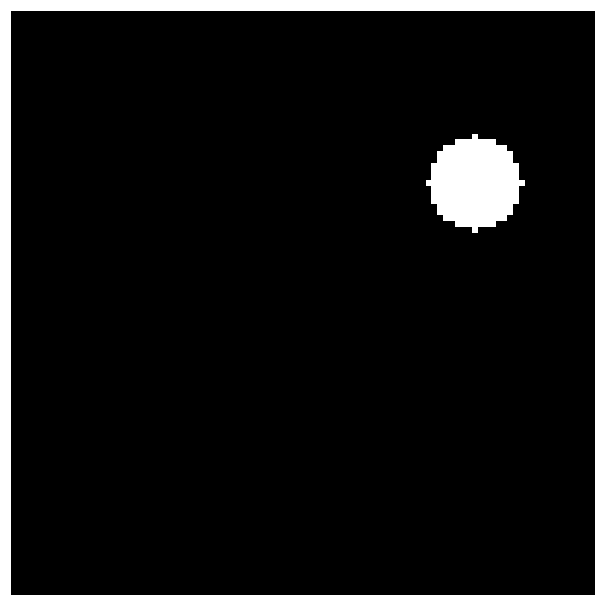

(b) Resultado do filtro reconstrução inf-geodésico

Figura 3.10: Filtro reconstrução inf-geodésico em uma imagem binária.

\subsubsection{Regiões Planas e Operadores Conexos}

Uma região plana em uma imagem em níveis de cinza é uma região conexa maximal que possui um nível de cinza constante $[3,15]$. Uma região plana pode ser um pixel isolado ou então uma imagem inteira. O tamanho de uma região plana é muito dependente da conectividade utilizada. Assim, duas regiões planas adjacentes usando conectividade 4 podem ser consideradas uma mesma quando a conectividade utilizada é 8. Por exemplo, a imagem binária da Figura 3.11(a) possui apenas duas regiões planas quando se usa conectividade 8 (Figura 3.11(b)) ou seis regiões planas quando se usa conectividade 4 (Figura 3.11(c)).

Em um outro exemplo, a imagem sintética da bandeira na Figura 3.12(a) possui apenas três regiões planas (usando conectividade 4 ou 8) como mostra a Figura 3.12(b). Imagens reais geralmente possuem milhares de regiões planas. A imagem real da bandeira na Figura 3.12(c) possui 57119 regiões planas utilizando a conectividade 4 e 48543 regiões planas utilizando a conectividade 8 (Figura 3.12(d)).

Filtro conexo é um operador crescente que possui a propriedade de unir regiões planas adjacentes da imagem. A aplicação de um filtro conexo nunca aumenta o número de regiões planas em uma 


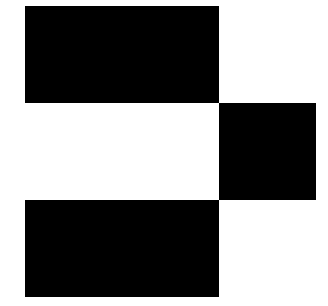

(a) Imagem original binária.

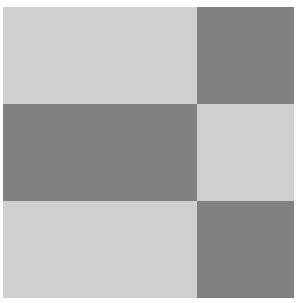

(b) Com conectividade 8 , são 2 regiões planas

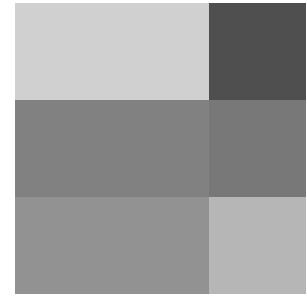

(c) Com conectividade 4 , são 6 regiões planas

Figura 3.11: Imagem apresenta número diferente de regiões planas dependendo da conectividade utilizada.

imagem. Todas as regiões planas que aparecem no resultado de um filtro conexo estavam na imagem original. A redução do número de regiões planas é uma característica desejável principalmente para a etapa de segmentação [13]. Outra propriedade importante dos filtros conexos é a preservação das bordas mais importantes da imagem original.

\subsubsection{Abertura e Fechamento por Reconstrução}

A definição dos marcadores é uma fase importante na aplicação dos filtros condicionais. Os marcadores podem ser definidos heuristicamente por uma outra imagem, como na dilatação e erosão condicionais, ou podem ainda ser obtidos automaticamente, através de alguma transformada simples na imagem original [15]. A abertura ou o fechamento são utilizados na obtenção automática de marcadores. O filtro abertura por reconstrução utiliza a abertura para obtenção dos marcadores e é definido como:

$$
f \circ g h=f \triangle_{g}(f \circ h)
$$

onde $f, g, h$ são funções em $K^{\mathbb{E}}, f$ é o sinal original, $g$ é o elemento estruturante que define a conectividade utilizada no filtro e $h$ é o elemento estruturante utilizado na definição dos marcadores automáticos.

O filtro dual à abertura por reconstrução é o fechamento por reconstrução definido como:

$$
f \bullet g h=f \nabla_{g}(f \bullet h),
$$




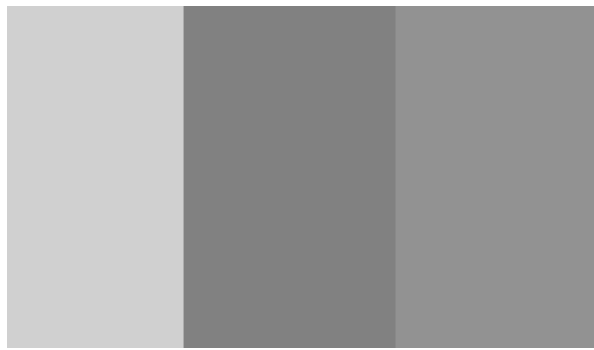

(a) Imagem sintética de uma bandeira.

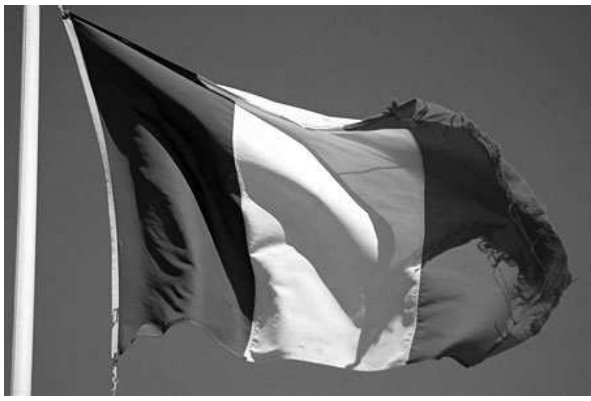

(c) Imagem real da mesma bandeira.

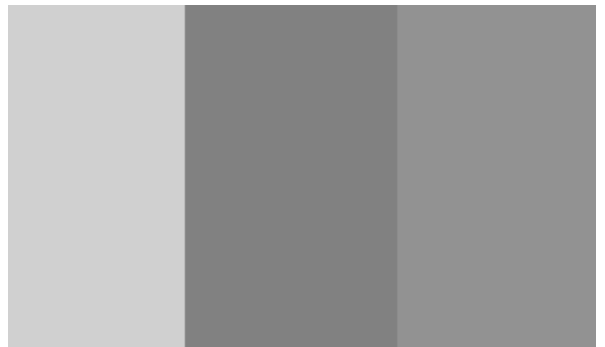

(b) Rótulos das regiões planas da imagem sintética.

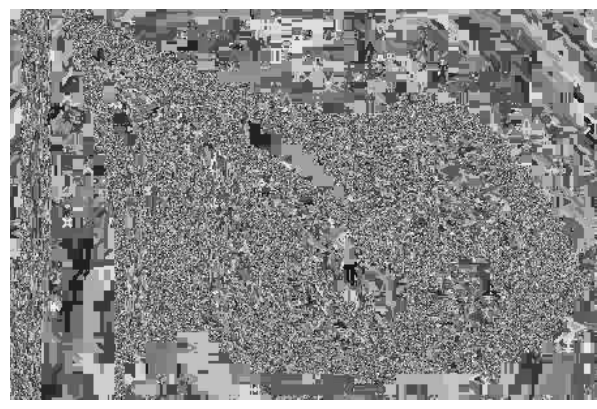

(d) Rótulos das regiões planas da imagem real.

Figura 3.12: Imagens reais geralmente possuem muito mais regiões planas que imagens sintéticas.

onde $f, g, h$ são funções em $K^{\mathbb{E}}, f$ é o sinal original, $g$ é o elemento estruturante que define a conectividade do filtro e $h$ é o elemento estruturante utilizado na definição automática dos marcadores.

A Figura 3.13(a) mostra algumas canetas em uma imagem em níveis de cinza. Utilizando o filtro fechamento por reconstrução é possível selecionar automaticamente apenas uma das canetas. Para isto, é utilizado como elemento estruturante uma linha com 100 pontos de comprimento e com $0^{\circ}$ (zero graus) de inclinação. Esta linha é utilizada como elemento estruturante do fechamento e apenas a caneta que também estava a zero graus de inclinação é reconstruída no resultado do filtro como mostra a Figura 3.13(b).

O filtro abertura top-hat por reconstrução é similar ao filtro abertura top-hat normal, porém utiliza-se uma abertura por reconstrução. Este filtro e seu dual fechamento top-hat por reconstrução 


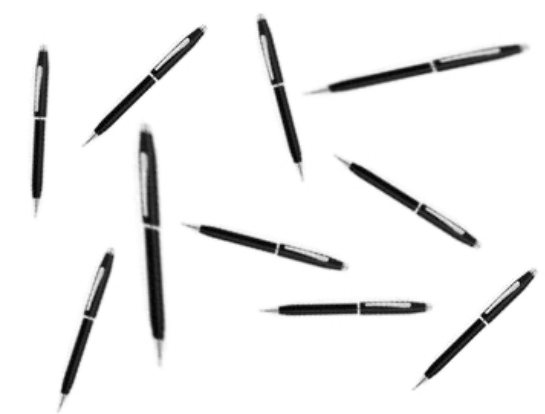

(a) Imagem original, canetas em níveis de cinza. (b) Resultado da aplicação do filtro fechamento por reconstrução.

Figura 3.13: Exemplo do filtro fechamento por reconstrução.

são definidos respectivamente como:

$$
\begin{aligned}
& f \hat{\circ}_{g} h=f-\left(f \circ_{g} h\right), \\
& f \hat{\bullet}_{g} h=\left(f \bullet_{g} h\right)-f,
\end{aligned}
$$

onde $f, g, h$ são funções em $K^{\mathbb{E}}, f$ é o sinal original, $g$ o elemento estruturante que define a conectividade e $h$ o elemento estruturante utilizado na definição do marcador automático.

O filtro abertura por área é utilizado para eliminar componentes conexos com área menor que um parâmetro especificado. Este filtro é implementado utilizando aberturas por reconstrução.

O filtro alternado seqüencial conexo é utilizado geralmente para diminuir o número de regiões planas em uma imagem. Por ser um operador conexo, as margens da imagem original são preservadas, melhorando assim a qualidade do resultado do filtro. É definido como:

$$
\begin{aligned}
& A S F_{o c, h, g}^{n}(f)=\left(\left(\left(\left(\left(f \bullet_{g} h\right) \circ_{g} h\right) \bullet_{g} 2 h\right) \circ_{g} 2 h\right) \ldots \bullet_{g} n h\right) \circ_{g} n h, \\
& A S F_{c o, h, g}^{n}(f)=\left(\left(\left(\left(\left(f \circ_{g} h\right) \bullet_{g} h\right) \circ_{g} 2 h\right) \bullet \bullet_{g} 2 h\right) \ldots \circ_{g} n h\right) \bullet_{g} n h,
\end{aligned}
$$

onde $f, g, h$ são funções em $K^{\mathbb{E}}, f$ é o sinal original, $g$ é o elemento estruturante que define a conectividade utilizada e $h$ é o elemento estruturante utilizado nas aberturas e fechamentos por reconstrução sucessivos, $O C$ significa que a cada ciclo ocorre um fechamento seguido de abertura e 
$C O$ significa que a cada ciclo ocorre uma abertura seguida de fechamento.

A Figura 3.14(a) mostra o resultado da aplicação do filtro alternado seqüencial conexo na imagem da Figura 3.12(c). O filtro foi aplicado por 20 iterações utilizando uma caixa de 3x3 pixels como elemento estruturante, definindo conectividade 8. A Figura 3.14(b) mostra os rótulos das regiões planas no resultado do filtro. O número de regiões planas caiu de 57119 para 8296 na conectividade utilizada.

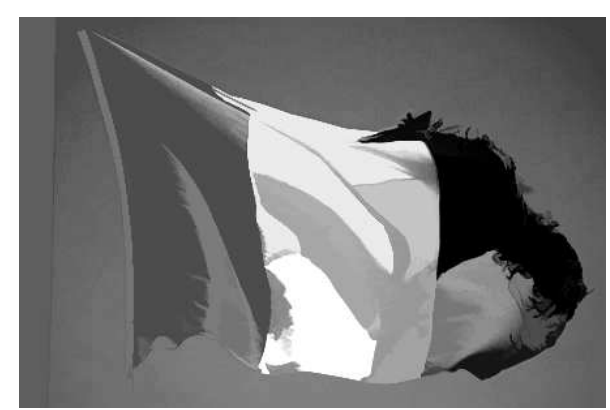

(a) Resultado do filtro alternado seqüencial conexo.

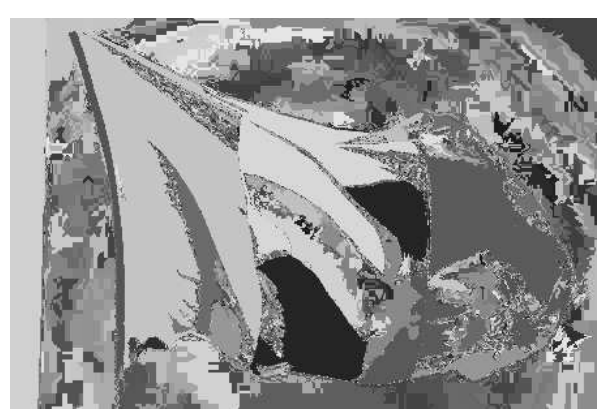

(b) Regiões planas no resultado.

Figura 3.14: Aplicação do filtro alternado seqüencial conexo para diminuição do número de regiões planas de uma imagem real em níveis de cinza.

\subsubsection{Filtros de Contraste e Volume}

O filtro $h$-Máxima remove qualquer pico com altura menor ou igual ao parâmetro $h$ e o seu filtro dual, o h-Mínima, remove qualquer vale com profundidade menor ou igual ao parâmetro $h$. É um filtro conexo e é utilizado na redução de regiões planas de uma imagem unindo as regiões planas adjacentes com níveis de cinza similares, ou seja, regiões de baixo contraste. Os filtros h-Máxima e h-Mínima são definidos, respectivamente, como:

$$
\begin{gathered}
\operatorname{HMax}_{h, g}(f)=f \triangle_{g}(f-h), \\
H \operatorname{Min}_{h, g}(f)=f \nabla_{g}(f+h),
\end{gathered}
$$

onde $f, g$ são funções em $K^{\mathbb{E}}, f$ é o sinal original, $g$ é o elemento estruturante que define a conectividade utilizada e $h \in \mathbb{Z}^{+}$é o parâmetro utilizado para a filtragem de contraste. 
Os filtros morfológicos v-Mínima e v-Máxima também são filtros conexos que removem quaisquer bases ou picos, respectivamente, com volume menor que o argumento especificado $v$. 


\section{Capítulo 4}

\section{Segmentação de Movimento Usando MM}

Neste capítulo, é apresentada uma nova técnica para segmentação de movimento em seqüências de vídeo utilizando algumas das operações morfológicas descritas no Capítulo 3. A técnica proposta se enquadra na abordagem de subtração de fundo, já que um modelo de fundo é construído. Porém, existe uma diferença fundamental entre a técnica proposta e os demais algoritmos de subtração de fundo descritos na Seção 2.3.2; ao invés de utilizar a intensidade dos valores dos pixels nos quadros da seqüência de vídeo, a técnica proposta utiliza-se dos contornos dos objetos que se movem na cena. O algoritmo é fácil de implementar e quando comparado com outros algoritmos da mesma abordagem apresenta ótimos resultados quantitativos e mostra-se mais robusto a falsos positivos e a falsos negativos em algumas situações analisadas.

A Seção 4.1 descreve o algoritmo da solução proposta. Na Seção 4.1.1, a estimação de fundo utilizada na solução é descrita. A Seção 4.1.2 descreve como os alvos são obtidos. A Seção 4.1.3 descreve os filtros morfológicos usados na etapa de filtragem de ruído. Uma heurística de coerência temporal que ajuda na eliminação de ruídos em vídeos muito ruidosos é descrita na Seção 4.1.4. E, finalmente, a Seção 4.2 descreve detalhes da implementação.

\subsection{Algoritmo da Solução Proposta}

A solução segue a abordagem de subtração de fundo. O Algoritmo 1 descreve em alto nível os passos da solução proposta. O algoritmo recebe como entrada uma seqüência de vídeo $\mathcal{V}$ com quadros em níveis de cinza. Como saída, ele produz uma outra seqüência de vídeo $\mathcal{V}^{\prime}$, onde cada quadro da seqüência é uma imagem binária que contém as bordas dos alvos da cena. A Figura 4.1 mostra o diagrama da solução. Para cada quadro da seqüência de vídeo de entrada, as bordas das 


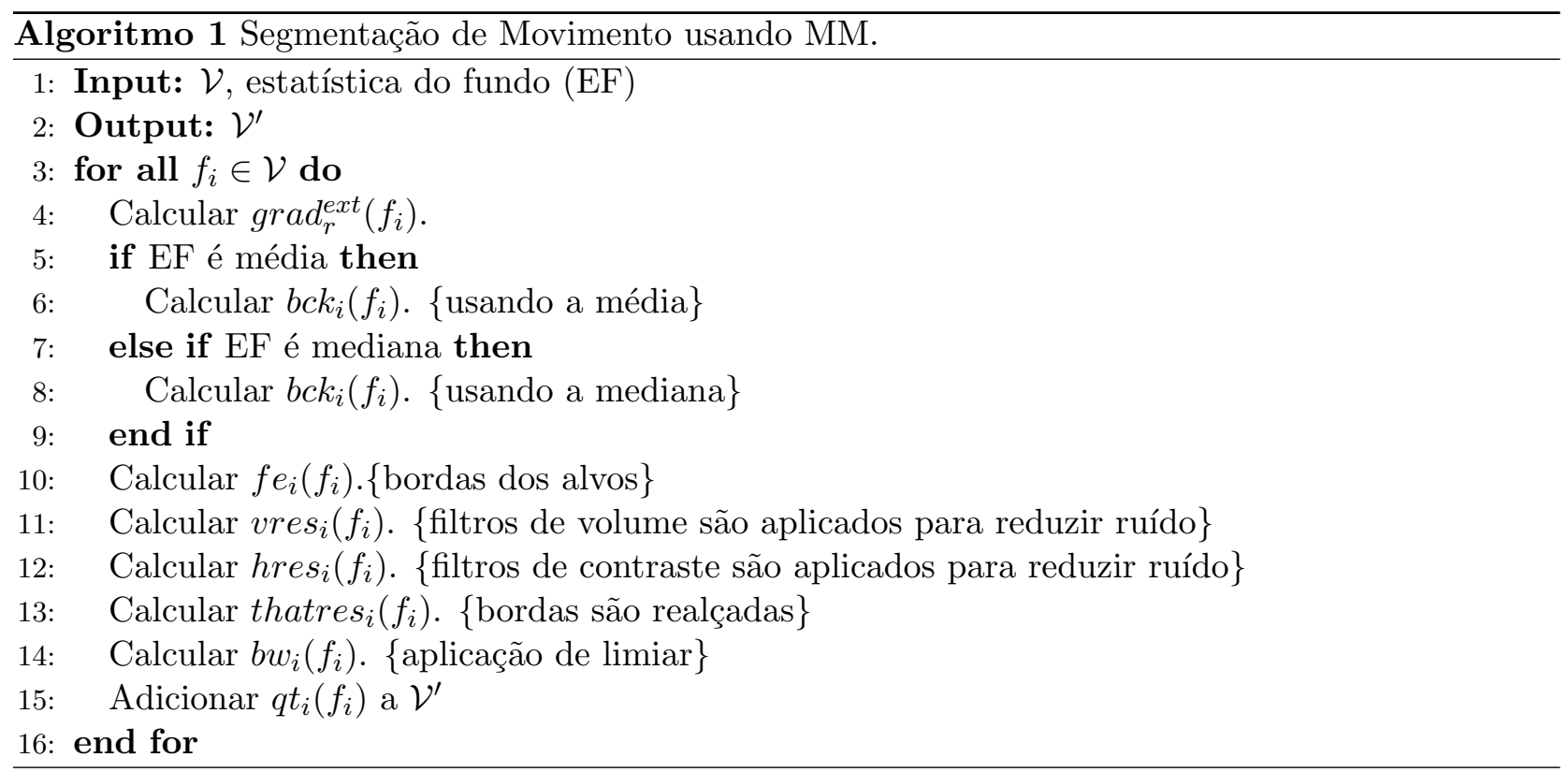

imagens são estimadas utilizando o gradiente morfológico externo. O modelo de fundo é estimado utilizando estas bordas. Os contornos dos alvos do quadro corrente são calculados utilizando uma subtração com saturação (Seção 3.1) entre os contornos do quadro e os do modelo de fundo. Após esta etapa, vários filtros morfológicos conexos são utilizados para redução de ruído no resultado. Como os filtros conexos não produzem novas bordas no resultado, as principais bordas do quadro original são preservadas enquanto as demais são eliminadas. Aplica-se então um filtro morfológico que preserva as regiões com os pixels de maiores intensidades e, em seguida, o operador limiar é aplicada. Em casos que os vídeos apresentam muito ruído, aplica-se uma heurística de coerência temporal, onde alguns contornos na imagem binária são eliminados por não estarem em posições aproximadas em quadros consecutivos. Os demais contornos são considerados como bordas dos alvos. A imagem resultante é adicionada a seqüência de vídeo de saída.

\subsubsection{Estimação do Fundo}

Para criar um modelo do fundo da cena, geralmente, aplica-se alguma estatística a um certo número de quadros no início da seqüência de vídeo. Os alvos são obtidos ao se comparar o quadro atual e o modelo estimado do fundo da cena. O algoritmo proposto estima o modelo de fundo através da mediana dos $m$ últimos quadros processados. Porém, ao contrário de outros algoritmos de 


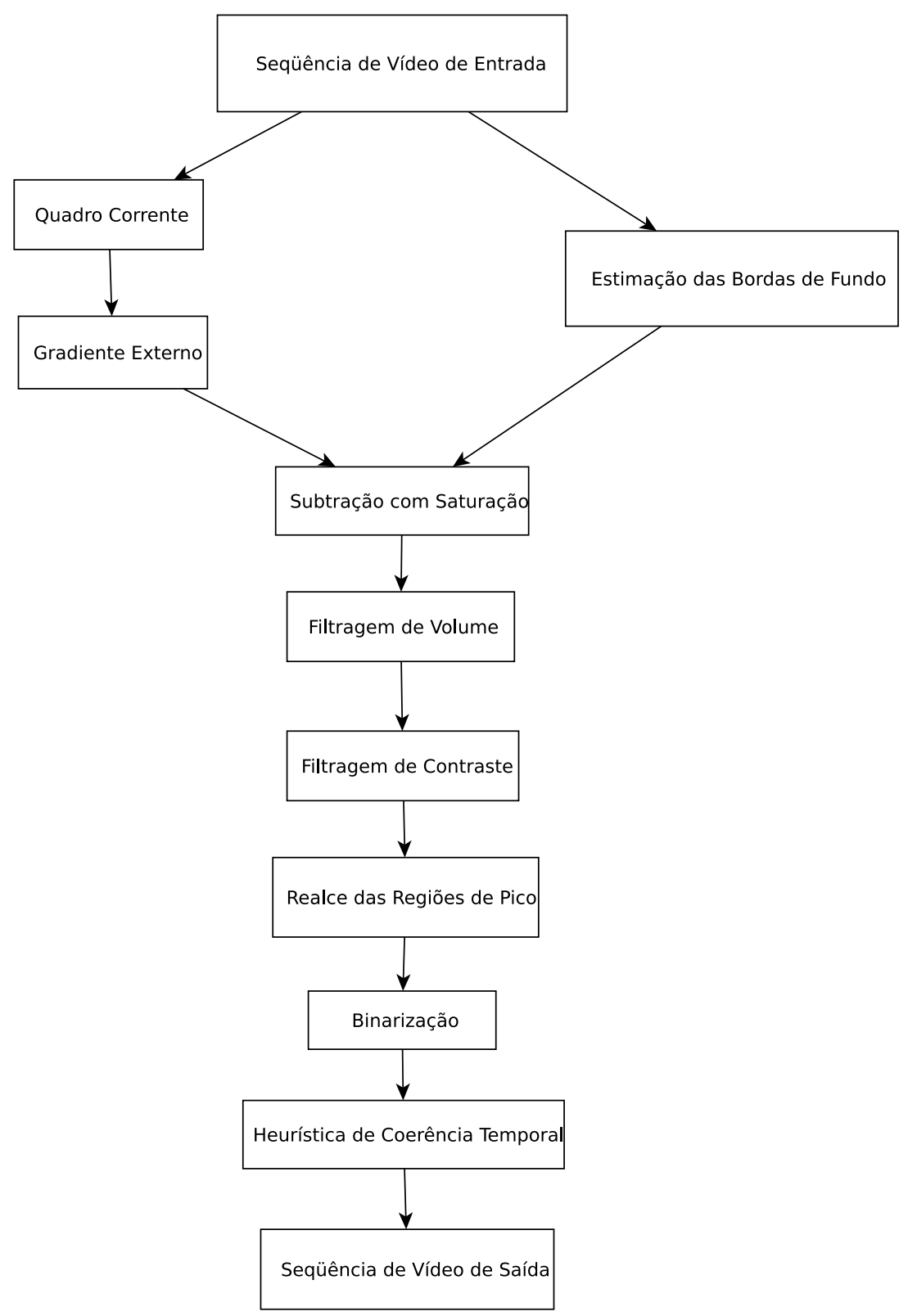

Figura 4.1: Esquema do algoritmo proposto.

subtração de fundo, a técnica proposta não utiliza as intensidades dos pixels, mas os contornos dos objetos nos quadros. Assim, para cada quadro da seqüência de vídeo, o gradiente morfológico externo 
(Seção 3.2.1) é utilizado para obter os contornos daquele quadro. O modelo de fundo é estimado a partir dessas bordas. A estimação do modelo de fundo usando a mediana dos $m$ últimos quadros é definida por:

$$
b_{c} k_{i}=\text { Mediana }_{i-m-1 \leq j \leq i-1}\left(\operatorname{grad}_{b}^{e x t}\left(f_{j}\right)\right),
$$

onde Mediana é a operação de cômputo da mediana, $f_{j} \in K^{\mathbb{E}}$ é o quadro de índice $j$ da seqüência de vídeo, $0<m<n$, é o número de quadros a serem considerados na estimação, $i$ é o índice do quadro atual na seqüência de vídeo e $b$ é o elemento estruturante utilizado no cômputo do gradiente externo.

Uma borda que se mantém em constante movimento durante o período de treinamento irá praticamente desaparecer do fundo estimado. Para um dado pixel, se ele não fez parte de uma borda durante mais da metade do período de treinamento, o fundo estimado apontará que este pixel não pertence a nenhuma borda. Se durante a maior parte do período de treinamento, o pixel fez parte de uma borda, o fundo estimado irá indicar que ele pertence a uma borda. Assim, o fundo estimado conterá, principalmente, as bordas dos objetos que permaneceram sem movimento durante o período de treinamento.

Uma alternativa na estimação de fundo é utilizar apenas um a cada $v$ quadros processados para recalcular o quadro de fundo. Esta solução diminui o tempo do algoritmo gasto na estimação do fundo sem uma perda significativa da qualidade do fundo estimado. Uma outra vantagem é utilizar um menor número de quadros abrangendo um período maior do vídeo o que contribui para melhorar a estimação do fundo.

\subsubsection{Obtenção dos Alvos}

Para obter as bordas dos alvos no quadro corrente utiliza-se o operador subtração com saturação entre as bordas do quadro atual e as bordas do fundo da cena estimadas no passo anterior. Formalmente, as bordas dos alvos durante o processamento do quadro $i$ da seqüência de vídeo $f e_{i}$ são estimadas por:

$$
f e_{i}=\operatorname{grad}_{b}^{e x t}\left(f_{i}\right)-b c k_{i},
$$

onde $f_{i} \in K^{\mathbb{E}}$ é o quadro atual, $b c k_{i}$ é o fundo estimado no passo anterior e $f e_{i}$ é o quadro que armazena as bordas estimadas dos alvos. 


\subsubsection{Filtragens de Ruído}

O resultado do processamento anterior pode, muitas vezes, ser ruidoso. Assim, uma etapa para remoção de ruído é necessária. Uma imagem em níveis de cinza pode ser vista como uma superfície topográfica, onde os pixels cujas intensidades são maiores que as intensidades de seus vizinhos são vistos como picos e os pixels cujas intensidades são menores que as de seus vizinhos são vistos como vales (Seção 2.1). A primeira etapa na redução de ruído do algoritmo proposto elimina picos e vales com volumes menores que o argumento especificado. O filtro morfológico v-Mínima eliminará as bases com volume menor que o argumento especificado e o filtro morfológico v-Máxima (Seção 3.4.4) eliminará os picos com volume menor que o argumento especificado do resultado anterior, $f e_{i}$. Este primeiro passo de eliminação de ruídos é definido por:

$$
\text { vres }_{i}=v \text {-Máxima }, b\left(v-\operatorname{Mínima}_{v, b}\left(f e_{i}\right)\right),
$$

onde $b$ é um elemento estruturante utilizado para definir a conectividade a ser utilizada, no caso, conectividade 4, e $v$ é o parâmetro passado para os operadores $v$-Mínima e $v$-Máxima. Foi definido, empiricamente, o valor 100 para $v$.

O próximo passo de redução de ruído é a utilização dos operadores morfológicos para a filtragem de contraste. O h-Mínima e o $h$-Máxima (Seção 3.4.4) eliminam, respectivamente, bases e picos com contraste menor que o argumento especificado $h$. Esses operadores são aplicados ao resultado anterior vres $_{i}$ :

$$
h e_{i}=h \text {-Máxima }, b\left(h-\text { Mínima }_{h, b}\left(\text { vres }_{i}\right)\right) \text {, }
$$

onde $b$ é um elemento estruturante utilizado para definir a conectividade 4 e $h$ é o parâmetro utilizado para definir o contraste mínimo. Foi usado valor 3 para $h$.

A seguir, é aplicado ao resultado anterior um filtro morfológico que vai extrair apenas as regiões dos picos. O filtro utilizado neste passo é a abertura top-hat por reconstrução (Seção 3.4.3):

$$
\text { thatres }_{i}=\text { hres }_{i} \hat{\mathrm{o}}_{b} d
$$

onde $b$ é um elemento estruturante utilizado para definir a conectividade 4 e $d$ é um elemento estruturante utilizado para seleção das regiões de picos do quadro, um disco, plano, de raio 3.

O resultado das filtragens de ruído é então convertido para binário usando o limiar trivial igual 
a 1.

$$
\left.b w_{i}=\operatorname{Th}_{(\text {thatres }}, 1\right)
$$

onde $T h$ representa o operador limiar.

\subsubsection{Heurística de Coerência Temporal}

Em vídeos de baixa qualidade, verifica-se que algumas bordas que não pertencem a objetos em movimento continuam no resultado final. Para estes casos, apresenta-se uma heurística para solucionar o problema que é baseada na coerência temporal das bordas, isto é, a suposição que a posição de uma borda do alvo não se altera muito em relação à sua posição nos quadros anteriores. Esta suposição baseia-se em taxas de exibição de vídeo em tempo real (tipicamente 15 a 30 quadros por segundo). Assim, a heurística, assumindo este pequeno deslocamento dos alvos entre os quadros sucessivos, calcula a dilatação dos dois últimos resultados convertidos para binário: $b w_{i-1}$ e $b w_{i-2}$. Como elemento estruturante desta dilatação, é utilizado um disco plano. Uma interseç̧ão entre a imagem binária atual $b w_{i}$ e as duas imagens binárias anteriores dilatadas vai manter apenas as bordas da imagem binária atual que estavam aproximadamente na mesma posição nos quadros anteriores. A heurística é formalizada como:

$$
q t_{i}=b w_{i} \wedge\left(b w_{i-1} \oplus c\right) \wedge\left(b w_{i-2} \oplus c\right)
$$

onde $\wedge$ é o operador de intersecção, $b w_{i}$ a imagem binária atual, $b w_{i-1}$ e $b w_{i-2}$ imagens binárias dos dois quadros anteriores e $c$ o elemento estruturante utilizado na dilatação das imagens binárias anteriores, um disco plano, de raio 3.

O resultado final $q t_{i}$ é então adicionado a seqüência de vídeo de saída $\mathcal{V}^{\prime}$.

A Figura 4.2 mostra a iteração do algoritmo processando o quadro 180 da seqüência Fight_OneManDown do Projeto CAVIAR. A Figura 4.2(a) mostra o quadro original, a Figura 4.2(b) mostra o modelo de fundo estimado pela mediana dos quadros 1 a 179. Na Figura 4.2(c), é mostrado as bordas dos objetos do quadro corrente obtidos a partir do gradiente morfológico externo (Seção 3.2.1). A Figura 4.2(d) mostra as bordas dos alvos do quadro corrente obtidos a partir da subtração com saturação das bordas do modelo de fundo das bordas do quadro corrente. A Figura 4.2(e) mostra o resultado após a aplicação das filtragens de volume, contraste e realce das áreas de picos. O resultado

final do algoritmo é mostrado na Figura 4.2(f) quando a imagem já foi convertida para binária e a heurística de coerência temporal foi aplicada. O resultado final mostra apenas as bordas dos alvos 
que estavam em movimento no quadro corrente da seqüência de vídeo. Foi aplicado em todas as figuras o operador negação para facilitar a visualização.

\subsection{Implementação}

O algoritmo proposto foi implementado em scripts do MATLAB. A versão utilizada foi a versão 6.5 (Release 13). Foi utilizada também a biblioteca de operadores morfológicos para o MATLAB MMACH versão $1.3[54,3]$ e a biblioteca de processamento de imagens do MATLAB a Image Processing Toolbox versão 3.2 (Release 13). O ambiente de implementação utilizado consiste de máquinas rodando sistema operacional GNU/Linux Debian, núcleo do sistema operacional na versão 2.16, processadores AMD Athlon com 1 GB de memória principal.

O aplicativo é chamado de dentro do ambiente MATLAB e todos os parâmetros são passados através de um arquivo de configuração. A Tabela 4.1 especifica os parâmetros de entrada do aplicativo situados neste arquivo de configuração. O parâmetro total_quadros indica o número de quadros do arquivo de vídeo de entrada que serão utilizados pelo algoritmo. O parâmetro tamanho_bloco especifica quantos quadros serão lidos do vídeo de entrada a cada momento. Se o parâmetro tamanho_bloco for igual ao parâmetro total_quadros apenas uma leitura será executada durante o processamento. Os parâmetros tipo_entrada, diretorio_entrada e fonte_entrada contêm, respectivamente, informações se a entrada é um diretório ou uma coleção de arquivos, o diretório onde está localizada a entrada e o nome do arquivo de entrada. O parâmetro salvar_alvo indica se o resultado do algoritmo será salvo em um arquivo de vídeo de saída. O parâmetro tipo_saida_alvo indica se a saída será um vídeo ou uma coleção de imagens, o parâmetro diretorio_saida indica o diretório onde será gravada a saída e o parâmetro nome_saida_alvo indica o nome do arquivo de vídeo de saída. Os parâmetros mostrar_alvo e modo_verbose mostram, respectivamente, uma janela com o resultado corrente e uma mensagem indicando o quadro que está sendo processado. Os parâmetros volume minimo, contraste minimo e conectividade têm influência direta no resultado do algoritmo e são passados como parâmetros respectivamente para os filtros de volume, de contraste e aos filtros morfológicos que esperam um parâmetro indicando a conectividade.

Um arquivo contendo todos os parâmetros utilizados na geração da saída é salvo no mesmo diretório e com o mesmo nome do arquivo de vídeo de saída, porém com a extensão .res. Com as informações lá contidas é possível regerar o mesmo resultado, garantindo assim a reprodutibilidade dos experimentos. 


\begin{tabular}{|l|l|}
\hline Parâmetro & Descrição \\
\hline total_quadros & Número de quadros que serão processados. \\
tamanho_bloco & Tamanho do buffer. \\
tipo_entrada & Se entrada é um vídeo ou um diretório de imagens. \\
diretorio_entrada & Diretório de entrada do vídeo. \\
fonte_entrada & Nome do arquivo de vídeo de entrada. \\
salvar_alvo & Gerar arquivo de vídeo de saída com resultado. \\
tipo_saida_alvo & Tipo de saída: vídeo ou diretório de imagens. \\
diretorio_saida_alvo & Diretório do arquivo de vídeo de saída. \\
nome_saida_alvo & Nome do arquivo de vídeo de saída. \\
mostrar_alvo & Janela mostrando resultados a cada quadro. \\
modo_verbose & Imprimir um aviso a cada linha processada. \\
volume_minimo & Argumento para os filtros de volume. \\
contraste_minimo & Argumento para os filtros de contraste. \\
conectividade & Conectividade dos filtros morfológicos: 4 ou 8. \\
\hline
\end{tabular}

Tabela 4.1: Parâmetros de entrada do arquivo de configuração utilizados na implementação do algoritmo de segmentação de movimento usando MM. 


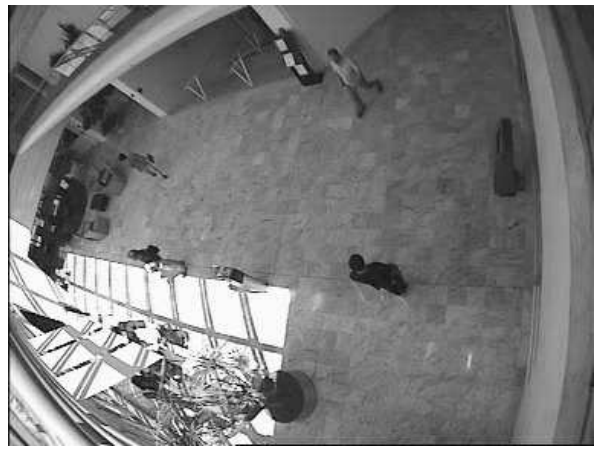

(a) Quadro original da seqüência.

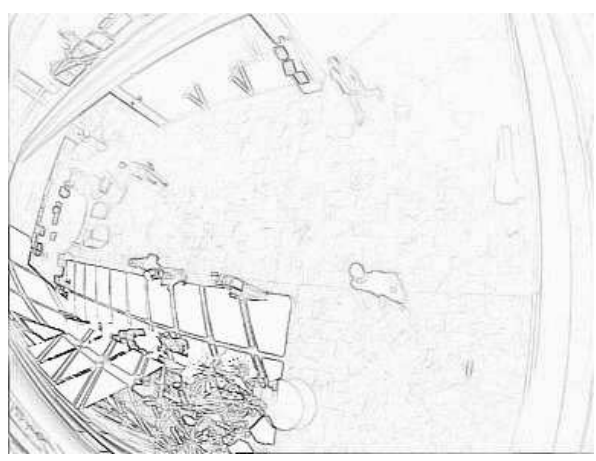

(c) Bordas do quadro corrente.

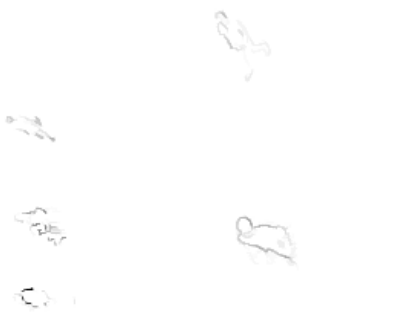

(e) Após as filtragens de ruído.

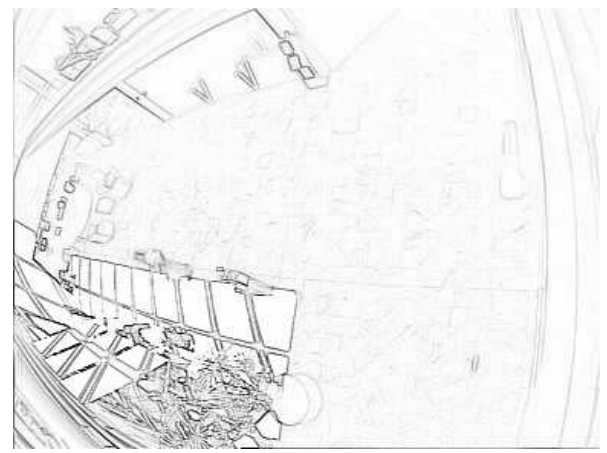

(b) Modelo de fundo.

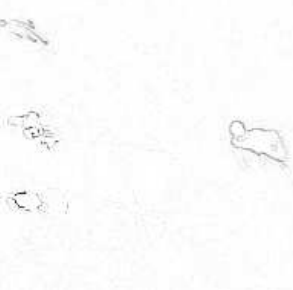

(d) Bordas dos alvos.

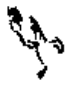

$+1$

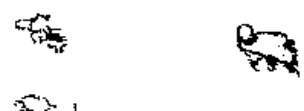

(f) Imagem final.

Figura 4.2: Etapas do algoritmo de segmentação de movimento usando Morfologia Matemática no processamento do quadro 180 da seqüência Fight_OneManDown do Projeto CAVIAR. 


\section{Capítulo 5}

\section{Resultados Experimentais}

Este capítulo descreve os resultados experimentais obtidos durante o trabalho. O algoritmo proposto e alguns algoritmos clássicos de segmentação de movimento foram implementados em uma mesma plataforma e foram testados em uma base de vídeos pública. Seus resultados são comparados utilizando algumas medidas de avaliação de desempenho relatados na literatura. A base de dados utilizada na avaliação do desempenho dos métodos é descrita na Seção 5.1. A Seção 5.2 descreve detalhes das implementações dos algoritmos. A Seção 5.3 mostra os resultados numéricos dos vídeos testados usando algumas técnicas de avaliação de resultados e a Seção 5.4 compara os algoritmos estudados em algumas situações específicas.

\subsection{Bases de Dados}

Atualmente, existem algumas bases de vídeos com o intuito específico de testar algoritmos de segmentação de movimento, principalmente no contexto de aplicações de vigilância inteligente [20]. As principais bases estão listadas na Tabela 5.1 [93]. Esta seção descreve a base pública de vídeos utilizada nos testes dos algoritmos implementados.

\subsubsection{Projeto CAVIAR}

O CAVIAR, sigla em inglês para Context Aware Vision using Image-based Active Recognition, é um projeto conjunto de Visão Computacional, focado principalmente na área de vigilância inteligente, entre a Universidade de Edimburgo, no Reino Unido; Instituto Superior Técnico, em Lisboa, Portugal e o Instituto Politécnico Nacional de Grenoble, França. O projeto CAVIAR disponibiliza sua base de dados em seu sítio na Web (http://homepages.inf.ed.ac.uk/rbf/CAVIAR). Os vídeos do projeto 


\begin{tabular}{|l|l|l|}
\hline Projeto & Descrição & Data \\
\hline PETS & $\begin{array}{l}\text { Seminários anuais para comparação de } \\
\text { métodos de vigilância inteligente. }\end{array}$ & 2000 até hoje. \\
iLIDS & Coleção de vídeos reais. & 2004 até hoje. \\
VERAAE & Focada em vigilância inteligente. & 2005 até hoje. \\
ARDA VACE & Reconhecimento de eventos em vídeo. & 2003 até hoje. \\
CAVIAR & Vigilância em centros de compras. & $2002-2005$. \\
ETISEO & Projeto financiado pelo Governo da França. & 2005-2006. \\
\hline
\end{tabular}

Tabela 5.1: Bases de vídeos para testes de aplicações de vigilância inteligente.

são coloridos, codificados em MPEG2, possuem uma resolução de 288 x 384 pixels e foram capturados a 25 quadros por segundo.

As seqüências de vídeo do projeto CAVIAR são dividas em 3 grupos:

- O primeiro desses grupos foram feitos especialmente para o projeto usando uma lente grande angular e mostram o salão de entrada dos Laboratórios INRIA, em Grenoble, França. Nos vídeos, atores realizam ações tais como a simulação de brigas, abandono de pacotes no cenário, caminham pelo cenário, andam em grupos e sozinhos e encontram-se em cena.

- O segundo grupo mostra clientes em um centro de compras de Portugal. As seqüências desse grupo também foram capturadas utilizando uma câmera grande angular. A visada da câmera mostra o corredor de frente com clientes entrando e saindo de lojas, andando em grupos ou sozinhos, parando diante de vitrines, cumprimentando-se e passando uns pelos outros.

- O terceiro grupo de vídeos mostra o mesmo cenário (ou seja o corredor do centro de compras em Portugal), porém de uma visada lateral.

A Tabela 5.2 mostra o número de vídeos, o número de quadros utilizados e o tempo por agrupamento de vídeos utilizados nos testes deste trabalho. A última linha da tabela totaliza os valores apresentados. As Tabelas 5.3, 5.4 e 5.5 mostram respectivamente as seqüências de vídeo do projeto CAVIAR dos grupos 1, 2 e 3 utilizadas nos testes. A coluna Número apresenta uma numeração seqüencial dos vídeos; na coluna Seqüência está o nome da seqüência e, em seguida, o número de quadros processados da seqüência. Todos os quadros das seqüências estão anotados. As anotações dos vídeos são utilizadas apenas na avaliação e comparação dos resultados obtidos. 


\begin{tabular}{|c|r|r|r|}
\hline Grupo & Vídeos & Quadros & Tempo (em seg.) \\
\hline 1 & 21 & 20527 & 821.08 \\
2 & 12 & 15949 & 637.96 \\
3 & 12 & 17317 & 692.68 \\
\hline Total & 45 & 53793 & 2151.72 \\
\hline
\end{tabular}

Tabela 5.2: Número de vídeos, totais de quadros e tempos de vídeo por agrupamento de vídeos e a totalização dos valores apresentados.

\begin{tabular}{|r|l|r|}
\hline Número & Seqüência & Quadros \\
\hline 1 & Browse1 & 1044 \\
2 & Browse2 & 876 \\
3 & Browse3 & 912 \\
4 & Browse4 & 1140 \\
5 & Browse_WhileWaiting1 & 792 \\
6 & Browse_WhileWaiting2 & 1896 \\
7 & Fight_OneManDown & 960 \\
8 & Fight_RunAway1 & 522 \\
9 & Fight_RunAway2 & 552 \\
10 & LeftBag_AtChair & 973 \\
11 & LeftBag_BehindChiar & 1068 \\
12 & LeftBag & 1440 \\
13 & LeftBag_PickedUp & 1356 \\
14 & LeftBox & 864 \\
15 & Meet_Split_3rdGuy & 924 \\
16 & Meet_WalkSplit & 624 \\
17 & Meet_WalkTogether1 & 708 \\
18 & Meet_WalkTogether2 & 828 \\
19 & Walk1 & 612 \\
20 & Walk2 & 1056 \\
21 & Walk3 & 1380 \\
\hline
\end{tabular}

Tabela 5.3: Seqüências de vídeo testadas do grupo 1 do projeto CAVIAR.

A Figura 5.1 mostra alguns quadros de uma seqüência do grupo 1, a seqüência Fight_RunAway2. Nesta seqüência, inicialmente uma pessoa está parada no centro do cenário. Em seguida, esta pessoa sai de cena e duas outras entram no cenário, simulam uma briga e fogem correndo em direções opostas. A Figura 5.2 mostra quadros da seqüência TwoEnterShop2cor do grupo 2. Neste vídeo, 


\begin{tabular}{|r|l|r|}
\hline Número & Seqüência & Quadros \\
\hline 1 & OneLeaveShop1cor & 295 \\
2 & ThreePastShop1cor & 1650 \\
3 & TwoEnterShop3cor & 1149 \\
4 & OneStopEnter1cor & 1500 \\
5 & ThreePastShop2cor & 1520 \\
6 & TwoLeaveShop1cor & 1343 \\
7 & ShopAssistant1cor & 1675 \\
8 & ShopAssistant2cor & 610 \\
9 & TwoEnterShop1cor & 1642 \\
10 & TwoEnterShop2cor & 1605 \\
11 & TwoLeaveShop2cor & 600 \\
12 & WalkByShop1cor & 2360 \\
\hline
\end{tabular}

Tabela 5.4: Seqüências de vídeo testadas do grupo 2 do projeto CAVIAR.

\begin{tabular}{|r|l|r|}
\hline Número & Seqüência & Quadros \\
\hline 1 & OneLeaveShop1front & 294 \\
2 & OneLeaveShopReenter2front & 560 \\
3 & ShopAssistant1front & 1675 \\
4 & ShopAssistant2front & 3000 \\
5 & ThreePastShop1front & 1650 \\
6 & ThreePastShop2front & 1520 \\
7 & TwoEnterShop1front & 1642 \\
8 & TwoEnterShop2front & 1598 \\
9 & TwoEnterShop3front & 1075 \\
10 & TwoLeaveShop1front & 1343 \\
11 & TwoLeaveShop2front & 600 \\
12 & WalkByShop1front & 2360 \\
\hline
\end{tabular}

Tabela 5.5: Seqüências de vídeo testadas do grupo 3 do projeto CAVIAR.

clientes aparecem andando por um dos corredores de um centro de compras, entram e saem das lojas, passam uns pelos outros e se cumprimentam. O vídeo mostra uma visada frontal ao corredor. A Figura 5.3 mostra quadros da seqüência TwoEnterShop2front do grupo 3. Os quadros das Figuras 5.2 e 5.3 mostram o mesmo cenário, aproximadamente ao mesmo tempo, mas de visadas diferentes. 


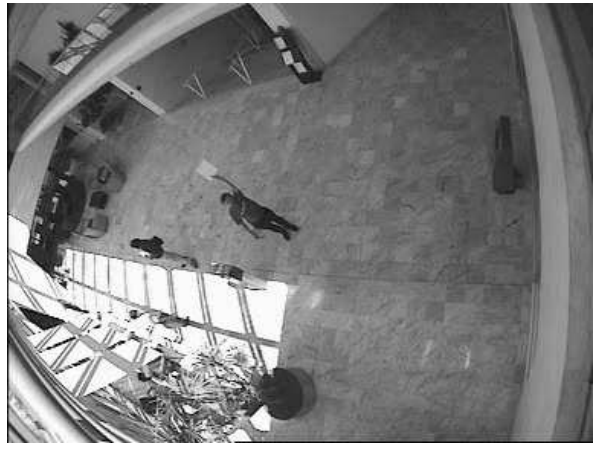

(a) Quadro 70.

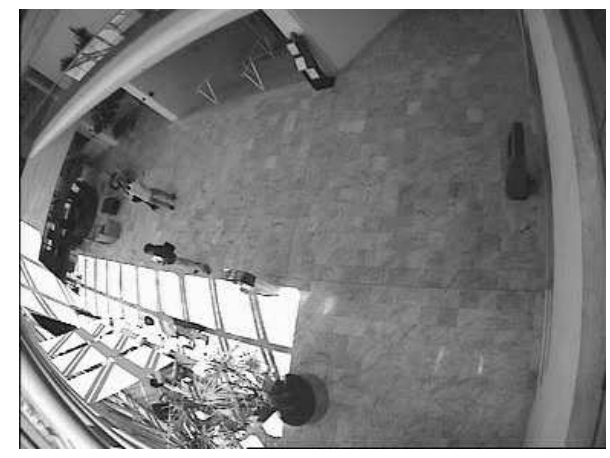

(c) Quadro 370 .

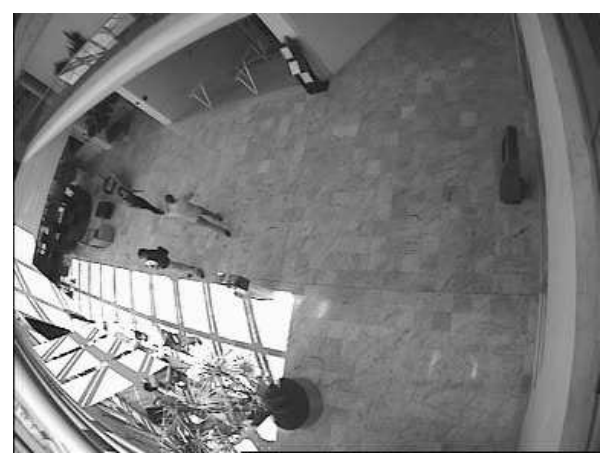

(b) Quadro 290 .

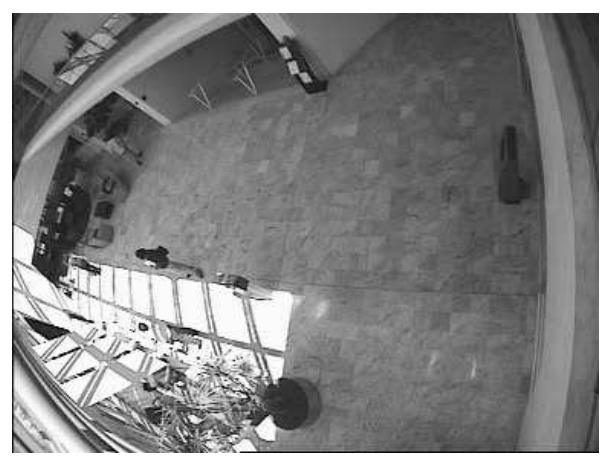

(d) Quadro 444 .

Figura 5.1: Alguns quadros de uma seqüência do grupo 1, no caso a seqüência Fight_RunAway2. 


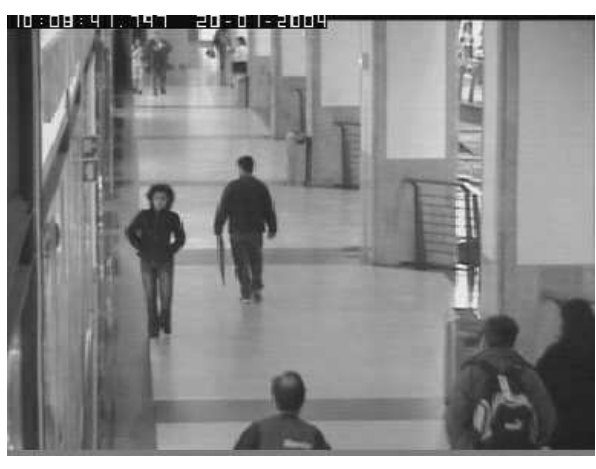

(a) Quadro 52.

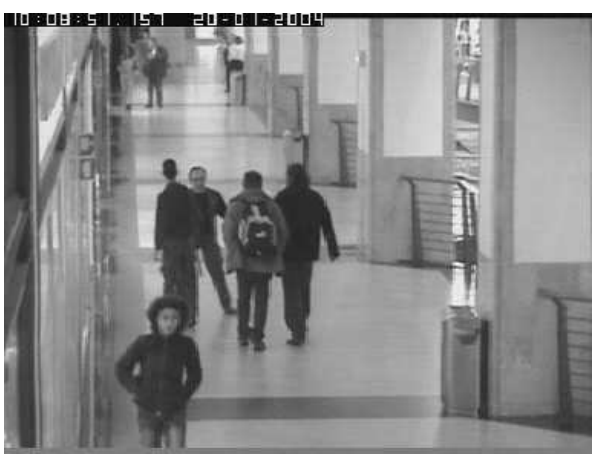

(c) Quadro 286.

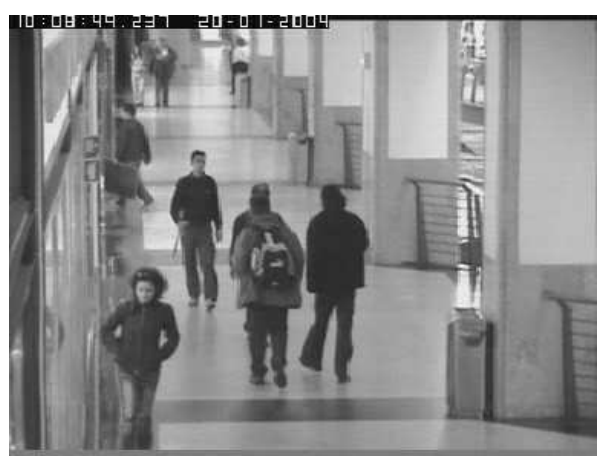

(b) Quadro 238 .

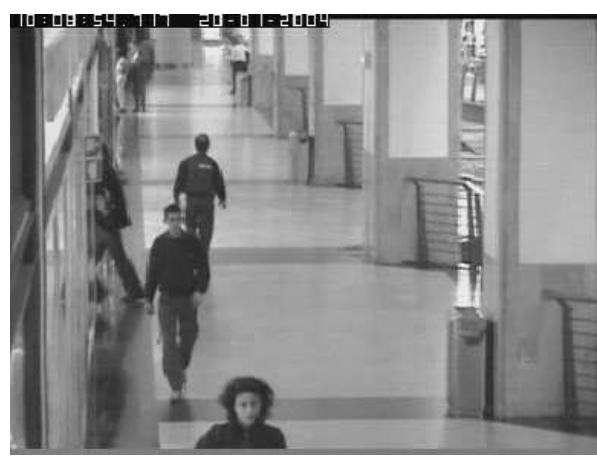

(d) Quadro 375 .

Figura 5.2: Quadros da seqüência TwoEnterShop2cor do grupo 2. 


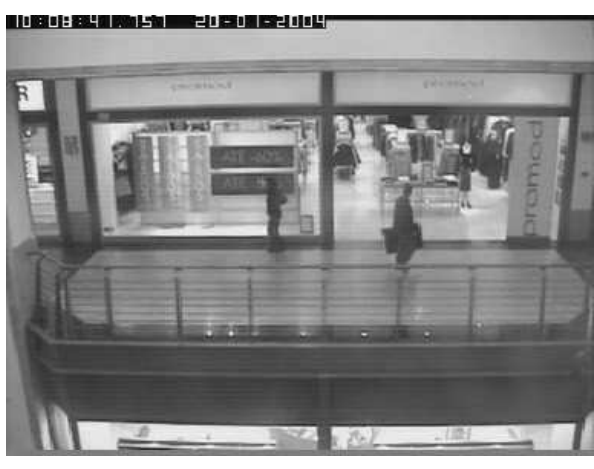

(a) Quadro 129.

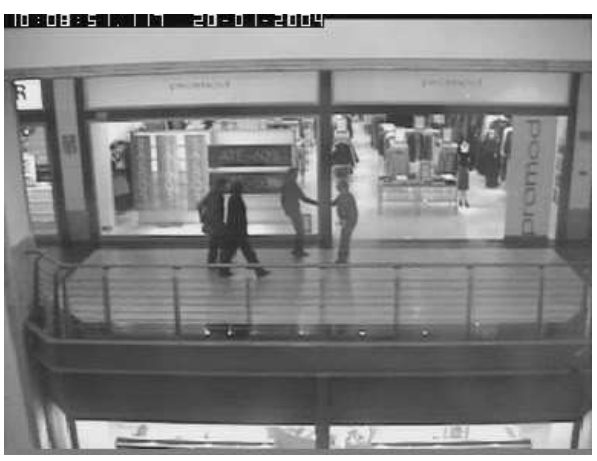

(c) Quadro 363.

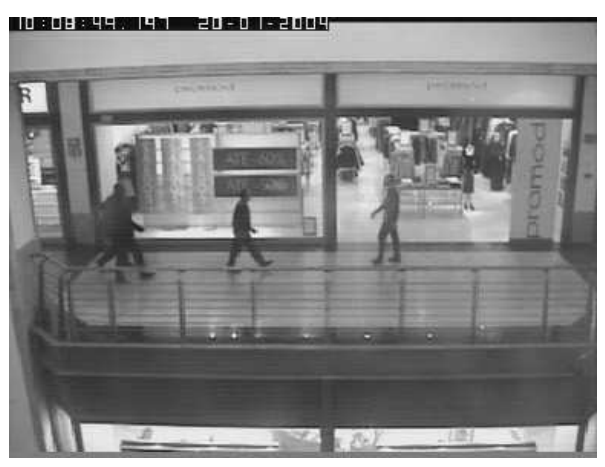

(b) Quadro 315 .

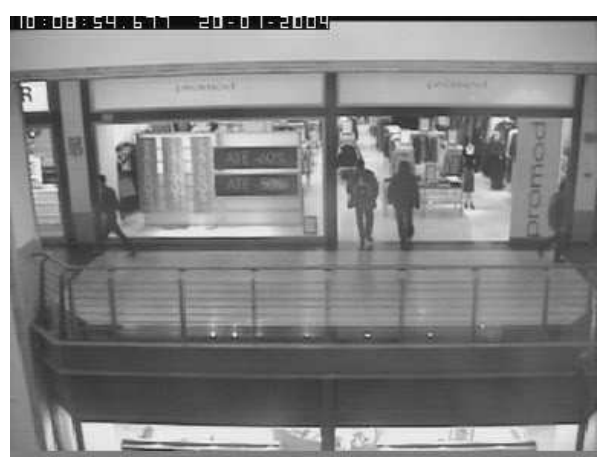

(d) Quadro 452.

Figura 5.3: Quadros da seqüência TwoEnterShop2front do grupo 3. Os quadros mostram aproximadamente o mesmo período dos quadros da Figura 5.2. 


\begin{tabular}{|l|l|c|}
\hline Algoritmo (Abreviatura) & Abordagem & Referência \\
\hline 2 quadros (DIF2) & Diferenciação temporal & \\
3 quadros (DIF3) & Diferenciação temporal & {$[11]$} \\
Fundo estimado pela média (SFME) & Subtração de fundo & \\
Fundo estimado pela mediana (SFMD) & Subtração de fundo & \\
Baseado em MM (MM) & Subtração de Fundo & \\
Fundo estimado pela mediana & Subtração de fundo & \\
dos últimos quadros (SFMDJ) & & \\
$W^{4}$ (W4) & Estatística & {$[29]$} \\
Gaussiana simples (GS) & Estatística & {$[91]$} \\
\hline
\end{tabular}

Tabela 5.6: Algoritmos de segmentação de movimento implementados.

\subsection{Implementações}

Para comparar com os resultados do algoritmo proposto, alguns algoritmos clássicos de segmentação de movimento foram implementados. A Tabela 5.6 lista os algoritmos de segmentação de movimento que foram implementados, a abordagem a que pertencem e, quando for o caso, o artigo de referência utilizado para implementação. Todas as implementações foram feitas utilizando a mesma plataforma: MATLAB versão 6.5, a biblioteca de imagens do próprio MATLAB e a biblioteca de Morfologia Matemática MMACH versão 1.3 [54,3].

Alguns dos algoritmos testados são muito suscetíveis a ruído. Assim, para diminuir o ruído dos resultados, foi aplicado em todos os resultados um filtro de abertura por área (Seção 3.4.3) que elimina todos os componentes conexos com área menor ou igual a, no caso, 10 pixels. Os parâmetros listados nesta seção foram definidos empiricamente.

\subsubsection{Diferenciação temporal}

A implementação do algoritmo de diferenciação temporal de dois quadros - DIF2 (Seção 2.3.1) segue a descrição básica da abordagem de diferenciação temporal. Ou seja, um pixel do quadro corrente é comparado ao seu correlato do quadro anterior; a diferença simétrica entre os dois valores de pixels é comparada a um limiar que o programa recebe como parâmetro. Se a diferença for maior que este limiar, o pixel é considerado alvo; caso contrário, o pixel é considerado fundo.

A implementação do algoritmo de diferenciação temporal de três quadros - DIF3 (Seção 2.3.1) 
baseou-se em [11]. Neste método, compara-se um pixel do quadro atual ao seu correlato do quadro anterior da mesma maneira que o algoritmo anterior. Uma outra comparação também é feita entre o pixel do quadro corrente e o seu correlato de dois quadros anteriores. Se em ambas as comparações o pixel for considerado alvo, a saída final classificará o pixel como alvo; caso contrário, será considerado fundo.

Os dois algoritmos de diferenciação temporal implementados possuem apenas um parâmetro que é o limiar utilizado na comparação com as diferenças simétricas. Foi definido um limiar igual a 20 nos teste realizados.

\subsubsection{Subtração de fundo}

A subtração de fundo estimado pela média - SFME (Seção 2.3.2) e a subtração de fundo estimado pela mediana - SFMD (Seção 2.3.2) possuem implementações similares. Os algoritmos utilizam um número específico de quadros no início da seqüência como período de treinamento. Durante o período de treinamento, os algoritmos não produzem um resultado, mas utilizam este período para estimar um modelo de fundo. A subtração de fundo pela média utiliza a média dos quadros do período de treinamento e a subtração de fundo pela mediana utiliza a mediana dos quadros do período de treinamento. Na etapa seguinte, cada pixel do quadro atual é comparado ao seu correlato do fundo estimado. Esta comparação é feita através da diferença simétrica e, caso esta diferença seja maior ou igual ao limiar lido como parâmetro, o pixel correspondente será considerado alvo; fundo, caso contrário.

Ambos os algoritmos utilizaram o limiar 30 na comparação entre o quadro atual e o modelo de fundo. Foram utilizados os 100 primeiros quadros das seqüências de vídeo como período de treinamento nos dois algoritmos.

O algoritmo de subtração de fundo estimado pela mediana dos últimos quadros - SFMDJ (Seção 2.3.2) é uma variação do SFMD que utiliza um número específico de quadros anteriores ao quadro atual para estimar o modelo de fundo através da mediana. Esta estimação ocorre a cada cinco quadros processados. Foram utilizados 50 quadros na estimação do fundo. O cálculo do alvo é idêntico ao utilizado nos algoritmos anteriores e o limiar utilizado na comparação do quadro atual com o modelo de fundo foi 30 . 


\subsubsection{Abordagem estatística}

A implementação do algoritmo $W^{4}$ - W4 (Seção 2.3.3) foi baseado em [29] e em [27]. É utilizado como parâmetro neste algoritmo apenas um número específico de quadros do período de treinamento. Durante o período de treinamento, são calculados, para cada pixel, a mediana, o desvio-padrão, o menor valor $(m)$, o maior valor $(n)$ e a maior diferença de valor do pixel em quadros consecutivos $(d)$. Os três últimos valores são calculados apenas se a diferença entre o valor do pixel e a mediana for menor ou igual a dois desvios-padrões. O pixel $f(x, y)$ será considerado alvo, se $(|f(x, y)-m| \leq$ $2 d) \wedge(|f(x, y)-n| \leq 2 d)$; e fundo, caso contrário.

O método gaussiano simples - GS (Seção 2.3.3) foi originalmente utilizado no projeto Pfinder [91]. Sua implementação foi baseada em [27]. O método recebe como parâmetros um número específico de quadros do período de treinamento, uma taxa de aprendizagem e um limiar. As médias e desviospadrões dos pixels durante o período de treinamento são calculados. Nesta implementação, cada pixel está em níveis de cinza ao invés do modelo YUV como proposto no algoritmo original. As médias e os desvios-padrões dos pixels são atualizados a cada iteração usando a taxa de aprendizado. O logaritmo da verossimilhança da diferença entre o valor do pixel corrente e sua média é calculado e comparado ao limiar lido como parâmetro (o valor utilizado foi -20). Se o resultado for menor que o parâmetro, o pixel é considerado alvo; e fundo, caso contrário. A taxa de aprendizado utilizada foi 0,005. Ambos algoritmos utilizam 100 quadros no período de treinamento.

\subsection{Resultados Quantitativos}

Nesta seção, são apresentados os resultados numéricos do algoritmo baseado em MM e dos demais algoritmos de segmentação de movimento implementados (Tabela 5.6). Os resultados numéricos foram obtidos utilizando as medidas e os coeficientes definidos na Seção 2.4. Todos os algoritmos utilizados nesta comparação possuem como entrada um vídeo e um conjunto de parâmetros e como saída um vídeo contendo uma máscara alvo-fundo por quadro (Seção 2.1). Um problema que surge na comparação dos algoritmos é a diferença de formato das diversas máscaras alvo-fundo que os algoritmos produzem. O algoritmo proposto neste trabalho retorna como saída apenas o contorno dos alvos. A maior parte dos algoritmos retorna o formato completo dos alvos do vídeo e os algoritmos de diferenciação temporal retornam as partes que estavam em movimento nos quadros comparados, ou seja, as partes do fundo que passaram a ser ocupadas pelos alvos ou, ao contrário, as partes dos alvos que passaram a ser ocupadas pelo fundo. A Tabela 5.7 mostra os tipos de máscaras alvo-fundo 


\begin{tabular}{|r|l|l|}
\hline Algoritmo & Tipo de Máscara Alvo-Fundo & Seção \\
\hline DIF2 & Regiões em movimento & 2.3 .1 \\
DIF3 & Regiões em movimento & 2.3 .1 \\
SFME & Formato completo do alvo & 2.3 .2 \\
SFMD & Formato completo do alvo & 2.3 .2 \\
SFMDJ & Formato completo do alvo & 2.3 .2 \\
W4 & Formato completo do alvo & 2.3 .3 \\
GS & Formato completo do alvo & 2.3 .3 \\
MM & Contornos do alvo & 4.1 \\
\hline
\end{tabular}

Tabela 5.7: Tipos de máscara alvo-fundo produzidas como saída em cada um dos algoritmos implementados.

que os algoritmos implementados produzem.

A utilização da caixa de Feret (Seção 2.1) dos resultados torna a comparação mais justa que uma comparação pontual, ou seja, pixel a pixel. A caixa de Feret $(\mathrm{CF})$ do contorno de um alvo comparada a CF do formato completo do alvo são bem próximas. A CF de regiões em movimento, no caso dos algoritmos de diferenciação temporal, também será mais próxima daquela $\mathrm{CF}$ do formato completo do que uma comparação pontual. A Figura 5.4 mostra a comparação entre as caixas de Feret de diferentes tipos de alvos. A base de vídeos do projeto CAVIAR também utiliza a CF dos alvos no padrão ouro que disponibiliza. Portanto, a utilização de caixas de Feret dos alvos no processo de avaliação dos resultados se mostra uma solução mais adequada para a comparação dos resultados dos diferentes algoritmos.

Para uma avaliação de resultados usando o método baseado em pixels, é necessário medir o número de positivos verdadeiros (TP), negativos verdadeiros (TN), falsos positivos (FP) e falsos negativos (FN). Estas medidas serão sempre em relação as caixas de Feret do padrão ouro e dos resultados. Assim, em cada quadro, para cada algoritmo testado, um pixel $p \in \mathbb{E}$ será classificado como:

- $\mathbf{T P}$ se $\left(p \in C F_{r}\right) \wedge\left(p \in C F_{o}\right)$,

- $\mathbf{T N}$ se $\left(p \notin C F_{r}\right) \wedge\left(p \notin C F_{o}\right)$,

- $\mathbf{F N}$ se $\left(p \notin C F_{r}\right) \wedge\left(p \in C F_{o}\right)$,

- $\mathbf{F P}$ se $\left(p \in C F_{r}\right) \wedge\left(p \notin C F_{o}\right)$,

onde $C F_{r}$ é a $C F$ do resultado e $C F_{o}$ é a $C F$ do padrão ouro. 


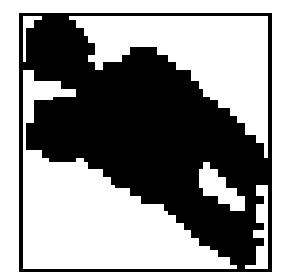

(a) Exemplo de um alvo com formato completo e sua caixa de Feret.

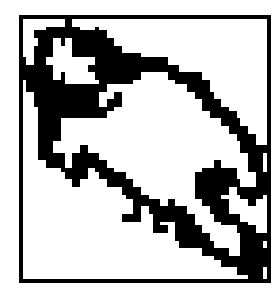

(b) Contorno de um alvo e sua caixa de Feret.

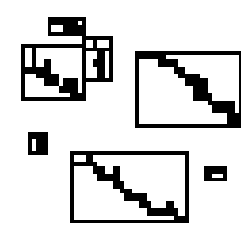

(c) Regiões em movimento e as caixa de Feret das regiões.

Figura 5.4: Os três tipos de alvos e as respectivas caixas de Feret.

Quanto maior o número de TP e de TN, melhor o resultado, isto é, maior é o número de pixels corretamente classificados no resultado. Quanto menor o número de FP e FN, melhor o resultado, ou seja, menor é o número de pixels classificados de maneira incorreta. A Figura 5.5 mostra como são feitas as medições descritas. Uma CF que delimita o componente conexo do padrão ouro é mostrada preenchida por listas verticais. A outra CF que delimita o componente conexo do resultado é mostrada preenchida por listas horizontais. A medida TP é igual ao número de pixels que aparecem na região preenchida por quadriculados. O FP é o número de pixels que aparecem na região que só possui listas horizontais. O FN é o número de pixels que aparecem na região só preenchida por listas verticais. O TN é o número de pixels que aparece na região branca da figura.

Vários dos algoritmos implementados utilizam um período de quadros iniciais como período de treinamento. Durante o período de treinamento, o algoritmo utiliza os quadros de entrada para produzir um modelo de fundo e, durante este período, a máscara alvo-fundo não é produzida na saída. A Tabela 5.8 mostra o número de quadros iniciais utilizados como período de treinamento para cada algoritmo implementado. Para evitar que o período de treinamento influencie a medição dos resultados, foram excluídos os 100 quadros iniciais de todas as saídas. Assim, as medidas ocorrerão apenas nos quadros em que todos os algoritmos produzem uma máscara alvo-fundo como resultado.

Os Gráficos 5.6(a), 5.6(b), 5.7(a) e 5.7(b) mostram, respectivamente, o boxplot dos verdadeiros positivos (TP) para os conjuntos de vídeos 1, 2 e 3 e para o total de vídeos testados do projeto CAVIAR. Boxplot é um gráfico que mostra várias medidas de uma só vez. Também chamado de 


\section{TN}

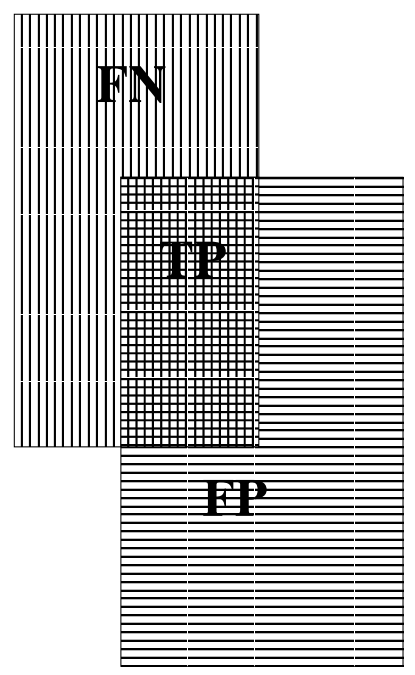

Figura 5.5: Esta figura mostra as medições dos pixels em um quadro da seqüência de vídeo. A CF do resultado do algoritmo está preenchida por listas horizontais e a CF do padrão ouro (gabarito) está na região preenchida por listas verticais. Os pixels classificados como TP são aqueles que pertencem a CF do resultado e a CF do padrão ouro. Ou seja, os pixels classificados como TP são aqueles situados na região quadriculada. Os pixels classificados como FN são aqueles que pertencem a CF do padrão ouro, mas não pertencem a CF do resultado. Estes pixels estão na região de listas verticais. Os pixels classificados como FP são aqueles que pertencem a $\mathrm{CF}$ do resultado, mas não pertencem a $\mathrm{CF}$ do padrão ouro, situando na região de listas horizontais. Os pixels classificados como TN são aqueles que não pertencem nem a CF do padrão ouro nem a CF do resultado, ou seja, são aqueles situados na região em branco da figura.

\begin{tabular}{|l|l|}
\hline Algoritmo & Quadros no Treinamento \\
\hline DIF2 & 1 \\
DIF3 & 1 \\
SFME & 100 \\
SFMD & 100 \\
SFMDJ & 100 quadros anteriores ao atual. \\
W4 & 100 \\
GS & 100 \\
MM & 2 \\
\hline
\end{tabular}

Tabela 5.8: Número de quadros iniciais utilizados como período de treinamento para cada algoritmo implementado. 
caixa e bigode, possui uma caixa que vai do primeiro quartil $(Q 1)$ ao terceiro quartil (Q3). Uma linha no interior da caixa que representa a mediana. As duas linhas que saem das duas extremidades da caixa, vão de $Q 1-1.5(Q 3-Q 1)$ a $Q 1$ e de $Q 3$ a $Q 3+1.5(Q 3-Q 1)$. Valores fora do intervalo $[Q 1-$ 1.5(Q3-Q1), Q3+1.5(Q3-Q1] são considerados observações discrepantes ou outliers. Os outliers não são mostrados nos gráficos deste trabalho. Os dois algoritmos de diferenciação temporal apresentam as menores medidas de TP nos 4 gráficos apresentados. Ou seja, estes algoritmos conseguem extrair a menor parte dos alvos em seus resultados quando comparado aos demais. Este resultado é esperado, visto que estes algoritmos apresentam nos resultados apenas as partes que se moveram nos dois ou três quadros comparados. Os demais algoritmos apresentam valores similares entre si. Vale destacar que a medida de TP no conjunto 2 é várias vezes maior que a medida nos conjuntos 1 e 3 , pois, no conjunto 2, os alvos estão (em média) mais próximos da câmera ocupando assim uma área maior do quadro. O algoritmo proposto apresentou resultados similares aos resultados dos demais algoritmos.

Os verdadeiros negativos (TN) são mostrados nos Gráficos 5.8(a), 5.8(b), 5.9(a) e 5.9(b) para, respectivamente, os conjuntos de vídeos 1, 2, 3 e o total de vídeos da base. Os valores de TN nos 4 gráficos são maiores que os valores de TP já que o fundo possui uma área maior que a área dos alvos nos quadros das seqüências testadas. Os dois algoritmos que possuem uma estimação de fundo fixa, SFME e SFMD, apresentam as menores medidas de TN em 3 dos 4 gráficos. Uma explicação seria a presença de alvos durante a estimação de fundo, com o movimento destes alvos na seqüência do vídeo, falsos positivos (chamados de fantasmas) permaneceriam nos resultados destes algoritmos durante todo o restante do processamento do vídeo, diminuindo, assim, o número de pixels corretamente classificados como fundo (TN). O valor de TN nos algoritmos de diferenciação temporal é bastante alto devido, principalmente, ao fato destes algoritmos produzirem muito poucos fantasmas (FP). O algoritmo MM apresentou valores médios de TN quando comparado aos demais algoritmos. Os algoritmos de diferenciação temporal apresentaram resultados nos conjuntos 1 e 2 inferiores aos resultados do conjunto 3 , onde praticamente todos os algoritmos apresentaram resultados similares.

Os falsos positivos (FP) são mostrados em 5.10(a), 5.10(b), 5.11(a) e 5.11(b) para, respectivamente, os conjuntos de vídeos 1, 2, 3 e o total de vídeos. O número de falsos positivos dos dois algoritmos que possuem estimação de fundo fixa é maior, na média, que o número dos demais algoritmos. A explicação para estes números é a mesma que diminui os números de TN para os dois algoritmos: alvos durante a modelagem de fundo provocam o aparecimento de fantasmas nos resultados durante todo o restante da seqüência de vídeo, o que acabou provocando o aumento dos valores de FP (e conseqüente diminuição nos valores de TN). Outro fator que aumentaria o número de FP na 


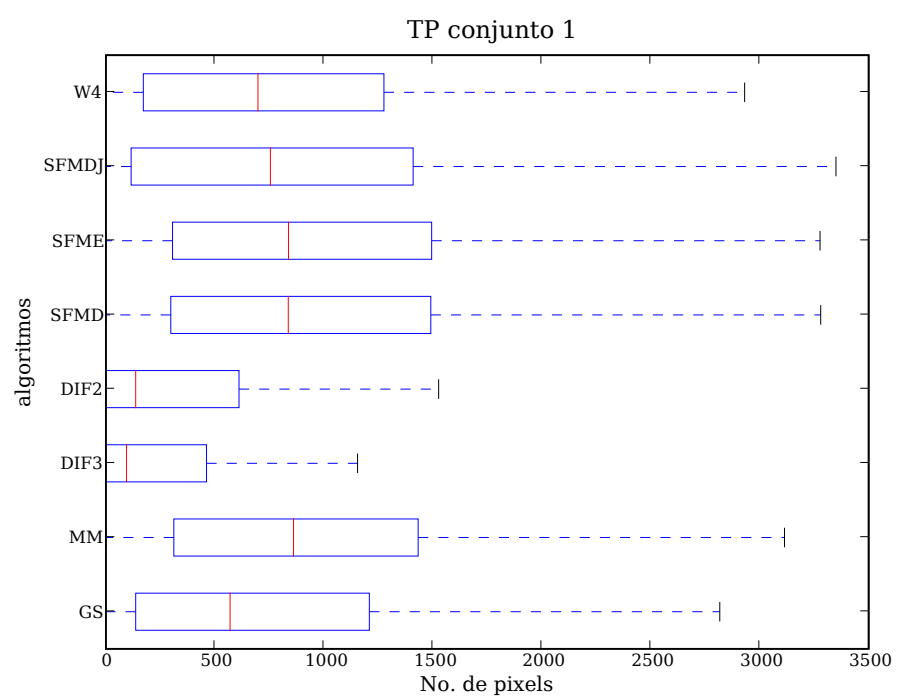

(a) Conjunto 1 .

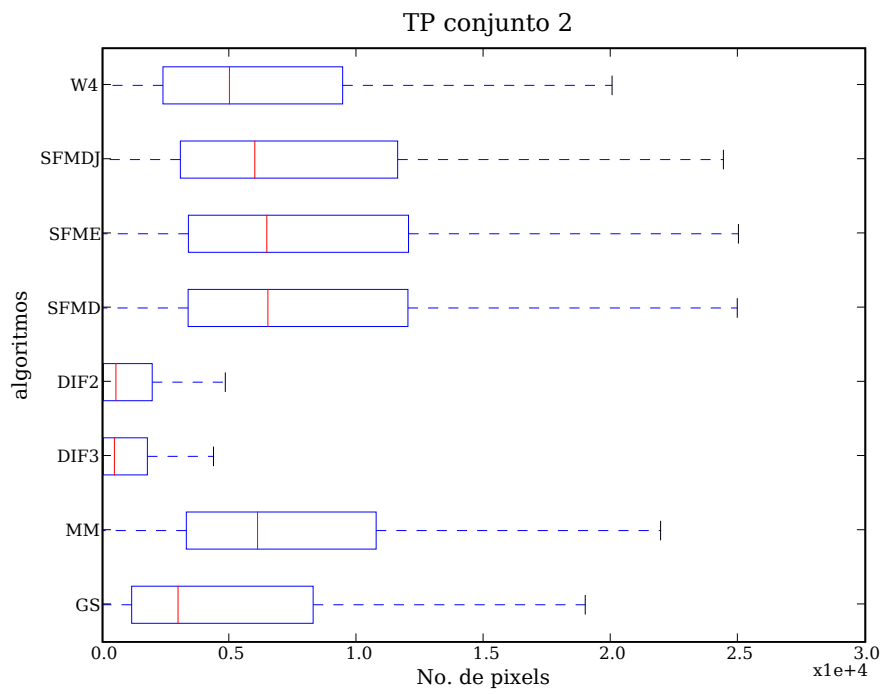

(b) Conjunto 2 .

Figura 5.6: Boxplot de TP dos conjuntos de vídeos 1 e 2 . 


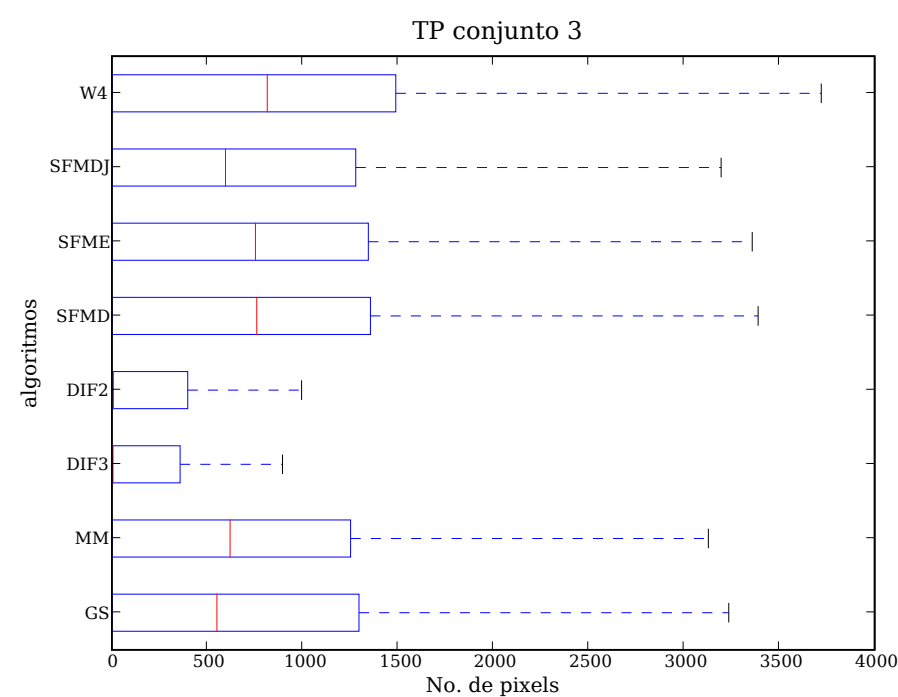

(a) Conjunto 3 .

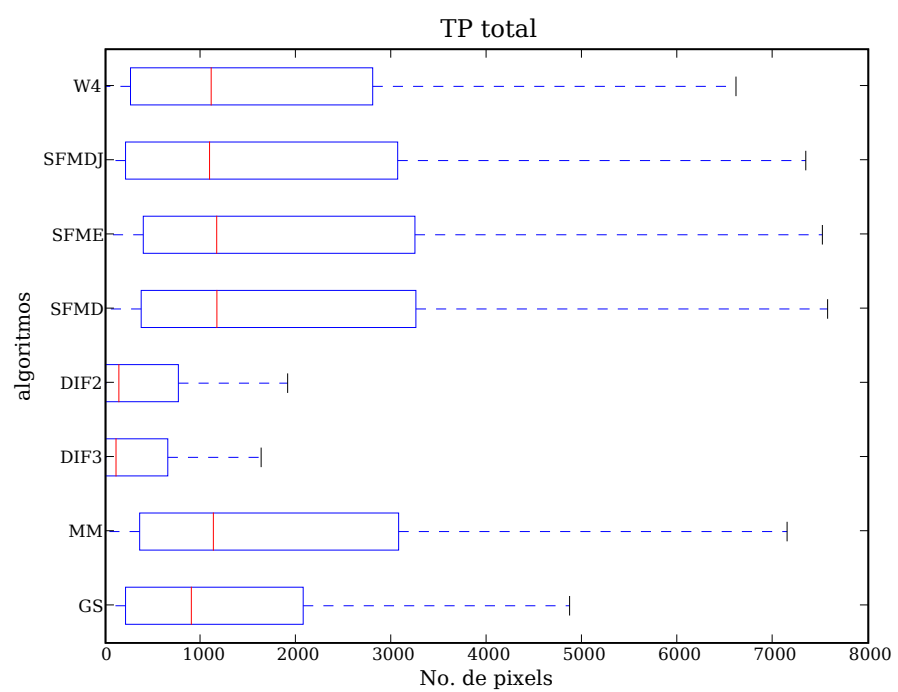

(b) Total dos vídeos.

Figura 5.7: Boxplot de TP do conjunto de vídeos 3 e do total dos vídeos. 


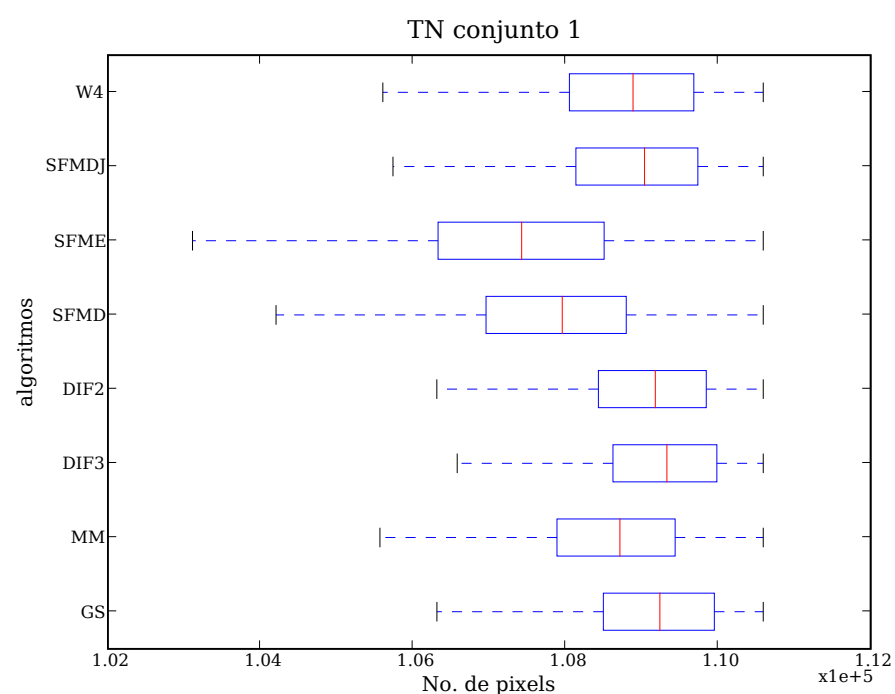

(a) Conjunto 1 .

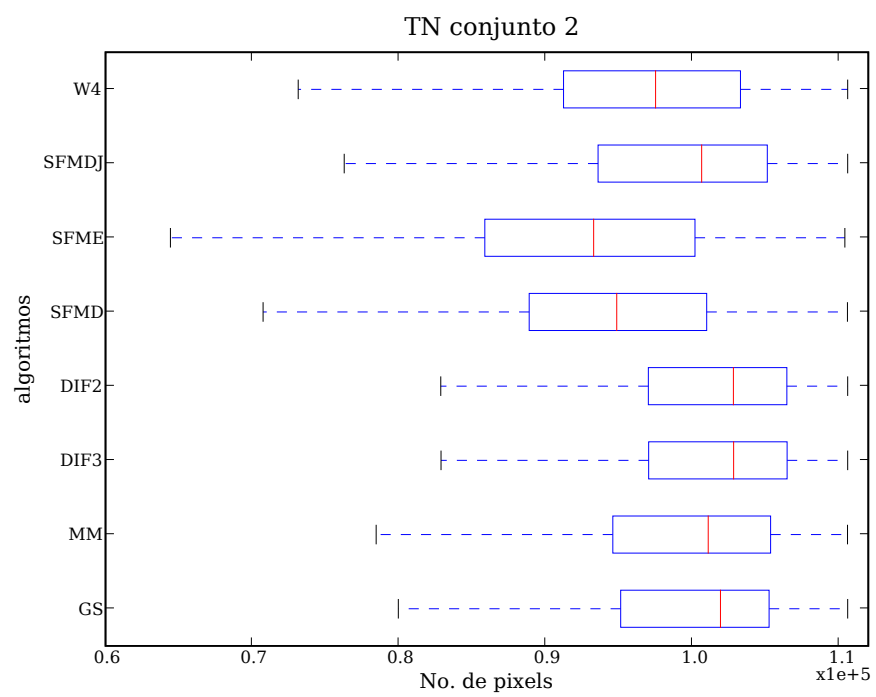

(b) Conjunto 2.

Figura 5.8: Boxplot de TN dos conjuntos de vídeos 1 e 2 . 


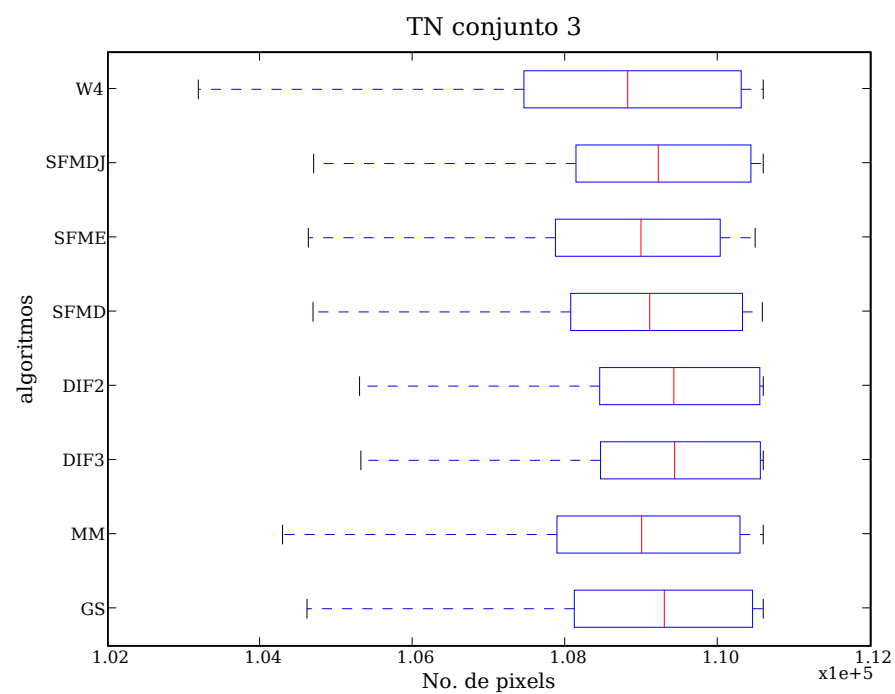

(a) Conjunto 3 .

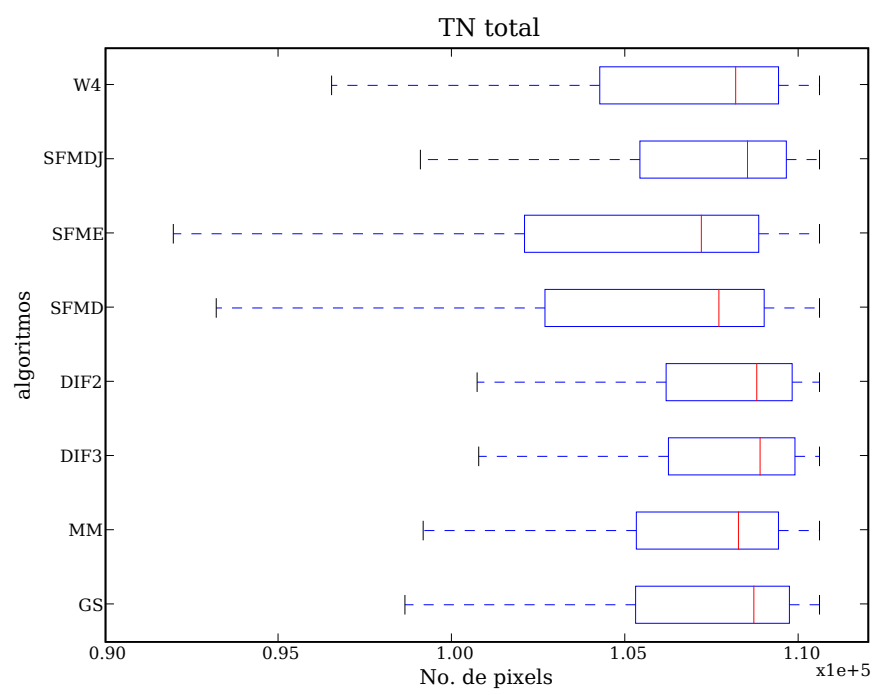

(b) Total dos vídeos.

Figura 5.9: Boxplot de TN do conjunto de vídeos 3 e do total dos vídeos. 
seqüência de vídeo é o fato que nem todos os alvos da cena estão devidamente marcados no padrão ouro. Assim, alvos que estão se deslocando fora do primeiro plano da cena ou no meio da vegetação (como ocorre nos vídeos do conjunto 1) são detectados por alguns dos algoritmos implementados, entretanto, como não aparecem no padrão ouro, acabam por aumentar o valor de FP para estes algoritmos. Os dois algoritmos de diferenciação temporal apresentam os menores valores de FP. O valor de FP destes algoritmos é principalmente devido a ruído. Estes algoritmos não apresentam problemas de fantasmas, já que não possuem modelo de fundo. O MM apresentou valores de FP similares aos valores dos demais algoritmos.

Os Gráficos 5.12(a), 5.12(b), 5.13(a) e 5.13(b) mostram o boxplot do número de falsos negativos (FN) para os conjuntos 1, 2, 3 e todos os vídeos, respectivamente. Nesta medida, os algoritmos de diferenciação temporal (DIF2 e DIF3) apresentam os maiores valores. Quanto maior o valor de FN, maior foi a proporção dos alvos em movimento que não foi detectada nos resultados. A principal causa para isto é o fato de serem algoritmos que apresentam resultados bem pobres da forma do alvo. O algoritmo MM apresentou valores baixos de FN na comparação com os demais algoritmos.

Os gráficos do tipo boxplot apresentados até aqui são excelentes ferramentas para apresentar várias estatísticas relativas às medidas, como a dispersão e a mediana. Porém, ainda é difícil identificar qual técnica apresenta melhor resultado em um determinado conjunto de vídeos. Para isto, será utilizado a média das medidas por quadro em formato de tabelas, propiciando, assim, uma comparação numérica entre os resultados obtidos pelos diferentes algoritmos. As Tabelas 5.9 e 5.10 resumem os gráficos boxplot anteriores relativos às quatro medições dos pixels (TP, TN, FP e FN) apresentando a média de cada medida por quadro para cada conjunto de vídeo testado e também para o total da base de vídeos. A Tabela 5.9 mostra as medições médias por quadro de TP, TN, FP e FN dos conjuntos 1 e 2, para cada algoritmo implementado. A Tabela 5.10 mostra os mesmos números para o conjunto de vídeo 3 e para o total geral de vídeos testados. As quatro medidas mostradas possuem valores entre 0 e 110592 que é o total de pixels de cada quadro dos vídeos testados.

A análise isolada de cada uma das quatro medidas baseadas em pixels não contribui muito para o processo de avaliação dos algoritmos de segmentação de movimento. Por exemplo, um alto valor de TP, que é um resultado desejado, pode estar acompanhado por um alto valor de FP, que não é um bom resultado. Assim, a utilização de coeficientes definidos na Seção 2.4.1 ajuda na análise dos resultados dos algoritmos, pois traduzem várias medidas em um valor absoluto. Os coeficientes a seguir apresentam valores entre 0 e 1. 


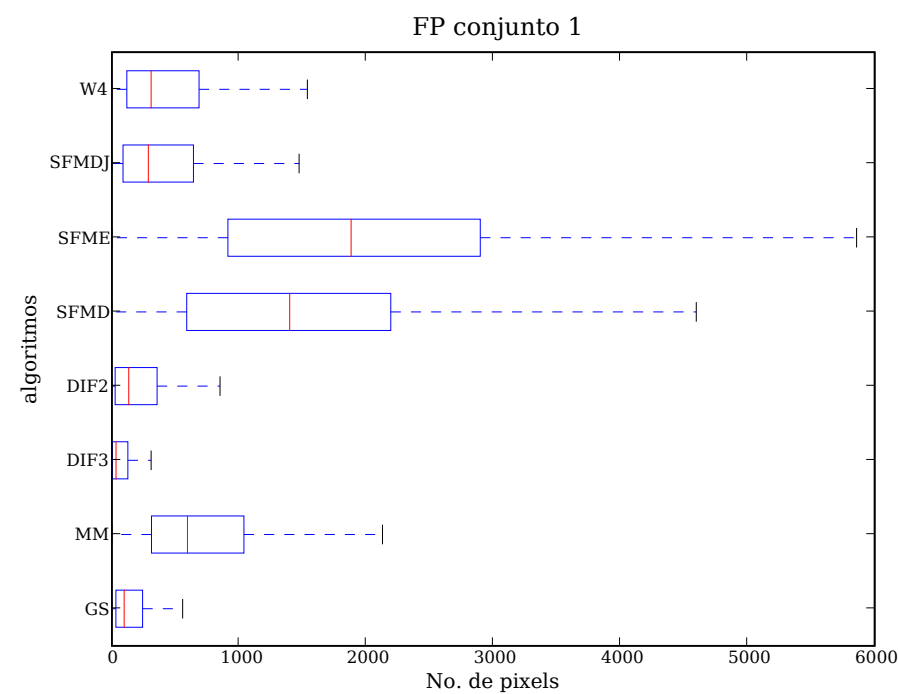

(a) Conjunto 1.

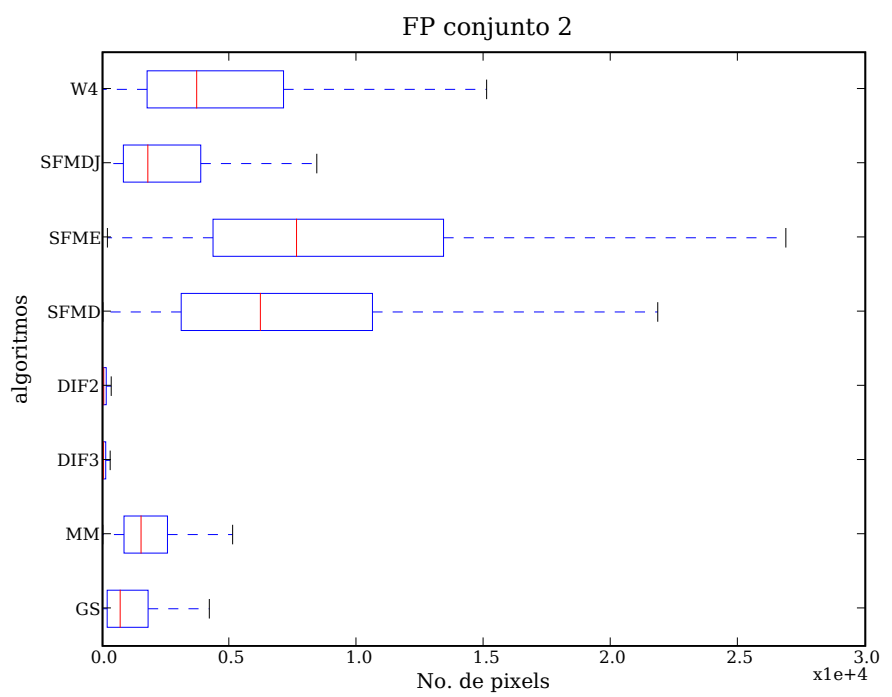

(b) Conjunto 2 .

Figura 5.10: Boxplot de FP dos conjuntos de vídeos 1 e 2 . 


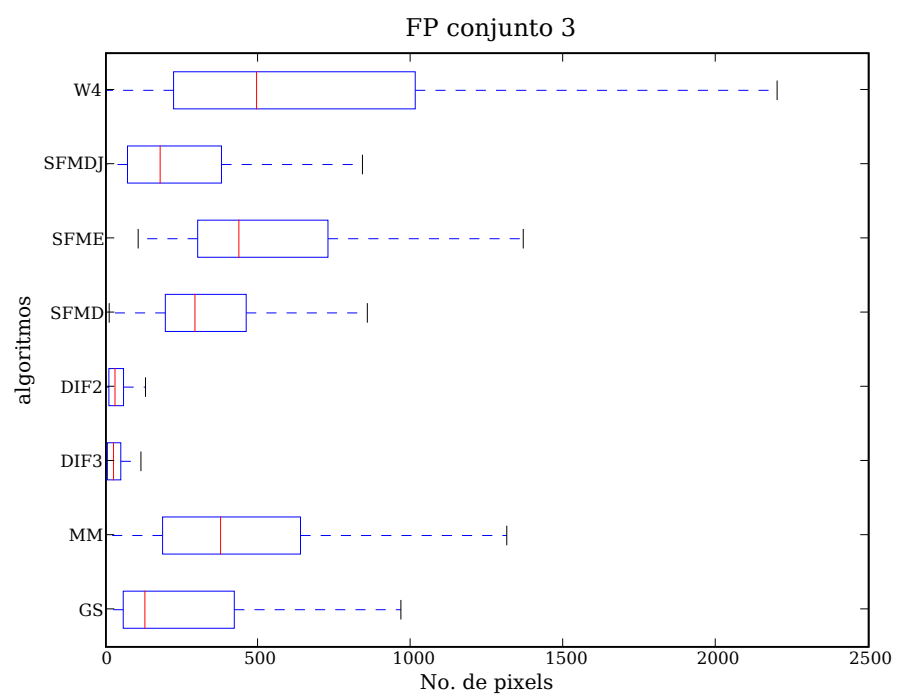

(a) Conjunto 3.

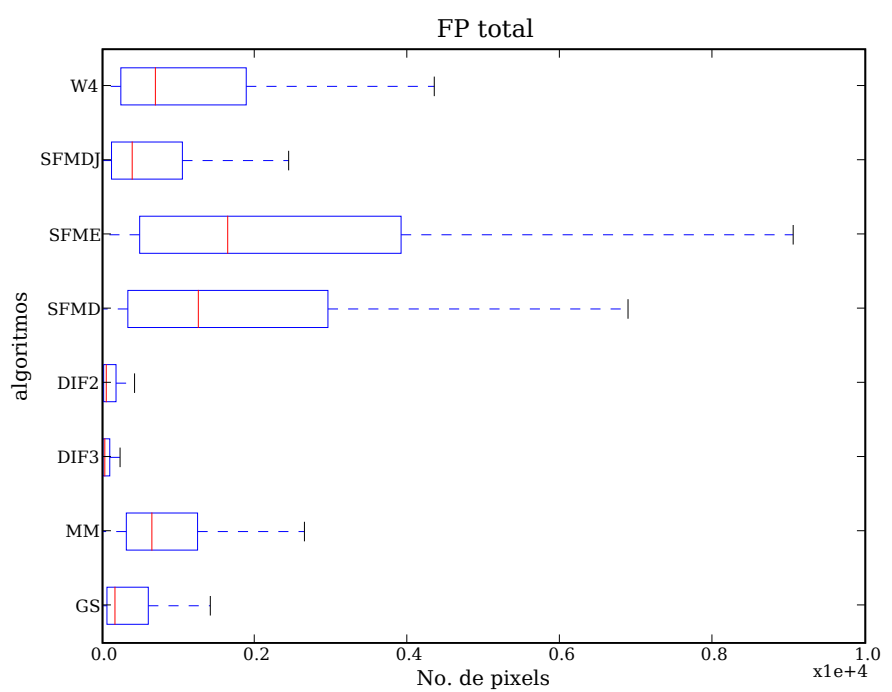

(b) Total dos vídeos.

Figura 5.11: Boxplot de FP do conjunto de vídeos 3 e do total dos vídeos. 


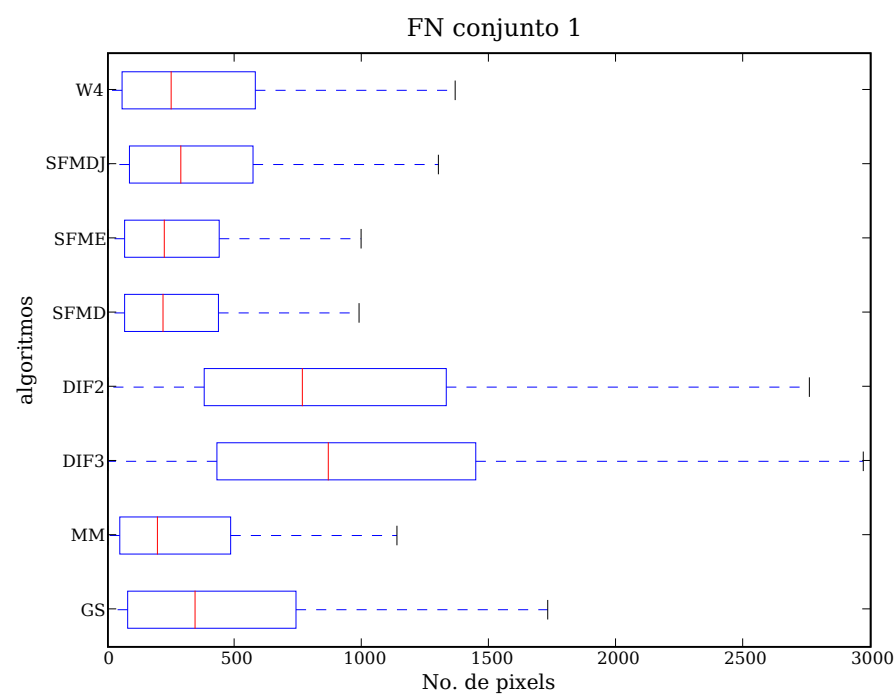

(a) Conjunto 1.

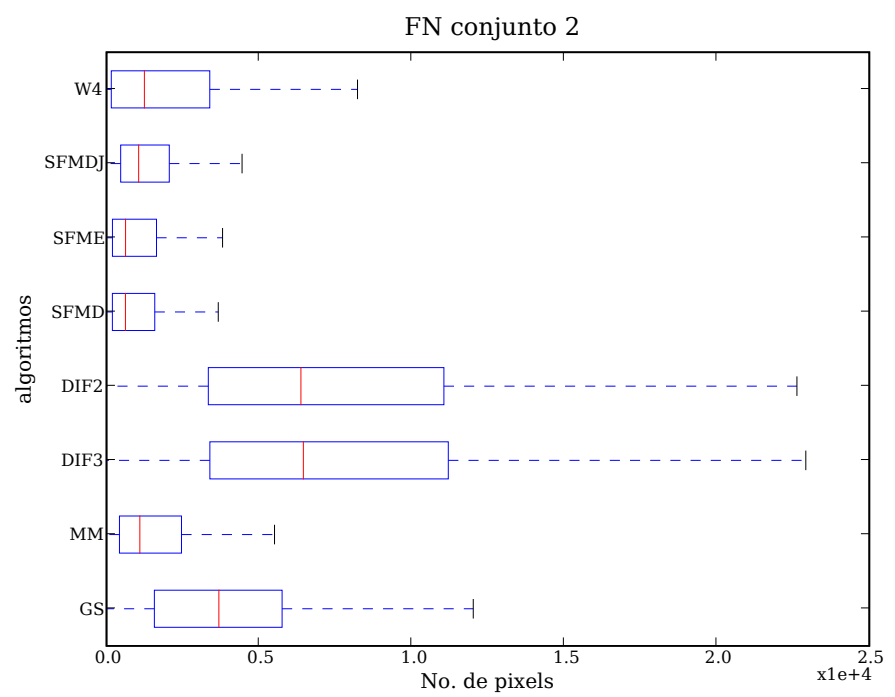

(b) Conjunto 2 .

Figura 5.12: Boxplot de FN dos conjuntos de vídeos 1 e 2 . 


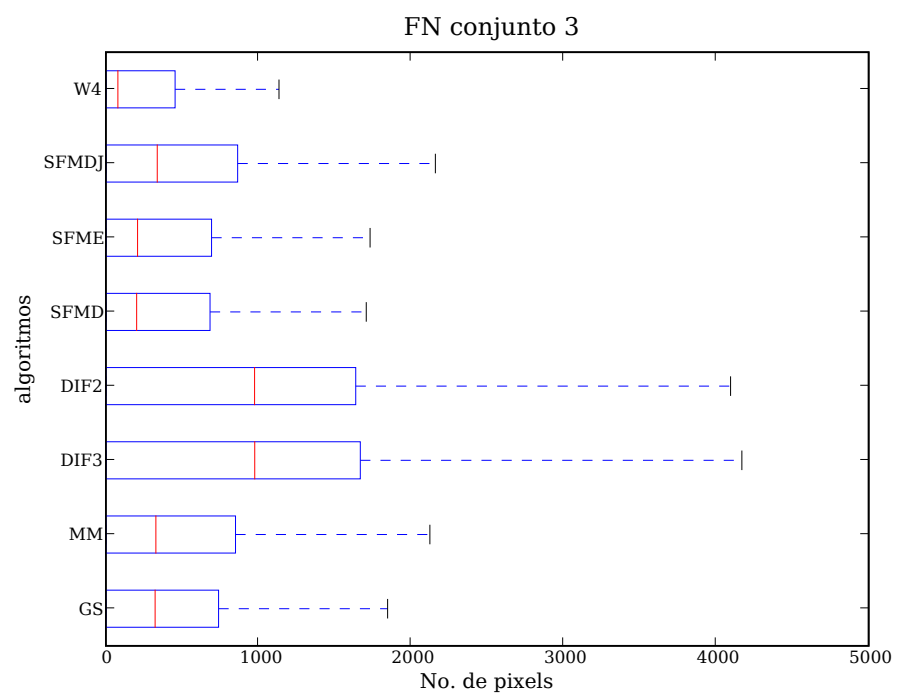

(a) Conjunto 3.

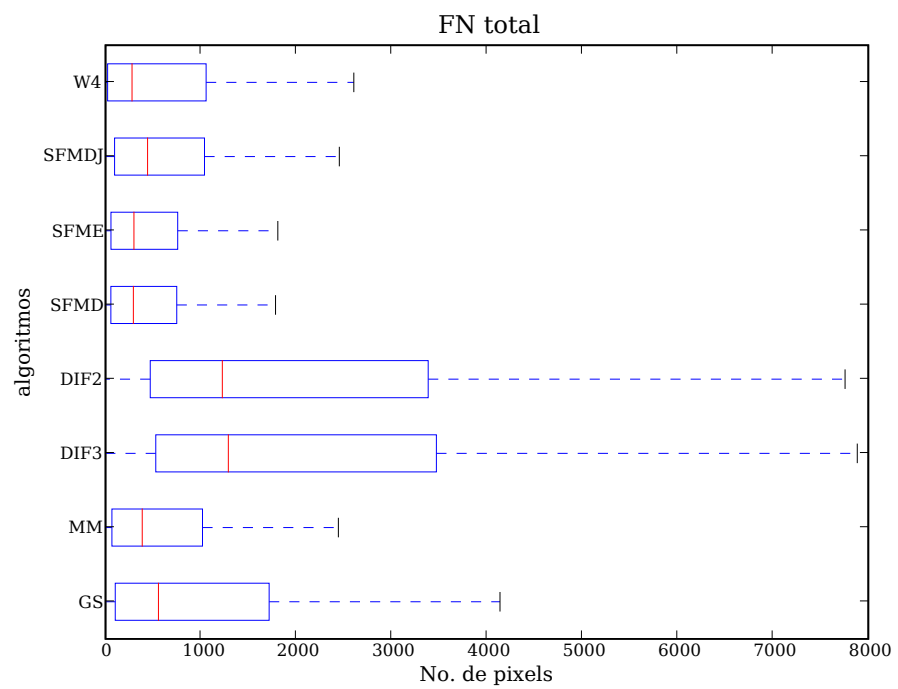

(b) Total dos vídeos.

Figura 5.13: Boxplot de FN do conjunto de vídeos 3 e do total dos vídeos. 


\begin{tabular}{|l||r|r|r|r||r|r|r|r|}
\hline \multicolumn{1}{|c||}{ Algoritmos } & \multicolumn{4}{c|}{ Conjunto 1 } & \multicolumn{4}{c|}{ Conjunto 2 } \\
\cline { 2 - 8 } & TP & TN & FP & FN & TP & TN & FP & FN \\
\hline DIF2 & 367 & 109010 & 253 & 962 & 1411 & 101081 & 139 & 7961 \\
DIF3 & 289 & 109165 & 98 & 1039 & 1305 & 101095 & 126 & 8066 \\
SFME & 1004 & 107354 & 1909 & 325 & 8292 & 91994 & 9227 & 1079 \\
SFMD & 1000 & 107820 & 1443 & 329 & 8309 & 94047 & 7174 & 1062 \\
SFMDJ & 911 & 108825 & 438 & 418 & 7921 & 98236 & 2984 & 1450 \\
W4 & 859 & 108758 & 505 & 470 & 6569 & 95120 & 6101 & 2802 \\
GS & 786 & 109063 & 200 & 543 & 5114 & 99924 & 1297 & 4257 \\
MM & 997 & 108550 & 713 & 332 & 7735 & 99293 & 1928 & 1636 \\
\hline
\end{tabular}

Tabela 5.9: Número médio de pixels, por quadro, para cada uma das medições (TP, TN, FP e FN), para os conjuntos de vídeos 1 e 2.

\begin{tabular}{|l||r|r|r|r||r|r|r|r|}
\hline \multicolumn{1}{|c||}{ Algoritmos } & \multicolumn{4}{c|}{ Conjunto 3 } & \multicolumn{4}{c|}{ Total } \\
\cline { 2 - 9 } & TP & TN & FP & FN & TP & TN & FP & FN \\
\hline DIF2 & 321 & 109055 & 60 & 1157 & 664 & 106652 & 156 & 3120 \\
DIF3 & 293 & 109064 & 50 & 1184 & 595 & 106717 & 91 & 3189 \\
SFME & 984 & 108582 & 533 & 494 & 3178 & 103159 & 3649 & 606 \\
SFMD & 993 & 108757 & 357 & 485 & 3185 & 104005 & 2803 & 600 \\
SFMDJ & 919 & 108832 & 283 & 559 & 3011 & 105659 & 1149 & 773 \\
W4 & 1088 & 108400 & 715 & 389 & 2643 & 104560 & 2248 & 1141 \\
GS & 969 & 108776 & 338 & 508 & 2141 & 106235 & 573 & 1643 \\
MM & 842 & 108659 & 455 & 636 & 2963 & 105816 & 992 & 822 \\
\hline
\end{tabular}

Tabela 5.10: Número médio de pixels, por quadro, para cada uma das medições (TP, TN, FP e FN), para o conjunto de vídeos 3 e para o total de vídeos testados.

Os Gráficos 5.14(a), 5.14(b), 5.15(a) e 5.15(b) mostram o percentual de classificação correta (PCC) dos conjuntos de vídeos 1, 2, 3 e do total de vídeos, respectivamente. Quanto mais perto de 1, melhor é o resultado do algoritmo segundo o PCC. Uma das críticas em relação ao PCC é a grande influência do número de TN no resultado do coeficiente. Como, geralmente, o número de pixels que constituem o fundo da cena é bem maior que o número de pixels que constituem os alvos, o valor do PCC torna-se muito alto. O valor do PCC para os dois algoritmos de fundo estático (SFME e SFMD) apresenta valores um pouco menores que os demais algoritmos testados. O principal motivo é o menor valor de TN que estes dois algoritmos possuem e como TN é a medida que mais influencia no resultado do PCC, o valor do PCC para os dois algoritmos fica um pouco abaixo dos demais. 
O MM apresentou bons resultados quando comparado aos demais algoritmos, principalmente no conjunto de vídeos 2. No conjunto de vídeos 1 e 2, os resultados dos algoritmos SFME e SFMD foram nitidamente inferiores aos demais algoritmos. Porém, no conjunto de vídeos 3, o resultados de ambos foram mais próximos dos resultados dos demais algoritmos. Uma explicação para isto é que no conjunto de vídeos 3 o tamanho médio dos alvos é inferior ao tamanho médio dos alvos nos outros conjuntos de vídeos. Assim, os fantasmas que diminuem o valor de TN nestes algoritmos têm menor peso no valor do coeficiente.

Excluindo o TN do cálculo do PCC, tem-se o coeficiente de Jaccard (JC). Os Gráficos 5.16(a), 5.16(b), 5.17(a) e 5.17(b) mostram o JC para os conjuntos 1, 2, 3 e total, respectivamente. Quanto maior o JC (mais próximo de 1), melhor o resultado do algoritmo. Mais uma vez os dois algoritmos de diferenciação temporal apresentaram os piores resultados em todos os gráficos. Os melhores valores de JC ficaram por conta da subtração de fundo utilizando a mediana dos últimos quadros (SFMDJ) e do algoritmo proposto neste trabalho (MM). Ambos possuem a característica de utilizarem a mediana como estatística de estimação de fundo e possuírem uma estimação de fundo dinâmica utilizando um intervalo de quadros passados. O fundo é estimado constantemente. Assim, o modelo de fundo pode se adequar às mudanças que, por ventura, ocorram na cena. Isto torna estes dois algoritmos bem mais robustos ao aparecimento de fantasmas. Caso ocorra o aparecimento de um fantasma no resultado, ele durará menos tempo que nos algoritmos de estimação estática de fundo. Uma diferença marcante entre os dois algoritmos é que um apresenta o alvo completo nos resultados e o outro apresenta apenas os contornos dos alvos. Mas, como as comparações estão sendo feitas utilizando as caixas de Feret, esta diferença não é significativa na avaliação dos seus resultados. Os resultados dos algoritmos nos 3 conjuntos de vídeo são bem diferentes. O SFMDJ e o MM são bem melhores que os demais no conjunto de vídeos 2, porém, nos outros dois conjuntos, apresentam apenas valores médios. Analisando a base toda, os dois algoritmos continuam com os melhores resultados, devido, principalmente, ao desempenho no conjunto 2.

A Tabela 5.11 resume os valores médios de PCC e JC por quadro para os conjuntos de vídeos 1 a 3 e para todos os vídeos testados. O algoritmo MM apresentou as maiores médias de PCC no conjunto total. Apresentou também as maiores médias de PCC no conjunto 2. Nos conjuntos 1 e 3 ficou em terceiro e quinto lugares, respectivamente. Analisando o coeficiente JC, o MM possui a segunda melhor média no geral e a melhor média do conjunto 2 de vídeos. Nos conjuntos 1 e 3 , o algoritmo MM ficou, respectivamente, em terceiro e sexto lugares. Uma diferença marcante entre o conjunto 2 e os conjuntos 1 e 3 é o tamanho dos alvos. No conjunto 2 os alvos estão bem mais 


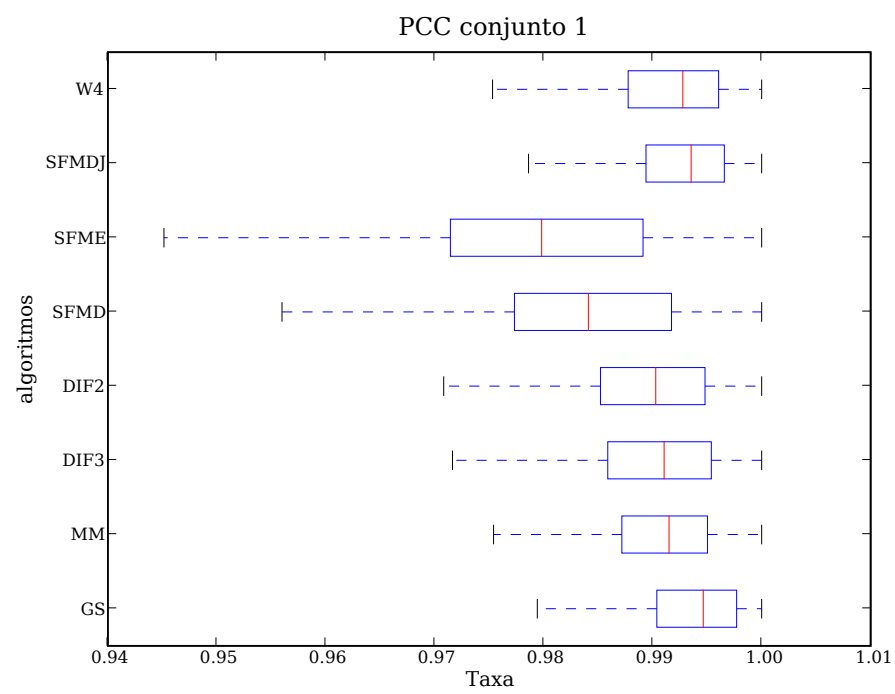

(a) Conjunto 1 .

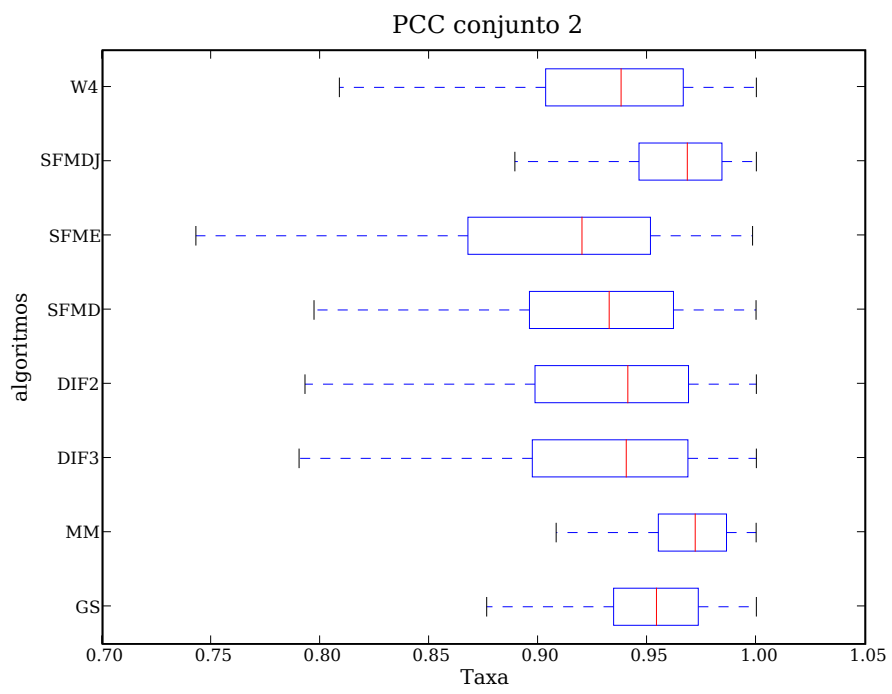

(b) Conjunto 2.

Figura 5.14: Boxplot de PCC dos conjuntos de vídeos 1 e 2. 


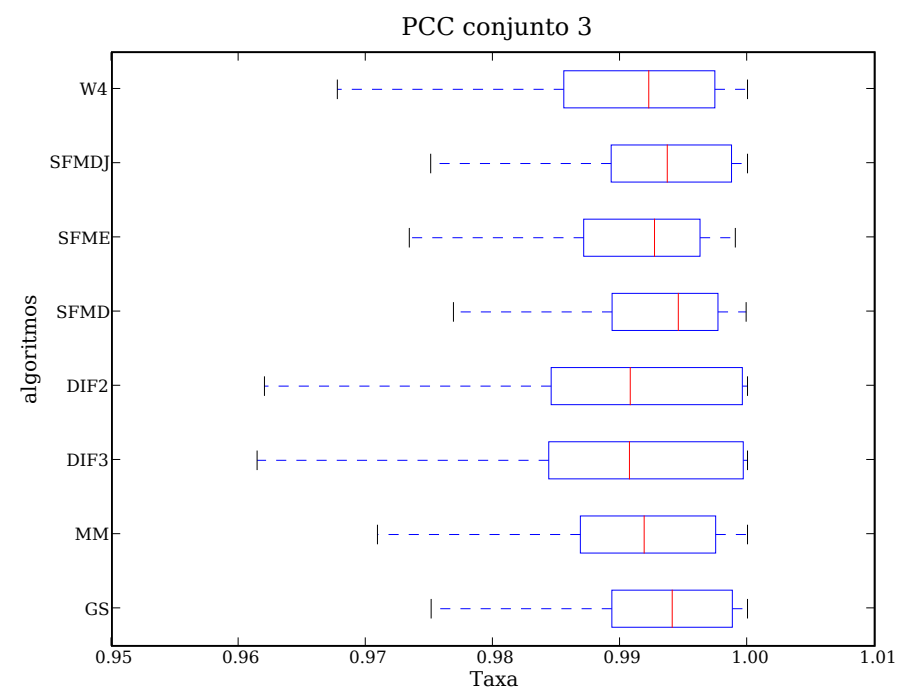

(a) Conjunto 3.

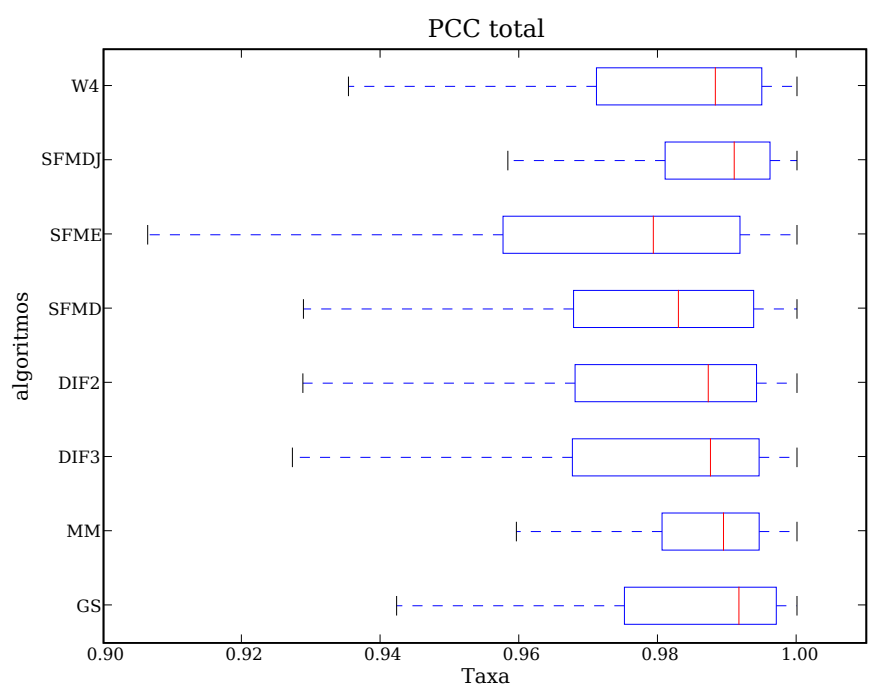

(b) Total dos vídeos.

Figura 5.15: Boxplot de PCC do conjunto de vídeos 3 e do total dos vídeos. 


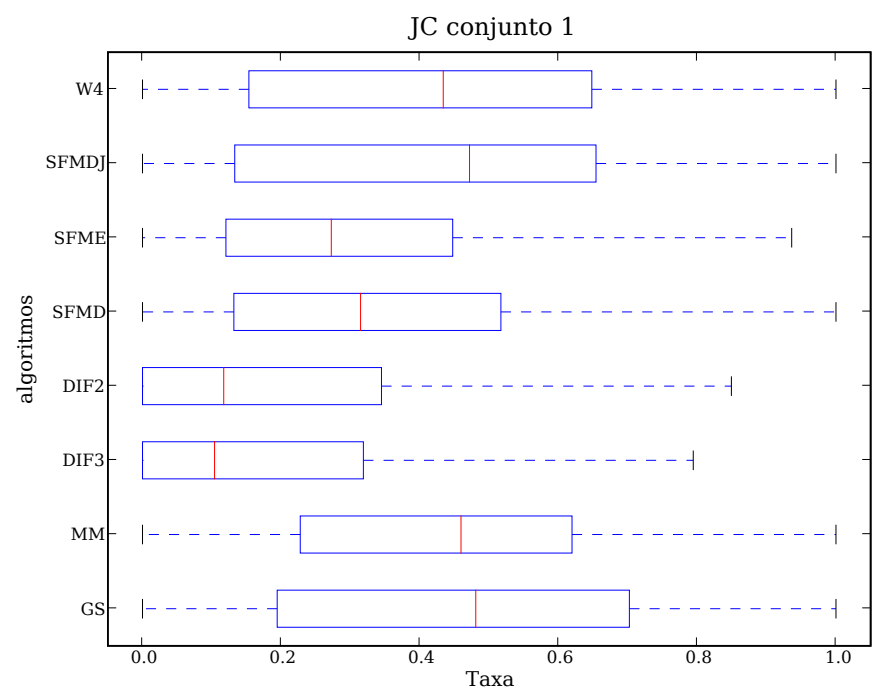

(a) Conjunto 1 .

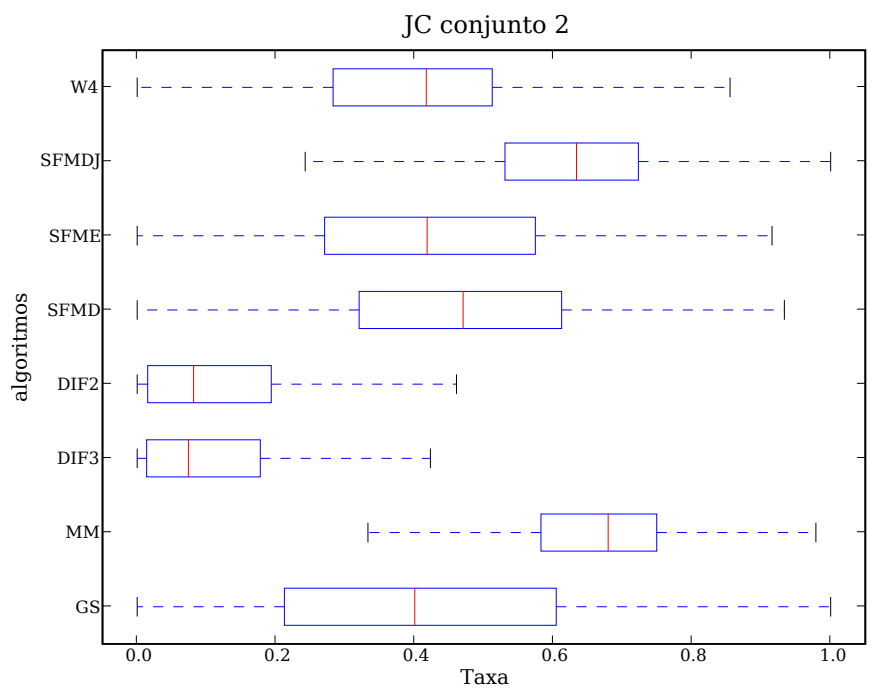

(b) Conjunto 2 .

Figura 5.16: Boxplot de JC dos conjuntos de vídeos 1 e 2 . 


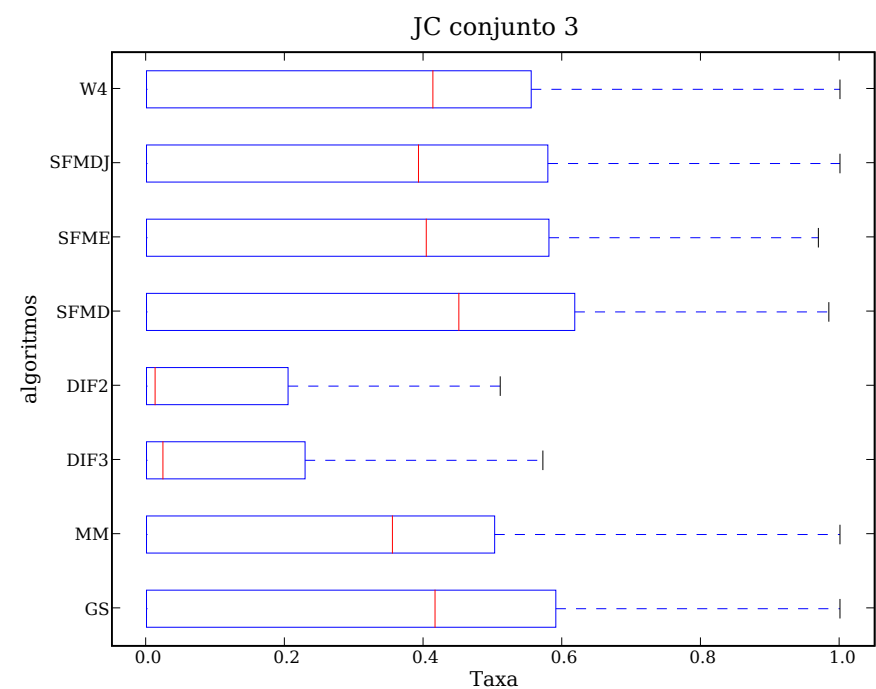

(a) Conjunto 3 .

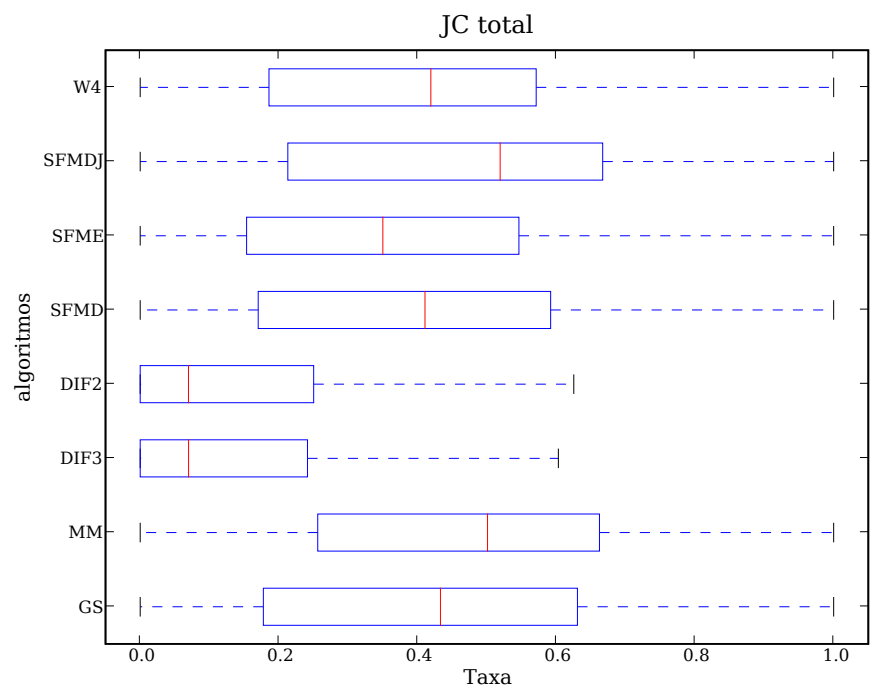

(b) Total dos vídeos.

Figura 5.17: Boxplot de JC do conjunto de vídeos 3 e do total dos vídeos. 


\begin{tabular}{|l||l|r||r|r||r|r||r|r|}
\hline \multicolumn{1}{|c||}{ Algoritmos } & \multicolumn{3}{c|}{ Conjunto 1 } & \multicolumn{2}{c|}{ Conjunto 2 } & \multicolumn{2}{c|}{ Conjunto 3 } & \multicolumn{2}{c|}{ Total } \\
\cline { 2 - 8 } & PCC & JC & PCC & JC & PCC & JC & PCC & JC \\
\hline DIF2 & 0.989 & 0.206 & 0.927 & 0.137 & 0.989 & 0.127 & 0.970 & 0.159 \\
DIF3 & 0.990 & 0.204 & 0.926 & 0.133 & 0.989 & 0.160 & 0.970 & 0.168 \\
SFME & 0.980 & 0.298 & 0.907 & 0.405 & 0.991 & 0.349 & 0.962 & 0.347 \\
SFMD & 0.984 & 0.335 & 0.926 & 0.447 & 0.992 & 0.377 & 0.969 & 0.382 \\
SFMDJ & 0.992 & 0.425 & 0.960 & 0.590 & 0.992 & 0.344 & 0.983 & 0.448 \\
W4 & 0.991 & 0.409 & 0.919 & 0.400 & 0.990 & 0.338 & 0.969 & 0.383 \\
GS & 0.993 & 0.456 & 0.950 & 0.408 & 0.992 & 0.367 & 0.980 & 0.412 \\
MM & 0.991 & 0.419 & 0.968 & 0.626 & 0.990 & 0.308 & 0.984 & 0.445 \\
\hline
\end{tabular}

Tabela 5.11: Valores médios de PCC e JC por quadro para os conjuntos de vídeos 1, 2, 3 e para o total de vídeos da base. 
próximos da câmera e é nesta situação que o algoritmo MM se mostra significativamente melhor que os demais algoritmos. Quando o tamanho dos alvos diminui nos outros conjuntos de vídeo, o algoritmo MM perde em desempenho para outros algoritmos, como o SFMDJ.

Alguns coeficientes devem ser analisados aos pares. É o caso da taxa de detecção (TRDR) e da taxa de falsos alarmes (FAR). A TRDR mostra qual o percentual de acerto do alvo do padrão ouro e a FAR mostra qual o percentual de erro do alvo detectado no resultado. Os Gráficos 5.18(a) e 5.18(b) mostram, respectivamente, o TRDR e o FAR para o conjunto de vídeos 1. Os Gráficos 5.19(a) e 5.19(b) mostram, respectivamente, o TRDR e o FAR para o conjunto de vídeos 2. Os Gráficos 5.20(a) e 5.20(b) mostram, respectivamente, o TRDR e o FAR para o conjunto de vídeos 3 e os Gráficos 5.21(a) e 5.21(b) mostram, respectivamente, o TRDR e o FAR para o total dos vídeos testados. Os resultados desejáveis observando estes dois coeficientes são possuir um alto TRDR (próximo de 1) e um baixo FAR (próximo de zero). Os algoritmos de diferenciação temporal apresentaram, no geral, baixos índices de TRDR e de FAR. O índice de TRDR é visivelmente menor que dos demais algoritmos e o índice FAR é ligeiramente menor. Este resultado condiz com os resultados anteriores apresentados para as outras medidas e coeficientes analisados. Os algoritmos de fundo estático (SFME e SFMD) apresentaram os valores mais altos de TRDR, porém, também apresentaram os valores mais altos de FAR. Três algoritmos apresentam altos índices de TRDR (SFMDJ, W4 e MM) e o GS apresenta valores médios de TRDR, enquanto que os valores de FAR são baixos para GS, SFMDJ e MM e médios para o W4. É importante observar uma anomalia que acontece principalmente no conjunto 3 de vídeos e influencia bastante o resultado dos coeficientes. Quando não existe alvos demarcados pelo padrão ouro em um determinado quadro, qualquer ruído no quadro provoca um valor mínimo (valor zero) para o TRDR e um valor máximo (valor 1) para o FAR. Ou seja, os piores valores possíveis.

A Tabela 5.12 mostra os valores de TRDR e FAR médios por quadro para os conjuntos de vídeos 1, 2 e 3 e para toda a base de vídeos testados. Como já descrito, estes dois coeficientes devem ser analisados em conjunto. Os melhores algoritmos são os que apresentam maiores valores de TRDR e menores valores de FAR. Para facilitar a comparação dos algoritmos testados, criou-se uma coluna (TOTAL) que soma o TRDR da base toda mais o complemento do FAR da base toda e divide por 2 para os valores fiquem entre 0 e $1, T O T A L=\frac{T R D R+(1-F A R)}{2}$. Assim, pode-se traduzir as duas medidas em um valor absoluto e único, onde quanto maior o valor, melhor o desempenho do algoritmo. Utilizando este critério, verifica-se que o algoritmo MM apresentou o melhor resultado, seguido de perto pelo algoritmo SFMDJ. Os algoritmos de diferenciação temporal ficaram com os piores resultados. É interessante notar que quando compara-se os dois algoritmos de diferenciação 


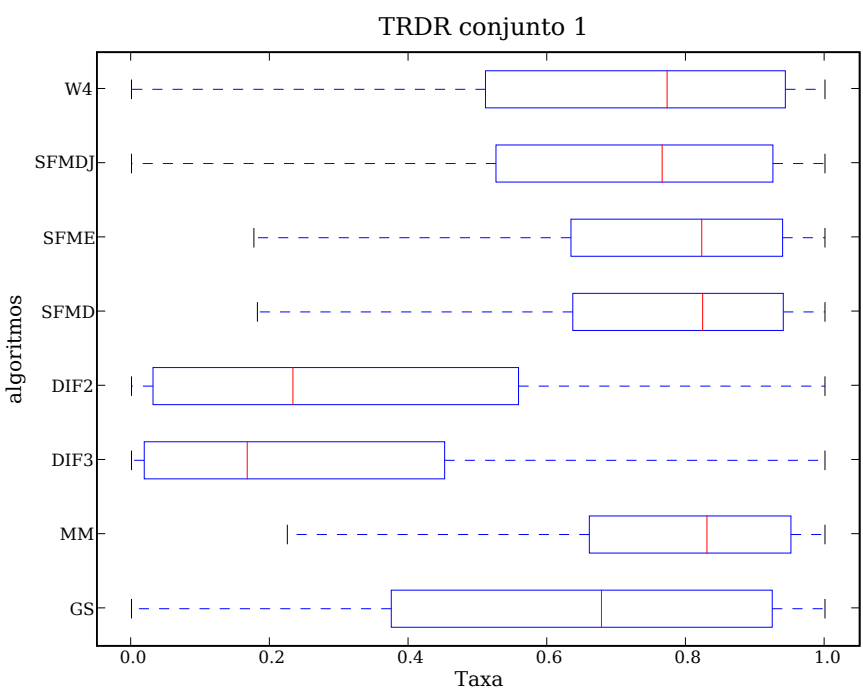

(a) TRDR.

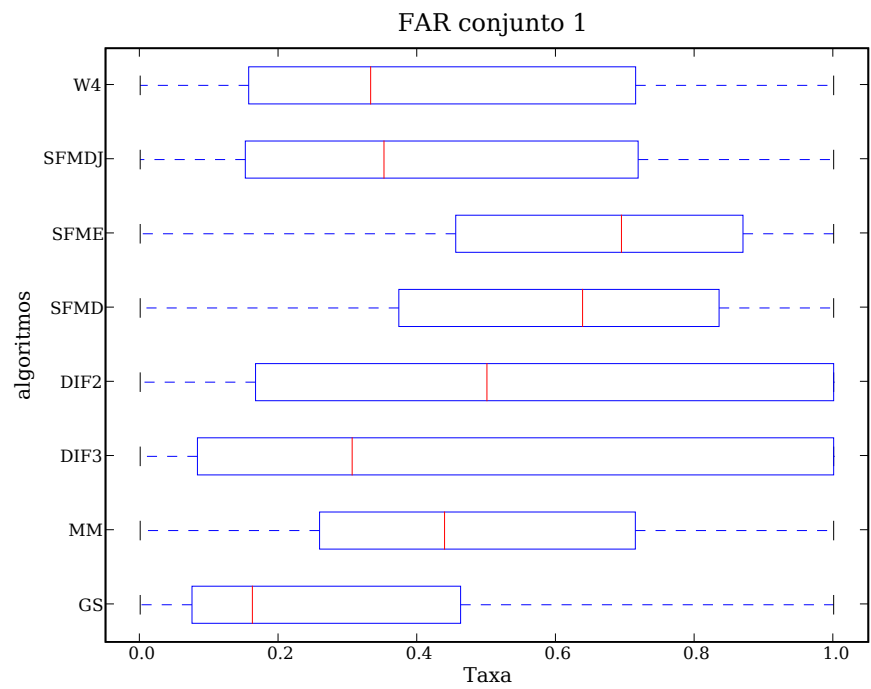

(b) FAR.

Figura 5.18: Boxplot do TRDR e FAR para o conjunto de vídeos 1. 


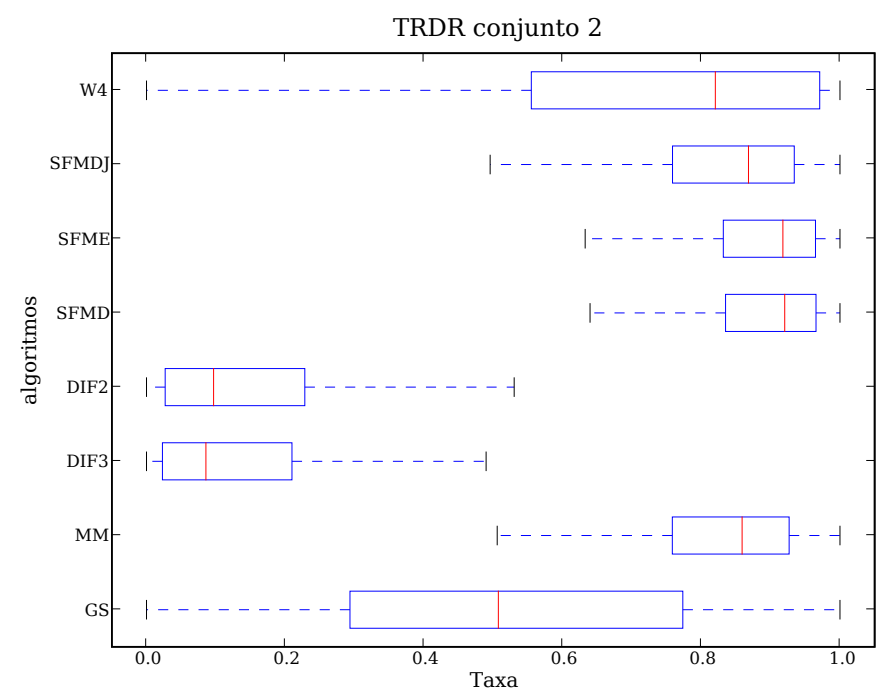

(a) TRDR.

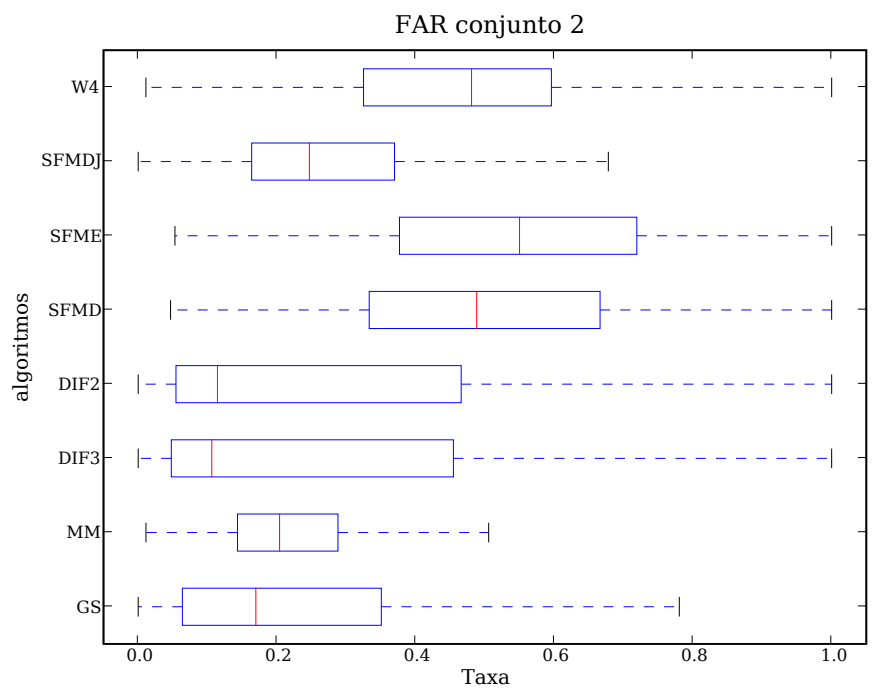

(b) FAR.

Figura 5.19: Boxplot de TRDR e FAR para o conjunto de vídeos 2. 


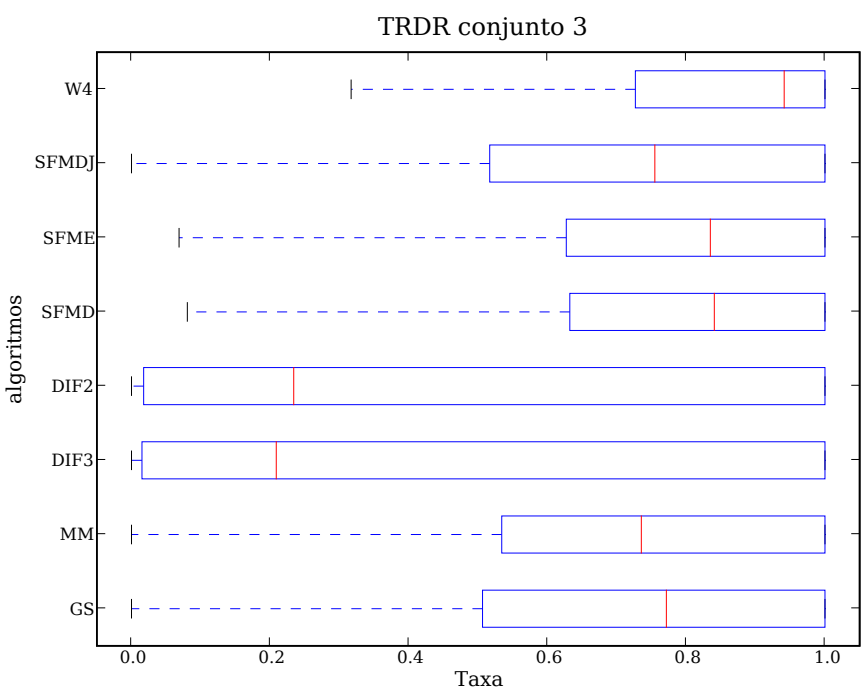

(a) TRDR.

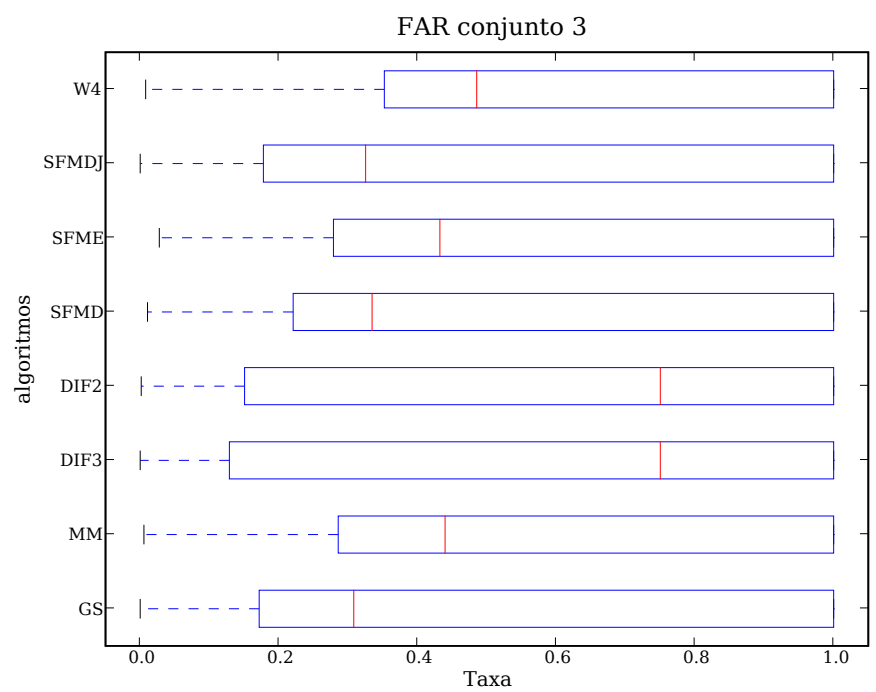

(b) FAR.

Figura 5.20: Boxplot de TRDR e FAR para o conjunto de vídeos 3. 


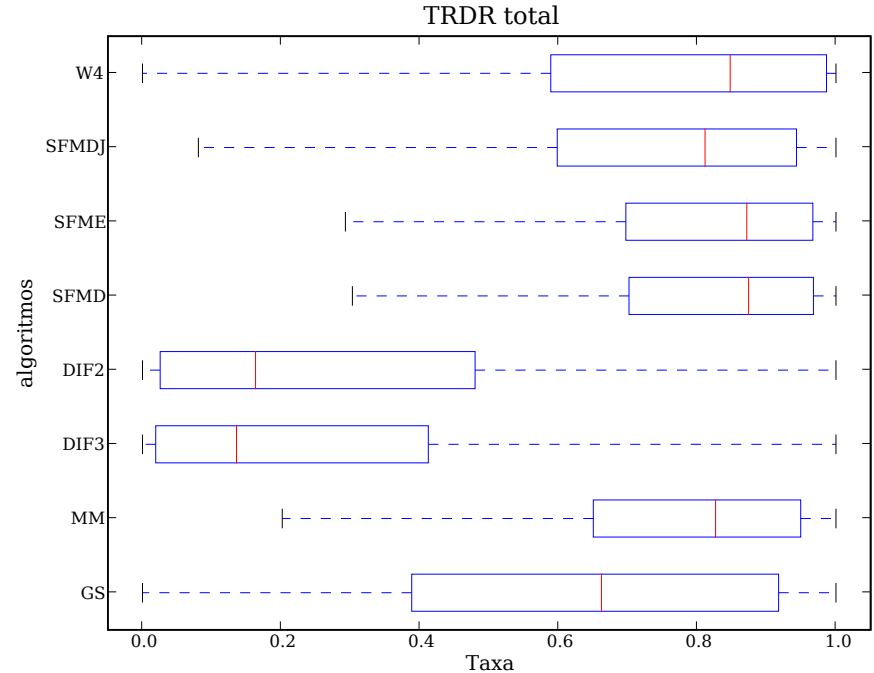

(a) TRDR.

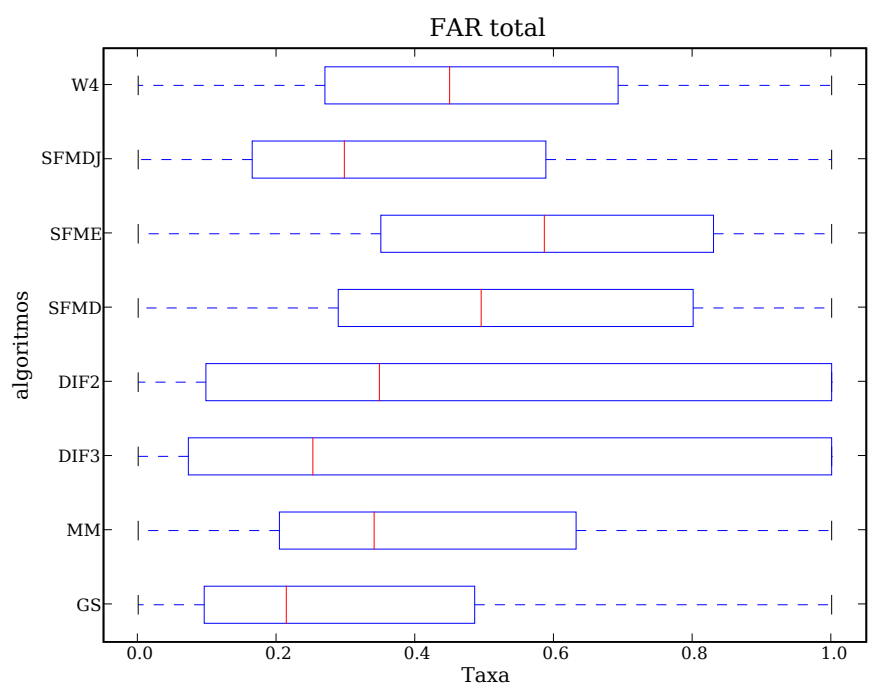

(b) FAR.

Figura 5.21: Boxplot de TRDR e FAR para o total dos vídeos. 


\begin{tabular}{|l||r|r||r|r||r|r||r|r|r|}
\hline \multicolumn{1}{|c||}{ Algoritmos } & \multicolumn{2}{|c|}{ Conjunto 1 } & \multicolumn{2}{|c|}{ Conjunto 2 } & \multicolumn{2}{c|}{ Conjunto 3 } & \multicolumn{3}{c|}{ Total } \\
\cline { 2 - 10 } & TRDR & FAR & TRDR & FAR & TRDR & FAR & TRDR & FAR & TOTAL \\
\hline DIF2 & 0.339 & 0.545 & 0.185 & 0.320 & 0.399 & 0.602 & 0.313 & 0.496 & 0.409 \\
DIF3 & 0.293 & 0.472 & 0.175 & 0.313 & 0.389 & 0.591 & 0.289 & 0.463 & 0.413 \\
SFME & 0.751 & 0.653 & 0.880 & 0.560 & 0.776 & 0.545 & 0.798 & 0.590 & 0.604 \\
SFMD & 0.749 & 0.608 & 0.882 & 0.514 & 0.779 & 0.495 & 0.799 & 0.543 & 0.628 \\
SFMDJ & 0.677 & 0.441 & 0.824 & 0.307 & 0.710 & 0.484 & 0.732 & 0.415 & 0.659 \\
W4 & 0.683 & 0.436 & 0.741 & 0.480 & 0.821 & 0.484 & 0.746 & 0.500 & 0.623 \\
GS & 0.624 & 0.325 & 0.535 & 0.262 & 0.718 & 0.463 & 0.628 & 0.351 & 0.639 \\
MM & 0.763 & 0.495 & 0.826 & 0.266 & 0.719 & 0.550 & 0.767 & 0.445 & 0.661 \\
\hline
\end{tabular}

Tabela 5.12: Valores médios de TRDR e FAR por quadro para os conjuntos de vídeos 1, 2, 3 e para o total de vídeos da base.

temporal por este critério, verifica que o DIF3 apresenta um valor na coluna TOTAL melhor que o DIF2. Este é um resultado esperado, visto que DIF3 utiliza uma comparação entre 3 quadros para diminuir o ruído [11]. Outra comparação interessante é entre os dois algoritmos de subtração de fundo estáticos. A estimação do fundo utilizando a mediana (SFMD) apresenta resultado superior à estimação de fundo utilizando a média (SFME). Este também é um resultado esperado, visto que, segundo [88], a mediana é uma estatística mais robusta para estimar um modelo de fundo. A comparação entre os dois algoritmos que utilizam a mediana como estatística de estimação de fundo (SFMD e SFMDJ) mostra que aquele que usa uma estimação dinâmica, o SFMDJ, apresenta resultados superiores àquele que utiliza uma estimação de fundo estática, o SFMD. Também um resultado esperado, visto que a estimação de fundo dinâmica recalcula constantemente o modelo de fundo e se adequa às alterações no cenário. Os dois algoritmos da abordagem estatística (GS e W4) também apresentaram bons resultados, com vantagem para o GS que utiliza um modelo de fundo baseado em uma gaussiana.

Uma outra avaliação dos resultados dos algoritmos de segmentação pode ser feita utilizando medidas baseadas em objetos ou componentes conexos (Seção 2.4.2). Nesta avaliação o número de pixels que acertam ou erram o alvo não influencia os resultados. As medidas baseadas em objetos medem se os componentes conexos do padrão ouro foram corretamente detectados, detectados parcialmente ou não detectados pelos resultados dos algoritmos. Estas medidas medem ainda quando um componente conexo do resultado é um ruído, ou seja, não existe um correspondente para este componente conexo no padrão ouro. Para considerar um componente conexo detectado utilizou-se 


\begin{tabular}{|l||r|r||r|r||r|r||r|r|r|}
\hline \multirow{2}{*}{ Algoritmos } & \multicolumn{2}{c|}{ Conjunto 1 } & \multicolumn{2}{c|}{ Conjunto 2 } & \multicolumn{2}{c|}{ Conjunto 3 } & \multicolumn{3}{|c|}{ Total } \\
\cline { 2 - 9 } & DR & NR & DR & NR & DR & NR & DR & NR & TOTAL \\
\hline DIF2 & 0.470 & 0.712 & 0.236 & 0.632 & 0.494 & 0.753 & 0.408 & 0.701 & 0.354 \\
DIF3 & 0.417 & 0.592 & 0.221 & 0.631 & 0.481 & 0.688 & 0.379 & 0.635 & 0.372 \\
SFME & 0.919 & 0.840 & 0.982 & 0.675 & 0.958 & 0.812 & 0.951 & 0.782 & 0.585 \\
SFMD & 0.911 & 0.829 & 0.981 & 0.667 & 0.958 & 0.792 & 0.947 & 0.769 & 0.589 \\
SFMDJ & 0.808 & 0.682 & 0.956 & 0.507 & 0.901 & 0.731 & 0.883 & 0.646 & 0.619 \\
W4 & 0.824 & 0.756 & 0.878 & 0.758 & 0.908 & 0.819 & 0.868 & 0.777 & 0.546 \\
GS & 0.807 & 0.541 & 0.673 & 0.589 & 0.923 & 0.651 & 0.805 & 0.592 & 0.607 \\
MM & 0.907 & 0.669 & 0.970 & 0.522 & 0.934 & 0.738 & 0.934 & 0.647 & 0.644 \\
\hline
\end{tabular}

Tabela 5.13: Valores médios de DR e NR por quadro para os conjuntos de vídeos 1, 2, 3 e para o total de vídeos da base.

um percentual de sobreposição entre a CF do resultado e a CF do padrão ouro igual a 20\%, o mesmo valor foi utilizado nos testes em [69]. Os Gráficos 5.22(a) e 5.22(b) mostram, respectivamente, a taxa de detecção (DR) e a taxa de ruído (NR) para o conjunto de vídeos 1. Os Gráficos 5.23(a) e 5.23(b) mostram, respectivamente, a DR e a NR para o conjunto de vídeos 2. Os Gráficos 5.24(a) e 5.24(b) mostram, respectivamente, a DR e a NR para o conjunto de vídeos 3 e os Gráficos 5.25(a) e 5.25(b) mostram a DR e a NR, respectivamente para o total dos vídeos testados. Analisando os gráficos boxplot notamos que quase todos os algoritmos apresentaram um DR com mediana 1, ou seja, em mais da metade dos quadros analisados $100 \%$ dos objetos foram detectados. A exceção foram os algoritmos de diferenciação temporal. Porém, a taxa de ruído dos algoritmos no geral também foi alta. Ocorreram vários objetos que não tinham correspondente no padrão ouro e foram classificados como ruído.

A Tabela 5.13 mostra os valores médios de DR e NR por quadro para os conjuntos de vídeos 1, 2 e 3 e para toda a base de vídeos testados. Nesta avaliação o tamanho dos componentes conexos não importa, apenas o percentual dos componentes conexos do padrão ouro que foram detectados (DR) e o percentual de componentes conexos dos resultados que são ruídos (NR). Aqui, novamente, é importante analisar as duas medidas em conjunto, visto que o ideal é obter um valor alto de DR (próximo de 1) e um valor baixo de NR (próximo de zero). Para facilitar a comparação dos algoritmos, foi criada uma coluna TOTAL que utiliza os dois coeficientes produzindo um valor absoluto. A fórmula utilizada para TOTAL é a soma de DR mais o complemento de NR e o resultado é dividido por 2 para manter os valores entre 0 e 1: TOT $A L=\frac{D R+(1-N R)}{2}$. O algoritmo MM, também por este 


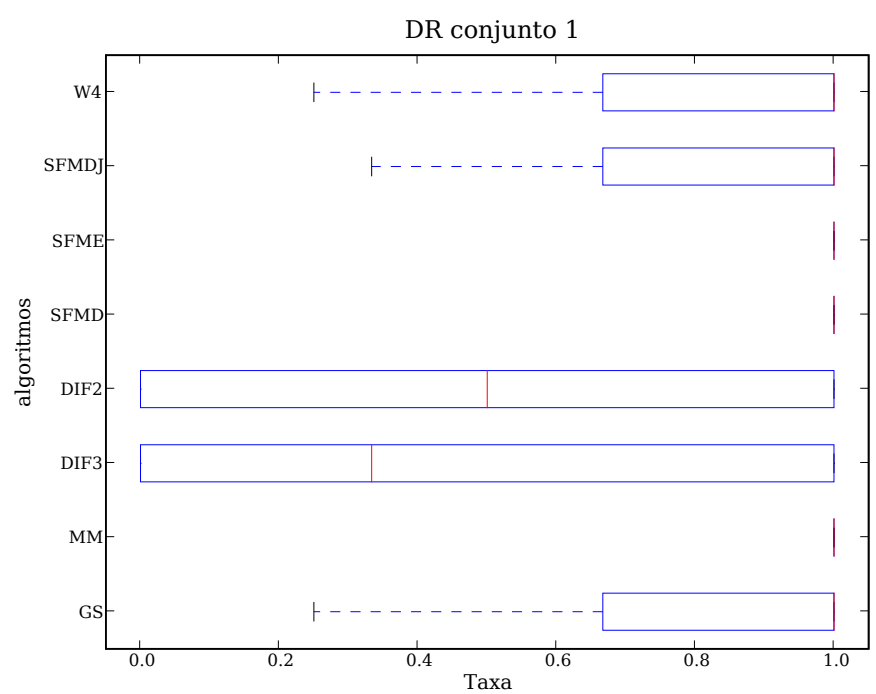

(a) DR.

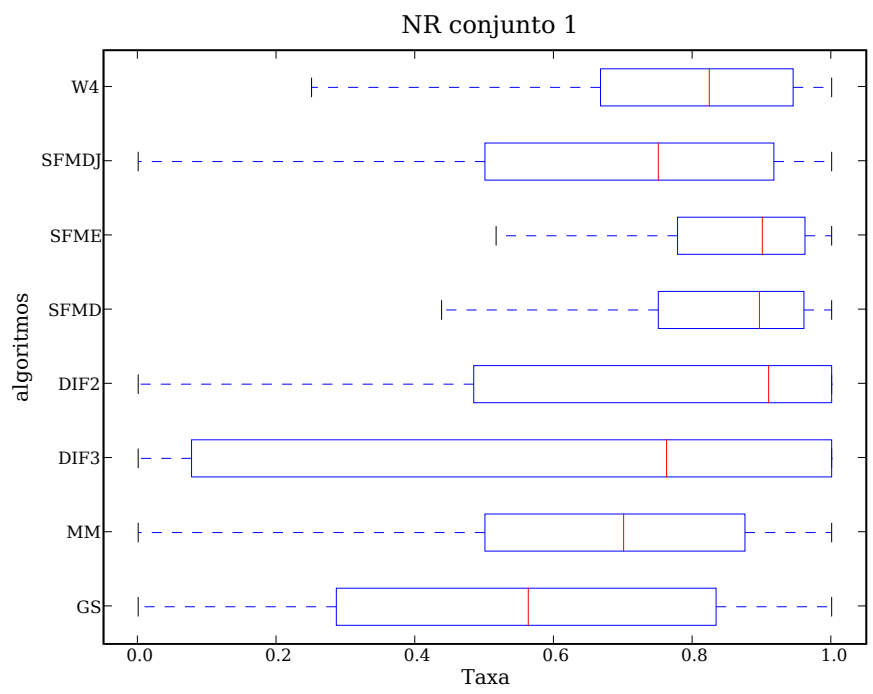

(b) NR.

Figura 5.22: Boxplot da DR e da NR para o conjunto de vídeos 1. 


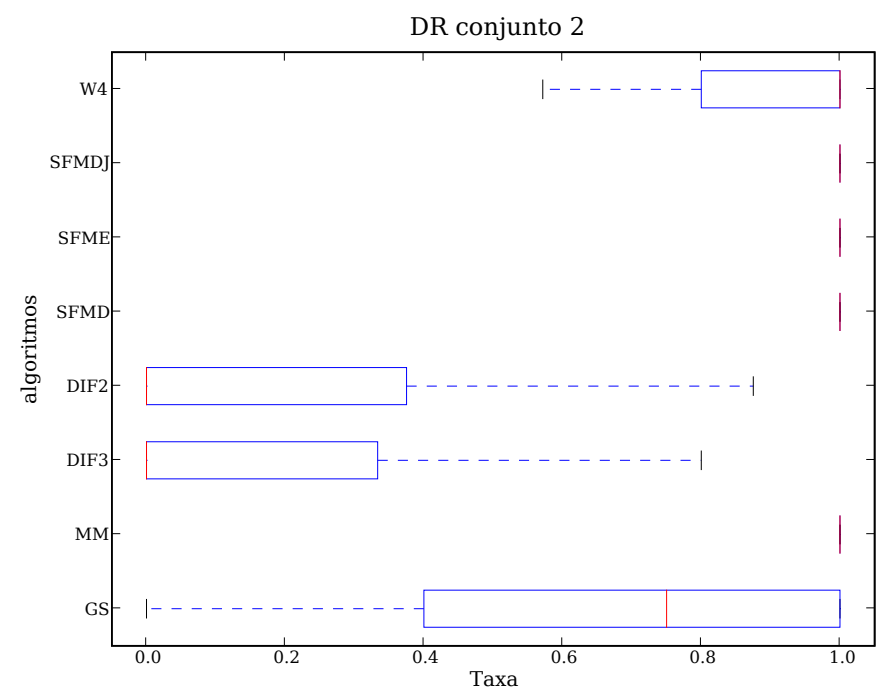

(a) DR

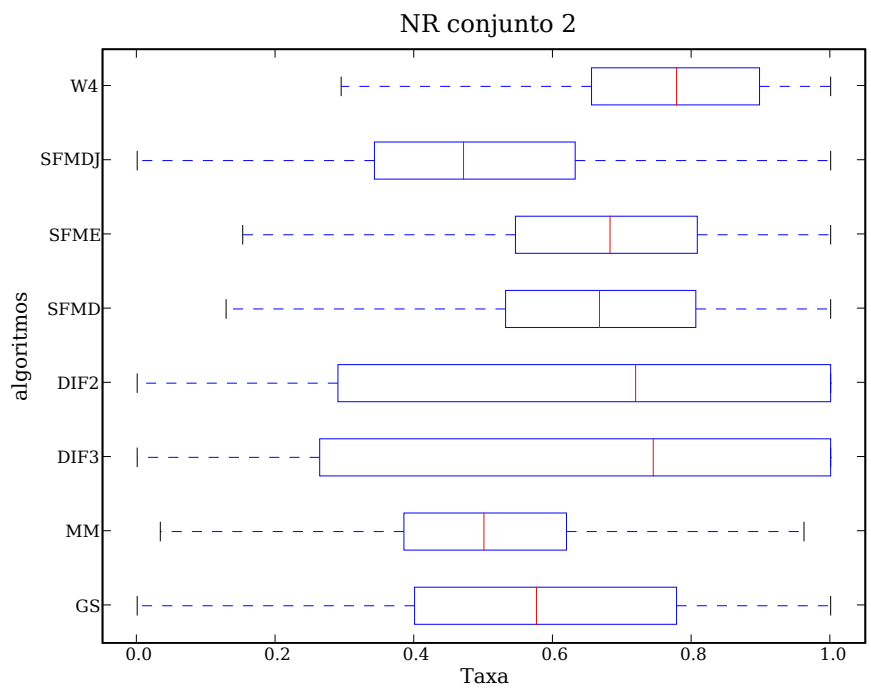

(b) Conjunto 2 .

Figura 5.23: Boxplot da DR e da NR para o conjunto de vídeos 2. 


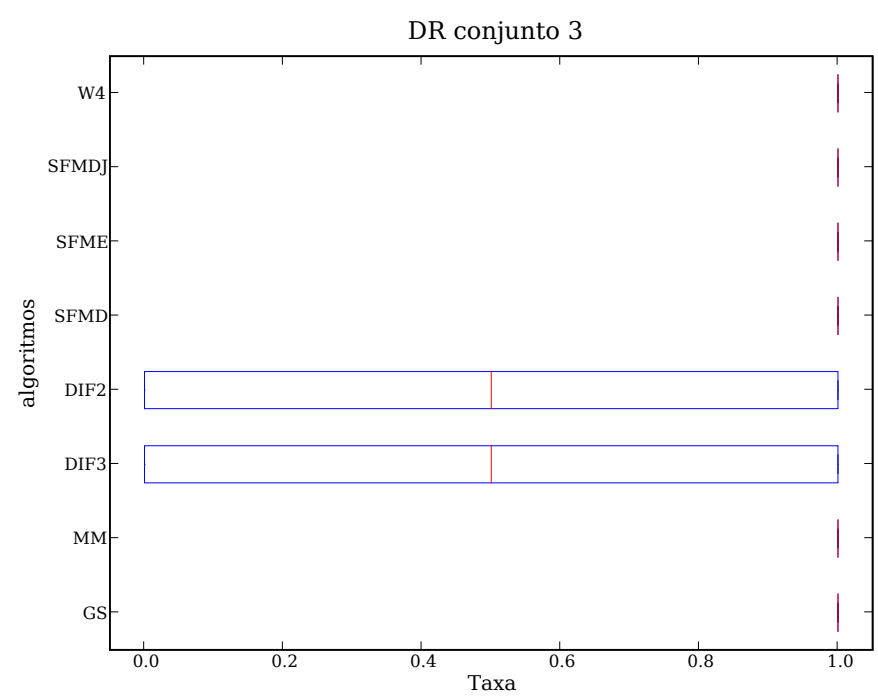

(a) DR.

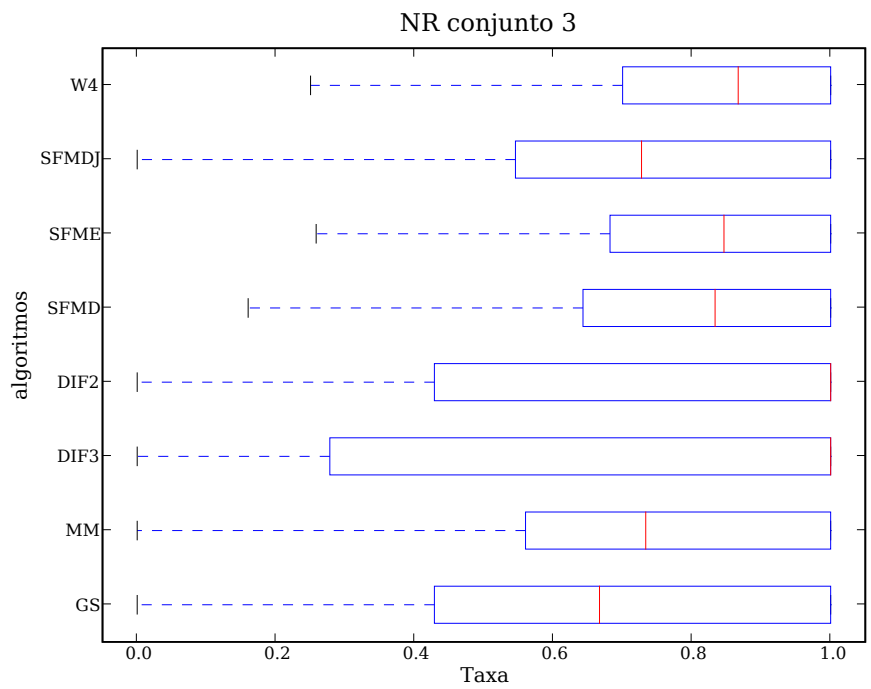

(b) NR.

Figura 5.24: Boxplot da DR e da NR para o conjunto de vídeos 3. 


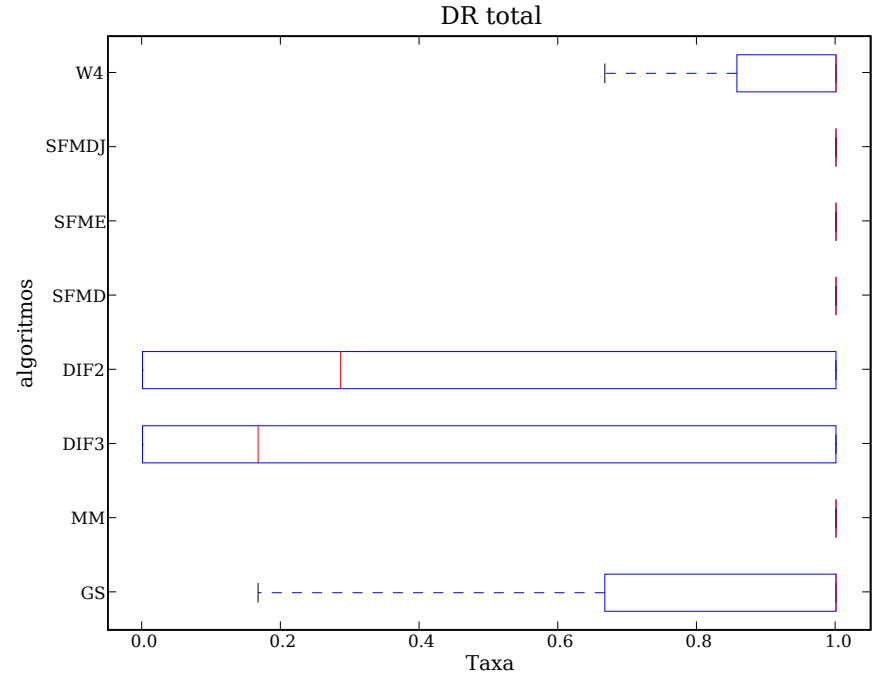

(a) DR.

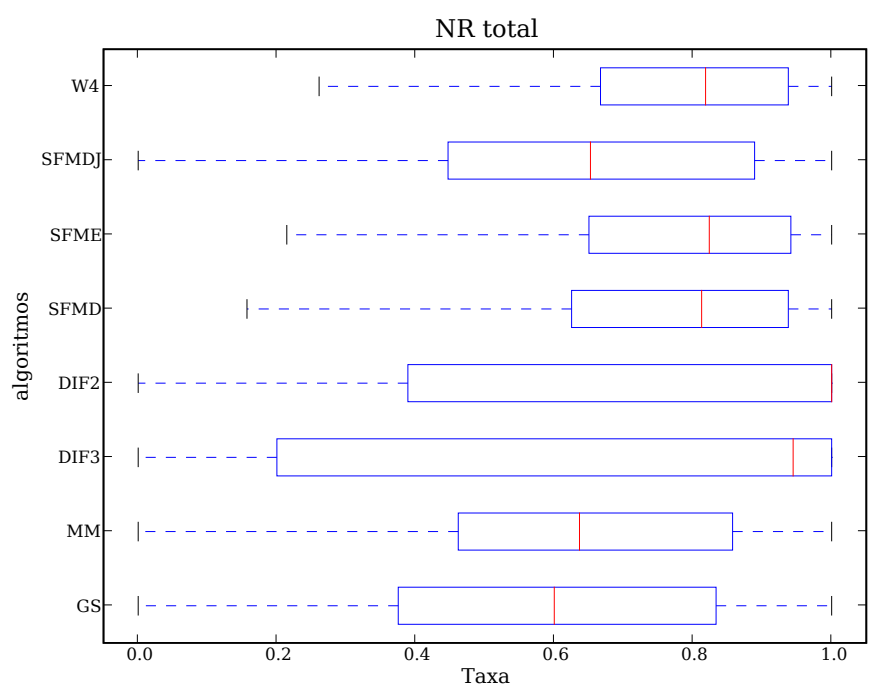

(b) NR.

Figura 5.25: Boxplot da DR e da NR para o total de vídeos. 
critério, apresentou o melhor resultado. As demais análises feitas em relação a Tabela 5.12 também se mantiveram.

\subsection{Análise de Situações Específicas}

A análise quantitativa é importante para uma comparação geral dos resultados dos algoritmos. Porém, existem situações particulares que ocorrem durante uma seqüência de vídeo que devem ser analisadas em detalhe. Verificou-se algumas situações em que o algoritmo MM, proposto neste trabalho, apresenta resultados melhores que os demais algoritmos testados. Porém, não foi feita uma medição quantitativa nestas situações específicas e a análise será apenas qualitativa. O algoritmo MM mostrou-se mais robusto a falsos positivos, a falsos negativos, apresentou uma menor necessidade de período de treinamento e não apresentou rastros quando comparado a outros algoritmos nas situações específicas. Estas situações analisadas explicam a superioridade de desempenho obtida pelo MM nos resultados numéricos apresentados na seção anterior.

A primeira situação a ser analisada ocorre nos algoritmos de estimação de fundo dinâmica, ou seja, aqueles algoritmos que recalculam constantemente o fundo da seqüência de vídeo e, com isto, conseguem se adaptar a eventuais alterações no cenário. Quando um alvo, que estava em movimento em um desses algoritmos, permanece imóvel por um longo período, ele é incorporado ao modelo de fundo e, com isto, desaparece do resultado. Quando o alvo começa a se mover novamente, um fantasma aparecerá na posição que o alvo estava. Isto ocorre porque nos algoritmos que lidam com a intensidade dos pixels, é feita uma diferença simétrica para comparar o quadro atual com o modelo de fundo. O resultado desta comparação produzirá duas regiões, sendo uma região, correta, a região onde o objeto realmente está no quadro atual e a outra, um fantasma, a região onde o objeto estava e que tinha sido incorporada ao fundo. Esta situação perdurará até que o modelo de fundo seja atualizado e passe a incorporar a parte do fundo da cena que voltou a estar visível. Entretanto, na situação descrita, o algoritmo MM não produz fantasmas. Como MM não utiliza intensidade dos pixels, não é feita uma diferença simétrica (responsável pela geração do fantasma) para comparar o quadro atual com o modelo de fundo. No MM, é utilizada a subtração com saturação que apenas elimina dos contornos do quadro atual aqueles pertencentes ao fundo. O resultado são os contornos do quadro atual que não pertencem aos contornos do modelo de fundo. Assim, nenhum contorno ou região fantasma aparece nos resultados. Obviamente, um sistema de controle de alvos poderia resolver este problema, independente do algoritmo de segmentação de movimento utilizado [46]. Porém, o algoritmo MM evita este problema sem nenhum controle adicional. A Figura 5.26 mostra a 
situação descrita comparando o resultado do algoritmo MM com o SFMDJ. A seqüência utilizada é a LeftBag_PickedUp do projeto CAVIAR. Nela, um homem caminha pela cena carregando uma maleta (Figuras 5.26(a), 5.26(b) e 5.26(c)), deixa a maleta em um canto do cenário (Figuras 5.26(d), 5.26(e) e 5.26(f)), a maleta parada no canto da cena é incorporada ao modelo de fundo, desaparecendo dos resultados (Figuras 5.26(g), 5.26(h) e 5.26(i)) e, ao pegar novamente a maleta, um fantasma aparece na posição onde a maleta estava no resultado do SFMDJ, porém, isto não acontece no resultado do MM (Figuras 5.26(j), 5.26(k) e 5.26(l)).

Uma outra situação que deve ser analisada é a rapidez com que o algoritmo MM consegue produzir resultados. Com apenas dois quadros de uma seqüência de vídeo, o algoritmo MM consegue produzir um resultado coerente. As Figuras 5.27(a) e 5.27(b) mostram o terceiro quadro da seqüência de vídeo Browse1 do Projeto CAVIAR e o resultado da segmentação de movimento produzida pelo algoritmo MM, as Figuras 5.27(c) e 5.27(d) mostram, respectivamente, o quarto quadro original da seqüência de vídeo e o resultado produzido pelo algoritmo MM e, finalmente, as Figuras 5.27(e) e 5.27(f) mostram os resultados respectivos do sétimo quadro da mesma seqüência de vídeo e o resultado do algoritmo MM. Pode-se notar a coerência dos resultados de segmentação de movimento desde os primeiros quadros da seqüência de vídeo. Dois quadros são necessários para produzir resultados por causa da heurística de coerência temporal que utiliza dois quadros anteriores ao quadro atual.

Outra situação a ser analisada ocorre na seqüência TwoEnterShop1cor do conjunto de vídeo 2. Durante os 350 primeiros quadros da seqüência, duas pessoas, uma mulher e um homem, permanecem conversando em primeiro plano, praticamente parados. Nos algoritmos que precisam de 100 quadros para o período de treinamento, estas duas pessoas serão incorporadas ao modelo de fundo e, quando elas se deslocarem, um fantasma aparecerá nos resultados. Mesmo no SFMDJ, que possui um modelo dinâmico de fundo, este fantasma aparecerá durante algum tempo nos resultados. Os algoritmos estatísticos GS e W4 mesmo atualizando os seus respectivos modelos de fundo, não conseguem eliminar a presença dos fantasmas no restante da seqüência de vídeo. O resultado apresentado pelo MM também é melhor que os resultados dos demais algoritmos. A Figura 5.28 ilustra esta situação. A Figura 5.28(a) mostra o quadro 101 original da seqüência, as Figuras 5.28(b), 5.28(c) e 5.28(d) mostram, respectivamente, os resultados da segmentação alvo-fundo para os algoritmos MM, GS e W4.

A última situação analisada ocorre na seqüência ShopAssistant2cor pertencente ao conjunto de vídeos 2. Nesta seqüência, a câmera mostra o corredor de uma visada frontal. As pessoas que caminham pelo corredor se aproximam (ou se afastam) da câmera. Nos algoritmos que lidam com 
a intensidade do pixel, quando uma pessoa caminhando pelo corredor está usando uma roupa de cor uniforme, alguns pixels passam um longo tempo apresentando valores de intensidade bastante próximos. Assim, vários destes pixels são incorporados ao modelo de fundo e passam a apresentar buracos nos alvos, os falsos negativos. Este problema, chamado de problema da abertura, é relatado como um dos desafios dos algoritmos de segmentação de movimento em [86]. Quando a pessoa se desloca um pouco mais, saindo da posição do pixel que foi incorporado ao fundo, este pixel passa a apresentar um falso positivo devido a comparação (diferença simétrica) com o modelo de fundo (situação similar a descrita anteriormente). Este comportamento forma alvos com buracos e um rastro após a passagem do alvo. A Figura 5.29 mostra a situação descrita comparando o algoritmo SFMDJ cujos resultados apresentam os falsos negativos e o rastro e o algoritmo MM que não apresenta tais problemas: as bordas dos alvos no algoritmo MM não desaparecem dos resultados e não existe a formação do rastro. 


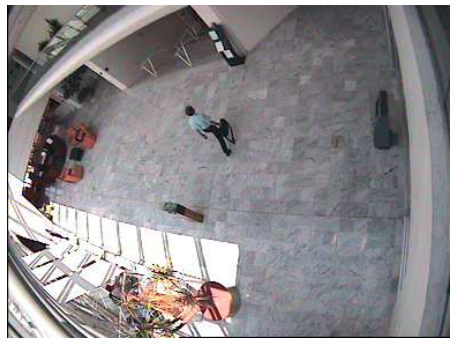

(a) Quadro 371 original.

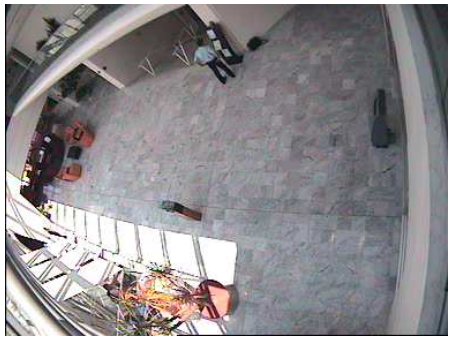

(d) Quadro 547 original.

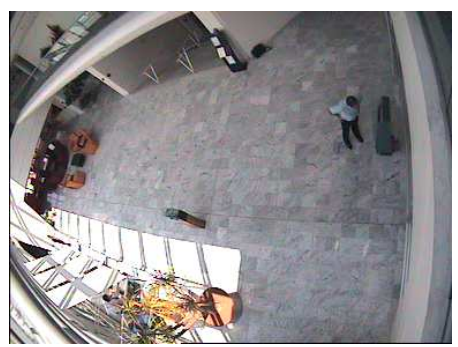

(g) Quadro 850 original.

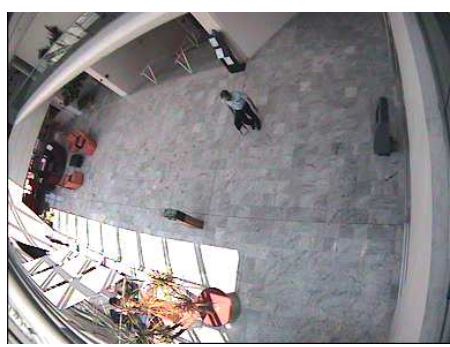

(j) Quadro 1055 original.

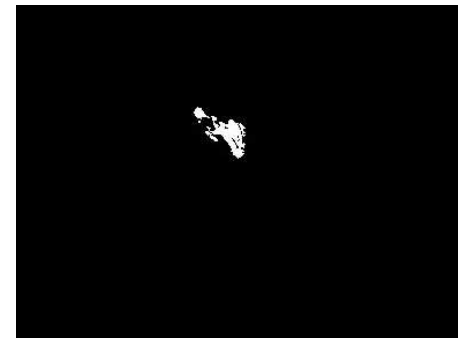

(b) Resultado do SFMDJ.

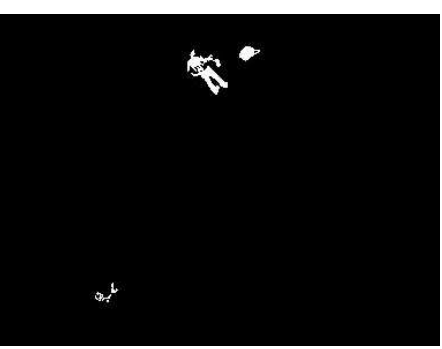

(e) Resultado do SFMDJ.

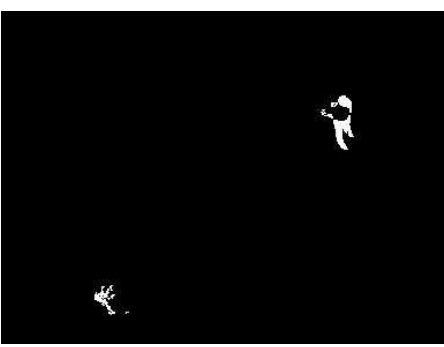

(h) Resultado do SFMDJ.

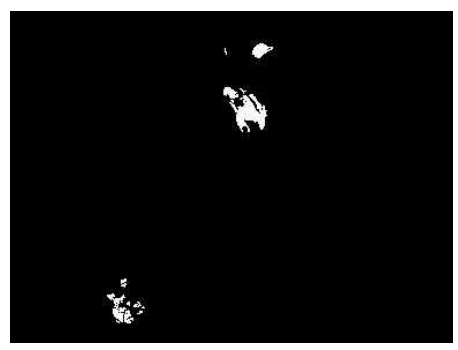

(k) Resultado do SFMDJ.

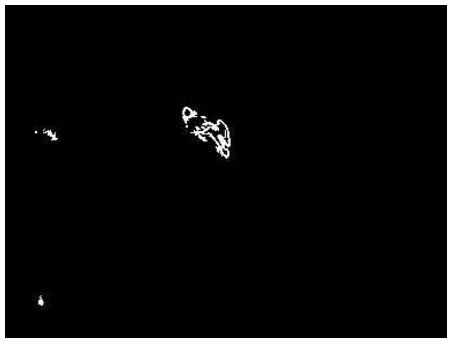

(c) Resultado do MM.

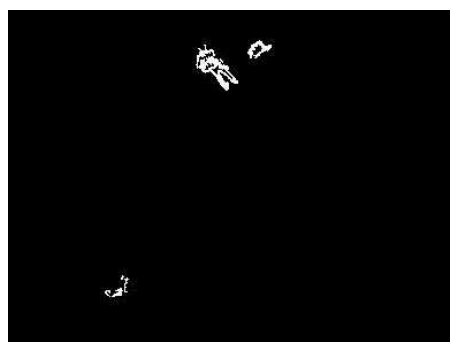

(f) Resultado do MM.

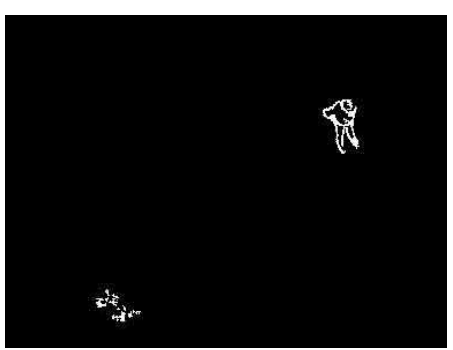

(i) Resultado do MM.

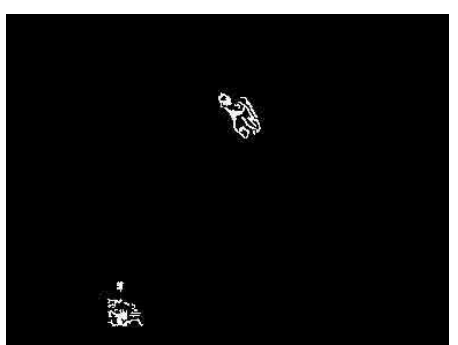

(1) Resultado do MM.

Figura 5.26: Situação específica que mostra a maior robustez a falsos positivos do algoritmo MM em relação ao SFMDJ. Quadros da seqüência LeftBag_PickedUp do Projeto CAVIAR. 


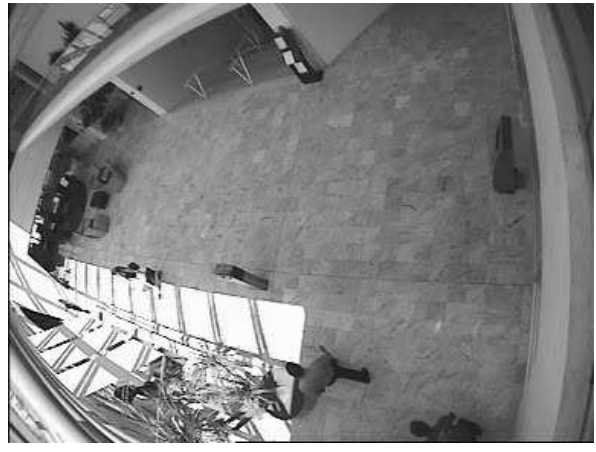

(a) Quadro 3 original.

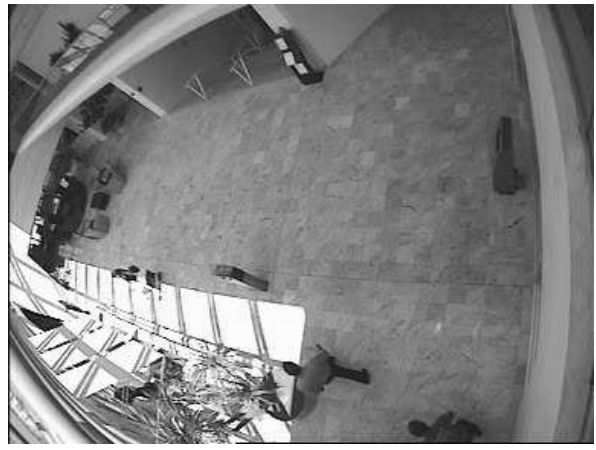

(c) Quadro 4 original.

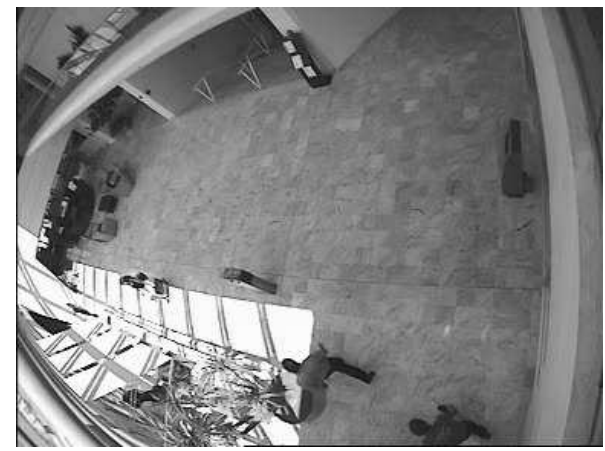

(e) Quadro 7 original.

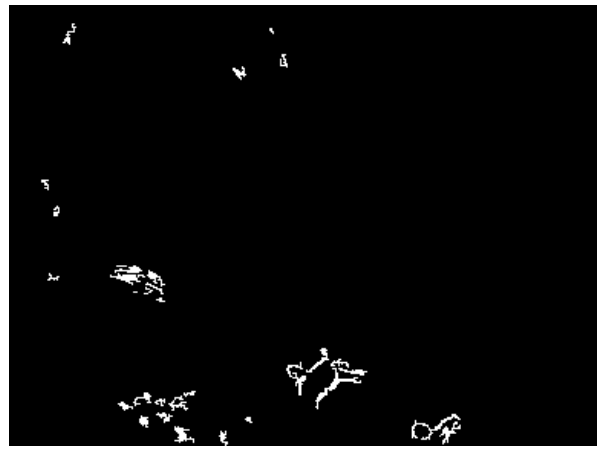

(b) Resultado do algoritmo MM.

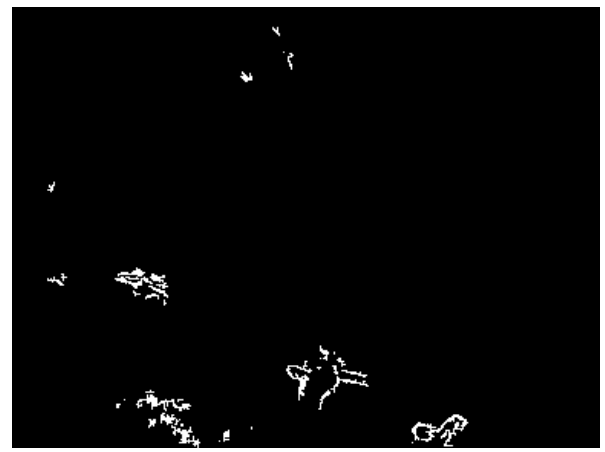

(d) Resultado do algoritmo MM.

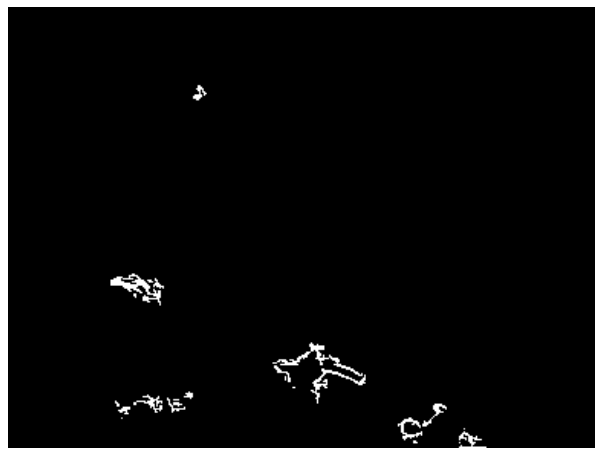

(f) Resultado do algoritmo MM.

Figura 5.27: Resultado do algoritmo MM em alguns quadros iniciais da seqüência Browse1 do projeto CAVIAR. 


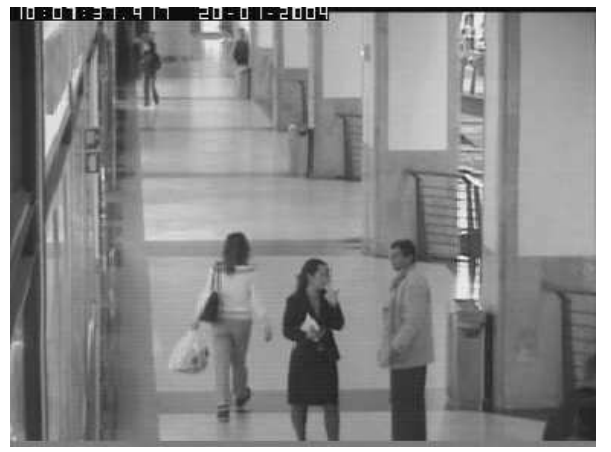

(a) Quadro 101 original.

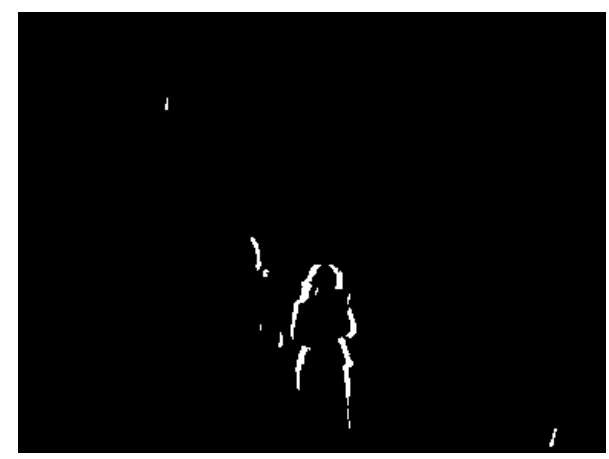

(c) Resultado do GS.

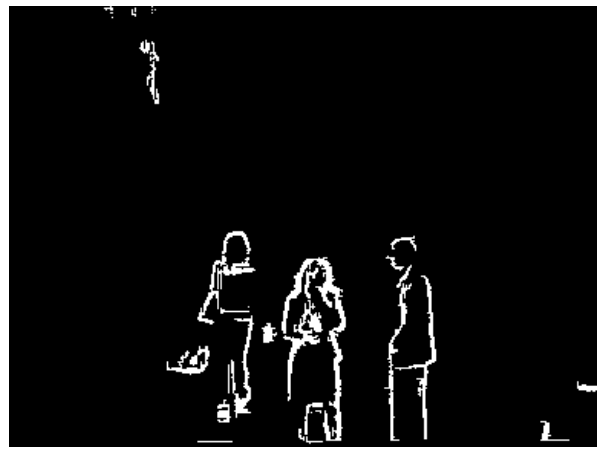

(b) Resultado do MM.

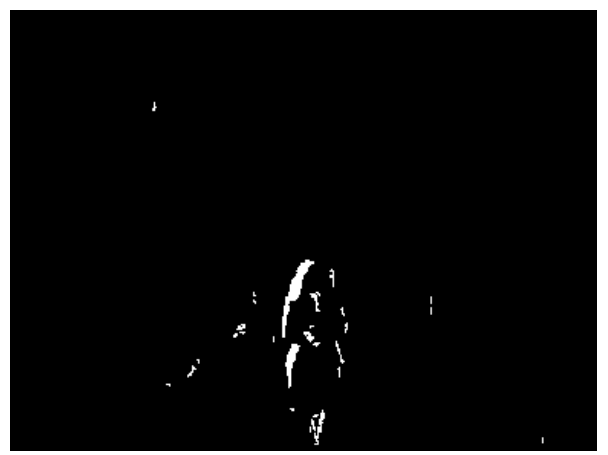

(d) Resultado do W4.

Figura 5.28: Resultados dos algoritmos MM, GS e W4 no quadro 101 da seqüência TwoEnterShop1cor ilustrando o melhor resultado do algoritmo MM após um período de treinamento onde alvos permaneceram em cena. 


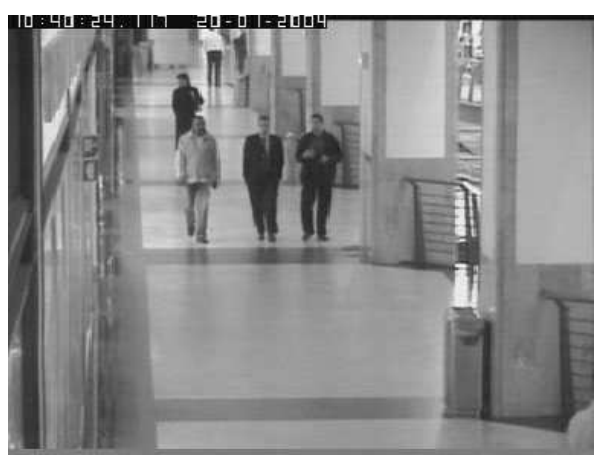

(a) Quadro 300 original.

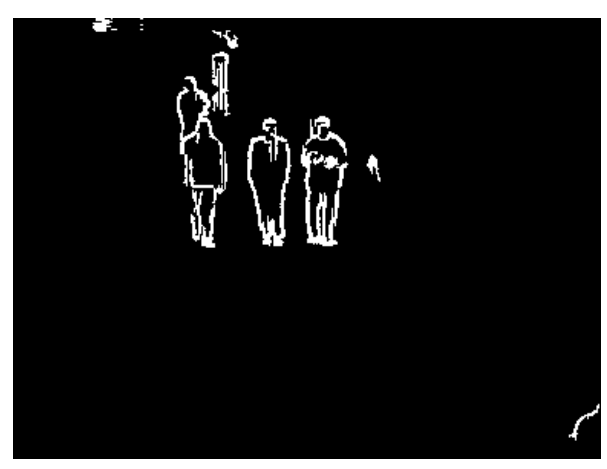

(b) Resultado do MM.

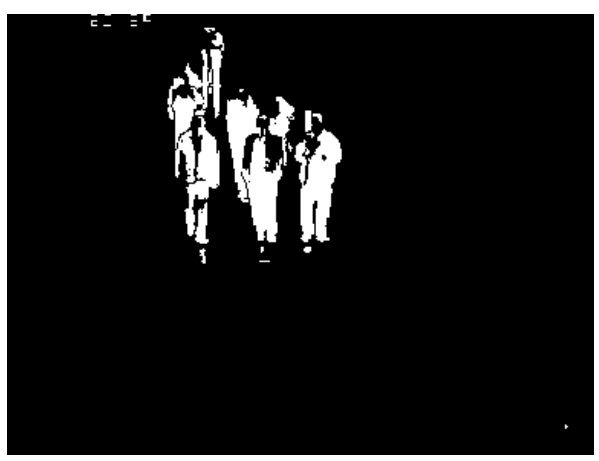

(c) Resultado do SFMDJ.

Figura 5.29: Resultados dos algoritmos MM e SFMDJ para o quadro 300 da seqüência ShopAssistant2cor mostrando a maior robustez a falsos negativos e o não aparecimento de rastros no algoritmo MM. 


\section{Capítulo 6}

\section{Conclusão}

Este trabalho apresentou o problema da segmentação de movimento em aplicações de análise de vídeo. Foram apresentados os aspectos gerais relativos aos algoritmos de segmentação de movimento como a iluminação, o registro, as restrições, os desafios, a etapa de pós-processamento e alguns métodos de avaliação de resultados. Também foram apresentadas as principais abordagens para tratar o problema: a diferenciação temporal, a subtração de fundo, a abordagem estatística e o fluxo óptico. Para cada abordagem, foram listados os principais algoritmos. Foi proposto também um novo algoritmo para segmentação de movimento fortemente baseado em filtros morfológicos e que utiliza contornos, obtidos através do gradiente morfológico externo, ao invés de utilizar a intensidade dos pixels aumentando assim a robustez a falsos positivos. A técnica proposta foi implementada juntamente com alguns algoritmos clássicos de segmentação de movimento descritos na Seção 2.3. Foi feito um teste comparativo dos algoritmos implementados na base pública de vídeo do projeto CAVIAR e o método apresentado neste trabalho apresentou ótimos resultados.

Uma avaliação quantitativa foi feita utilizando duas abordagens distintas. A primeira delas baseada em medições pixel a pixel (Seção 2.4.1) e a outra é baseada em componentes conexos (Seção 2.4.2). Na avaliação pixel a pixel, foram utilizados vários coeficientes que traduzem as medições pixel a pixel (TP, TN, FP e FN) em números absolutos que medem a eficiência de cada algoritmo. O algoritmo proposto neste trabalho apresentou o melhor coeficiente médio de PCC por quadro levandose em consideração todos os vídeos testados. Usando o coeficiente JC, o algoritmo MM obteve o segundo melhor coeficiente considerando toda a base e o melhor coeficiente se for considerado apenas os vídeos do conjunto 2. Pelos coeficientes TRDR e FAR, que devem ser analisados em conjunto, o algoritmo MM também obteve a melhor posição (considerando a base de vídeos inteira). Pela 
avaliação baseada em coeficientes conexos, os coeficientes DR e NR foram utilizados e eles também devem ser analisados em conjunto. Segundo estes coeficientes, o algoritmo MM também obteve a melhor nota, considerando toda a base de vídeos. Assim, de acordo com esta avaliação quantitativa que testou 45 vídeos em três conjuntos de vídeos distintos e quase 50000 quadros, pode-se concluir que o algoritmo MM apresenta os melhores resultados médios dentre todos os algoritmos testados. Ainda de acordo com a avaliação quantitativa efetuada, o algoritmo MM apresentou os melhores resultados no conjunto de vídeos 2 , onde obteve resultados significativamente melhores que os resultados dos demais algoritmos. Este conjunto apresenta como característica principal a maior proximidade dos alvos com a câmera, assim os alvos nestas seqüências de vídeo aparecem maiores que os alvos dos outros dois conjuntos. O algoritmo MM é, então, uma boa opção para ser utilizado em aplicações que possuam alvos bem próximos da câmera, como em aplicações com entrada de vídeo a partir de uma webcam por exemplo.

A avaliação quantitativa também corroborou algumas conclusões esperadas. As duas abordagens de avaliação de resultados utilizadas neste trabalho, a abordagem pixel a pixel e a abordagem baseada em objetos, apresentaram resultados similares, analisando os resultados das duas duplas de coeficientes complementares, TRDR e FAR (para a abordagem pixel a pixel) e DR e NR (para a abordagem baseada em objetos). Dentre os algoritmos de diferenciação temporal testados, o algoritmo DIF3 apresentou resultados superiores aos resultados do DIF2. Estes resultados numéricos confirmam a afirmação em [11], onde o DIF3 é proposto. Os autores afirmam que ele seria mais robusto que o DIF2. Foi constatado numericamente que ambos os algoritmos de diferenciação temporal apresentaram os piores resultados dentre os algoritmos testados. Também é um resultado esperado, visto que os algoritmos de diferenciação temporal apresentam o formato mais pobre dos alvos e são os mais suscetíveis a ruídos. Comparando os algoritmos de subtração de fundo, verificou-se que a mediana é uma estatística mais propícia para ser utilizada na estimação do modelo de fundo do que a média, já que o algoritmo SFMD apresentou resultados melhores do que o SFME. Em [88], já havia sido feito tal afirmação. Outra constatação é que a estimação dinâmica de fundo é superior a estimação estática de fundo, já que o SFMDJ foi superior ao SFMD e também ao SFME. Novamente é um resultado esperado visto que, na estimação dinâmica de fundo, o modelo de fundo recalculado a cada novo quadro torna o algoritmo mais robusto a alterações no cenário que, por acaso, ocorram. Dentre os algoritmos estatísticos, o GS que utiliza um modelo gaussiano para seu modelo de fundo foi superior ao W4. Também é um resultado esperado, pois o modelo de fundo do GS é superior ao modelo de fundo adotado pelo W4. 
Uma afirmação que os testes quantitativos deste trabalho não confirmaram foi a superioridade de desempenho dos algoritmos da abordagem estatística em relação aos algoritmos da abordagem de subtração de fundo. Algumas possíveis causas para isto são: em primeiro lugar, foi utilizado apenas uma banda por pixel em todos os algoritmos implementados, os pixels dos quadros estão em níveis de cinza. O algoritmo GS foi desenvolvido para trabalhar com o modelo de cor YUV que possui três bandas por pixel. O fato de trabalhar apenas com quadros em níveis de cinza pode ter afetado de maneira negativa o desempenho dos dois algoritmos de abordagem estatística. Outra possível causa para o fraco desempenho dos dois algoritmos quando comparados aos algoritmos de subtração de fundo é que ambos precisam de um período de treinamento livre de alvos para uma estimação perfeita do modelo de fundo. Durante os testes realizados, foram utilizados os primeiros 100 quadros de cada seqüência como período de treinamento. Em muitas destas seqüências, havia alvos no período de treinamento e a presença destes alvos provocou a criação de modelos de fundo inconsistentes. Estes modelos perduraram por toda a seqüência prejudicando o desempenho dos algoritmos. A atualização do modelo de fundo foi outra possível causa que provocou o baixo desempenho dos algoritmos da abordagem estatística. Se a atualização do modelo de fundo ocorresse de maneira eficiente, o modelo de fundo seria corrigido ao longo da seqüência, mesmo que o modelo de fundo tivesse sido criado de modo inconsistente, com alvos durante o período de treinamento. Porém, a taxa de aprendizado, usada no algoritmo GS para definir a velocidade com que as alterações do fundo são incorporadas ao modelo [62], não foi suficiente para corrigir um modelo de fundo inconsistente durante a seqüência. Taxas de aprendizado podem funcionar bem em uma seqüência e não tão bem em outra, elas dependem muito da seqüência: fundo, alvos, velocidade de deslocamento dos alvos, etc. Foi utilizada uma única taxa de aprendizado para todas as seqüências testadas e, provavelmente, a taxa de aprendizado única não conseguiu atualizar o modelo de fundo da maneira mais efetiva possível [51].

Certas situações comuns em uma seqüência de vídeo também foram analisadas. De acordo com esta análise, o algoritmo MM apresenta uma maior robustez ao aparecimento de falsos positivos ou fantasmas quando comparado aos demais algoritmos testados. Essa robustez é devida, principalmente, ao fato de não utilizar as intensidades dos pixels e sim os contornos dos quadros. A utilização das intensidades dos pixels implica no uso do operador de diferença simétrica para comparar o quadro atual e o modelo estimado de fundo. Este operador, em algumas situações, pode gerar falsos positivos nos resultados. O algoritmo MM utiliza uma subtração com saturação que apenas elimina contornos presentes no modelo de fundo do conjunto de contornos do quadro atual. Com isto, não 
existe a possibilidade de aparecer "falsos contornos" nos resultados.

Uma destas situações analisadas é quando um alvo permanece parado por tempo suficiente para ser incorporado ao fundo do modelo. Isto acontecerá em algoritmos que estimam o fundo de maneira dinâmica. Quando o alvo, depois de incorporado ao modelo de fundo, tornar a se mover aparecerá um fantasma na posição em que o alvo se encontrava. Este problema não ocorrerá no algoritmo MM. Uma outra situação analisada que também ocorre em algoritmos de estimação dinâmica de fundo é quando os alvos possuem velocidade aparente muito pequena e texturas homogêneas. Assim, um determinado pixel no interior do alvo pode passar por um longo período apresentando valores de intensidades muito próximos. Este pixel vai acabar sendo incorporado ao modelo de fundo e passará a ser erroneamente classificado como fundo. O alvo passa, então, a apresentar buracos em seu interior (falsos negativos). Este problema, já listado em [86], é chamado de problema da abertura. O problema persiste até que o alvo esteja fora da posição do pixel. Neste momento, o pixel que tinha seu valor anterior classificado como fundo, passará a ter seu valor classificado como alvo e apresentará um rastro atrás do alvo, um falso positivo. O algoritmo MM não apresenta este problema. Primeiro, como o MM lida com contornos, praticamente não existe o problema da abertura. Os pixels de um contorno estão na pequena região entre a textura do alvo e a textura do fundo e praticamente qualquer movimento do alvo vai provocar alterações significativa nos valores dos pixels que estão nesta região. Assim, dificilmente um pixel do contorno do alvo ficará por um período longo apresentando valores de intensidade de pixel semelhantes, apesar de haver movimento. A explicação para que o MM não apresente o rastro é a mesma que o torna mais robusto a falsos positivos: a não utilização da diferença simétrica.

Uma outra característica importante do algoritmo proposto neste trabalho é a simplicidade. Não são necessários modelos complexos e de difícil implementação. Os conceitos são simples e a implementação é direta, apresentando um bom resultado final quando comparado aos demais algoritmos. O MM apresenta resultados também desde os primeiros quadros da seqüência. Não é necessário um longo período de treinamento para gerar um modelo de fundo consistente e só então começar a gerar a máscara alvo-fundo. Dois quadros apenas são suficientes para que o MM comece a produzir a máscara alvo-fundo.

\subsection{Trabalhos Futuros}

Esta seção apresenta algumas propostas de extensão do presente trabalho. 
A Seção 2.2.2 apresentou uma série de problemas que a iluminação pode causar aos resultados dos algoritmos de segmentação de movimento. Um estudo comparativo interessante seria utilizar os métodos de avaliação de desempenho, descritos na Seção 2.4, para medir os resultados dos vários algoritmos implementados neste trabalho em diferentes situações relacionadas a iluminação, tais como presença de superfícies espelhadas na cena (que aumentam o número de falsos positivos), sombras (que geram problemas na segmentação) e alterações de posicionamento e intensidade das fontes de luz. A análise quantitativa iria mostrar quais dentre os algoritmos estudados são mais robustos aos problemas de iluminação presentes na cena. Alguns algoritmos de detecção [41,22] e remoção de sombras [19] podem também ser implementados e testados. Os resultados dos testes podem, então, medir numericamente a eficiência de tais algoritmos.

Outra possível extensão para a solução proposta é ampliá-la de maneira tal que consiga lidar com seqüências de vídeo capturadas de câmeras em movimento. Para isto é necessário que exista o registro (Seção 2.2.3) entre quadros sucessivos de modo a ser possível detectar e segmentar os alvos em movimento na seqüência. Como a solução proposta lida com os contornos da cena, uma possível maneira de obter o registro seria a operação de correlação entre quadros consecutivos da seqüência como etapa de pré-processamento. Visto que, geralmente, a maior parte dos contornos dos quadros envolvidos são pertencentes ao fundo da cena, apenas a correlação poderia ser suficiente para obter o registro dos quadros consecutivos. Poderia ser feita também uma comparação com outras técnicas de registro existentes $[77,90,89]$.

Uma outra possível extensão para este trabalho seria o acréscimo de uma etapa ao algoritmo proposto para recuperar o formato completo dos alvos da cena. A recuperação apenas dos contornos dos alvos na cena é suficiente para várias aplicações, como, por exemplo, a vigilância inteligente. Nestas aplicações, apenas a detecção e a segmentação de uma caixa de Feret que envolva os alvos é suficiente. Porém, existem aplicações que necessitam que o formato completo do alvo seja recuperado, como aplicações de estimação de pose ou para reconhecimento de ações na cena. Como o algoritmo MM produz contornos dos alvos, uma possibilidade é utilizar estes contornos como ponto de partida para a geração automática de marcadores de uma segmentação por Watershed [6,72,37].

Um outro trabalho, continuação deste, seria um estudo mais profundo dos métodos de avaliação dos algoritmos de segmentação de movimento [53]. A Seção 2.4 lista vários métodos de avaliação de desempenho para as técnicas de segmentação de movimento, porém, falta uma análise melhor listando os pontos fortes e fracos de cada um dos métodos. Este trabalho também poderia incluir uma revisão bibliográfica mais completa desses métodos de avaliação de desempenho e, possivelmente, a proposta 
de novos métodos de avaliação.

A parte experimental do trabalho, que consistiu na implementação de sete algoritmos clássicos ao lado da solução proposta, pode ser ampliada com a implementação de dois outros algoritmos de segmentação de movimento. O primeiro deles é o Wallflower que ataca o problema da segmentação em três níveis diferentes e são relatados bons resultados [86]. O outro é o Método Gaussiano Múltiplo ou a Mistura de Gaussianas $[81,82]$ que suporta fundos dinâmicos e adapta-se a alterações na cena como mudanças na iluminação. O Método Gaussiano Múltiplo, também conhecido pela sigla $M O G^{1}$, foi implementado. Porém, não houve prazo hábil para incluir sua avaliação quantitativa no presente trabalho.

Um outro ponto de investigação seria a comparação de vários métodos de obtenção de contornos. Ao lado do gradiente morfológico, poderiam ser testados filtros baseados no operador gradiente [24], como o filtro de Roberts, Prewitt [8] ou o Sobel [45], filtros baseados no operador laplaciano [24], contornos detectados a partir da Transformada de Fourier [12] e contornos detectados a partir de análises multiescala, como a Transformada de Marr-Hildreth [35,58]. Todos estes métodos seriam avaliados por critérios como a detecção de contornos mais robusta a ruídos (a que gere menos falsos positivos), a maior detecção dos contornos (a que gere menos falsos negativos) e a de melhor desempenho (a detecção mais rápida). Uma avaliação quantitativa compararia os resultados de cada um dos métodos.

O tempo de resposta é um item muito importante para aplicações de análise de vídeo, principalmente para as aplicações de vigilância inteligente. Assim, uma possível extensão a este trabalho seria trabalhar no MM de modo a melhorar o tempo de resposta do algoritmo. O ideal seria a obtenção de resultados em tempo real.

Os contornos resultantes do algoritmo MM podem não ser completos. Se fossem completos, eles seriam equivalentes aos formatos completos dos alvos produzido pela maioria dos algoritmos de segmentação de movimento tradicionais. Em [12], são citados algoritmos que produzem o contorno a partir de uma região e preenchem um contorno completo produzindo uma região. Como o contorno produzido pelo MM pode não ser completo, esta equivalência entre o contorno e a região completa não é válida. Ainda segundo [12], estas duas saídas (contornos e regiões) produzem características diferentes. Poderia ser feito, então, um estudo comparativo entre características extraídas dos contornos oriundos do MM e características extraídas do formato completo dos alvos. Ambos vetores de

\footnotetext{
${ }^{1}$ do inglês Mixture of Gaussians
} 
características teriam suas eficiências medidos em um processo de mais alto nível como a classificação ou o rastreamento de alvos. Caso as características oriundas do MM tenham desempenho comparável às características vindas da região completa dos alvos, a etapa de recuperação completa dos alvos (possível extensão deste trabalho) poderia ser considerada desnecessária.

Em [47], são apresentados o algoritmo MM e uma análise qualitativa preliminar. Em [49] e em [48], são apresentados a análise quantitativa entre o algoritmo MM e os demais algoritmos implementados. Um artigo mostrando a comparação dos algoritmos e os resultados quantitativos finais está sendo elaborado. 


\section{Referências Bibliográficas}

[1] J. Aggarwal and Q. Cai, Human motion analysis: A review, Computer Vision and Image Understanding: CVIU 73 (1999), no. 3, 428-440.

[2] J. Amat, A. Casals, and M. Frigola, Stereoscopic system for human body tracking in natural scenes, Proceedings IEEE International Workshop on Modelling People, 1999, pp. 70-76.

[3] J. Barrera, G. J. F. Banon, R. A. Lotufo, and R. Hirata Jr., MMach: a Mathematical Morphology Toolbox for the Khoros System, Electronic Imaging 7 (1998), no. 1, 174-210.

[4] J. Barron, D. Fleet, and S. Beauchemin, Performance of optical flow techniques, International Journal of Computer Vision 12 (1994), no. 1, 43-77.

[5] F. Bashir and F. Porikli, Performance evalution of object detection and tracking systems, Proceedings IEEE International Workshop, IEEE Computer Society, June 2006.

[6] S. Beucher and F. Meyer, Mathematical Morphology in Image Processing, ch. 12. The Morphological Approach to Segmentation: The Watershed Transformation, pp. 433-481, Marcel Dekker, 1992.

[7] L. Brown, A survey of image registration techniques, ACM Computing Surveys 24 (1992), no. 4, $325-376$.

[8] K. Castleman, Digital image processing, Prentice Hall, 1996.

[9] C. Cedras and M. Shah, Motion-based recognition, a survey, Image and Vision Computing 13 (1995), no. 2, 129-154.

[10] R. Collins, A. Lipton, and T. Kanade, Introduction to the special section on video surveillance, IEEE Transactions on Pattern Analysis and Machine Intelligence 22 (2000), no. 8, 745-746.

[11] R. Collins, A. Lipton, T. Kanade, H. Fujiyoshi, D. Duggins, Y. Tsin, D. Tolliver, N. Enomoto, O. Hasegawa, P. Burt, and L. Wixson, A system for video surveillance and monitoring, Tech. report, Robotics Inst., Carnegie-Mellon Univ., Pittsburgh, PA, 2000, Tech. Rep. CMU-RI-TR$00-12$. 
[12] L. Costa and R. Cesar Jr., Shape analysis and classification, 1st edition ed., CRC Press, 2001.

[13] J. Crespo, R. W. Schafer, J. Serra, C. Gratin, and F. Meyer, The flat zone approach: A general low-level region merging segmentation method, Signal Processing 62 (1997), no. 1, 37-60.

[14] J. Crowley, Context driven observation of human activity, Proceedings European Symposium on Ambient Intelligence, Oct. 2003.

[15] E. Dougherty and R. Lotufo, Hands-on morphological image processing, SPIE Press, 2003.

[16] R. Duda, P. Hart, and D. Stork, Pattern classification, John Wiley and Sons, 2001.

[17] J. Ferryman, S. Maybank, and A. Worral, Visual surveillance for moving vehicles, International Journal of Computer Vision 37 (2000), no. 2, 187-197.

[18] C. Finch, Special effects: Creating movie magic, Abbeville Press, 1984.

[19] G. Finlayson, S. Hordley, and M. Drew, Removing shadows from images, European Conference on Computer Vision, 2002.

[20] R. Fisher, Pets04 surveillance ground truth data set, Proceedings Sith IEEE International Workshop on Performance Evaluation of Tracking and Surveillance, May 2004, pp. 1-5.

[21] J. Foley, A. van Dam, S. Feiner, and J. Hughes, Computer graphics: Principles and practice in c, 2nd. ed., Addison Wesley Professional, 1995.

[22] G. Fung, N. Yung, G. Pang, and A. Lai, Towards detection of moving cast shadows for visual traffic surveillance, IEEE International Conference on Systems, Man, and Cybernetics, vol. 4, 2001, pp. 2505-2510.

[23] D. Gavrila, The visual analysis of human movement: A survey, Computer Vision and Image Understanding 73 (1999), no. 1, 82-93.

[24] R. Gonzalez and R. Woods, Digital image processing, second ed., Addison-Wesley Publishing Company, 2002.

[25] D. Grest, J. Frahm, and R. Koch, A color similarity measure for robust shadow removal in real time, Vision, Modeling, and Visualization, 2003, Munich, Germany, November 2003.

[26] G. Hager and P. Belhumeur, Efficient region tracking with parametric models of geometry and illumination, IEEE Transactions On Pattern Analysis and Machine Intelligence 20 (1998), no. 10, 1025-1039. 
[27] D. Hall, J. Nascimento, P. Ribeiro, E. Andrade, P. Moreno, S. Pesnel, T. List, R. Emonet, R. Fisher, J. Santos-Victor, and J. Crowley, Comparison of target detection algorithms using adaptive background models, Proceedings 2nd Joint IEEE International Workshop, IEEE Computer Society, 2005, pp. 113-120.

[28] I. Haritaoglu, D. Harwood, and L. Davis, W4: Who? when? where? what? a real time system for detecting and tracking people, 3rd. International Conference on Face \& Gesture Recognition, 1998, p. 222.

[29] _ W4: Real-time surveillance of people and their activities, IEEE Transactions On Pattern Analysis and Machine Intelligence 22 (2000), no. 8, 809-830.

[30] H. Heijmans, Mathematical morphology: A geometrical approach in image processing, Nieuw Archief voor Wiskunde 10 (1992), 237-276.

[31]__ Morphological image operators, Academic Press, Boston, 1994.

[32] _ _ Mathematical morphology: A modern approach in image processing based on algebra and geometry, SIAM Review 37 (1995), no. 1, 1-36.

[33] _ Mathematical morphology: Basic principles, Proceedings, 1995.

[34] _ Composing Morphological Filters, IEEE Transactions on Image Processing 6 (1997), no. $5,713-723$.

[35] E. Hildreth, Implementation of a theory of edge detection, Tech. report, Massachusetts Institute of Technology, Cambridge, MA, USA, 1980, Technical Report AITR-579.

[36] R. Hirata Jr., Segmentação de Imagens por Morfologia Matemática, Master's thesis, Instituto de Matemática e Estatística - USP, março 1997.

[37] R. Hirata Jr., J. Barrera, and R. A. Lotufo, A Tutorial on Image Segmentation via Mathematical Morphology with Khoros, Khoros' 97 proceedings, Khoral Research, Khoral Research Inc., Editors, March 1997, pp. 192-206.

[38] B. Horn and B. Schunck, Determining optical flow, Artificial Intelligence 17 (1981), 185-203.

[39] W. Hu, T. Tan, L. Wang, and S. Maybank, A survey on visual surveillance of object motion and behaviors, IEEE Transactions on Systems, Man, and Cybernetics-Part C: Applic. and Reviews 34 (2000), no. 3, 334-352.

[40] O. Javed and M. Shah, Tracking and object classification for automated surveillance, Lecture Notes in Computer Science (2002), no. 2353, 343-357. 
[41] C. Jiang and M. Ward, Shadow identification, Proceedings CVPR'92, IEEE Computer Society, June 1992, pp. 606-612.

[42] R. A. Johnson and D. W. Wichern, Applied multivariate statistical analysis, Prentice-Hall, 1992.

[43] T. Kailath, A view of three decades of linear filtering theory, IEEE Transactions on Information Theory 20 (1974), no. 2, 146-181.

[44] T. Kanade, R. Collins, A. Lipton, P. Burt, and L. Wixson, Advances in cooperative multi-sensor video surveillance, Proceedings DARPA Image Understanding Workshop, 1998, pp. 3-24.

[45] N. Kanopoulos, N. Vasanthavada, and R. Baker, Design of an image edge detection filter using the sobel operator, IEEE Journal of Solid-State Circuits 23 (1988), 358-367.

[46] K. Kim, D. Harwood, and L. Davis, Background updating for visual surveillance, Lecture Notes in Computer Science (2005), no. 3804, 337-346.

[47] A. Lara and R. Hirata Jr., Motion segmentation using mathematical morphology, Brazilian Symposium on Computer Graphics and Image Processing, 19 (SIBGRAPI) (Manuel Menezes de Oliveira Neto and Rodrigo Lima Carceroni, eds.), IEEE Computer Society, 8-11 Oct. 20062006.

[48] _ _ A morphological gradient-based method to motion segmentation, Sessão de pôster do VIII International Symposium on Mathematical Morphology, 2007.

[49] __ Segmentação de movimento usando morfologia matemática, Workshop de Teses e Dissertações do XX Brazilian Symposium on Computer Graphics and Image Processing, 2007.

[50] A. Lepisk, The use of optic flow within background subtraction, Master's thesis, Royal Institute of Technology, Stockholm, Sweden, 2005.

[51] L. Li, R. Luo, W. Huang, K. Leman, and W. Yau, Adaptive background subtraction with multiple feedbacks for video surveillance, Lecture Notes in Computer Science (2005), no. 3804, 380-387.

[52] R. Lillestrand, Techniques for change detection, IEEE Transactions on Computers 21 (1972), no. $7,654-659$.

[53] T. List, J. Bins, J. Vazquez, and R. Fisher, Performance evaluating the evaluator, Proceedings 2nd Joint IEEE International Workshop, IEEE Computer Society, October 2005, pp. 129-136.

[54] R. Lotufo, F. Zampirolli, R. Hirata Jr., and J. Barrera, Mmachlib functions and mmach operators, Universidade Estadual de Campinas - UNICAMP, Faculdade de Engenharia Elétrica e de Computação - FEEC, Departamento de Engenharia de Computação e Automação Industrial DCA, CP 6101, Cidade Universitária Zeferino Vaz, 13083-970, Campinas, SP, february 97 ed., February 1997, This work has been supported by ProTeM-CC/CNPq through the AnIMoMat 
project, contract 680067/94-9. This manual has been used during the Brazilian Workshop'97 on Mathematical Morphology.

[55] Y. Lu, W. Ga, and F. Wu, Automatic video segmentation using a novel background model, IEEE International Symposium on Circuits and System, vol. 3, 2002, pp. 807-810.

[56] B. Lucas and T. Kanade, An iterative image-registration technique with an application to stereo vision, DARPA Image Understanding Workshop, 1981, pp. 121-130.

[57] J. Makhoul, Linear prediction: A tutorial review, Proceedings of the IEEE 63 (1975), no. 4, $561-580$.

[58] D. Marr and E. Hildreth, Theory of edge detection, Proceedings of Royal Society of London, 1980, pp. 187-217.

[59] G. Matheron, Random sets and integral geometry, John Wiley, 1975.

[60] Y. Matsushita, K. Nishino, K. Ikeuchi, and M. Sakauchi, Illumination normalization with timedependent intrinsic images for video surveillance, IEEE Transactions on Pattern Analysis and Machine Intelligence 26 (2004), no. 10, 1336-1347.

[61] A. McIvor, Background subtraction techniques, Proceedings of Image and Video Computing New Zealand (IVCNZ'00), 2000.

[62] S. McKenna, S. Jabri, Z. Duric, H. Wechsler, and A. Rosenfeld, Tracking groups of people, Computer Vision and Image Understanding 80 (2000), no. 1, 42-56.

[63] T. Moeslund and E. Granum, A survey of computer vision-based human motion capture, Computer Vision and Image Understanding 81 (2001), no. 3, 231-268.

[64] T. Moeslund, A. Hilton, and V. Krüger, A survey of advances in vision-based human motion capture and analysis, Computer Vision and Image Understanding 104 (2006), 90-126.

[65] J. Nascimento, M. Figueiredo, and J. Marques, Motion segmentation for activity surveillance, 1st Workshop on Systems, Decision and Control Robotic Monitoring and Surveillance, Lisbon, June 2005.

[66] _ Segmentation and classification of human activities, Proceedings Workshop on Human Activity Recognition and Modelling (HAREM 2005), September 2005, pp. 79-86.

[67] J. Nascimento and J. Marques, New performance evaluation metrics for object detection algorithms, 6th International Workshop, May 2004.

[68] _ Novel metrics for performance evaluation of object detection algorithms, 1st ISR Workshop, June 2005. 
[69] _ Performance evalution of object detection algorithms for video surveillance, IEEE Transactions on Multimedia 8 (2006), no. 4, 761-774.

[70] S. Negahdaripour, Revised definition of optical flow: integration of radiometric and geometric cues for dynamic scene analysis, IEEE Transactions On Pattern Analysis and Machine Intelligence 20 (1998), no. 9, 961-979.

[71] R. Oliveira, P. Ribeiro, J. Marques, and J. Lemos, A video system for urban surveillance: Function integration and evaluation, International Workshop on Image Analysis for Multimedia Interactive Systems, 2004.

[72] M. Pardàs and P. Salembier, 3d morphological segmentation and motion estimation for image sequences, Signal Processing 38 (1994), no. 1, 31-43.

[73] B. Phong, Illumination for computer generated pictures, Commun. ACM 18 (1975), 311-317.

[74] R. Radke, S. Andra, O. Al-Kofabi, and B. Roysam, Image change detection algorithms: A systematic survey, IEEE Transactions on Image Processing 14 (2005), no. 3, 294-307.

[75] P. Rosin, Thresholding for change detection, Computer Vision Image Understanding 86 (2002), no. 2, 79-95.

[76] P. Rosin and E. Ioannidis, Evaluation of global image thresholding for change detection, Pattern Recognition Letters 24 (2003), no. 14, 2345-2356.

[77] J. Sato and R. Cipolla, Image Registration Using Multi-scale Texture Moments, Image of Vision Computing 13 (1995), no. 5, 341-353.

[78] J. Serra, Image analysis and mathematical morphology, Academic Press, 1982.

[79] S. Smith and J. Brady, Asset-2: Real time motion segmentation and shape tracking, IEEE Transactions on Pattern Analysis and Machine Inteligence 17 (1995), no. 8, 814-820.

[80] P. Spagnolo, T. D'Orazio, M. Leo, and A. Distante, Moving object segmentation by background subtraction and temporal analysis, Image and Vision Computing 24 (2006), no. 5, 411-423.

[81] C. Stauffer and W. Grimson, Adaptive background mixture models for real-time tracking, IEEE Computer Society Conference on Computer Vision and Pattern Recognition (CVPR'99), vol. 2, 1999, p. 2246.

[82] _ Learning patterns of activity using real-time tracking, IEEE Transactions on Pattern Analysis and Machine Intelligence 22 (2000), no. 8, 747-757.

[83] E. Stringa, Morphological change detection algorithms for surveillance applications, Proceedings British Machine Vision Conference, 2000, pp. 402-412. 
[84] A. Tavakkoli, M. Nicolescu, and G. Bebis, Automatic robust background modeling using multivariate non-parametric kernel density estimation for visual surveillance, Lecture Notes in Computer Science (2005), no. 3804, 363-370.

[85] D. Toth, T. Aach, and V. Metzler, Illumination-invariant change detection, Proceedings. 4th IEEE Southwest Symposium, IEEE Computer Society, 2000, pp. 3-7.

[86] K. Toyama, J. Krumm, B. Brumitt, and B. Meyers, Wallflower: Principles and practice of background maintenance, 7th International Conference on Computer Vision (ICCV99), vol. 1, 1999, p. 255.

[87] R. Unnikrishnan, C. Pantofaru, and M. Hebert, Toward objective evaluation of image segmentation algorithms, IEEE Transactions on Pattern Analysis and Machine Intelligence 29 (2007), no. 6, 929-944.

[88] L. Wang, W. Hu, and T. Tan, Recent developments in human motion analysis, Pattern Recognition 36 (2003), no. 3, 585-601.

[89] X. Wang and J. Tian, Image registration based on maximization of gradient code mutual information, Image Analisys and Stereology 24 (2005), 1-7.

[90] R. Woods, S. Grafton, J. Watson, N. Sicotte, and J. Maziotta, Automated Image Registration: II. Intersubject Validation of Linear and Nonlinear Models, Computer Assisted Microscopy 22 (1998), no. 1, 153-165.

[91] C. Wren, A. Azerbayejani, T. Darrell, and A. Pentland, Pfinder: Real-time tracking of the human body, IEEE Transactions on Pattern Analysis on Machine Intelligence 19 (1997), no. 7, 780-785.

[92] A. Yilmaz, O. Javed, and M. Shah, Object tracking: A survey, ACM Computer Surveys (CSUR) 38 (2006), no. 4, 13.

[93] D. Young and J. Ferryman, Pets metrics: On-line performance evaluation service, Proceedings 2nd Joint IEEE Int. Workshop, IEEE Computer Society, 2005.

[94] B. Zitova and J. Flusser, Image registration methods: A survey, Image and Vision Computing 21 (2003), no. 11, 977-1000. 